A NEW MORMOOPID BAT FROM THE OLIGOCENE (WHITNEYAN AND EARLY ARIKAREEAN) OF FLORIDA,

AND PHYLOGENETIC RELATIONSHIPS OF THE MAJOR CLADES OF MORMOOPIDAE (MAMMALIA: CHIROPTERA)

GARY S. MORGAN, NICHOLAS J. CZAPLEWSKI, AND NANCY B. SIMMONS
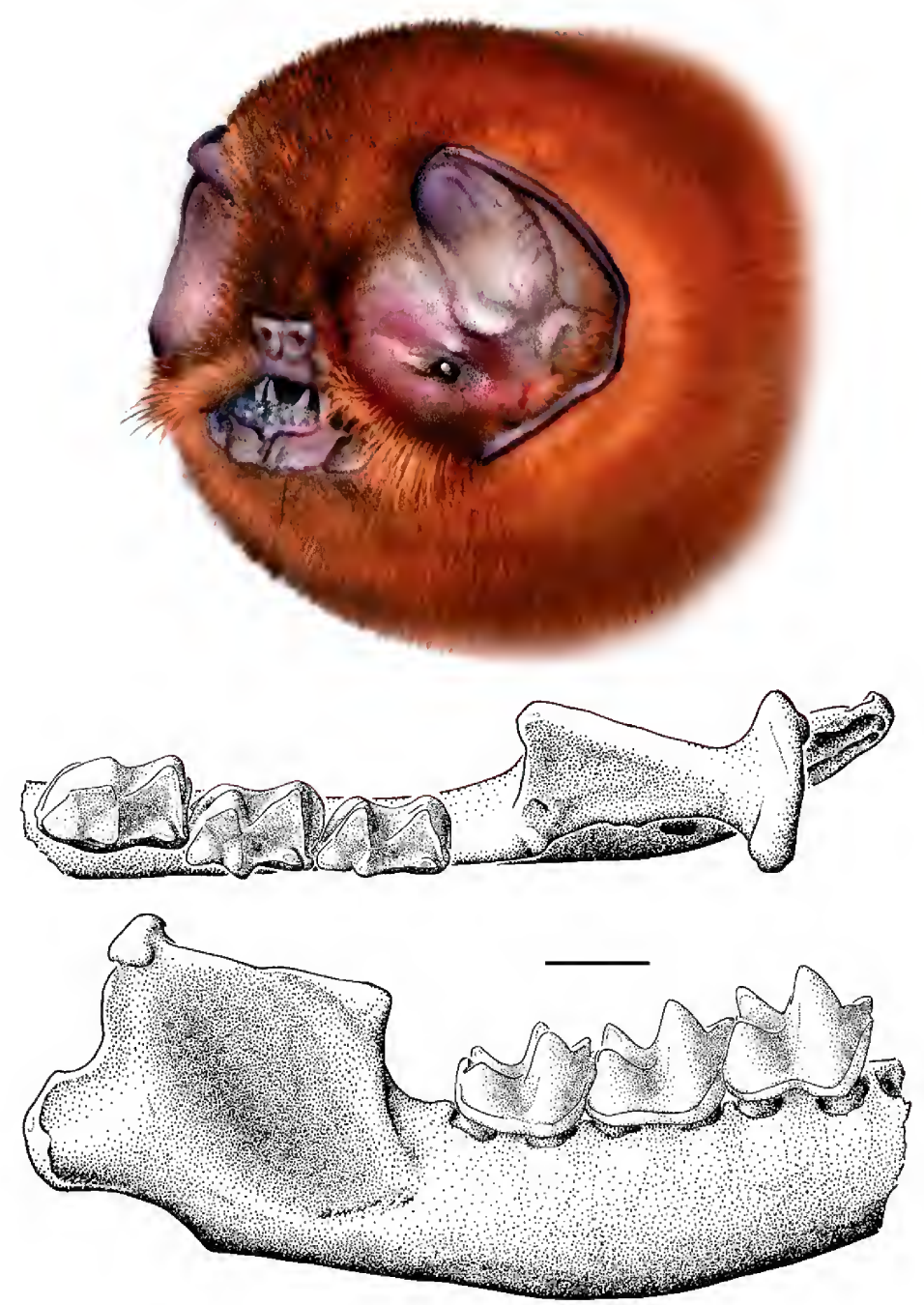

BULLETIN OF THE AMERICAN MUSEUM OF NATURAL HISTORY 


\title{
A NEW MORMOOPID BAT FROM THE OLIGOCENE (WHITNEYAN AND EARLY ARIKAREEAN) OF FLORIDA, AND PHYLOGENETIC RELATIONSHIPS OF THE MAJOR CLADES OF MORMOOPIDAE (MAMMALIA: CHIROPTERA)
}

\author{
GARY S. MORGAN \\ New Mexico Museum of Natural History, Albuquerque, NM \\ NICHOLAS J. CZAPLEWSKI \\ Oklahoma Museum of Natural History, University of Oklahoma, Norman
}

NANCY B. SIMMONS

Department of Mammalogy, Division of Vertebrate Zoology,

American Museum of Natural History

BULLETIN OF THE AMERICAN MUSEUM OF NATURAL HISTORY

Number 434, 141 pp., 18 figures, 6 tables

Issued June 17, 2019 


\section{CONTENTS}

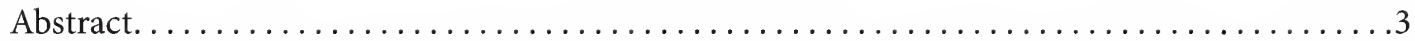

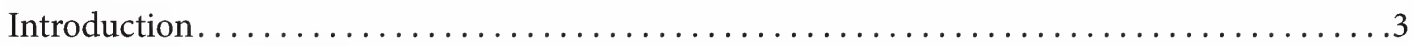

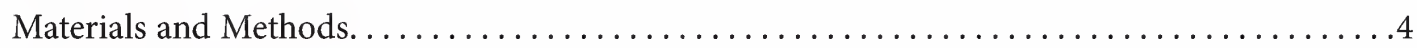

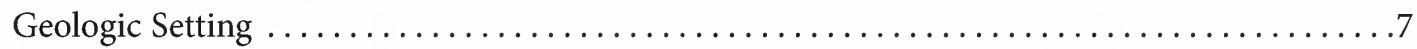

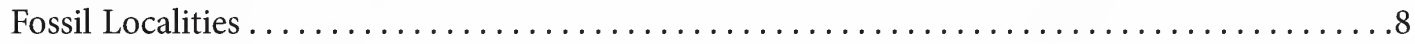

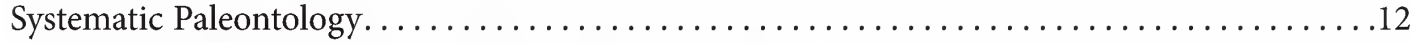

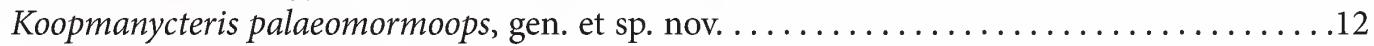

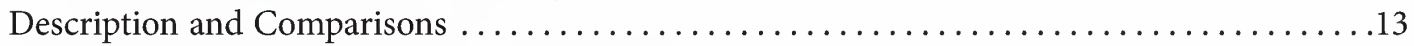

Character Descriptions and State Distributions.......................... 42

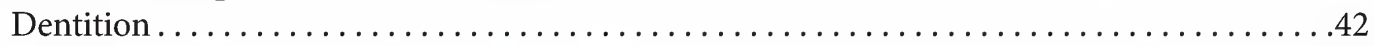

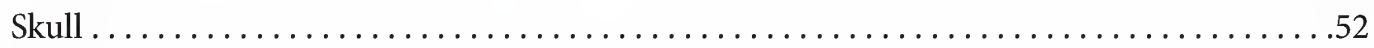

Vomeronasal Complex and Brain ..................................... 64

Trachea and Hyoid Apparatus . . . . . . . . . . . . . . . . . . . . . . . . . . . . . . .

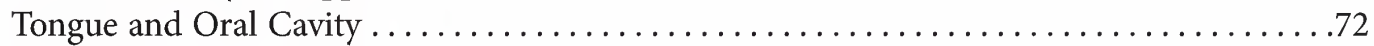

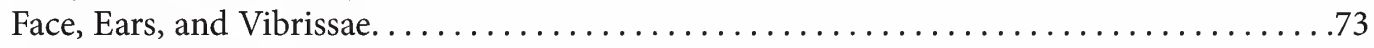

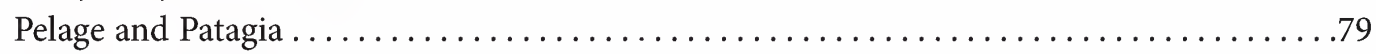

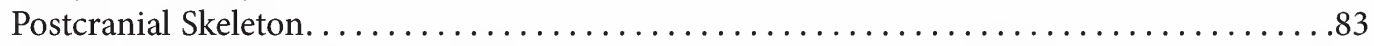

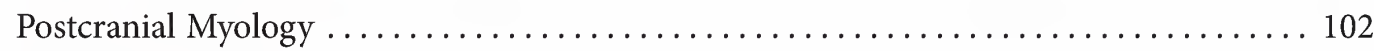

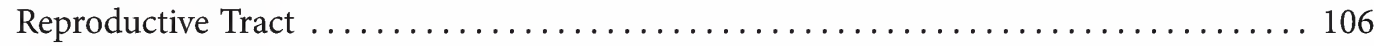

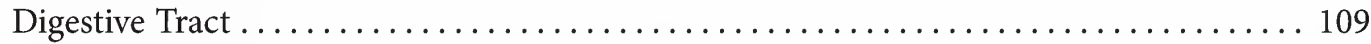

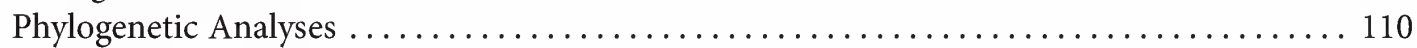

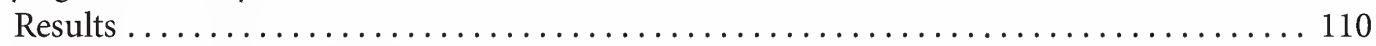

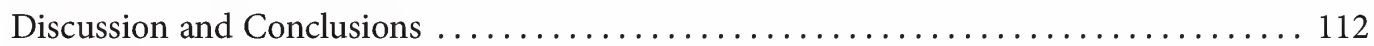

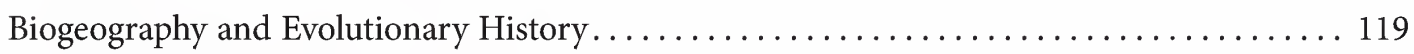

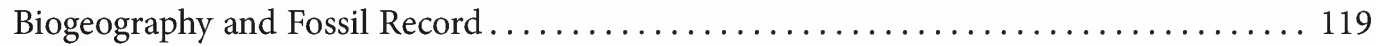

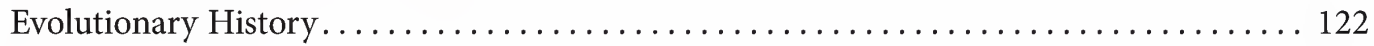

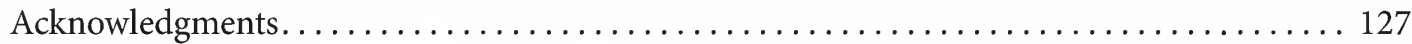

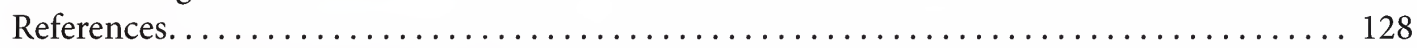

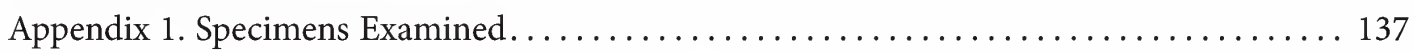




\begin{abstract}
A new genus and species of fossil bat, Koopmanycteris palaeomormoops, representing an ancient member of the endemic Neotropical family Mormoopidae, is described from the Oligocene of Florida. This new species is known from two paleokarst deposits in northern peninsular Florida, the early Oligocene (Whitneyan, 30-32 Ma) I-75 Local Fauna in Alachua County and the late Oligocene (early Arikareean, 26-28 Ma) Brooksville 2 Local Fauna in Hernando County. The discovery of Koopmanycteris extends the fossil record of the Mormoopidae back in time almost 30 million years. Compared to most other described taxa of North American Tertiary bats, the fossil sample of Koopmanycteris palaeomormoops is substantial, consisting of 50 specimens including: $\mathrm{P} 4$, all lower teeth from $\mathrm{p} 3$ through $\mathrm{m} 3$, dentary, petrosal, humerus, proximal radius, and femur. Koopmanycteris is morphologically intermediate between the two living genera of mormoopids, Mormoops and Pteronotus, but is most similar to the former taxon. Characters shared by Koopmanycteris and Mormoops include: large anterolabial basin on P4; large, double-rooted p3; secondary process ventral to angular process on dentary; absence of groove separating capitulum into medial and lateral portions on distal humerus; presence of prominent ridge on posterolateral edge of distal humeral shaft; rounded extremity on proximal radius; and presence of a prominent ridge or tubercle on posterodistal shaft of femur. All of these features appear to be relatively derived, with the exception of the large, double-rooted p3. In several mandibular characters, Koopmanycteris more closely resembles Pteronotus, including: pronounced posteroventral process on the symphysis; lack of curvature of ventral edge of horizontal ramus between posterior edge of symphysis and p4; and less pronounced dorsal upturning of ascending ramus compared to Mormoops. Koopmanycteris retains the primitive dental morphology of Mormoops, with a large double-rooted p3, and the primitive posterior mandibular morphology of Pteronotus, with the lesser degree of dorsal flexion of the ascending ramus. A phylogenetic analysis including all known extant mormoopid lineages as well as representative outgroups from other noctilionoid clades confirms that Koopmanycteris and Mormoops are sister taxa. These findings indicate that the lineages leading to Pteronotus and Mormoops were distinct by $\sim 30 \mathrm{Ma}$. The fossil record tentatively indicates that the Mormoopidae originated in North America in the early Oligocene or earlier, and may not have reached South America until the Pliocene following the onset of the Great American Biotic Interchange. Several lines of evidence support this hypothesis: (1) the earliest fossil record of the Mormoopidae is in the early Oligocene of Florida; (2) the greatest diversity and endemism of modern mormoopid species is in the West Indies; and (3) the absence of a pre-late Pleistocene record, lack of endemism, and marginal recent distribution of mormoopids in South America. Most species of living mormoopids are obligate cave dwellers, suggesting that the occurrence of caves and paleokarst deposits has affected both their modern distribution and fossil record.
\end{abstract}

\section{INTRODUCTION}

Mormoopidae is a small family of bats endemic to the Neotropics. As presently conceived, it comprises two genera (Mormoops and Pteronotus) and perhaps as many as 20 species, two of which are extinct late Pleistocene/Holocene forms (Smith, 1972; Simmons and Conway, 2001; Simmons, 2005a; Gutiérrez and Moliari, 2008; Clare et al., 2013; Thoisy et al., 2014; Pavan and Marroig, 2016, 2017; Pavan et al., 2018). Commonly known as leaf-chinned bats or ghost-faced bats, extant mormoopids range from the southwestern United States to southern Brazil, and are also widely distributed in the Caribbean (Koopman, 1993, 1994; Simmons, 2005a). The fossil range of many species is somewhat greater than their current ranges, with cave deposits in Brazil, peninsular Florida, and many islands in the Greater Antilles, Lesser Antilles, and Bahamas preserving mormoopid remains in areas that no longer support living populations (Cartelle and Abuhid, 1994; Czaplewski and Cartelle, 1998; Morgan, 2001; Velazco et al., 2013; Salles et al., 2014). However, 
prior to the discoveries reported here, which were mentioned in several previous papers as an undescribed genus and species of Oligocene mormoopid from Florida (e.g., Morgan and Czaplewski, 2012), no fossil mormoopids have been found in pre-Pleistocene deposits.

A new genus and species of bat belonging to Mormoopidae is described here based on a substantial collection of fossils from two Oligocene sites in northern peninsular Florida: the early Oligocene (Whitneyan North American Land Mammal Age, NALMA) I-75 Local Fauna (LF) in Alachua County and the late Oligocene (early Arikareean NALMA) Brooksville 2 LF in Hernando County (fig. 1). A total of 44 fossils from the type locality, Brooksville 2, and a smaller sample of six specimens from the somewhat older I-75 site together comprise the hypodigm for the new species. Altogether this sample includes more than 10 partial dentaries, most of the lower dentition, $\mathrm{P} 4$, petrosal, humerus, radius, and femur. The Florida Oligocene fossils share morphological characters with both living genera of mormoopids, Mormoops and Pteronotus, including features of the lower dentition, dentary, proximal and distal ends of the humerus, and proximal femur. However, the Florida Oligocene mormoopid possesses a suite of unique characters that establishes its distinctiveness at the generic level from both extant mormoopid genera. The oldest previous record of the family Mormoopidae consisted of a partial skeleton representing the extant Pteronotus parnellii complex from the early Pleistocene of El Salvador in Central America (Webb and Perrigo, 1984). The discovery of the Florida fossils therefore extends the fossil history of mormoopids back some 30 million years. In addition, this discovery provides new information on the early evolution, historical biogeography, and phylogenetic relationships of this interesting family of bats.

\section{MATERIALS AND METHODS}

Chiropteran dental terminology follows Menu and Sigé (1971) and Legendre (1985). The abbre- viations for tooth positions in mammals are standard, with upper case letters for upper teeth and lower case letters for lower teeth: I/i (upper/ lower incisors), $\mathrm{C} / \mathrm{c}$ (upper/lower canines), $\mathrm{P} / \mathrm{p}$ (upper/lower premolars), and $\mathrm{M} / \mathrm{m}$ (upper/lower molars). We use the terminology of Staněk (1933), Henson (1970a), Simmons and Geisler (1998), and Giannini et al. (2006) in describing the petrosal. The terminology for chiropteran postcranial elements follows Smith (1972), Czaplewski and Morgan (2000), and Morgan and Czaplewski (2003). Other abbreviations are: local fauna (LF); millions of years before present (Ma); North American land mammal age (NALMA). All measurements are in $\mathrm{mm}$ and were taken with an ocular micrometer inserted in the eyepiece of a Zeiss binocular microscope.

All of the I-75 mormoopid fossils and most of the Brooksville 2 specimens are housed in the vertebrate paleontology collection of the Florida Museum of Natural History, University of Florida, Gainesville (UF). A sample of six mormoopid fossils from Brooksville 2 is housed in the paleontology collection at the South Carolina State Museum in Columbia (SCSM). We compared the Brooksville 2 and I-75 mormoopid fossils to several skulls and complete skeletons of each of the extant species/species complexes of Mormoopidae. Comparisons of the fossil mormoopids to selected outgroup taxa, including genera representing the five other noctilionoid families (Furipteridae, Mystacinidae, Noctilionidae, Phyllostomidae, and Thyropteridae), as well as the emballonurid Saccopteryx bilineata, were limited to the dental and postcranial characters discussed in the section on Character Descriptions and State Distributions. The modern comparative skeletons of Mormoopidae and selected outgroup taxa (list of comparative material examined in appendix 1) are from the mammal collections of the American Museum of Natural History, New York (AMNH); the Florida Museum of Natural History, University of Florida (UF-M); the Museum of Southwestern Biology, Department of Biology, University of New Mexico (MSB); the Museum of Vertebrate Zool- 
ogy, University of California at Berkeley (MVZ); the Royal Ontario Museum, Toronto, Canada (ROM); the Oklahoma Museum of Natural History, University of Oklahoma (OMNH); and the National Museum of Natural History, Smithsonian Institution, Washington, DC (USNM). All recent specimens consist of skulls and mandibles with complete postcranial skeletons.

Our hypothesis of relationships is based on parsimony analyses including 10 mormoopid ingroups and 11 outgroup taxa. The ingroup sample includes the Floridian fossil taxon (Koopmanycteris palaeomormoops), two extant species of Mormoops, six extant lineages currently recognized in Pteronotus (see below), and a Pleistocene fossil Pteronotus (P. pristinus). We did not include Mormoops magna, a late Quaternary species from Cuba and Hispaniola, because it is known only from isolated humeri (Silva Taboada, 1974; Velazco et al., 2013). Recent analyses of gene sequences, morphometric data, and echolocation calls from across the range of mormoopids have shown that there are many previously unrecognized cryptic species in the genus Pteronotus, most notably among populations previously referred to $P$. parnellii but also in the $P$. davyi and $P$. personatus lineages (Lewis-Oritt et al., 2001; Dávalos, 2006; Gutiérrez and Moliari, 2008; Clare et al., 2013; Thoisy et al., 2014; Rojas et al., 2016; Pavan and Marroig, 2016, 2017; Pavan et al., 2018 ). Nevertheless, the traditionally recognized species appear to represent monophyletic lineages, so these taxa represent appropriate operational taxonomic units (OTUs) for phylogenetic analysis even if many are actually species complexes. Because the majority of our comparative data were collected prior to the recent recognition of multiple species in what was once called $P$. parnellii, we treated all these taxa as a single OTU, which we call the "Pteronotus parnellii complex." Nominal taxa included in this group are: $P$. parnellii sensu stricto, $P$. alitonus, $P$. pusillus, $P$. portoricensis, $P$. mexicanus, $P$. mesoamericanus, $P$. fuscus, $P$. paraguanensis, and P. rubiginosus. Monophyly of this group has been strongly supported in all recent analyses (Lewis-
Oritt et al., 2001; Dávalos, 2006; Gutiérrez and Moliari, 2008; Clare et al., 2013; Thoisy et al., 2014; Rojas et al., 2016; Pavan and Marroig, 2016, 2017; Pavan et al., 2018). Similarly, we included the "Pteronotus personatus complex" $(P$. personatus and P. psilotis) and "Pteronotus davyi complex" ( $P$. davyi and P. fulvus) as OTUs in our study. Monophyly of the Pteronotus personatus complex has been strongly supported in all analyses in which both personatus and psilotis have been sampled (Dávalos, 2006; Thoisy et al., 2014; Rojas et al., 2016; Pavan and Marroig, 2016, 2017). The situation is slightly more complicated with Pteronotus davyi. Weak support has been found in some studies (e.g., Thoisy et al., 2014; Rojas et al., 2016) for a sister-group relationship between $P$. davyi and $P$. gymnonotus excluding $P$. fulvus (long considered conspecific with $P$. davyi), which implies that $P$. davyi sensu lato is paraphyletic. However, more recent comprehensive analyses by Pavan and Morroig $(2016,2017)$ concluded that $P$. davyi and P. fulvus are in fact sister taxa, so we treated them together as the "Pteronotus davyi complex" in this study.

We included 11 outgroups in our study, 10 of which represent other noctilionoid families. This set of taxa included three extant members of Phyllostomidae (Macrotus waterhousii, Macrotus californicus, and Artibeus jamaicensis), two members of Noctilionidae (Noctilio albiventris and Noctilio leporinus), one member of Furipteridae (Furipterus horrens), one member of Thyropteridae (Thyroptera tricolor), and two members of Mystacinidae (Mystacina tuberculata and Mystacina robusta). The inclusion of Thyropteridae and Furipteridae in Noctilionoidea has received strong support in numerous analyses of large molecular data sets (e.g., Hoofer et al., 2003; Teeling et al., 2005, 2012; Miller-Butterworth et al., 2007; Meredith et al., 2011; Rojas et al., 2016).

We additionally included in our study one member of the extinct family Speonycteridae (Speonycteris aurantiadens), a fossil noctilionoid group described by Czaplewski and Morgan (2012) based on specimens from I-75 and Brooksville 2. A second species of Speonycteris, S. natu- 
ralis, was excluded from our phylogenetic analysis because it was described from a single tooth. Based on an unconstrained analysis of over 100 craniodental characters, Czaplewski and Morgan (2012) concluded that Speonycteris was a crown clade noctilionoid but could not be placed confidently in any extant family. Depending on the subset of taxa and characters used, Speonycteris was found to variously fall either closer to Mormoopidae or Phyllostomidae. Sometimes Speonycteris was placed as the sister group to a Mormoopidae + Noctilionidae + Mystacinidae clade; it always grouped with Mormoopidae, Phyllostomidae, Noctilionidae, and Mystacinidae, but never within any of these groups (Czaplewski and Morgan, 2012). Accordingly, including Speonycteris in our analysis was necessary to fully evaluate the relationships of Koopmanycteris.

Finally, an 11th taxon, Saccopteryx bilineata (Emballonuridae), was included to provide an unambiguous root for our phylogenetic trees. Emballonurids fall well outside the noctilionoid clade in all recent phylogenetic analyses (Hoofer et al., 2003; Teeling et al., 2005, 2012; MillerButterworth et al., 2007; Meredith et al., 2011), and the availability of extensive comparative morphological data for Saccopteryx in Simmons and Conway (2001) made it an attractive choice as a distal outgroup to root our trees. We chose not to include in our sample any representatives of Myzopodidae, a Malagasy endemic family sometimes recovered as the most basal branch within Noctilionoidea (e.g., Teeling et al., 2005, 2012; Miller-Butterworth et al., 2007; Gunnell et al., 2014), because more comprehensive analyses by Meredith et al. (2011) and Amador et al. (2018) found support for placement of Myzopodidae outside Noctilionoidea as either the basal branch in Vespertilionoidea or as the sister group of Emballonuroidea.

We employed an expanded version of Simmons and Conway's (2001) morphological data set to evaluate relationships of Koopmanycteris. Representatives of Thyropteridae and Furipteridae were not included in that study because the authors did not accept their relationship to noc- tilionoids, instead relying on Simmons and Geisler's (1998) assessment of higher-level bat relationships to guide outgroup choice. Because there is now overwhelming evidence that thyropterids and furipterids nest high in the noctilionoid tree, we considered it prudent to include them in our study for the sake of completeness. Including these additional taxa as well as Koopmanycteris and Speonycteris required us to expand the breadth of data sampled for analysis. We added 36 new characters as well as additional character states to many existing characters to accommodate the morphologies seen among the larger taxon sample in our study. The revised data set included 21 taxa and 245 characters, representing a $24 \%$ increase in the number of species and a $17 \%$ increase in the number of characters over those employed in Simmons and Conway's (2001) analyses. The resulting ratio of characters to taxa was 11.67. Many of the new characters we added to the data set involve features of the lower jaw and dentition, petrosal, humerus, and femur, which are the elements known for Koopmanycteris.

As was done by Simmons and Conway (2001), we used reductive character coding and hierarchical characters sensu Simmons (1993) and Wilkinson (1995). Missing data resulting from either lack of observations or appropriately preserved specimens (scored "NPA" for "not presently available") or the effects of evolution (scored “-" for inapplicable) ranged from $0.4 \%$ to $29.4 \%$ across the extant taxa sampled (mean = $13.1 \%)$. Missing data rates for the fossil taxa were much higher, ranging from $75.1 \%$ to $86.9 \%$ (mean $=80.9 \%)$. Most of the morphological characters were binary $(164=67 \%)$, and the remaining characters were multistate $(81=33 \%)$. Fifty-four multistate characters described progressive gradations in size, shape, degree of development, meristic counts, or color patterns, and these were treated as ordered in analyses. The remaining multistate characters were treated as unordered.

Our complete data set includes 35 characters of the dentition, 34 characters of the skull, 5 
characters of the vomeronasal complex and the brain, 19 characters of the trachea and hyoid apparatus, 7 characters of the tongue and oral cavity, 24 characters of the face, ears, and vibrissae, 14 characters of pelage and patagia, 74 characters of the postcranial skeleton, 21 characters of postcranial myology, 6 characters of the reproductive tract, and 5 features of the digestive tract. Of these, Koopmanycteris palaeomormoops could be scored for 61 characters, or $24.9 \%$ of the total. Pteronotus pristinus, another fossil mormoopid, was scored for 47 characters or $19.2 \%$ of the total characters. Speonycteris aurantiadens, the third fossil in our study, could be scored for only 32 characters, or $13.1 \%$ of the total characters. Additional details of the character set are described in the Character Descriptions section below. The matrix resulting from these data is published online and can be accessed through MorphoBank (http://www.morphobank.org/) as MorphoBank Project 240.

We used PAUP* Version 4.0, build 161 (Swofford, 2002) for phylogenetic analyses and MacClade 4.08a (Maddison and Maddison, 2005) to investigate character optimizations. All parsimony analyses were run as heuristic searches with 10,000 replications, a random addition sequence, and stepwise addition. Bootstrap analyses were run with 10,000 replicates with maxtrees set to 1000 . We ran multiple analyses of our data set including parsimony analyses based on all morphological characters (including soft tissue features and others that could not be scored in the fossil), osteological characters only (dental, cranial, and postcranial characters), and a scaffold analysis (including all characters) in which relationships among the extant taxa were constrained based on results of previous molecular studies. Relationships among outgroups in the scaffold followed Meredith et al. (2011) and Rojas et al. (2016) for relationships among extant families, and the scaffold for ingroup relationships (i.e., among extant mormoopid lineages) was based on Dávalos (2006), Rojas et al. (2016), and Pavan and Marroig $(2016,2017)$. Trees in all analyses were rooted with Saccopteryx bilineata.

\section{GEOLOGIC SETTING}

Surface outcrops throughout much of northern peninsular Florida consist of marine limestones of Eocene and Oligocene age. Sometime in the late early Oligocene, about 30 million years ago (Ma), Florida first emerged above sea level. Throughout most of the remainder of the Cenozoic, some portion of the Florida peninsula was above water depending upon changes in relative sea level. From the Oligocene to the Recent, northern Florida's highly soluble Paleogene limestones have been acted upon by both chemical and physical erosional processes that have caused them to develop into one of the most extensive karst terrains in North America (Lane, 1986). From a paleontological standpoint, the most significant aspect of the northern Florida karst geomorphic province is the abundance of terrestrial vertebrate deposits occurring in current or former caves, fissures, and sinkholes (Morgan and Hulbert, 2008). The Paleogene limestones in northern Florida are commercially mined for road bedding and other construction materials. Most of the fossil deposits in paleokarst features have been discovered as a result of these mining operations. Several hundred named vertebrate fossil sites of karst origin are known from this region. Nowhere else in North America are paleokarst vertebrate fossil deposits of Cenozoic age found in such abundance. The oldest of these fossil sites is early Oligocene (Whitneyan) in age and sites are found throughout the remainder of the Cenozoic, with the largest concentration in the late Pleistocene (Rancholabrean).

The richest Tertiary bat faunas known from Florida, including I-75 (early Oligocene), Brooksville 2 (late Oligocene), and Thomas Farm (early Miocene), were derived from sediment-filled fissures or sinkholes in Paleogene limestones. The presence of bat fossils in these and many other paleokarst deposits from northern peninsular Florida strongly indicates that some, if not most, of these sites represent the remnants of former cave systems. These paleokarst deposits often con- 
tain substantial samples of other groups of small vertebrates in addition to bats, including frogs, salamanders, lizards, snakes, and birds, as well as marsupials, insectivores, lagomorphs, and rodents (Morgan and Hulbert, 2008; Morgan and Czaplewski, 2012; Czaplewski and Morgan, 2012). Like other karst deposits, these consist of isolated pockets of sediment that cannot be directly correlated stratigraphically. However, the abundance of small mammals, as well as other groups of agediagnostic mammals such as carnivores, horses, and artiodactyls, generally allows detailed biochronologic comparisons with other faunas of similar age in Florida and western North America (Tedford et al., 2004).

\section{FOSSIL LOCALITIES}

I-75 Local Fauna: The I-75 Local Fauna (LF) was discovered in 1965 during the construction of Interstate Highway 75 (I-75) through the southwestern edge of Gainesville, Alachua County, in northern peninsular Florida (fig. 1). The site was located in a roadcut at the southwest corner of the intersection of I-75 and Florida State Route 121, but was destroyed by road building activities shortly after its discovery. Mervin Kontrovitz of the University of Florida initially discovered the I-75 site, which was worked by Florida State Museum (now Florida Museum of Natural History) field crews. The fossiliferous sediments in the I-75 site consisted of massive, slightly sandy, dark brown to black clays, deposited in a small karst solution feature $5 \mathrm{~m}$ in diameter and $2 \mathrm{~m}$ deep, developed in Eocene marine limestone (Patton, 1969).

Considering the small size of the fossiliferous deposit, the I-75 site has a rather extensive vertebrate fauna composed of about 45 species. Patton (1969) provided a preliminary vertebrate faunal list from the I-75 site and Holman (1999) and Holman and Harrison $(2000,2001)$ described the snake fauna, but most of the mammals from this site are still unpublished. The fossils from I-75 are mostly fragmentary, consisting of isolated teeth, ends of limb bones, carpals, tarsals, and phalanges. The lower vertebrate fauna includes anurans (both bufonids and scaphiopodids), indeterminate sirenid salamanders, a small land tortoise, a pond turtle, the lizard Peltosaurus, and an impressive snake fauna consisting of nine species of boids and colubrids (Holman, 1999). The fauna of large mammals (see below) consists of (from Patton, 1969; Hayes, 2000, 2005): two species of carnivores (amphicyonid Daphoenus and the small mustelid Palaeogale), a horse (Miohippus sp.), a tayassuid, two small oreodonts, and a small leptomerycid artiodactyl (Leptomeryx sp.) that is the most abundant mammal in the fauna.

The diverse microvertebrate fauna from I-75 was recovered through the use of standard screenwashing techniques. In the 1960s, screens finer than standard window screen were not in general use and thus teeth of very small taxa probably were lost. Small mammals from the I-75 LF include a marsupial (Herpetotherium $\mathrm{cf}$. $H$. merriami; Hayes, 2005), a large lipotyphlan (Centetodon cf. C. wolff), seven species of bats (two undescribed emballonurids, the basal noctilionoids Speonycteris aurantiadens and S. naturalis, the mormoopid Koopmanycteris palaeomormoops, a natalid, and a vespertilionid (Morgan and Czaplewski, 2003, 2012, in prep.; Czaplewski and Morgan, 2012), a lagomorph (Palaeolagus sp.), and four species of rodents (Eutypomys sp., a heteromyid, and two eomyids).

Marine vertebrates also were recovered from I-75, including sharks, rays, and bony fish (Patton, 1969; Tessman, 1969). Because of the association of marine, freshwater, and terrestrial taxa, Patton (1969) suggested that there may have been some reworking of the I-75 deposit. Subsequent studies have shown that numerous late Paleogene and Neogene sites throughout Florida document the association of marine and terrestrial vertebrates, although the taphonomic explanation for this faunal mixture is as yet unclear (Morgan, 1993a). In the majority of Florida sites containing a mixture of marine and nonmarine vertebrates, the marine vertebrates far outnumber the terrestrial component 


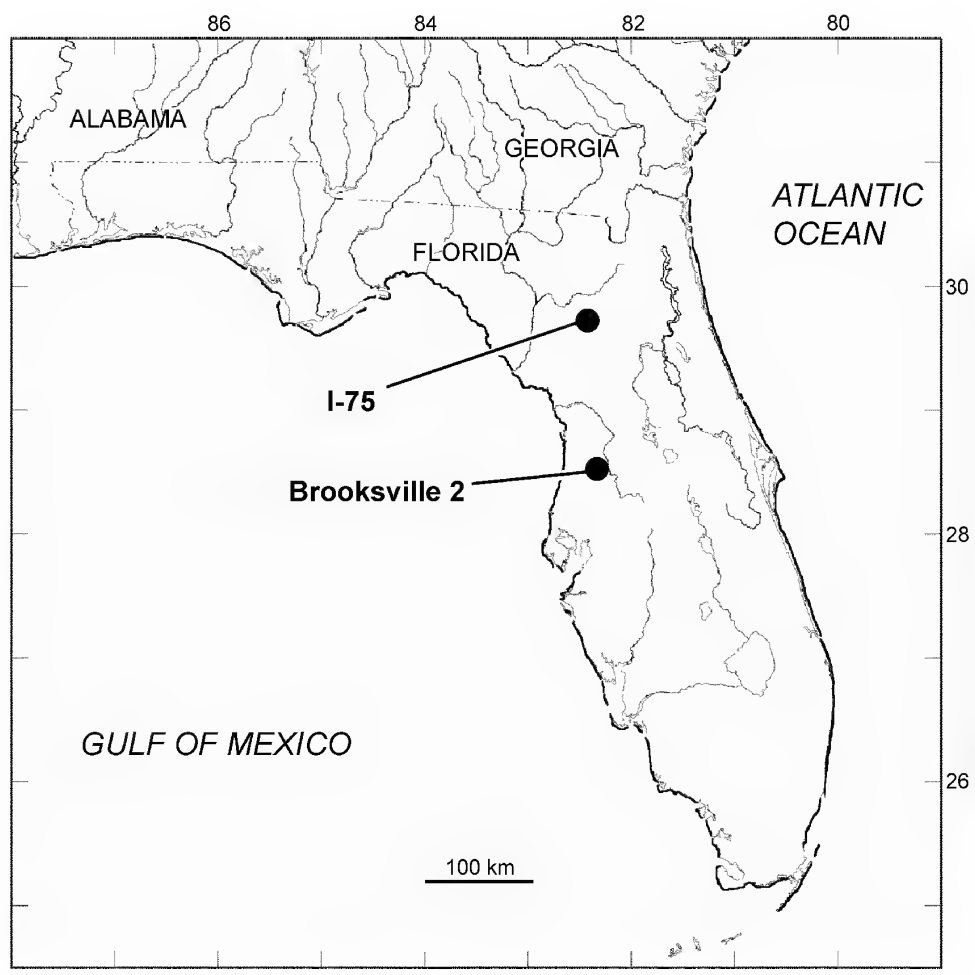

FIGURE 1. Map of Florida showing the location of the two known fossil sites for Koopmanycteris palaeomormoops, the early Oligocene (Whitneyan) I-75 Local Fauna, Alachua County, and the late Oligocene (early Arikareean) Brooksville 2 Local Fauna, Hernando County.

of the fauna, and most teeth of small mammals are isolated and show some evidence of transport and water wear. However, terrestrial vertebrates dominate the I-75 fauna and there are several partial mandibles and maxillae with teeth representing bats and other small mammals. Furthermore, most of the isolated teeth and limb bones are well preserved and show little evidence of water wear. The most plausible explanation would seem to be that the terrestrial vertebrates from the I-75 site were deposited subaerially in a small cave or fissure. Shortly thereafter, sea level rose and the marine vertebrates were deposited, with minor reworking. Florida had only recently emerged above sea level in the late early Oligocene and probably consisted of a short, narrow peninsula of very low relief. A slight rise in sea level would have been sufficient to inundate most of the land present in Florida at that time, including the cave/fissure represented by the I-75 site.

I-75 is the oldest land vertebrate fauna known from Florida, considered to be Whitneyan (early Oligocene) by Patton (1969) and most subsequent workers (Savage and Russell, 1983; Emry et al., 1987; Prothero and Emry, 2004). The Whitneyan NALMA represents a restricted interval of time in the early Oligocene (30-32 Ma, Woodburne and Swisher, 1995; Prothero and Emry, 2004). Whitneyan faunas have not been definitively recognized outside of the northern Great Plains in Nebraska and South Dakota. The following is a brief discussion of the most biochronologically diagnostic land mammals present in the I-75 fauna.

Four isolated teeth of a brachydont horse from I-75 are identified as Miohippus sp., although Patton referred these teeth to Mesohip- 
pus. These teeth compare more closely to those of Miohippus than Mesohippus on the basis of the characters discussed by Prothero and Shubin (1989), including larger size and well-developed hypostyles on the upper molars. Miohippus occurs from the Chadronian through the early Arikareean, but is most typical of Whitneyan and Arikareean faunas (Emry et al., 1987; Prothero and Shubin, 1989). The I-75 Miohippus teeth appear to be most similar in size and morphology to those of $M$. intermedius from the late Whitneyan of South Dakota. A large sample of isolated teeth is tentatively referred to the small leptomerycid artiodactyl Leptomeryx. Patton (1969) and Hayes (2005) referred these teeth to Nanotragulus; however, the I-75 taxon lacks diagnostic features of the Arikareean genus Nanotragulus (Frailey, 1979). Leptomeryx occurs from the Chadronian through the early Arikareean, whereas Nanotragulus first appears in the early Arikareean (Prothero and Emry, 2004; Tedford et al., 2004).

The geolabidid lipotyphlan Centetodon is represented in the I-75 LF by a partial upper molar and three complete lower molars. The morphology and size of the I-75 Centetodon teeth are similar to those of $C$. wolff from the Orellan and Whitneyan of South Dakota, the largest species in the genus (Lillegraven et al., 1981). Hayes (2005) identified two upper molars from I-75 as the marsupial Herpetotherium cf. H. merriami, originally described from the early Arikareean John Day Formation of Oregon. A single upper cheektooth of a small leporid is tentatively referred to Palaeolagus, the most common rabbit in Orellan and Whitneyan faunas, which went extinct in the early Arikareean. The large beaverlike rodent Eutypomys is represented by about 20 teeth from the I-75 fauna. Eutypomys is typical of Whitneyan and Orellan faunas in the Great Plains, but survived into the early Arikareean (Macdonald, 1963, 1970; Tedford et al., 1996; Prothero and Emry, 2004).

The mammals present in the I-75 site do not clearly establish the age of this fauna because most of the age-diagnostic taxa range from the
Orellan through the early Arikareean. The presence of Centetodon, Palaeolagus, Eutypomys, Miohippus, and Leptomeryx establishes a pre-late Arikareean age (older than $26 \mathrm{Ma}$; Lillegraven et al., 1981; Tedford et al., 1996, 2004; Albright et al., 2008), as these genera are not known to survive into the late Arikareean. All five of these genera occur in both the Orellan and Whitneyan. A post-Orellan age is suggested by the presence of an advanced species of Miohippus near $M$. intermedius. The similarity of bats from I-75 and Brooksville 2 suggests these two faunas are fairly close in age. The absence of mammals from I-75 that are clearly indicative of the Arikareean (e.g., Nanotragulus) favors a Whitneyan age, probably late Whitneyan (about 30-31 Ma; Prothero and Emry, 2004), which is just a few million years older than the late early Arikareean (26-28 Ma) Brooksville 2 LF. Although the chiropteran faunas from I-75 and Brooksville 2 are similar, the remainder of the mammalian assemblages from these two sites has few species in common (Hayes, 2000).

The I-75 site provides the earliest record of the taxonomic diversity and community structure of North American middle Cenozoic chiropteran faunas. About 40 specimens representing seven species of bats are known from I-75, including: Koopmanycteris palaeomormoops, the new genus and species of Mormoopidae described herein; two new species, one large and one small, belonging to an undescribed genus of Emballonuridae; one large and one small species of Speonycteris, S. aurantiadens and $S$. naturalis, respectively, described as a new family (Speonycteridae) of basal noctilionoids; an indeterminate genus and species of Natalidae; and a large species of Vespertilionidae (Morgan and Czaplewski, 2003, 2012, in prep.; Czaplewski and Morgan, 2012). The most abundant bats in the I-75 fauna are the large emballonurid and the mormoopid Koopmanycteris.

BrooksviLle 2 LF: The Brooksville 2 site was discovered in 1994 in an abandoned limestone quarry about $10 \mathrm{~km}$ northeast of Brooksville in Hernando County in west-central Florida (fig. 
1). The site consists of clays and sands filling karst solution features in the marine lower Oligocene Suwannee Limestone (Hayes, 2000). FLMNH field crews visited the site on a number of occasions between April 1994 and February 1995. Vertebrate fossils were found scattered on the surface; however, because of the abundance of microvertebrates and the rarity of larger mammals, the fossils were collected primarily by screenwashing. A total of approximately $500 \mathrm{~kg}$ of sediments were collected and washed from the Brooksville 2 site, constituting a large portion of the fossiliferous sediments contained in the solution features (Hayes, 2000).

The vertebrate assemblage from Brooksville 2 is composed predominantly of small terrestrial vertebrates, including frogs, lizards, snakes, and a diverse fauna of small mammals. Mediumsized mammals are represented primarily by isolated teeth, and large mammals, such as rhinocerotids, are absent. Hayes (2000) described the Brooksville lipotyphlans, carnivores, lagomorphs, and selected taxa of rodents, and briefly reviewed the ungulates, and Hayes (2005) described the marsupials. Morgan and Czaplewski (2012) discussed the chiropteran fauna from Brooksville 2, and Czaplewski and Morgan (2012) described a new bat from this site, Speonycteris aurantiadens. Mead (2013) reported three vertebrae of a tiny scolecophidian snake from Brooksville 2. The ungulates and carnivores from the site include: a horse (Miohippus sp.); an indeterminate oreodont; two small artiodactyls (Nanotragulus loomisi and the camelid Nothokemas waldropi); and six species of carnivores (the tiny enigmatic Palaeogale minuta, the musteloids Acheronictis webbi and Arikarictis chapini, and the canids Enhydrocyon cf. E. pahinsintewakpa, Osbornodon wangi, and Phlaocyon taylori). In addition to bats, the small mammal fauna consists of a didelphid marsupial (Herpetotherium fugax), two lipotyphlans (the geolabidid Centetodon magnus and the erinaceid Parvericius montanus), a lagomorph (Megalagus abaconis), and numerous rodents including several species of sciurids, several eomyids, two het- eromyids, a castorid (Agnotocastor sp.), and an undescribed genus and species of entoptychine geomyid (Hayes, 2000, 2005).

Hayes (2000) determined the age of the Brooksville 2 LF through biochronologic comparisons with other Florida and Gulf Coast Arikareean faunas (Albright, 1998) and with Arikareean faunas from western North America. Preservation of the Brooksville fossils in an isolated karst feature precludes direct stratigraphic correlation with described Oligocene and Miocene stratigraphic units from northern Florida. We follow Albright et al. (2008) for the updated calibration and subdivisions of the Arikareean NALMA. The maximum age of Brooksville 2 is constrained by the presence of the erinaceid Parvericius and entoptychine rodents, both of which appear at the beginning of the late early Arikareean (Ar2, 28 Ma; Tedford et al., 1996). The minimum age is limited by the occurrence of Centetodon, Megalagus, Agnotocastor, and Miohippus, all of which are thought to have become extinct at the end of the early Arikareean ( $26 \mathrm{Ma})$. Albright et al. (2008) recorded the range of Miohippus as extending into the early late Arikareean (Ar3) in the John Formation of Oregon, disappearing at about $24 \mathrm{Ma}$. On the basis of the first and last occurrences of these mammalian genera, Hayes (2000) placed the Brooksville 2 LF in the late early or "medial" Arikareean (late Oligocene, between 24 and $28 \mathrm{Ma}$; Ar2 of Woodburne and Swisher, 1995, and Tedford et al., 2004). The updated calibration of the Arikareean places the Ar2/Ar3 boundary at 26 $\mathrm{Ma}$, with the time range of the Ar2 restricted to 26-28 Ma (Albright et al., 2008). The similarity between the chiropteran faunas of the Whitneyan I-75 LF and the Brooksville 2 LF supports an early Arikareean age for Brooksville, between 26 and $28 \mathrm{Ma}$. Other Florida Arikareean faunas include Cow House Slough, Live Oak/SB 1A, White Springs, and Buda (Frailey, 1978, 1979; Albright, 1998; Hayes, 2000; MacFadden and Morgan, 2003; Czaplewski and Morgan, 2015).

The chiropteran sample from Brooksville 2 consists of about 200 fossils representing five 
species, including: the small mormoopid Koopmanycteris palaeomormoops described herein; the large bat Speonycteris aurantiadens in the extinct family Speonycteridae; two undescribed species, one large and one small, representing a new genus of emballonurid; and an isolated tooth of a large molossid (Czaplewski et al., 2003a; Czaplewski and Morgan, 2012; Morgan and Czaplewski, 2012, in prep.). Brooksville shares all these species, except the molossid, with the I-75 site. After Thomas Farm, Brooksville 2 has the second largest bat sample from any North American mid-Cenozoic site, and the third most diverse bat fauna following Thomas Farm and I-75. The Brooksville 2 and I-75 bat faunas are numerically dominated by taxa from two families currently restricted to the tropics, Mormoopidae and Emballonuridae.

SYSTEMATIC PALEONTOLOGY

\section{ORDER CHIROPTERA BLUMENBACH, 1779}

\section{SUBORDER YANGOCHIROPTERA KOOPMAN, 1985}

FAMILY MORMOOPIDAE SAUSSURE, 1860

\section{Koopmanycteris palaeomormoops,}

gen. et sp. nov.

Figures 2-13

Holotype: UF 157765, right dentary with $\mathrm{p} 4-\mathrm{m} 3$ and alveoli for i1-p3, from Brooksville 2 LF, early Arikareean, Hernando County, Florida.

Paratypes: All specimens are from the Brooksville 2 LF. SCSM 2004.35.1, partial right dentary with $\mathrm{m} 1-\mathrm{m} 3$ and complete ascending ramus; UF 209954, right dentary fragment with p3 and alveoli for i1-p1; UF 182782, left P4; UF 179949, complete left humerus; UF 179922, left proximal radius; UF 179948 , left proximal femur; UF 179947, right distal femur.

Referred Specimens: Brooksville 2 Local Fauna: UF 179985, partial right dentary with p4m2; UF 179951, partial right dentary with p4, $\mathrm{m} 2$ and alveoli for $\mathrm{c}-\mathrm{p} 3, \mathrm{m1}$; UF 157767, partial left dentary with m1-m2; SCSM 2004.35.2, left dentary fragment with m1-m2; UF 157766, partial right dentary with $\mathrm{m} 2-\mathrm{m} 3$, including most of the ascending ramus except for the tip of the coronoid process; SCSM 2004.35.3, partial left dentary with $\mathrm{m} 3$ and complete ascending ramus; SCSM 2004.35.4, partial right dentary with p3; UF 179957, edentulous left dentary with partial ascending ramus; UF 179990, UF 182816, right m1 (2); UF 182815, left m1; UF 182810, right m2; UF 179901, right petrosal; UF 179937, right proximal humerus; SCSM 2004.35.5, left proximal humerus; UF 179907, 179908, 179938; right distal humerus (3); UF 179905, 179906, left distal humerus (2); UF 179917-179919, 1179941, right proximal radius (4); UF 179916, 179920, 179921, 179923-179925, 179943, 179970, 179973, 209955, left proximal radius (10); SCSM 2004.35.6, left proximal femur.

I-75 Local Fauna: UF 121718, partial left dentary with $\mathrm{p} 4$, trigonid of $\mathrm{m} 1$, and alveolus for $\mathrm{p} 3$; UF 121719, partial left dentary with $\mathrm{p} 4$ and alveoli for i2-p3; UF 121720, partial right dentary with $\mathrm{m} 1$ and alveoli for $\mathrm{p} 3-\mathrm{p} 4$; UF 121733, edentulous partial left dentary with alveoli for $\mathrm{m} 2-$ $\mathrm{m} 3$ and anterior edge of ascending ramus ; UF 121721, left proximal femur; UF 121722, right proximal femur.

Type Locality: Brooksville 2 Local Fauna, Hernando County, Florida, late early Arikareean (Ar2), late Oligocene.

Етумоlogy: The generic epithet derives from Koopman, in honor of the late Karl F. Koopman, formerly of the American Museum of Natural History, in recognition of his monumental contributions to our knowledge of the systematics, evolution, and biogeography of the Chiroptera, and nycteris, Greek meaning "bat." The specific epithet is composed of palaeos, Greek for "ancient" or "old," mormo, Greek for a kind of nighttime monster or ghost, and ops, Greek for "face."The species name "palaeomormoops" or "ancient ghost face" alludes to this species being the oldest known member of the ghost-faced bat family Mormoopidae, and also 
indicates its phylogenetic relationship with the extant genus Mormoops.

Diagnosis: Lower p3 large, double rooted, outline in occlusal view diamond shaped, with anterior portion of tooth rounded and posterior portion pointed. Lower p4 squarish to slightly rectangular in occlusal view, somewhat narrower anteriorly than posteriorly, with well-developed cingulum on anterior, labial, and posterior margins, but with cingular development weak to absent on the lingual margin. Lower $\mathrm{m} 1$ and $\mathrm{m} 2$ nyctalodont. Paraconid on $\mathrm{m} 1$ highly reduced, positioned labially about halfway between protoconid and metaconid. Metaconid on $\mathrm{m} 1$ and $\mathrm{m} 2$ taller than entoconid. Dentary with ascending ramus strongly upturned dorsally compared to horizontal ramus; angular process and articular condyle both located well dorsal to alveolar margin of toothrow; coronoid process with its anterior edge essentially vertical; articular condyle located well dorsal to tip of coronoid process; small secondary process present on ascending ramus immediately ventral to angular process. Upper P4 with large, rounded anterior basin, broad talon basin, and tall, sharp central cusp (protocone). Proximal humerus with head elliptical in shape, transversely flattened and directed proximally, and angled toward lesser trochanter. Distal humerus with articular surface moderately offset laterally from humeral shaft; capitulum not differentiated into medial and lateral ridges; well-developed spinous process separated from medial edge of trochlea by deep notch; epitrochlea a well-developed rounded process with small concavity at proximomedial corner. Proximal end of radius gently rounded, not triangular. Proximal articular surface of radius with two articular facets. Femur with greater trochanter and lesser trochanter highly reduced; greater trochanter larger than lesser trochanter and triangular in shape. Distinct tubercle or short ridge present on posterodistal femoral shaft just proximal to distal articular surface. Femur comparatively long, more than three times longer than alveolar length of toothrow.

\section{DESCRIPTION AND COMPARISONS}

Dentary and Lower Dentition: The type specimen of Koopmanycteris palaeomormoops (UF 157765, fig. 2) is a right dentary that preserves the entire horizontal ramus with $\mathrm{p} 4-\mathrm{m} 3$ and the alveoli for the incisors, canine, and p1, p3. The teeth and dentary of Koopmanycteris (tables 1,2 ) are similar in overall size to those of the Pteronotus davyi complex and Mormoops blainvillei (use of this spelling rather than blainvillii follows Opinion 462 of the International Commission on Zoological Nomenclature, 1958).

Koopmanycteris has three lower premolars, which is the primitive condition in bats (Simmons and Geisler, 1998; Giannini and Simmons, 2007a). All mormoopids retain three lower premolars, although the morphology of the intermediate premolar (p3) varies among the genera. The identity of the anteriormost of the lower premolars is controversial. The maximum number of premolars known among extant eutherians is four, meaning that one premolar was lost in the lineage leading to bats (Giannini and Simmons, 2007a). Most authors have followed Miller (1907) in considering $\mathrm{p} 1$ as the missing lower premolar in bats; however, Thomas (1908), Simmons and Conway (2001), and Giannini and Simmons (2007a) regarded the first lower premolar as the $\mathrm{p} 1$, and considered the $\mathrm{p} 2$ to be the missing lower premolar in the Chiroptera. For the reasons discussed in Giannini and Simmons (2007a), we consider the anteriormost lower premolar in mormoopids and other bats with three premolars to be the p1. See more detailed discussion below under Character Descriptions (char. 14).

The type dentary has the same dental and alveolar formula as seen in Mormoops: two incisors, canine, a large single-rooted $\mathrm{pl}$, a fairly large double-rooted p3 (represented only by an alveolus in the type; $\mathrm{p} 3$ is present in two other dentaries from Brooksville 2), a large double-rooted $\mathrm{p} 4$, and double-rooted $\mathrm{m} 1-\mathrm{m} 3$. The presence of a large, double-rooted $\mathrm{p} 3$ readily distinguishes the type and other dentaries of Koopmanycteris from all species of Pteronotus, which have a tiny, sin- 


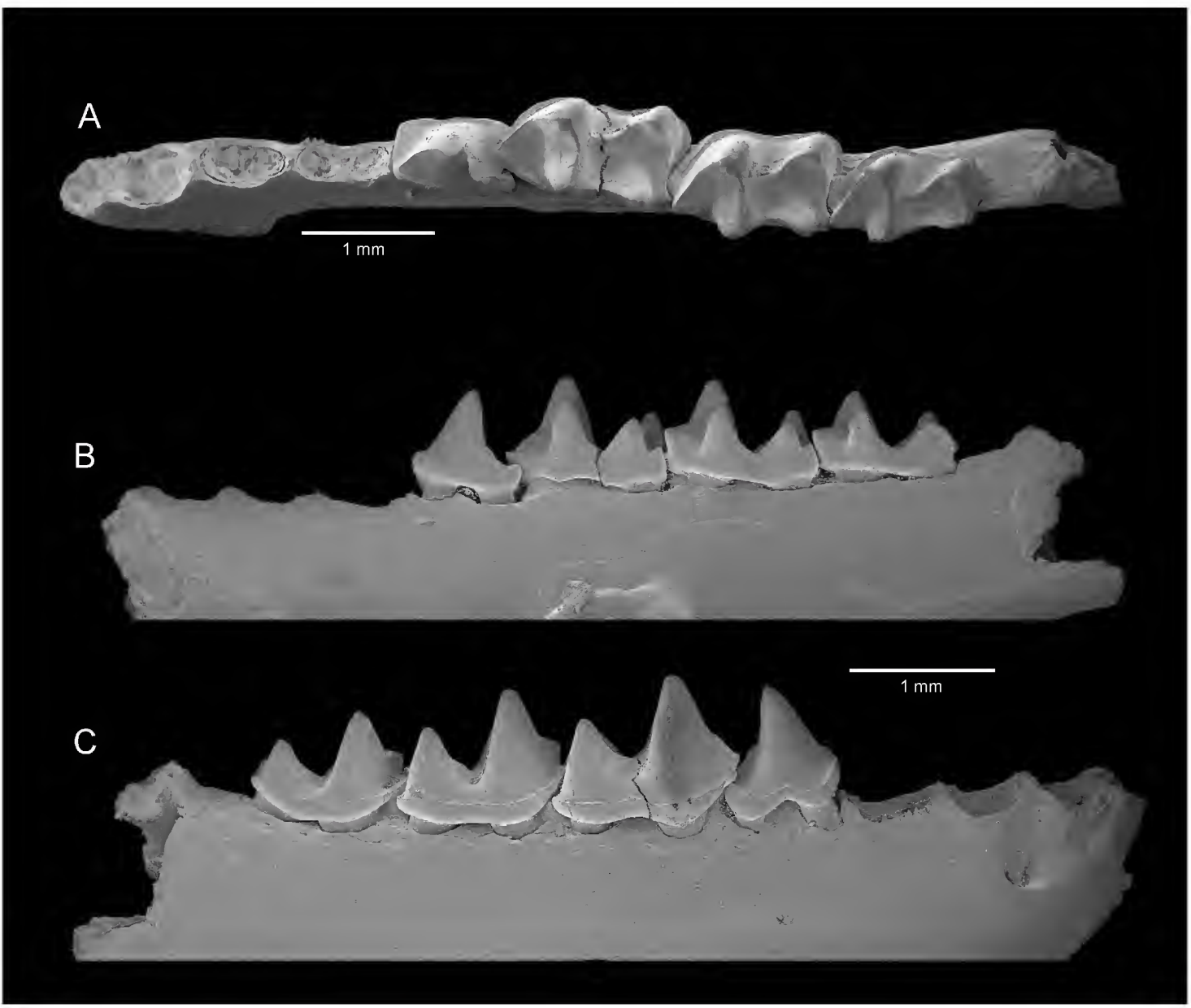

FIGURE 2. Koopmanycteris palaeomormoops, new genus and species, from the late Oligocene (early Arikareean) Brooksville 2 Local Fauna, Hernando County, Florida. Holotype (UF 157765) right dentary with p4$\mathrm{m} 3$ in $\mathbf{A}$, occlusal, $\mathbf{B}$, lingual, and $\mathbf{C}$, labial views.

gle-rooted p3. The extinct genus Speonycteris has a very small, double-rooted p3. Only one of the two described species of Speonycteris, S. aurantiadens, is known from the lower dentition (Czaplewski and Morgan, 2012). All further comparisons of the lower dentition and dentary of Speonycteris are of $S$. aurantiadens.

No mandibles of Koopmanycteris preserve the lower incisors, canine, or p1. Isolated teeth representing these tooth positions are also absent in the sample of Koopmanycteris. However, the alveoli for these teeth are present in several specimens (alveolar measurements in table 1), including: three dentaries from Brooksville 2; the holotype
(UF 157765) and paratype (UF 209954), both of which have the alveoli for i1, i2, canine, and pl, and a partial mandible with the alveolus for $\mathrm{p} 1$ (UF 179951); and a dentary from I-75 with alveoli for the canine and p1 (UF 121791). The alveoli for the canine and single-rooted $\mathrm{pl}$ are similar in size and shape. Both are elliptical, somewhat elongated anteroposteriorly, with the canine alveolus slightly larger, more rounded, and broader. The $\mathrm{pl}$ alveolus is separated from the canine alveolus anteriorly and the $\mathrm{p} 3$ alveolus posteriorly by thin ridges of bone. No diastemata separate the $\mathrm{p} 1$ from either the canine or $\mathrm{p} 3$. The alveoli for the il and i2 are similar in size and shape, with the il alveo- 
TABLE 1

Measurements (in mm) of the Alveoli of the Lower Incisors, Canine, and First Premolar of Koopmanycteris palaeomormoops

All measurements are of the alveoli for the tooth position listed, not the actual teeth. Abbreviations: APL, anteroposterior length; W, maximum width; N, sample size;

$\mathrm{OR}$, observed range; and $\mathrm{X}$, mean.

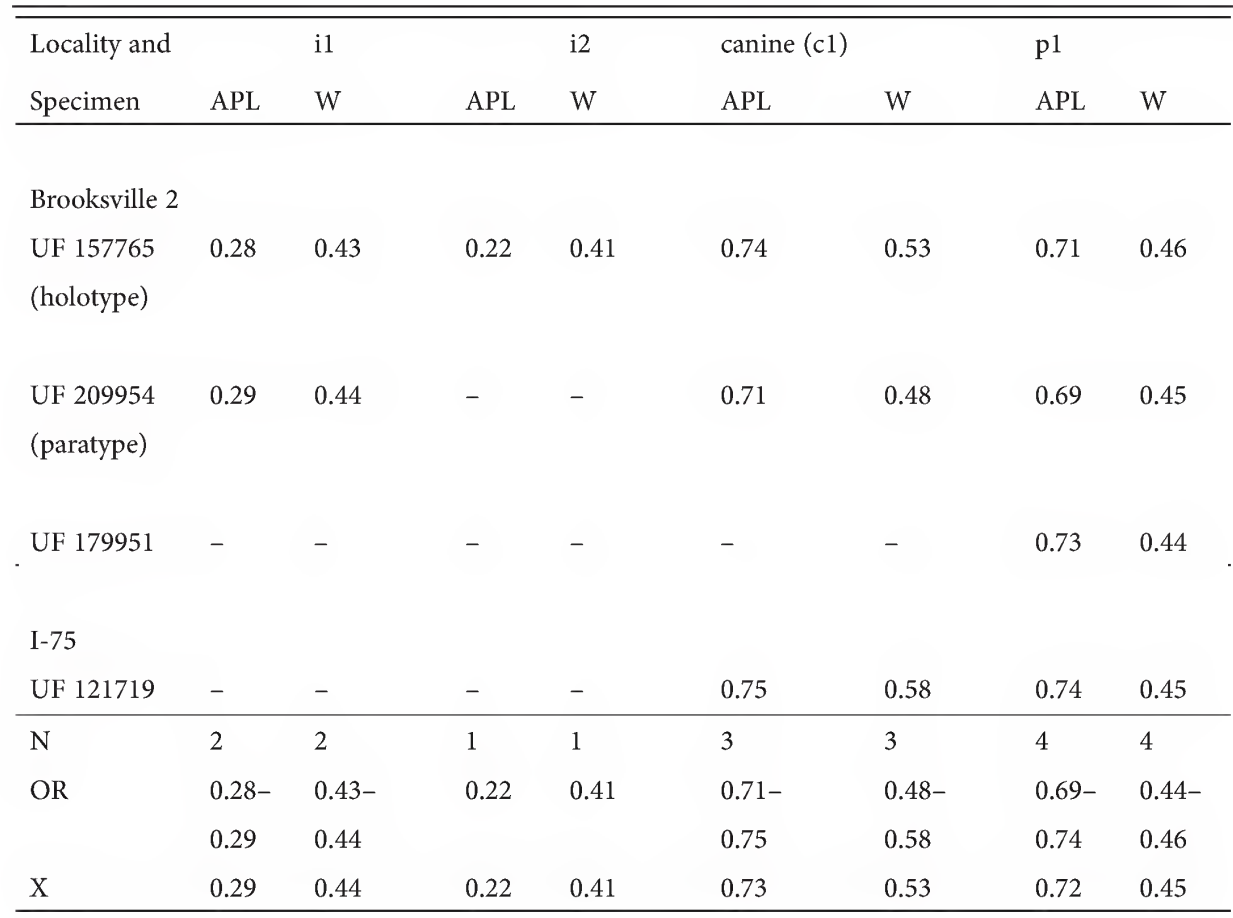

lus slightly larger (table 1). Both alveoli are compressed anteroposteriorly and are nearly twice as wide transversely as long. The il is just posterior to the mandibular symphysis, while the i2 is located slightly posterior and labial to the il and anterior and lingual to the canine.

Koopmanycteris lacks diastemata between the lower premolars, reflecting an anteroposterior compression of the lower premolar series compared to extant Mormoops. There is a distinct diastema or gap between $\mathrm{p} 3$ and $\mathrm{p} 4$ in $M$. megalophylla and a narrower diastema between $\mathrm{p} 1$ and $\mathrm{p} 3$. The $\mathrm{p} 3$ and $\mathrm{p} 4$ are more elongated and rectangular in $M$. blainvillei and the diastemata between $\mathrm{p} 1$ and $\mathrm{p} 3$ and between $\mathrm{p} 3$ and $\mathrm{p} 4$ are present but reduced compared to M. megalophylla. All species of Pteronotus lack diastemata between the lower premolars and have a highly reduced $\mathrm{p} 3$, and therefore the entire premolar region in members of this genus is anteroposteriorly compressed compared to Mormoops and, to a lesser extent, Koopmanycteris. Speonycteris is more similar to Pteronotus in having a very small p3, and also lacks diastemata between the premolars. A comparison of the alveolar length of the premolar series (posterior alveolus of canine to posterior alveolus of $\mathrm{p} 4$ ) to the alveolar length of the lower toothrow (posterior alveolus of canine to posterior alveolus of $\mathrm{m} 3$ ) provides a general indication of the degree of premolar compression in the mormoopid genera. The premolars comprise $42 \%-45 \%$ of the alveolar toothrow length in Mormoops, whereas the premolars comprise only $31 \%-33 \%$ of the alveolar toothrow length in Pteronotus. The length of the premolar series in Koopmanycteris is $38 \%$ of the 


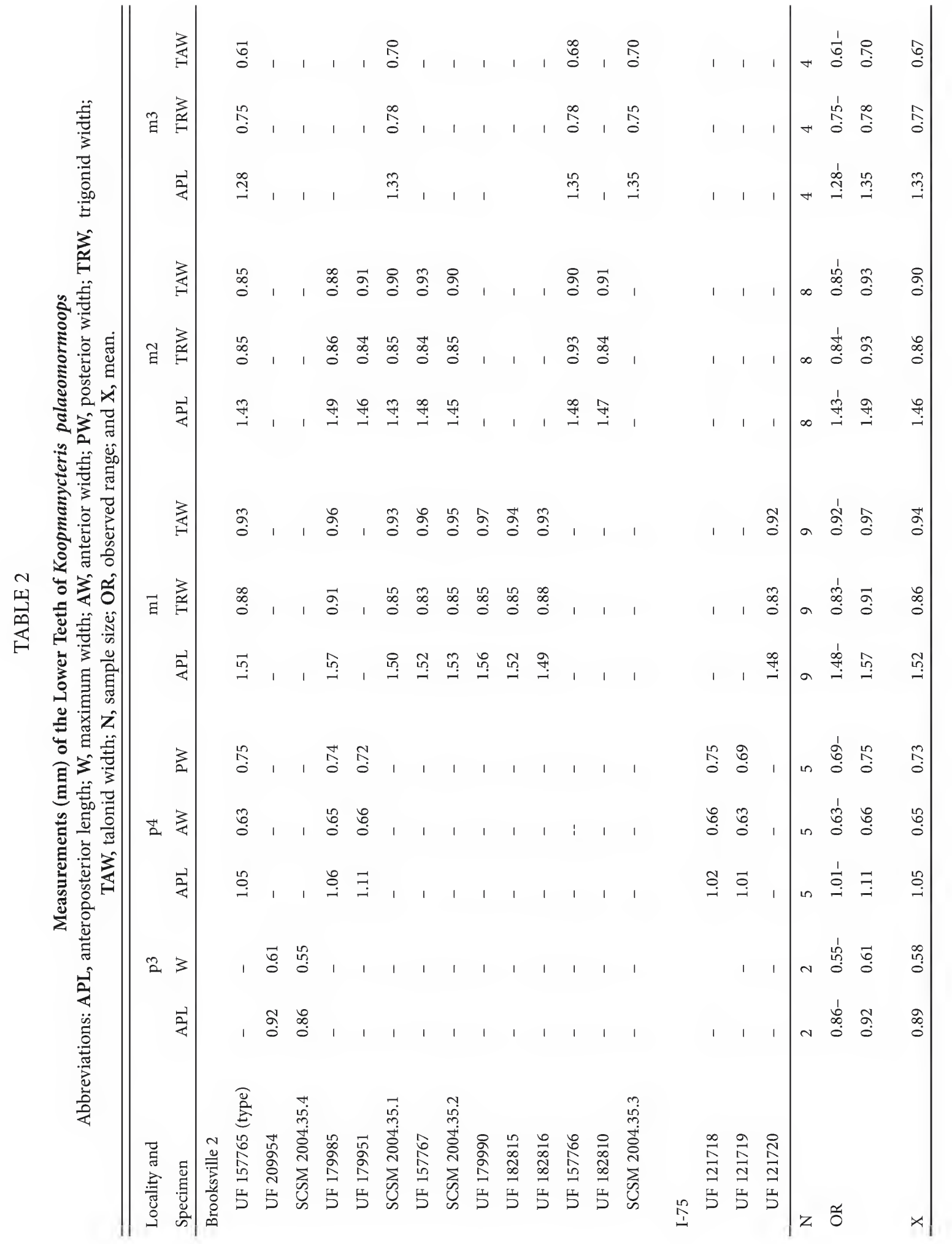


alveolar length in the holotype, the only fossil specimen in which this measurement could be taken. Thus, Koopmanycteris is intermediate between the two living genera in the length of the premolar series, longer than Pteronotus because of the large unreduced $\mathrm{p} 3$ but shorter than Mormoops because of the lack of diastemata between the premolars. The length of the premolars in Speonycteris is $35 \%$ and $36 \%$ of the alveolar toothrow length in the two dentaries in which measurements could be taken, intermediate between Koopmanycteris and Pteronotus.

Only the two alveoli for $\mathrm{p} 3$ are present in the holotype dentary of Koopmanycteris palaeomormoops. However, two other partial dentaries from Brooksville 2 contain a well-preserved p3, UF 209954 (paratype; fig. 3, table 2) and SCSM.2004.35.4. The p3 in these two specimens is a fairly large, double-rooted tooth. It is diamond shaped in occlusal view, somewhat longer than wide, with the anterior point of the diamond slightly more rounded and the posterior tip more sharply pointed. There is a conical, centrally located protoconid. A strong ridge or crest connects the anterior point of the p3 with the central cusp. A somewhat lower crest connects the central cusp to the posterior tip of the tooth. In labial view, the $\mathrm{p} 3$ is sharply triangular in shape. The anteriormost extension of the $\mathrm{p} 3$ is situated at a slightly higher level than the posterior extension of this tooth, which terminates in a rather prominent cuspid. There is a strong labial cingulum. The lingual cingulum is weaker, especially posteriorly. The $\mathrm{p} 3$ differs somewhat between the two species of Mormoops, but in general is rectangular in occlusal aspect rather than diamond shaped as in Koopmanycteris, and is about one and one-half to two times as long as wide. Even though Mormoops megalophylla is larger than Koopmanycteris in most dental measurements, the $\mathrm{p} 3$ of the fossil is more robust, similar in length but much broader. The $\mathrm{p} 3$ of Koopmanycteris is totally unlike the $\mathrm{p} 3$ in all species of Pteronotus, which is tiny, round, and single rooted. The p3 of Speonycteris is much smaller than in Koopmanycteris, broader than long, and has a more rounded occlusal outline, not diamond shaped. Although the $\mathrm{p} 3$ of Speonycteris is very small as in Pteronotus, it is unlike that genus in being double rooted, with a strong basal cingulum and a sharp conical main cusp. The diamond-shaped $\mathrm{p} 3$, with a sharply pointed cuspid medially positioned on the posterior edge, is unique to Koopmanycteris within the Mormoopidae. In fact, the configuration of the $\mathrm{p} 3$ is diagnostic for each of these four genera: large, rectangular, and two-rooted in Mormoops; large, diamond shaped, and two-rooted in Koopmanycteris; small, roundish (broader than long), and two-rooted in Speonycteris; and tiny, round, and single rooted in Pteronotus.

The $\mathrm{p} 4$ in the holotype of Koopmanycteris palaeomormoops is two-rooted, squarish to slightly rectangular in occlusal view, a little longer than wide, and somewhat narrower on the anterior margin and broader on the posterior margin. This tooth has a sharp conical cusp that is centrally positioned or very slightly posterior to the midpoint of the tooth, with the tip oriented somewhat posteriorly. In labial view, the main cusp is acutely triangular in shape and terminates in a sharp point that is slightly lower than the protoconid of $\mathrm{m} 1$. Low crests connect the tip of the central cusp to small cusps located on the anterolingual and posterolingual corners. Well-developed anterior, labial, and posterior cingula are present, but the lingual cingulum is weak. On the labial side are two downswept portions of the crown and cingulum, one above each root, separated by a prominent median notch. These curves give the basal portion of the crown and labial cingulum a notably sinuous shape in labial view. The p4 in Koopmanycteris is comparatively broader than in Mormoops. The anterior margin is straight (at a right angle to the long axis of toothrow) in both Koopmanycteris and Mormoops with no indentation for the p3. In Pteronotus, the anterolingual margin of $\mathrm{p} 4$ has a distinct notch or indentation where it contacts the posterior edge of $\mathrm{p} 3$. The $\mathrm{p} 4$ of Koopmanycteris is similar in size to that of Mormoops megalophylla, even though the molars of M. megalophylla are considerably larger. The p4s 


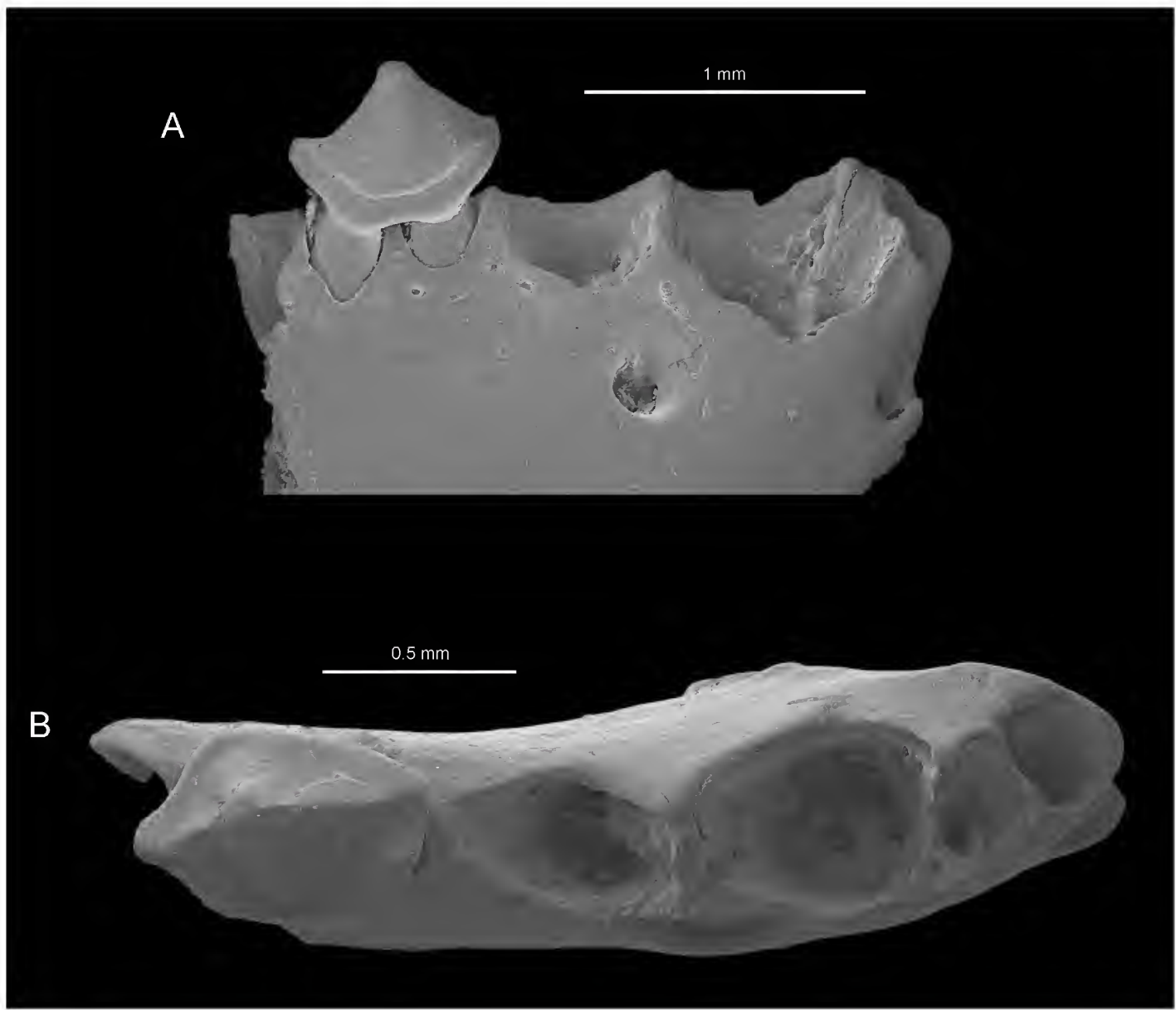

FIGURE 3. Koopmanycteris palaeomormoops, anterior portion of right dentary with $\mathrm{p} 3$ and alveoli for incisors, canine, and single-rooted p1 (UF 209954, paratype) in A, labial and B, occlusal views.

of M. megalophylla and Koopmanycteris are similar in morphology, whereas the $\mathrm{p} 4$ of $M$. blainvillei is more rectangular and elongated, almost twice as long as it is wide. Compared to that of Speonycteris, the $\mathrm{p} 4$ of Koopmanycteris is much smaller, more rectangular in occlusal outline (compared to squarish in Speonycteris), the main cusp is shorter, more triangular in shape, and more posteriorly oriented, and the tooth lacks a prominent posterolingual cuspid on the lingual cingulum.

The lower premolars in the species of Pteronotus differ from one another somewhat in size and shape, but all Pteronotus possess a greatly reduced, single rooted, circular, peglike p3 located on the lingual margin of the toothrow.
This character alone readily distinguishes all species of Pteronotus from Koopmanycteris palaeomormoops, which has a comparatively large, unreduced, double-rooted p3. In most species of Pteronotus, the posterolabial corner of the pland the anterolabial corner of $\mathrm{p} 4$ come fairly close to meeting along the labial margin of the toothrow. The large p1 and p4 in Speonycteris are located rather close to one another but are clearly separated by the much smaller $\mathrm{p} 3$. The $\mathrm{p} 1$ and $\mathrm{p} 4$ are widely separated in Koopmanycteris and Mormoops by the unreduced p3. Even though the lower molars of Koopmanycteris palaeomormoops and Pteronotus davyi are similar in size, the fossil species has a considerably longer mandibular 
toothrow because of its unreduced premolars, especially the $\mathrm{p} 3$.

The $\mathrm{m} 1$ and $\mathrm{m} 2$ of Koopmanycteris have a similar morphology and, unless otherwise noted, the following description applies to both teeth (figs. 4, 5; see measurements in table 2). Except for the paraconid, the cusps on both teeth are fairly tall and sharply triangular in shape. The paraconid is the smallest of the major cusps and is especially reduced on $\mathrm{ml}$. The protoconid is the tallest cusp, followed by the metaconid. The entoconid and hypoconid are approximately the same height. In labial view, the protoconid is about twice as tall as the hypoconid. In lingual view, the metaconid is distinctly taller than the entoconid, although these two cusps are much closer in size than either is to the much larger protoconid. The talonid is slightly broader than the trigonid. The paraconid differs between $\mathrm{m} 1$ and $\mathrm{m} 2$ and will be described separately for the two teeth. The paraconid on $\mathrm{ml}$ is very small, forming a low, flat shelf at almost the same level as the trigonid valley. The paraconid is not located on the lingual margin on $\mathrm{ml}$ but is offset labially toward the middle of the tooth, about halfway between the metaconid and protoconid. The paraconid is barely one-quarter the height of the metaconid. The paraconid on $\mathrm{m} 2$ is larger and somewhat taller than on $\mathrm{m} 1$, about half as tall as the metaconid. The paraconid is located slightly labial to the lingual margin on $\mathrm{m} 2$ but is not offset as far labially as on $\mathrm{m} 1$. Because of the reduced paraconid on $\mathrm{m} 1$ compared to $\mathrm{m} 2$, the paracristid also differs between the two teeth. About halfway between the paraconid and protoconid on $\mathrm{m} 1$, the paracristid has a distinct notch that forms a gently obtuse angle $\left(\sim 150^{\circ}\right)$. Posterior to this notch, the paracristid rises almost vertically to the protoconid. Because the paraconid is larger on $\mathrm{m} 2$, the notch in the paracristid forms a much sharper angle between the paraconid and protoconid $\left(\sim 100^{\circ}\right)$. The protocristid on $\mathrm{ml}$ and $\mathrm{m} 2$ is not quite perpendicular to the long axis of the tooth, angling slightly posteriorly from the protoconid to the metaconid.
The entocristid on $\mathrm{m} 1$ and $\mathrm{m} 2$ is narrow, sharp, and runs parallel to the lingual margin of the tooth. It originates at the base of the metaconid and forms a deep, acutely angled notch between the metaconid and entoconid. The cristid obliqua originates at the base of the trigonid about halfway between the protoconid and metaconid. This crest connects to the trigonid in a slightly more labial position in $\mathrm{m} 1$ than in $\mathrm{m} 2$, and thus forms a less acute angle with the hypoconid on $\mathrm{m} 1$ as compared to $\mathrm{m} 2$. The cristid obliqua bears a shallow but distinct notch where it contacts the hypoconid. Both the $\mathrm{m} 1$ and $\mathrm{m} 2$ are nyctalodont; the postcristid connects the hypoconid to the hypoconulid, and the entoconid is separated from the hypoconulid and postcristid by a narrow valley. The labial cingulum is well developed; it is broad labial to the trigonid but narrower labial to the talonid. There is a narrow but distinct distal cingulum that is continuous with the labial cingulum around the base of the hypoconid, and extends lingually to the base of the hypoconulid. A lingual cingulum is absent.

The $\mathrm{m} 3$ of Koopmanycteris is similar to the $\mathrm{m} 2$, and most of the features described in the preceding paragraphs also apply to $\mathrm{m} 3$. The most notable difference between the $\mathrm{m} 3$ and the $\mathrm{m} 1 /$ $\mathrm{m} 2$ of Koopmanycteris is that the entoconid is greatly reduced and does not form a prominent cusp. However, the entoconid is clearly separate from and anterior to the lingual end of the postcristid, so $\mathrm{m} 3$ is nyctalodont like $\mathrm{m} 1$ and $\mathrm{m} 2$. The hypoconulid is also notably smaller on $\mathrm{m} 3$ than $\mathrm{m} 1 / \mathrm{m} 2$. The talonid is distinctly narrower than the trigonid on $\mathrm{m} 3$ (table 2), whereas the talonid is slightly broader than the trigonid on $\mathrm{m} 1 / \mathrm{m} 2$. The distal cingulum extends almost to the lingual margin of the tooth on $\mathrm{m} 3$; this cingulum terminates at the base of the hypoconulid on $\mathrm{m} 1 / \mathrm{m} 2$.

The lower molars of Koopmanycteris are broader and shorter than in Mormoops, but are narrower than in Speonycteris and most species of Pteronotus. The $\mathrm{m} 1$ and $\mathrm{m} 2$ in the fossils are more similar to Mormoops, but are broader transversely, and the cusps are not as delicate 
and spikelike. The cusps on the fossil are more inflated and bulbous than in Mormoops, but not as inflated as in Pteronotus. The $\mathrm{ml}$ of Mormoops is longer than in Koopmanycteris, especially the trigonid and in particular the paraconid, which is elongated into a narrow, sharp, anteriorly oriented, triangular-shaped cusp that overlaps the posterior one-third of the p4 extending to the base of the main cusp in Mormoops. The paraconid is shorter in Koopmanycteris, barely overlapping the posterior cingulum and posterolingual cusp on $\mathrm{p} 4$. The anterior cingulum of $\mathrm{ml}$ overlaps the posterior margin of $\mathrm{p} 4$ in Pteronotus and Speonycteris, whereas the paraconid of $\mathrm{ml}$ overlaps the posterior edge of p4 in Koopmanycteris and Mormoops. The paraconid on $\mathrm{m} 1$ is much smaller in Koopmanycteris than in either of the two living genera or Speonycteris, and is located farther labially, about halfway between the protoconid and metaconid. The $\mathrm{ml}$ paraconid is slightly labial to the lingual margin in Mormoops and is on the lingual margin in Pteronotus and Speonycteris. The paraconid on $\mathrm{ml}$ is barely onequarter the height of the metaconid in Koopmanycteris, about half the height of the metaconid in Mormoops, and about three-quarters the height of the metaconid in Pteronotus and Speonycteris. The trigonid is noticeably compressed anteroposteriorly on $\mathrm{m} 1 / \mathrm{m} 2$ in Pteronotus and Speonycteris compared to Koopmanycteris and Mormoops, with the result being that the trigonid is shorter than the talonid. The trigonid is slightly longer than the talonid on the $\mathrm{m} 1$ of Koopmanycteris and Mormoops, and on $\mathrm{m} 2$ the trigonid and talonid are approximately equal in length. Another result of the anteroposterior compression of the trigonid in Pteronotus and Speonycteris is that the paraconid is located farther posteriorly, and thus the angle formed between the paracristid and protocristid is more sharply acute than in either Koopmanycteris or Mormoops. The metaconid is distinctly taller than the entoconid in Koopmanycteris, whereas these two cusps are approximately equal in height in Mormoops, Pteronotus, and Speonycte- ris. The talonids on $\mathrm{m} 1$ and $\mathrm{m} 2$ in Koopmanycteris and Mormoops are slightly broader than the trigonids, whereas in Pteronotus and Speonycteris the talonids are considerably broader than the trigonids. Both Koopmanycteris and Mormoops have a deep talonid basin that has the appearance of a pit immediately posterior to the trigonid on $\mathrm{m} 1$ and $\mathrm{m} 2$. The talonid basin is shallower in Pteronotus. The cristid obliqua on the $\mathrm{m} 1$ and $\mathrm{m} 2$ of Pteronotus connects to the trigonid in a more lingual position than in Koopmanycteris and Mormoops, and thus this crest forms a more acute angle with the trigonid in Pteronotus compared with the other two genera. Like Koopmanycteris, the $\mathrm{m} 1$ and $\mathrm{m} 2$ of Mormoops and Speonycteris are nyctalodont (the postcristid connects the hypoconid with the hypoconulid). Three taxa in Pteronotus ( $P$. macleayii, $P$. quadridens, and the $P$. personatus complex) have a nyctalodont $\mathrm{m} 1$ and $\mathrm{m} 2$. In contrast, the remaining species of Pteronotus ( $P$. gymnonotus and members of the $P$. davyi and $P$. parnellii complexes) have a myotodont $\mathrm{m} 1$ and $\mathrm{m} 2$ in which the postcristid connects the hypoconid and entoconid, leaving the hypoconulid as a small, separate cusp projecting posteriorly from the posterolingual margin of the tooth. The $\mathrm{m} 3$ is nyctalodont in all mormoopids that have a hypoconulid on that tooth (Koopmanycteris and Mormoops).

Figure 4 is a composite drawing showing the restoration of the dentary of Koopmanycteris palaeomormoops, based on the holotype (UF 157765) and several other UF and SCSM specimens. The dentary of Koopmanycteris is comparatively long and slender. In lateral view, the ventral margin of the horizontal ramus is essentially straight posterior to the symphysis between the $\mathrm{p} 3$ and $\mathrm{ml}$, curves ventrally below the $\mathrm{m} 2$, and curves back dorsally under the $\mathrm{m} 3$. The mandibular symphysis is shaped like an elongated ellipse oriented at a $45^{\circ}$ angle to the toothrow, and it extends posteriorly to the level of the mental foramen between $\mathrm{c}$ and p1. There is a prominent, posteriorly oriented, hooklike process on the posteroventral edge of the symphysis in the fossil. The type dentary of Koop- 

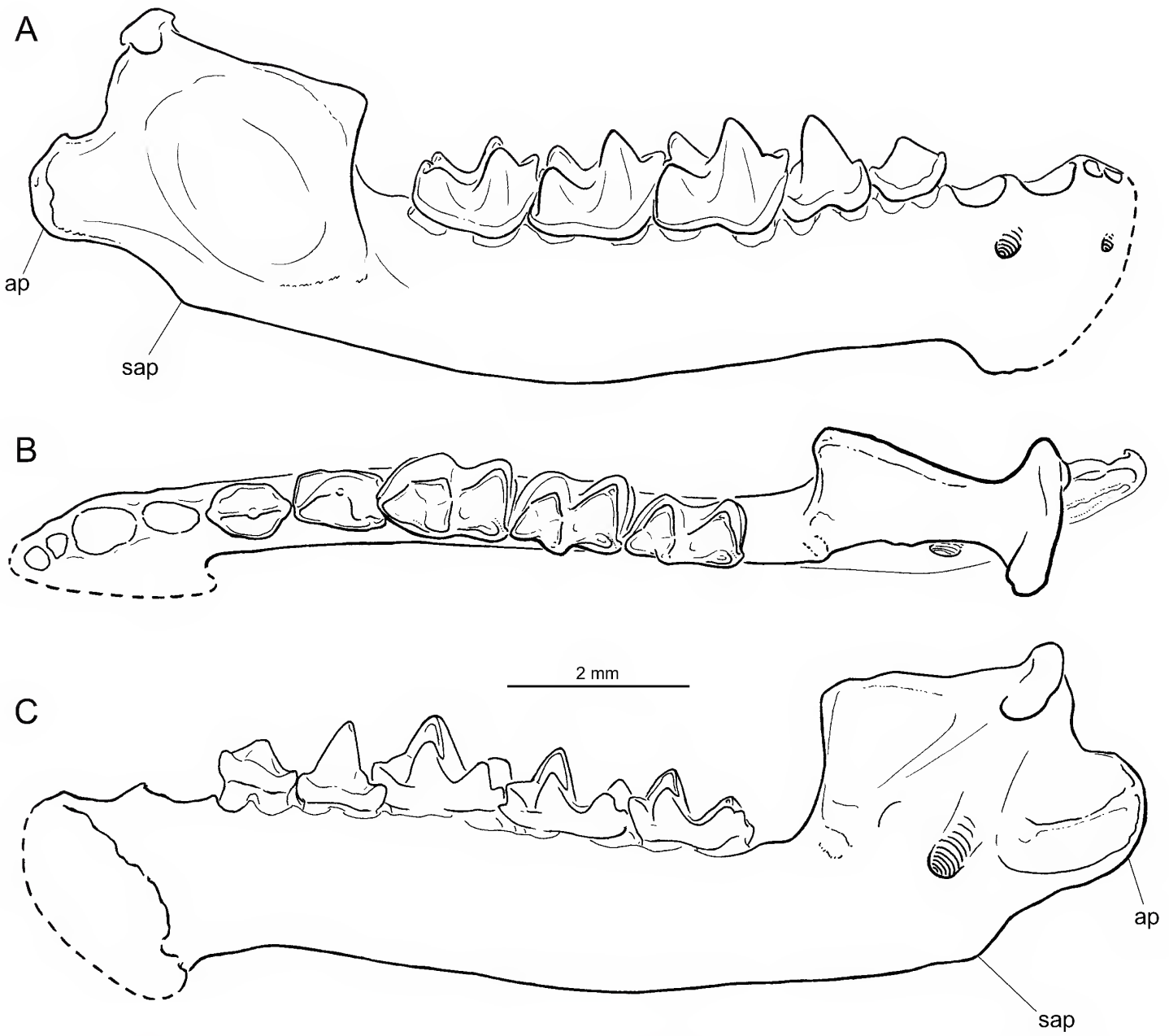

FIGURE 4. Outline restoration of the lower jaw of Koopmanycteris palaeomormoops based on several UF and SCSM specimens. A, labial view; B, occlusal view; C, lingual view. Abbreviations: ap, angular process; sap, secondary angular process.

manycteris has a deep, rounded, pitlike mental foramen located between the canine and $\mathrm{p} 1$ alveoli, about halfway between the alveolar toothrow and the ventral edge of the horizontal ramus.

The degree of ventral curvature of the dentary in Koopmanycteris is most similar to Pteronotus in which the horizontal ramus also reaches its maximum downward curvature ventral to the $\mathrm{m} 2$. The ventral margin of the dentary is more highly curved in Mormoops, with a distinct dorsal curvature or concavity ventral to the premolars, and then becomes strongly convex posteriorly reaching its maximum curvature ventral to $\mathrm{m} 3$. The ventral edge of the dentary in Speonycteris is essentially straight below the entire toothrow. Compared to Koopmanycteris, the mandibular symphysis in Mormoops forms a shallower or more obstuse angle with the toothrow and extends somewhat farther posteriorly, ventral to the $\mathrm{p} 1$, and the posteroventral process is weak to absent. The mandibular symphysis in Pteronotus is more similar to that of Koopmanycteris; it forms a sharper angle with the toothrow than in Mormoops although not as acute as in the fossils. The symphysis in Pteronotus extends posteriorly ventral to the $\mathrm{p} 1$ or $\mathrm{p} 3$, and the posteroventral process is present. The man- 
dibular symphysis of Speonycteris is similar to that of Koopmanycteris, forming about a $45^{\circ}$ angle with the toothrow, extending posteriorly below the p1, and with a distinct process on its posteroventral extremity. The mental foramen is small in Mormoops compared with the fossils and is located in a more ventral position. Pteronotus has a larger mental foramen than Mormoops, but it is not as large or as deep as in the holotype of Koopmanycteris, and like Mormoops it is located lower on the dentary than in the fossil. The mental foramen of Speonycteris is located in a similar position to that of Koopmanycteris, between the canine and $\mathrm{p} 1$ alveoli, slightly above the midline between the alveolar margin of the toothrow and the ventral edge of the horizontal ramus. There is some variation in the dorsoventral position of the mental foramen in Koopmanycteris (see below), slightly above the midline in several referred dentaries but about midway between the toothrow and ventral edge of the ramus in the type dentary.

Two partial right dentaries of Koopmanycteris palaeomormoops from Brooksville 2 (UF 209954, fig. 3; SCSM 2004.35.4) preserve the anterior portion of the jaw, including the mandibular symphysis and p3, and the alveoli for $\mathrm{i} 1-\mathrm{i} 2, \mathrm{c}$, and p1. These two dentaries are very similar and thus the following description applies to both specimens. They also agree closely with the holotype dentary of K. palaeomormoops, although the horizontal ramus is somewhat more robust. The number, morphology, and size of the incisor, canine, and premolar alveoli and the morphology of the mandibular symphysis are similar in the three specimens. UF 209954 has a very small, round anterior mental foramen located on the mandibular symphysis directly ventral to the first incisor and at the same level on the ramus as the larger posterior (= primary) mental foramen. The type dentary and SCSM 2004.35.4 are slightly damaged in this area, and thus the tiny anterior mental foramen is not preserved. In UF 209954, both mental foramina are positioned slightly above the midline between the ventral and alveolar margins of the horizontal ramus. Compared to the type, the primary mental foramen in these two dentaries is not quite as large and is located in a slightly more dorsal position. It is clear from the alveoli of $\mathrm{p} 1, \mathrm{p} 3$, and $\mathrm{p} 4$ in the type dentary, and in UF 209954 and SCSM 2004.35.4, that there were no diastemata present between the lower premolars in Koopmanycteris.

Three dentaries of Koopmanycteris from Brooksville 2 preserve the posterior portion of the horizontal ramus and the ascending ramus with the articular condyle and the coronoid and angular processes (SCSM 2004.35.1, paratype, fig. 5; SCSM 2004.35.3; UF 157766, fig. 6). The anatomical position of the ascending ramus is described relative to the alveolar plane of the mandibular toothrow. The mandibular toothrow is assumed to be horizontal and the other morphological features are described as located ventral or dorsal to the toothrow. However, this is with the understanding that these descriptions may not accurately represent the true anatomical position of the dentary. According to Smith (1972), Czarnecki and Kallen (1980), and Simmons and Conway (2001), the rostrum of Mormoops and Pteronotus is upturned dorsally, not the braincase, and therefore the plane of the mandibular toothrow is not horizontal in life position, but angles ventrally from anterior to posterior. No cranial fragments of Koopmanycteris are present in the Brooksville or I-75 fossil samples, and accordingly there is no way to correctly orient the jaws relative to the presumed dorsal upturning of the rostrum. To maintain the internal consistency of the descriptions, the lower jaws of Koopmanycteris, Mormoops, Pteronotus, and Speonycteris are described and illustrated with the toothrows horizontal, although this probably does not represent the actual orientation of the dentary in life.

These three dentaries of Koopmanycteris have a distinct, angular to slightly rounded process on the ventral margin of the ramus, here called the secondary angular process, at the position of the mandibular angle where the ventral edge of the ascending ramus curves strongly dorsally (figs. 5, 


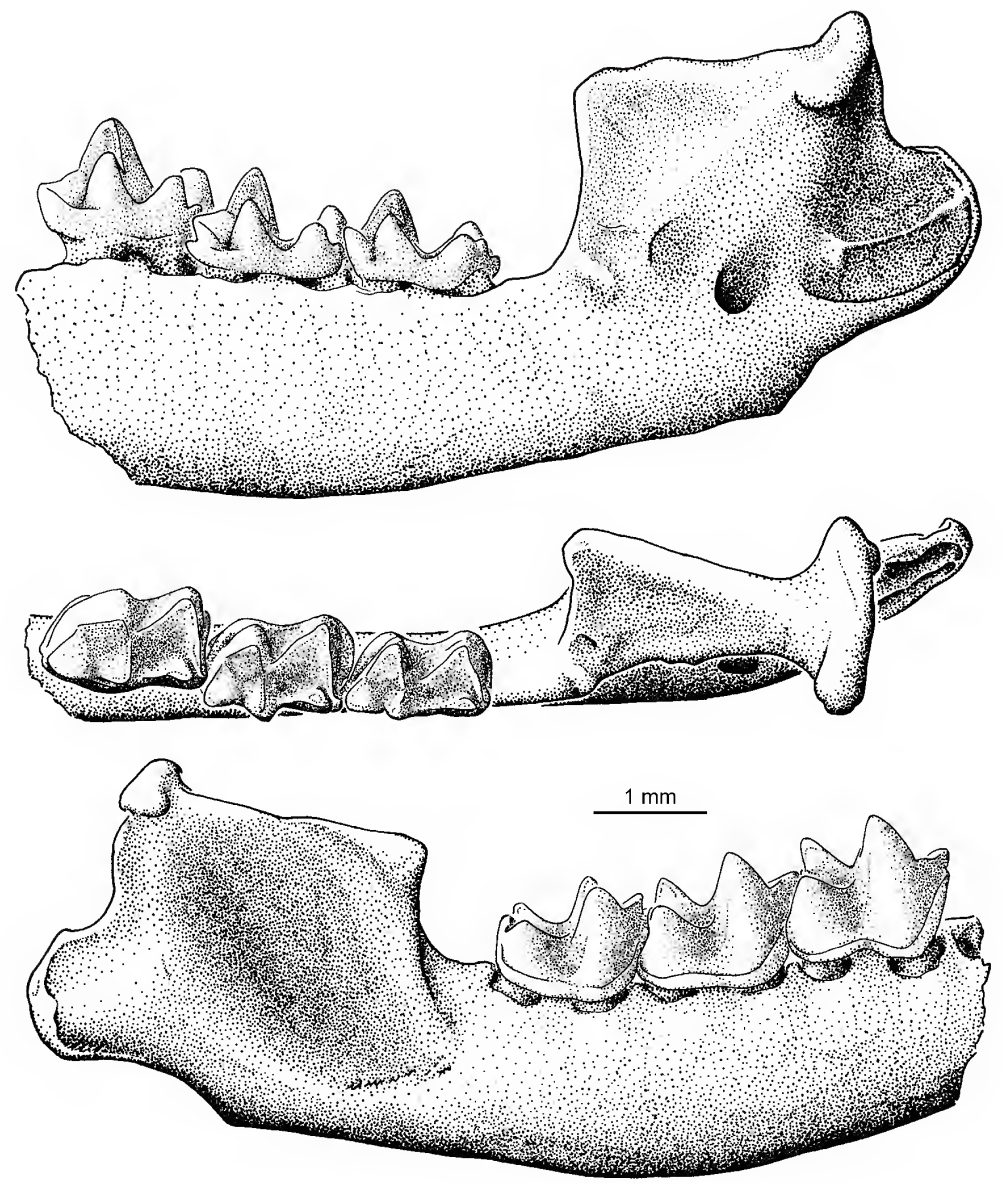

FIGURE 5. Koopmanycteris palaeomormoops, camera lucida drawing of partial right dentary with intact ascending ramus and m1-m3 (SCSM.2004.35.1, paratype). At top, lingual view; middle, occlusal view; at bottom, labial view.

6). This process is located slightly anterior and ventral to the larger angular process and about two-thirds the distance posteriorly between the coronoid process and the articular condyle (= condyloid process) in the anteroposterior dimension. The angular process consists of a broad, rounded flange on the posterior margin of the ascending ramus about halfway between the smaller secondary angular process ventrally and the articular condyle dorsally. The angular process is located well dorsal to the alveolar margin of the mandibular toothrow and extends considerably farther posteriorly than the articular condyle. The articular condyle is located much farther dorsally than the toothrow, about twice the distance from the ventral edge of the ramus to the alveolar toothrow. The articular condyle is located slightly dorsal to the tip of the coronoid process. The thin ridge of bone connecting the tip of the coronoid to the articular condyle is angled very gently dorsally from anterior to posterior. In dorsal view, the coronoid and angular processes extend laterally just beyond the level of the labial edge of the horizontal ramus. Posterior to the $\mathrm{m} 3$, the anterior margin of the coronoid process is essentially vertical and oriented at a right angle to the mandibular toothrow, although the tip of the coronoid is recurved very slightly 


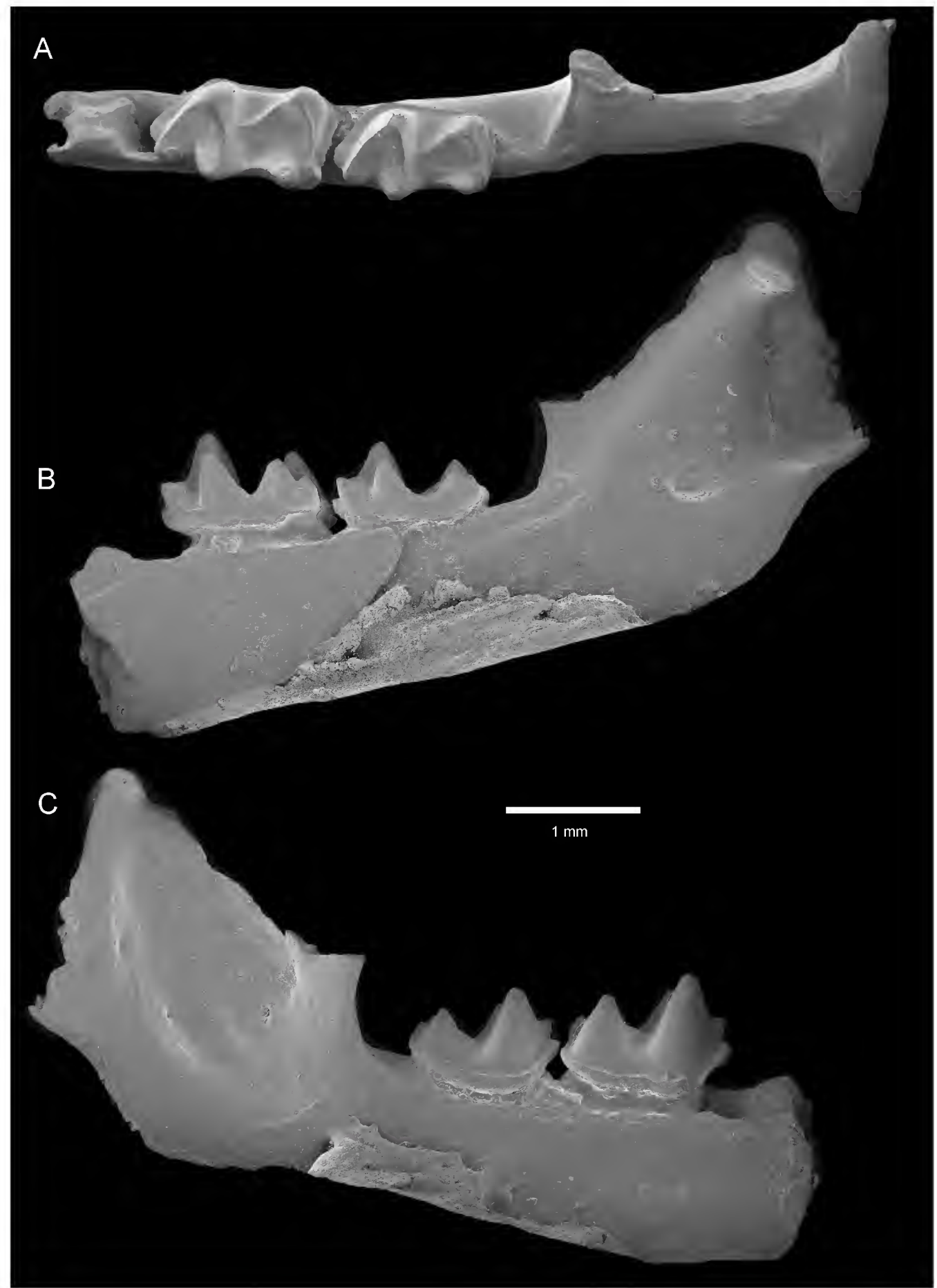

FIGURE 6. Koopmanycteris palaeomormoops, posterior portion of right dentary with $m 2-m 3$ (UF 157766) in $\mathbf{A}$, occlusal, $\mathbf{B}$, lingual, and $\mathbf{C}$, labial views. 
anteriorly. The posterior mandibular foramen on the internal surface of the ascending ramus is positioned at the level of the alveolar toothrow and about halfway between the tip of the coronoid and the articular process in the anteroposterior dimension.

Mormoops is similar to Koopmanycteris in possessing a secondary angular process at the posteroventral corner of the mandibular angle anterior and ventral to the angular process. However, in Mormoops this secondary angular process is larger, more rounded and flangelike, and is located in a more posterodorsal position, directly ventral to the articular condyle on the posterior margin of the ascending ramus. Pteronotus exhibits variation in degree of development and orientation of the secondary angular process. This structure is poorly developed in most individuals but is more developed and more prominent in others, with variation occurring both within and between species. A secondary angular process appears to be lacking in the only specimen of Speonycteris that preserves the posterior portion of the dentary. Like Koopmanycteris, Mormoops has a rounded, flangelike angular process on the posterior margin of the ascending ramus that is ventral to the articular condyle and dorsal to the smaller secondary angular process. As in Koopmanycteris, the angular process in Mormoops extends noticeably posterior to the condyle and is also positioned well dorsal to the occlusal plane of the toothrow. The articular condyle is also located far dorsal to the toothrow in Mormoops. The articular condyle is located in a much more dorsal position than the tip of the coronoid in Mormoops, and as such the ridge of bone connecting them forms a steep, dorsally directed angle from anterior to posterior. The mandibular foramen of Mormoops is located more posteriorly than in Koopmanycteris, closer to the articular condyle and slightly more dorsally than in the fossils, just above the alveolar toothrow. Compared to its vertical orientation in the fossils, the anterior margin of the coronoid process is reflected noticeably anteriorly in
Mormoops, beyond vertical in most specimens, forming about an $80^{\circ}$ angle with the mandibular toothrow. The ventralmost portion of the angular process is preserved in one dentary of Speonycteris, and is located well ventral to the alveolar margin of the toothrow. The coronoid process and articular condyle are not preserved in the sample of dentaries of Speonycteris.

The depth of the ascending ramus becomes noticeably narrower posterior to the $\mathrm{m} 3$ in Pteronotus compared to Koopmanycteris and Mormoops. Just dorsal to the mandibular angle on the posterior margin of the ascending ramus, Pteronotus has a narrow, pointed, laterally oriented angular process located at or just dorsal to the level of the toothrow. The angular process in Pteronotus is much narrower, more elongated, and has a stronger posterolateral orientation than in Mormoops and Koopmanycteris in which this process is more rounded, much broader in the vertical dimension, and is oriented more posteriorly. The ascending ramus of Pteronotus is not as noticeably upturned dorsally relative to the toothrow as in Mormoops. The anterior edge of the coronoid process posterior to $\mathrm{m} 3$ is vertical in Pteronotus, like Koopmanycteris, not recurved anteriorly as in Mormoops. The mandibular foramen is more posterior in Pteronotus than in Koopmanycteris, just anterior to the articular condyle, but like Koopmanycteris is at the level of the mandibular toothrow and not dorsal to the toothrow as in Mormoops. The mandibular foramen is located in a more anterior position in Speonycteris, much closer to the anterior edge of the ascending ramus than to the posterior edge, and is well below the alveolar margin of the toothrow.

The ascending ramus and anterior edge of the coronoid process in Koopmanycteris are similar to Pteronotus in being strongly upturned dorsally compared to most other bats; however, the ascending ramus in the fossils is not as strongly upturned dorsally as in Mormoops. The entire ascending ramus, including the articular and coronoid processes, is upturned dorsally at about a $90^{\circ}$ angle in Pteronotus and Koopmanycteris. 
The ascending ramus is even more strongly upturned dorsally in Mormoops such that the anterior margin of the coronoid process is bent forward or reflected anteriorly beyond vertical. The degree of upturning of the ascending ramus in Speonycteris cannot be evaluated because the coronoid process and articular condyle are not preserved in any dentaries of this genus.

There are four partial mormoopid dentaries from the I-75 LF (UF 121718-121720, 121733) that are very similar in almost all morphological characters and size to the dentaries of Koopmanycteris palaeomormoops from Brooksville 2, and they are confidently referred to that species. One of the I-75 dentaries preserves the $\mathrm{p} 4$ and the anterior half of the horizontal ramus from the symphysis posterior to the $\mathrm{m} 1$ (UF 121719). It has three alveoli between the double-rooted $\mathrm{p} 4$ and the large rounded canine alveolus, thus giving a total of five premolar alveoli. The dentary in the two living species of Mormoops is similar to UF 121719 in having five premolar alveoli, accommodating a large single-rooted p1, a slightly smaller double-rooted p3, and a large double-rooted $\mathrm{p} 4$. The presence of five premolar alveoli clearly separates the fossil from Pteronotus, which has only four premolar alveoli owing to the single-rooted p3. UF 121719 confirms that the morphology of the $\mathrm{p} 4$, number and shape of the premolar alveoli, and the overall dental formula of Koopmanycteris are more similar to Mormoops than to Pteronotus. However, UF 121719 and the three dentaries from Brooksville 2 that preserve the anterior half of the dentary (UF 157765, UF 209954, SCSM 2004.35.4) do demonstrate some differences with Mormoops in the premolar region. The distance between the canine and $\mathrm{ml}$ is reduced in Koopmanycteris compared to Mormoops, indicating that there has been significant anteroposterior compression in this region in the former species, which is reflected in the lack of diastemata between the premolar alveoli in the fossil mandibles. The anterior and posterior alveoli of p3 in Koopmanycteris are separated from the posterior edge of the alveolus for $\mathrm{p} 1$ and the anterior alveolus for $\mathrm{p} 4$, respectively, by extremely thin ridges of bone. In Mormoops, in particular M. megalophylla, there is a noticeable diastema between the alveoli of p3 and p4 and a shorter diastema between $\mathrm{p} 1$ and $\mathrm{p} 3$.

In UF 121719, a large, round, deep mental foramen sits in a well-developed concavity wedged between the alveoli of $\mathrm{cl}$ and $\mathrm{p} 1 \mathrm{imme-}$ diately ventral to the alveolar margin. The position of the mental foramen in UF 121719 is somewhat more dorsal than in the three dentaries from Brooksville that preserve the mental foramen (UF 157765, UF 209954, SCSM 2004.35.4). The mental foramen in the Brooksville jaws is located slightly above the midline between the alveolar toothrow and the ventral margin of the dentary. Compared to Koopmanycteris, the mental foramen in Mormoops is smaller, located slightly farther posteriorly below $\mathrm{p} 1$, and is in a more ventral position about halfway between the alveolar and ventral margins of the horizontal ramus. The ventral margin of the horizontal ramus in UF 121719 is very straight posterior to the mandibular symphysis between $\mathrm{cl}$ and $\mathrm{m} 1$. The ventral margin of the ramus between the mandibular symphysis and $\mathrm{ml}$ is also straight in Pteronotus, but is concave in Mormoops. As in the three dentaries of Koopmanycteris from Brooksville that preserve the mandibular symphysis, the symphysis in the I-75 fossil is elliptical in shape, forms an acute angle of about $45^{\circ}$ with the ventral margin of the ramus, and has a sharp process on its posteroventral terminus located directly ventral to the mental foramen between the $\mathrm{cl}$ and $\mathrm{p} 1$. Pteronotus is similar to Koopmanycteris in the presence of a prominent process on the posteroventral edge of the mandibular symphysis. The symphysis forms a sharper angle with the ramus in Pteronotus than Mormoops, but not as acute as in Koopmanycteris, and the symphysis in Pteronotus extends slightly farther posteriorly than in the fossils, ventral to $\mathrm{p} 1$ or $\mathrm{p} 3$. The mandibular symphysis forms a more obtuse angle with the ventral margin of the mandible in Mormoops than in the fossils, the posteroventral process is absent, 
and the symphysis extends somewhat farther posteriorly (ventral to $\mathrm{p} 1$ in $M$. megalophylla, ventral to anterior root of $\mathrm{p} 3$ in $M$. blainvillei).

The p4 of UF 121719 is slightly broader posteriorly than anteriorly, giving this tooth a somewhat trapezoidal occlusal outline. The sharply conical protoconid is located in the center of the tooth and the tip curves slightly posterolingually. A low crest curves anterolingually from the base of this central cusp ending in a short, rounded cusp located on the anterolingual corner of the tooth. Another crest extends in a straight line posteriorly from the base of the central cusp ending in second low cusp located on the posterolingual corner of the tooth. A well-developed cingulum extends from the anterolingual cusp along the anterior edge of the tooth, the entire length of the labial edge, and then along the posterior margin terminating at the posterolingual cusp. A very weak lingual cingulum is present. The p4 of UF 121719 is essentially identical to the $\mathrm{p} 4$ in one of the dentaries of Koopmanycteris palaeomormoops from Brooksville 2 (UF 179985).

A second dentary fragment of Koopmanycteris from I-75 (UF 121718) is broken anterior to the $\mathrm{p} 3$ alveolus but preserves the $\mathrm{p} 4$ and the trigonid of $\mathrm{m} 1$. The $\mathrm{p} 4$ of UF 121718 is very similar to that of UF 121719, with several minor exceptions reflecting some individual variation. The $\mathrm{p} 4$ of UF 121718 is more rectangular or elongated anteroposteriorly, whereas UF 121719 is slightly more squarish in shape. The protoconid of $\mathrm{p} 4$ in UF 121718 is somewhat taller than this cusp in UF 121719. Despite some minor variation in the sample of five p4s of $K$. palaeomormoops (three from Brooksville 2, two from I-75), these premolars are all slightly rectangular to almost squarish in shape and are slightly narrower anteriorly than posteriorly.

The size and morphology of the p4s in UF 121718 and 121719 are most similar to M. megalophylla, whereas the 4 of M. blainvillei is somewhat narrower and more elongated. The p4 of Mormoops differs from the I-75 p4s in several characters. The anterior edge is perpendicular to the longitudinal axis of the toothrow in Koopmanycteris or slopes very slightly anteriorly from the lingual to the labial margin. The anterior margin of $\mathrm{p} 4$ slopes slightly posteriorly in Mormoops from the lingual to the labial margin. In lateral view, the anterior margin of the main cusp in the I-75 teeth is more vertical than in Mormoops. Both the anterior and posterior faces of the protoconid of $\mathrm{p} 4$ are concave in Mormoops; only the posterior margin is concave in the fossils and not to the degree observed in Mormoops. The posterolingual cusp is smaller in the I-75 fossils than in Mormoops and projects just slightly posterior to the posterior margin of $\mathrm{p} 4$. In Mormoops the posterolingual cusp extends well beyond the posterior margin. Mormoops has a more developed lingual cingulum than Koopmanycteris. The $\mathrm{p} 4$ varies somewhat in shape in the species of Pteronotus, from almost square to slightly rectangular, but consistently differs from Koopmanycteris in the presence of an indentation or concavity on its anterolingual corner where this tooth contacts the tiny, rounded $\mathrm{p} 3$.

A third partial dentary of Koopmanycteris palaeomormoops from I-75 contains a complete $\mathrm{m} 1$ and the alveoli for $\mathrm{p} 3$ and $\mathrm{p} 4$ (UF 121720). The $\mathrm{m} 1$ in this jaw is slightly damaged, with the tips of both the hypoconid and entoconid broken off. The m1 in UF 121720 is very similar to the partial $\mathrm{ml}$ of UF 121718, and to the eight complete $\mathrm{m} 1 \mathrm{~s}$ in the Brooksville 2 sample, including the type, described in detail above. The $\mathrm{m} 1$ in UF 121720 is shorter and broader than in Mormoops, but not as broad transversely as in Pteronotus, especially the talonid. The paraconid is much smaller and more lingually placed in Koopmanycteris than in either of the two living genera, almost halfway between the metaconid and protoconid. Both the fossil $\mathrm{ml}$ and Mormoops are characterized by having a deep pit or concavity in the talonid basin immediately posterior to the trigonid. The talonid basin is shallower in Pteronotus.

A fourth dentary of Koopmanycteris from I-75 (UF 121733) preserves the posterior third of the horizontal ramus and the anterior edge of 


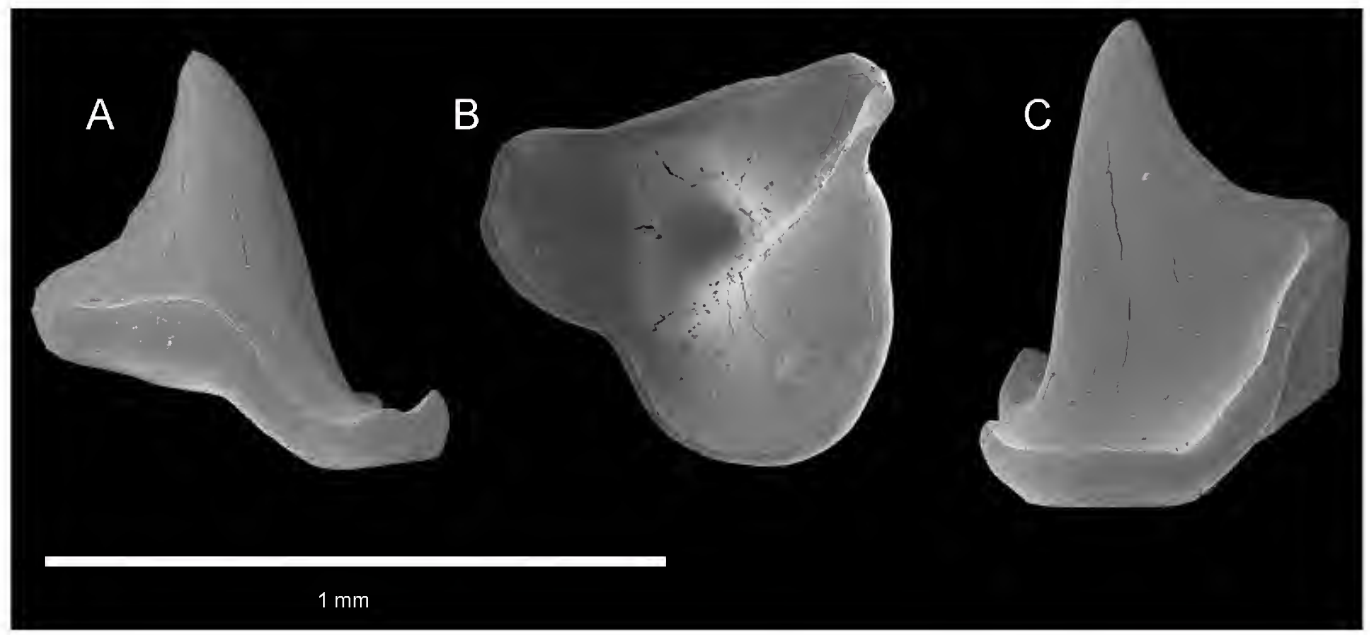

FIGURE 7. Koopmanycteris palaeomormoops left P4 (UF 182782, paratype) in A, anterior/mesial, B, occlusal, and $\mathbf{C}$, posterior/distal views.

the coronoid process. The anterior edge of the coronoid process is essentially vertical in UF 121733, meeting the alveolar margin of the toothrow at about a $90^{\circ}$ angle. In this feature Koopmanycteris more closely resembles Pteronotus in which the anterior edge of the coronoid process also forms about a $90^{\circ}$ angle with the toothrow. The anterior edge of the coronoid process and the dorsal tip of the coronoid are more sharply upturned dorsally in Mormoops and are recurved slightly anteriorly beyond a $90^{\circ}$ angle with the alveolar margin of the toothrow. In all four dentaries of Koopmanycteris from I-75, as well as the dentaries from Brooksville 2, the horizontal ramus is thicker or more robust labiolingually than in Mormoops, but is not as deep dorsoventrally. The horizontal ramus of Koopmanycteris is also somewhat more robust labiolingually than in similar-sized species of Pteronotus (e.g., members of the $P$. davyi complex). The dorsoventral depth of the horizontal ramus is similar in Koopmanycteris and Pteronotus, whereas the ascending ramus is noticeably deeper in Koopmanycteris.

Upper Dentition: A single isolated P4 (UF 182782, paratype; fig. 7) is the only tooth in the hypodigm of Koopmanycteris palaeomormoops from the upper dentition. Upper molars of six other taxa of bats are known from I-75 and Brooksville 2, including Speonycteris aurantiadens and $S$. naturalis, a large and a small species representing an undescribed genus of emballonurid, a vespertilionid, and a molossid. These upper molars are either too large (i.e., both species of Speonycteris) or are so radically different in morphology (the emballonurids, vespertilionid, and molossid) that they could not possibly represent Koopmanycteris. The combined sample of Koopmanycteris from Brooksville 2 and I-75 contains more than 10 dentaries with teeth and several isolated teeth, so this mormoopid is not rare. The absence of mormoopid upper molars in the sample is inexplicable and unfortunate.

The P4 referred to Koopmanycteris from Brooksville 2 has a broad, deep talon basin lingually. It has a tall, sharp conical protocone that is recurved posteriorly. The protocone is located about midway along the anteroposterior length of the tooth and positioned somewhat medial to the lingual margin. The anterolabial portion of the tooth consists of a low, broadly rounded basin. This basin is separated from the talon basin by a gently curving indentation located at the anterolingual base of the protocone. The anterolabial region has two low, rounded cusps, one on the anterior edge and one on the lingual 
edge, connected by a low, rounded crest. The conical protocone is connected posteriorly to a prominent cusp located on the posterolabial corner of the tooth crown by a sharp ridge. This ridge ascends at a very steep angle from the protocone to the posterior cusp. In labial view, the anterolabial basin and talon basin are on the same level, whereas the posterolabial cusp is located about halfway between anterolabial basin and the tip of the protocone.

The $\mathrm{P} 4$ of Koopmanycteris is more similar to the P4 of Mormoops, especially M. blainvillei, than to that of Pteronotus. Compared to Koopmanycteris palaeomormoops, the $\mathrm{P} 4$ of Mormoops blainvillei is slightly longer anteroposteriorly, narrower transversely, and the posterior margin of the talon basin is not as distinctly separated from the posterolabial portion of the tooth. However, the overall morphology of the P4s in these two taxa is similar, including the low, rounded anterolabial basin, broad low talon basin, and high conical protocone with sharp bladelike crest connecting it to the posterolabial corner of the tooth. The P4 of Mormoops megalophylla is even longer and narrower than that of M. blainvillei, much more so than Koopmanycteris, in which this tooth is shorter and broadly rounded. In particular, the anterolabial basin is narrower and more elongated and the talon basin is narrower in M. megalophylla than in the fossil. The P4 of Pteronotus differs from that of Koopmanycteris in several important characters. A broad anterolabial basin is lacking on Pteronotus, which instead has a small cusp along the anterior cingulum at the anterolabial base of the protocone. Because it lacks the anterolabial basin, the anteroposterior length of $\mathrm{P} 4$ is shorter in Pteronotus compared to Koopmanycteris. The protocone is shorter and more rounded in Pteronotus compared to the tall, sharply pointed protocone in Koopmanycteris and Mormoops. A single partial $\mathrm{P} 4$ of Speonycteris is missing the lingual portion of the tooth. The P4 of Speonycteris differs from Koopmanycteris in having a much stronger indentation along the labial margin and a thick shearing crest connecting the protocone to the posterolabial corner of the tooth. The P4 of Koopmanycteris has a nearly straight labial margin lacking a prominent indentation and a thin, sharp crest extending from the protocone to the posterolabial margin.

Petrosal: The single right petrosal from the Brooksville 2 locality, UF 179901 (fig. 8), is referred to Koopmanycteris because of its morphological resemblance to petrosals of recent mormoopids, especially Mormoops, and because of the relative abundance of $K$. palaeomormoops in the fossil sample. The petrosal is in excellent condition, intact with the exception of the anterior petrosal process (which is broken) and a flange of bone along the anteromedial edge on the prefacial commissure between the ampulla of the anterior semicircular canal and the cochlea (similarly broken and absent).

As noted by Ekdale (2013), surprisingly few studies of the petrosal in mammals are available; Staněk (1933) provided a useful early study for several modern bats. Most studies of the petrosal in bats and other mammals published in recent years have focused on volumetric reconstructions of the internal membranous labyrinth as revealed by computed tomography scans (CT scans). For example, Ekdale (2013) surveyed the labyrinth in many orders of mammals including several bats, and Davies et al. (2013) studied the vestibular system of bats including Mormoops megalophylla and a member of the Pteronotus parnellii complex. No CT scans are yet available for our fossil petrosal. However, because of the low level of ossification and open structure of the petrosal in echolocating bats with a phanerocochlear cochlea, it is possible to make external measurements (on petrosals) including some that imitate, but do not strictly equal, a few of the internal measurements of the labyrinth made on volumetric endocasts or scans by Ekdale (2013: fig. 3). Measurements we made included linear and angular measurements for the petrosal referred to Koopmanycteris, and also for specimens of Mormoops megalophylla and members of the Pteronotus davyi, P. personatus, and P. parnellii complexes (table 3 ). 

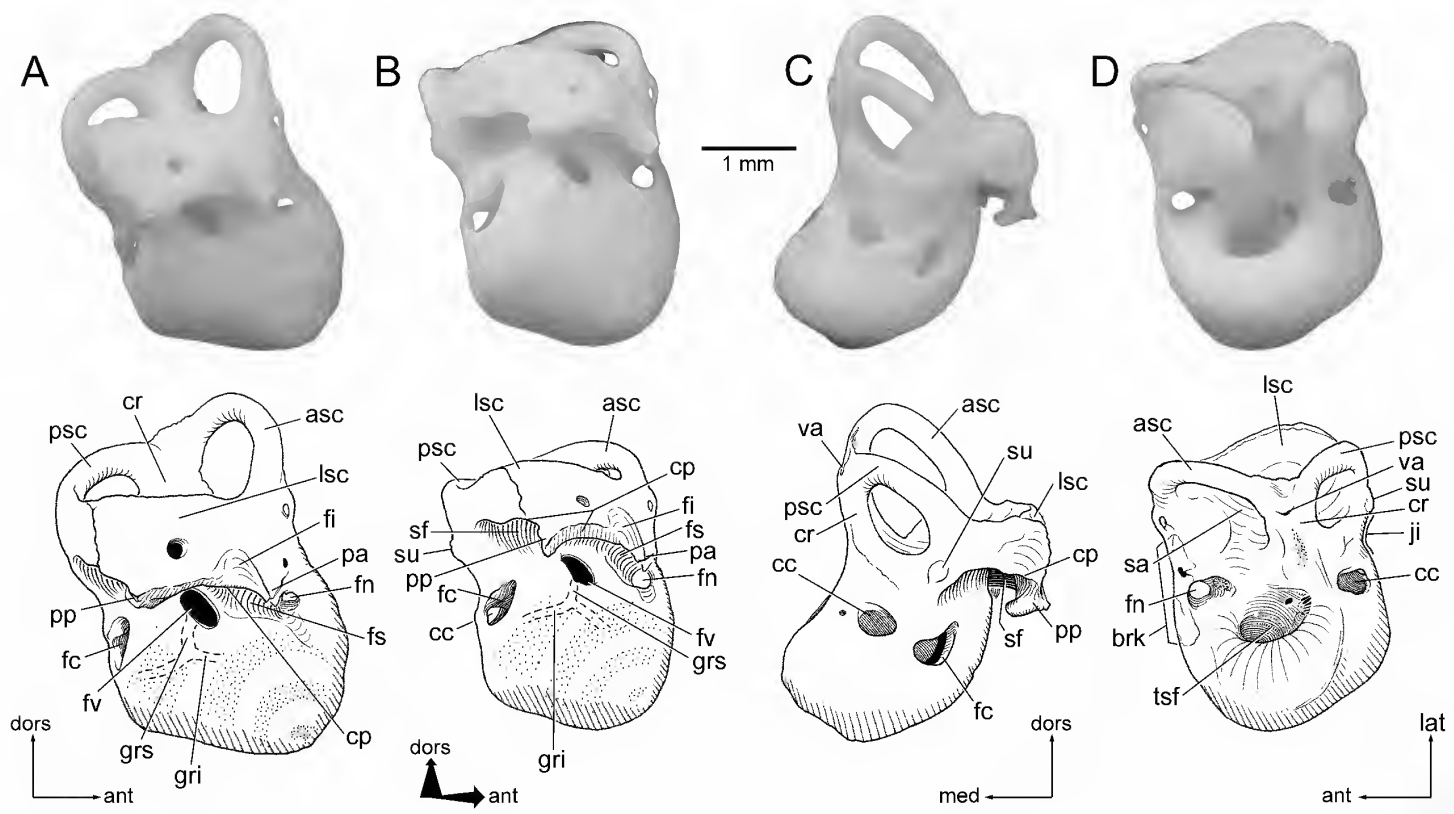

FIGURE 8. Right petrosal (UF 179901) from Brooksville 2 Quarry, Florida, referred to Koopmanycteris palaeomormoops. Photographs above and drawings below in $\mathbf{A}$, lateral view, oriented with the lateral semicircular canal parallel to the horizon; B, ventrolateral view; C, posterior view; D, dorsal (endocranial) view. Abbreviations: ant, anterior; asc, anterior semicircular canal; brk, broken area along the prefacial commissure; cc, cochlear canaliculus (opening of cochlear aqueduct or perilymphatic duct); $\mathbf{c p}$, crista parotica; $\mathbf{c r}$, common crus; dors, dorsal; fc, fenestra cochleae; fi, medial wall of fossa incudis; fn, facial canal (for cranial nerve VII); fs, facial sulcus (semicanal for facial nerve); fv, fenestra vestibuli for footplate of stapes; gri, groove for internal carotid artery; grs, groove for stapedial artery; ji, jugular incisure; lat, lateral; lsc, lateral semicircular canal; med, medial; pa, base of broken anterior petrosal process; pp, posterior petrosal process; psc, posterior semicircular canal; sa, subarcuate fossa; sf, fossa for stapedius muscle; su, tubercle connected in life by soft tissue to a small spinelike projection near the paroccipital process; tsf, spiral foraminous tract within the internal acoustic meatus; va, opening of vestibular aqueduct; vent, ventral.

The petrosal of Koopmanycteris is phanerocochlear (with petrosal wall thin and labyrinth visible externally; see also char. 46; Novacek, 1985a, 1991). The pars cochlearis is comparable in size to that of recent members of the Pteronotus davyi and $P$. personatus complexes, and slightly smaller than that of Mormoops megalophylla. The pars cochlearis resembles those of recent mormoopids in having been loosely attached to the basisphenoid via ligaments and/or thin splints of bone. In extant mormoopids, there is a small process or point of attachment on the lateral end of the posterior semicircular canal near its junction with the lateral semicircular canal and anteromedial to the cochlear canaliculus. This process appears to act as an anchor point for ligamentous suspension from a small, anteroventrally projecting, spinelike process anteromedial to the paroccipital process of the cranium. On the petrosal of Koopmanycteris this process appears as a small, rounded tubercle (fig. 8B, C, D: su). In Mormoops and members of the Pteronotus personatus complex, this process is a little higher and more elongate, forming a short crest or ridge, while in members of the $P$. davyi complex, it occurs as a small tubercle as in Koopmanycteris. The point of attachment is a larger, shallow, subcircular hollow instead of a process in the P. parnellii complex, unlike in the other mormoopid taxa. 


\section{TABLE 3}

\section{Comparative External Measurements of the Petrosal of Koopmanycteris, Mormoops, and Pteronotus (Mormoopidae)}

Measurements (in mm and degrees) following Ekdale (2013). Aspect ratio of SC = height of semicircular canal arc divided by width; stapedial ratio = long axis of fenestra vestibuli over short axis; and $\mathrm{SC}$ angle $=$ semicircular canal angles formed between planes of anterior, lateral, and posterior canals (in degrees). Abbreviations: A, anterior; FV, fenestra vestibuli length and width; L, lateral; P, posterior; SC, semicircular canal; ; FC, fenestra cochleae.

\begin{tabular}{|c|c|c|c|c|c|c|c|c|c|}
\hline \multirow[t]{2}{*}{ Measurement } & \multirow{2}{*}{$\begin{array}{l}\text { Koopmanycteris } \\
\text { palaeomormoops } \\
\text { UF } 179901\end{array}$} & \multicolumn{2}{|c|}{$\begin{array}{l}\text { Mormoops } \\
\text { m. megalophylla }\end{array}$} & \multicolumn{2}{|c|}{$\begin{array}{l}\text { Pteronotus } \\
\text { davyi fulvus }\end{array}$} & \multicolumn{2}{|c|}{$\begin{array}{l}\text { Pteronotus } \\
\text { personatus psilotis }\end{array}$} & \multicolumn{2}{|c|}{$\begin{array}{l}\text { Pteronotus parnellii } \\
\text { mexicanus }\end{array}$} \\
\hline & & $\begin{array}{l}\text { OMNH } \\
26720 \\
\end{array}$ & $\begin{array}{l}\text { OMNH } \\
31083 \\
\end{array}$ & $\begin{array}{l}\text { OMNH } \\
26736 \\
\end{array}$ & $\begin{array}{l}\text { OMNH } \\
14243 \\
\end{array}$ & $\begin{array}{l}\text { OMNH } \\
27773 \\
\end{array}$ & $\begin{array}{l}\text { OMNH } \\
38769 \\
\end{array}$ & $\begin{array}{l}\text { OMNH } \\
26749 \\
\end{array}$ & $\begin{array}{l}\text { OMNH } \\
26758 \\
\end{array}$ \\
\hline SC angle A-L & 101 & 83 & 90 & 89 & 94 & 89 & 97 & 95 & 96 \\
\hline SC angle A-P & 108 & 90 & 96 & 89 & 91 & 86 & 92 & 88 & 89 \\
\hline SC angle L-P & 102 & 101 & 95 & 101 & 100 & 80 & 105 & 94 & 92 \\
\hline Height A SC & 1.65 & 1.8 & 2.0 & 1.5 & 1.45 & 1.25 & 1.3 & 1.95 & 1.65 \\
\hline Width A SC & 1.65 & 1.75 & 1.8 & 1.6 & 1.65 & 1.4 & 1.45 & 2.15 & 2.1 \\
\hline $\begin{array}{l}\text { Aspect ratio } \\
\text { A SC }\end{array}$ & 1.00 & 1.03 & 1.11 & 0.94 & 0.88 & 0.89 & 0.90 & 0.51 & 0.79 \\
\hline Height L SC & 1.65 & 1.35 & 1.55 & 1.45 & 1.1 & 1.1 & 1.4 & 1.85 & 1.85 \\
\hline Width L SC & 1.3 & 1.65 & 1.9 & 1.6 & 1.35 & 1.35 & 1.5 & 1.9 & 2.05 \\
\hline $\begin{array}{l}\text { Aspect ratio L } \\
\text { SC }\end{array}$ & 1.27 & 0.82 & 0.82 & 0.91 & 0.81 & 0.81 & 0.93 & 0.97 & 0.90 \\
\hline Height P SC & 1.35 & 1.55 & 1.55 & 1.4 & 1.5 & 1.15 & 1.1 & 1.15 & 1.15 \\
\hline Width P SC & 1.15 & 1.15 & 1.15 & 1.0 & 1.1 & 1.05 & 1.2 & 1.45 & 1.3 \\
\hline $\begin{array}{l}\text { Aspect ratio } \mathrm{P} \\
\mathrm{SC}\end{array}$ & 1.17 & 1.35 & 1.35 & 1.40 & 1.36 & 1.09 & 0.92 & 0.79 & 0.88 \\
\hline FV long axis & 0.48 & 0.64 & 0.64 & 0.44 & 0.46 & 0.46 & 0.42 & 0.60 & 0.62 \\
\hline FV short axis & 0.24 & 0.28 & 0.26 & 0.22 & 0.22 & 0.24 & 0.20 & 0.28 & 0.26 \\
\hline $\begin{array}{l}\text { Stapedial } \\
\text { ratio }\end{array}$ & 2.00 & 2.29 & 2.46 & 2.00 & 2.09 & 1.92 & 2.10 & 2.14 & 2.38 \\
\hline FC long axis & 0.64 & 0.80 & 0.78 & 0.48 & 0.46 & 0.48 & 0.42 & 1.12 & 0.90 \\
\hline FC short axis & 0.38 & 0.40 & 0.44 & 0.36 & 0.36 & 0.32 & 0.24 & 0.82 & 0.80 \\
\hline FC long:short & 1.68 & 2.00 & 1.77 & 1.33 & 1.28 & 1.50 & 1.75 & 1.37 & 1.12 \\
\hline
\end{tabular}

The fenestra cochleae in Koopmanycteris is crescent shaped and larger than the fenestra vestibuli, with a maximum diameter greater than $25 \%$ of the external width of the first half turn of the cochlea. The fenestra cochleae is also larger than the fenestra vestibuli in Mormoops and members of the Pteronotus davyi and $P$. parnellii complexes. In $P$. personatus, the fenestra cochleae is about the same size or only slightly larger than the fenestra vestibuli. The shape of the fenestra cochleae in Mormoops is similar to that in Koopmanycteris, but in the Pteronotus species it is subcircular with a flattened or sometimes downcurved dorsal edge. In the $P$. parnellii complex alone, the posterior end of the crista parotica overhangs the dorsal edge of the fenestra cochleae. 
The cochlear canaliculus is about the same size as the fenestra vestibuli and smaller than the fenestra cochleae in Koopmanycteris and in Mormoops. In members of the Pteronotus personatus and $P$. davyi complexes, the cochlear canaliculus is larger than both the fenestra vestibuli and the fenestra cochleae. In contrast, the cochlear canaliculus is much larger than the fenestra vestibuli and about the same size as the fenestra cochleae in the P. parnellii complex.

The pars canalicularis of the petrosal of Koopmanycteris probably had a mastoid exposure and contact surface with the mastoid region of the cranium along the crista parotica and lateral semicircular canal, as in recent mormoopids as well as in many other bats. The semicircular canals all are open and lack lamina caps or flanges in Koopmanycteris. Mormoops has laminar flanges at the anterior and posterior ends of the lateral semicircular canal that extend part way up the bases of the anterior and posterior semicircular canals. In Mormoops and other bats these flanges partly enclose the lobus petrosus of the paraflocculus of the brain within the subarcuate fossa. The posterior of the two flanges is more exposed through openings in the mastoid region of the skull in Mormoops, while the anterior flange is more exposed in members of the Pteronotus personatus and $P$. davyi complexes. The flanged condition is also seen in the P. parnellii complex, but the flanges are smaller. In members of the $P$. davyi complex, the thin bony flanges are absent, as in Koopmanycteris. In members of the Pteronotus personatus complex, the anterior flange of the lateral semicircular canal is large and rises to a point before descending slightly to contact the anterior semicircular canal, while the posterior flange is small. In some bat families (e.g., Emballonuridae, Rhinolophidae) a thin bony lamina completely covers the area between the three semicircular canals, closing off the subarcuate fossa and forming a closed mastoid exposure of the pars canalicularis.

The crista parotica of Koopmanycteris bears a small perforation through its middle just above the fenestra vestibuli. This small perforation is also seen in Mormoops, is variably present in the Pteronotus personatus and $P$. davyi complexes, and is absent in $P$. parnellii complex. The anterior petrosal process (processus petrosus anterior) is broken off at its base in the available petrosal of Koopmanycteris. The posterior petrosal process in Koopmanycteris has a small projection extending medially toward, but not reaching, the base of the cochlea just posterior to the fenestra vestibuli (fig. 8C: pp). The same projection is present in Mormoops and the Pteronotus personatus and $P$. davyi. Members of the $P$. parnellii complex lack a posterior petrosal process. The medial wall of the fossa incudis occurs as a small recess on the outer edge of the crista parotica in Koopmanycteris (fig. 8A, B: fi) and Mormoops. In Pteronotus species, this portion of the fossa incudis is rudimentary or absent. The stapedial fossa in Koopmanycteris is broad, deep, and long. Its size and shape are similar in Mormoops and members of the Pteronotus personatus and $P$. davyi complexes. The stapedial fossa is very narrowly constricted in the P. parnellii complex.

In Koopmanycteris the bony edge of the petrosal is broken just anteromedial to the ampulla of the anterior semicircular canal along the prefacial commissure (fig. 8D: brk). Along the prefacial commissure, Mormoops has a relatively thick and high, rounded flange of bone, whereas members of the Pteronotus personatus and $P$. davyi complexes have a lower and thinner flange. In $P$. parnellii there is a low and thick, ovate tubercle at this location instead of a flange of bone. The breakage pattern in Koopmanycteris suggests that this flange had been relatively large, as in Mormoops, or perhaps intermediate in size or shape between those of Mormoops and members of the Pteronotus personatus and $P$. davyi complexes. Unfortunately, configuration of this structure cannot be assessed because of the breakage.

Humerus: Much of this discussion is based on the paratype complete left humerus from Brooksville 2 (UF 179949, figs. 9, 10), although additional information on variation was gleaned from seven other partial humeri from Brooksville 2, two proximal humeri (UF 179937; SCSM 


\section{TABLE 4}

\section{Measurements ( $\mathrm{mm})$ of the Humerus of Koopmanycteris palaeomormoops}

All measurements were taken with an ocular micrometer inserted in the eyepiece of a Zeiss binocular microscope, except for the total length which was taken with digital calipers. Abbreviations: $\mathbf{N}$, sample size; OR, observed range; and $\mathbf{X}$, mean.

\begin{tabular}{|c|c|c|c|c|c|}
\hline Specimen & $\begin{array}{l}\text { total } \\
\text { length }\end{array}$ & $\begin{array}{l}\text { proximal } \\
\text { width }\end{array}$ & $\begin{array}{l}\text { midshaft } \\
\text { width }\end{array}$ & $\begin{array}{l}\text { maximum } \\
\text { distal width }\end{array}$ & $\begin{array}{l}\text { width of distal } \\
\text { articular surface }\end{array}$ \\
\hline UF 179949 & 28.02 & 3.15 & 1.40 & 3.75 & 2.60 \\
\hline UF 179905 & -- & -- & 1.35 & 3.63 & 2.60 \\
\hline UF 179906 & -- & -- & 1.25 & 3.72 & 2.65 \\
\hline UF 179907 & -- & -- & 1.35 & -- & 2.50 \\
\hline UF 179908 & -- & -- & 1.40 & -- & -- \\
\hline UF 179938 & -- & -- & -- & 3.65 & 2.65 \\
\hline $\mathrm{N}$ & 1 & 1 & 5 & 4 & 5 \\
\hline \multirow[t]{2}{*}{ OR } & -- & -- & $1.25-$ & $3.63-$ & $2.50-$ \\
\hline & & & 1.40 & 3.75 & 2.65 \\
\hline $\mathrm{X}$ & 28.02 & 3.15 & 1.35 & 3.69 & 2.60 \\
\hline
\end{tabular}

2004.35.5) and five distal humeri (UF 179905179908, 179938; table 4). Koopmanycteris has an elliptical to flattened humeral head that is canted or angled slightly in the direction of the lesser tuberosity. The head is flattened and comes to a sharp point at its proximalmost extremity. In proximal view, the humeral head of Koopmanycteris tapers to a point anteriorly and is oriented anteroposteriorly, parallel to the medial and lateral edges of the shaft. The comparatively small humeral head is separated from the greater tuberosity by a distinct notch. The greater and lesser tuberosities are about the same height, extending just slightly proximal to the humeral head. The greater tuberosity is more or less vertical and located closer to the head, whereas the lesser tuberosity extends medially from the head at about a $45^{\circ}$ angle. There is a weak groove on the lateral surface of the greater tuberosity. In posterior view, there is a distinct bend or concavity between the distal end of the greater tuberosity and the lateral edge of the shaft. The proximal edge of the lesser tuberosity forms a high, sharp ridge, and there is no concavity at its posterior terminus. In medial view, the pectoral ridge is rather short, its anterior edge is almost vertical (parallel to the shaft), and its distal edge is almost horizontal to the shaft.

The entire distal articular surface of the humerus is moderately offset laterally in Koopmanycteris, with the medial edge of the trochlea located about halfway between the center and medial edge of the shaft. The distal articular surface consists of two parts, a rather broad capitulum that is only weakly convex distally (not strongly rounded) and the trochlea. The groove between the capitulum and trochlea is shallow and of medium breadth. There is no evidence of a groove separating the capitulum into medial and lateral portions or ridges. The epitrochlea or medial epicondyle is of medium breadth. The medial edge of the epitrochlea is rounded; there is a slight indentation or notch distolateral to it, and between it and the distal spinous process. There is a deep notch separating the distal spinous process (= spinous process of epitrochlea, 

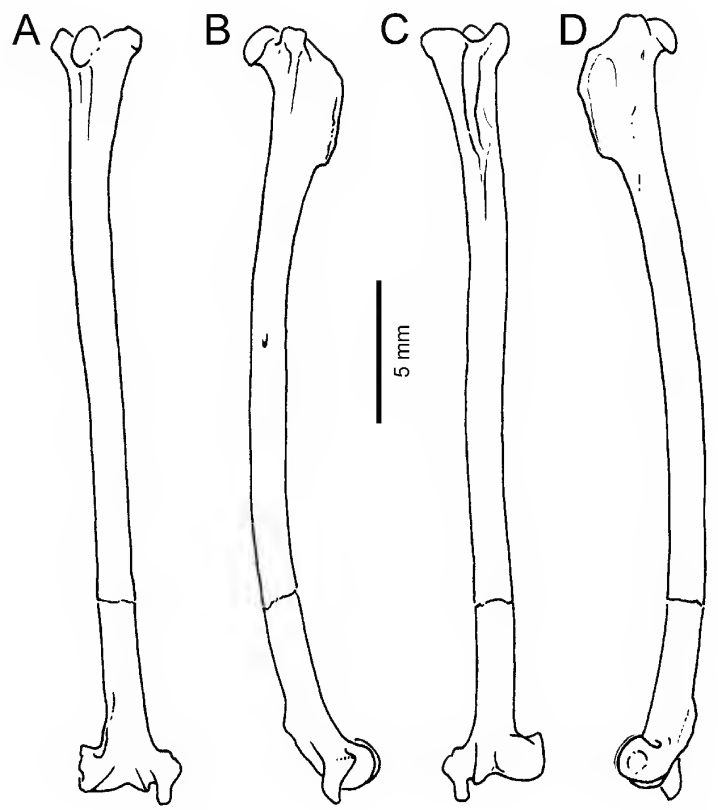

FIGURE 9. Complete left humerus of Koopmanycteris palaeomormoops (UF 179949, paratype) in A, posterior, B, medial, $\mathbf{C}$, anterior, and $\mathrm{D}$, lateral views.

hereinafter called "spinous process") and epitrochlea from the trochlea. The spinous process extends well distal to the distal edge of the trochlea. The proximomedial edge of the epitrochlea has a distinct rounded concavity. In medial view, the spinous process, especially the anterior surface, forms a distinct angle with the shaft of the humerus. On the posterior surface of the distal humeral shaft there is a well-developed ridge extending from the articular surface onto the medial third of the shaft. This ridge is located about halfway between the center and lateral edge of the shaft. In lateral or medial view, this ridge forms a low convexity. This ridge is somewhat variable in the sample of distal humeri of Koopmanycteris; it is always present but forms a higher ridge or convexity in some specimens than others. This ridge is continuous with the posterolateral edge of the articular surface. The distal portion of the humeral shaft is rounded in cross section.

The humeral head differs in shape in the various species of mormoopids. The humerus of Speonycteris is unknown, precluding comparisons with that genus. Koopmanycteris is most similar to Mormoops in which the head is noticeably flattened transversely and narrowed to a pointed process proximally, and is either vertical or angled slightly toward the lesser tuberosity. In species of Pteronotus, the humeral head is relatively larger, much larger than in fossils of Koopmanycteris of similar overall size. The head in Pteronotus is elliptical or ovoid, rounded proximally, and not transversely flattened and pointed. The humeral head in Pteronotus is canted or angled toward the greater tuberosity, which is the opposite direction from the canting seen in Koopmanycteris and Mormoops. In the latter genera, the comparatively smaller humeral head is separated from the greater tuberosity by a distinct notch. The head in Pteronotus is located very close to the greater tuberosity, and is not separated from it by a noticeable notch. In proximal view, the head of Koopmanycteris and Mormoops tapers to a point anteriorly and is oriented anteroposteriorly, parallel to the medial and lateral edges of the shaft. The humeral head of Pteronotus does not taper anteriorly and is oriented 

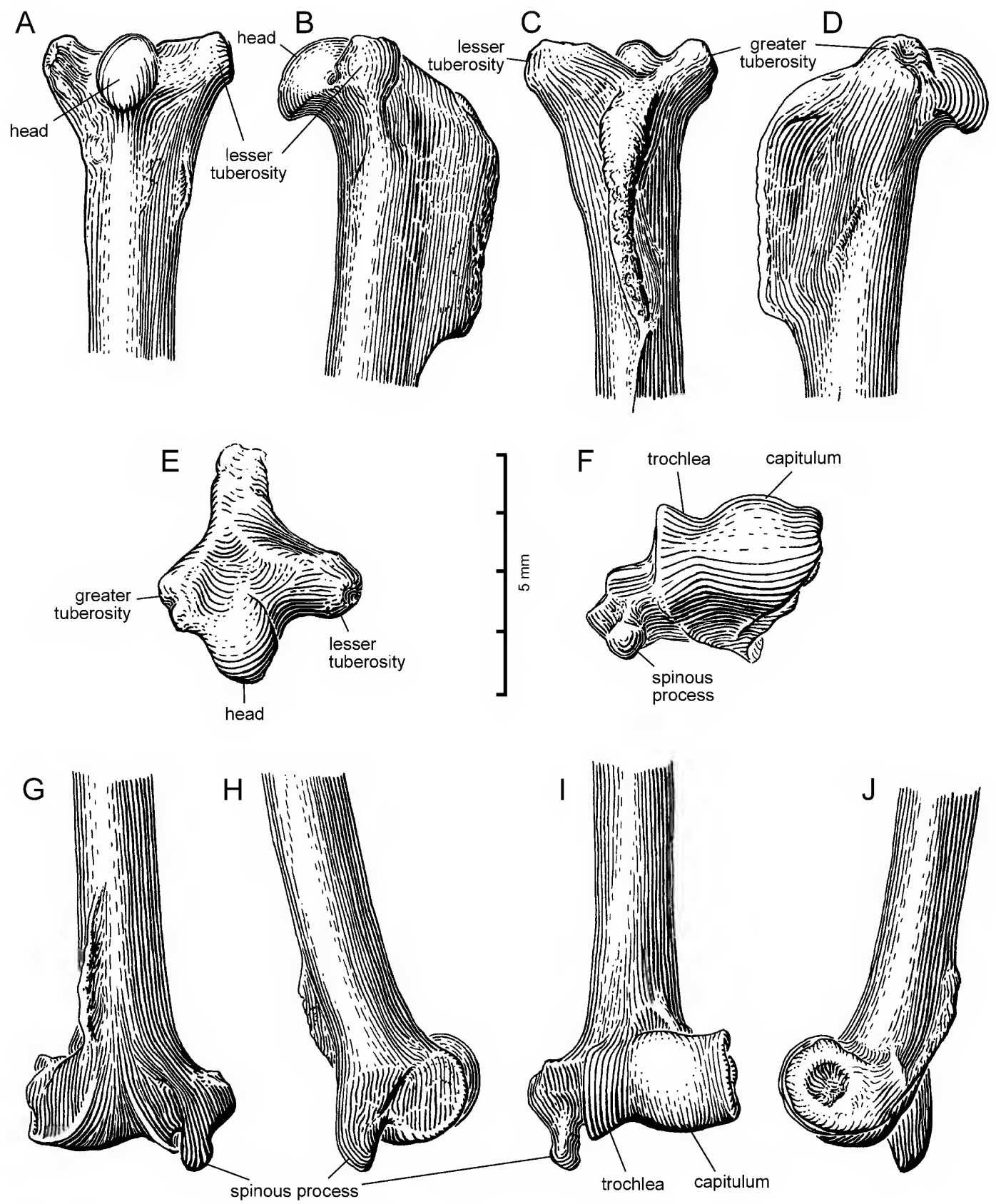

FIGURE 10. Left humerus of Koopmanycteris palaeomormoops (UF 179949, paratype). Proximal end in A, posterior, B, medial, C, anterior D, lateral, and E, proximal views. Distal end in F, distal, G, posterior, $\mathbf{H}$, medial, I, anterior, and J, lateral views. 
at about a $45^{\circ}$ angle connecting with the greater tuberosity and creating a rounded concavity immediately anterior to the head and posterior to the proximalmost extension of the pectoral ridge. This concavity is absent in the fossils and Mormoops because the anteriormost extension of the humeral head occupies this position. In both proximal and medial views, there is an obvious elliptical concavity on the proximal edge of the lesser tuberosity at its posterior extremity in Pteronotus. The proximal edge of the lesser tuberosity forms a high, sharp ridge in both the fossils and Mormoops and this concavity is absent. The greater and lesser tuberosities are about the same height in Koopmanycteris and Mormoops, extending just slightly proximal to the humeral head. In Pteronotus, the greater tuberosity extends proximal to the head, but the lesser tuberosity is either at the same level as the head or distal to it. In the fossils and Mormoops, the greater tuberosity is almost vertical and located closer to the head, whereas the lesser tuberosity extends medially from the head at about a $45^{\circ}$ angle. The lesser tuberosity extends almost horizontally from the head in Pteronotus, which accounts for its more distal location. Mormoops has a rather deep groove on the lateral surface of the greater tuberosity that begins at its proximolateral tip and extends distomedially to the lateral surface of the head. This groove is present but weaker in Koopmanycteris and is absent in Pteronotus. In posterior view, there is a distinct bend or concavity between the distal end of the greater tuberosity and the lateral edge of the shaft in Koopmanycteris and Mormoops. The distal edge of the greater tuberosity is more or less continuous with the shaft in Pteronotus, with only a slight curve. Pteronotus has a rather broad flange that extends from the lesser tuberosity about $20 \%$ of the length of the shaft on the medial edge. The entire proximal end of the humerus appears broader in Pteronotus because of this prominent flange. In Mormoops this flange is mostly absent, except for an elevated ridge about $1 \mathrm{~mm}$ in length on the medial edge of the shaft in the position of the distal terminus of the flange in Pteronotus. The paratype humerus of Koopmanycteris palaeomormoops (UF 179949) has a very slight ridge in this area. This specimen lacks the flange of Pteronotus as well as the distal process of Mormoops. However, a referred proximal humerus from Brooksville 2 (UF 179937) has a narrow flange that is similar in morphology to the much broader flange of Pteronotus. In medial view, the pectoral ridge in the fossils and Mormoops is somewhat shorter, its anterior edge is almost vertical (parallel to the shaft), and its distal edge is almost horizontal to the shaft compared to Pteronotus. The pectoral ridge in Pteronotus is longer, broader proximally (not parallel to the shaft), and meets the shaft distally at a gentler angle, $110^{\circ}$ or more.

The entire distal articular surface of the humerus is moderately offset laterally in Koopmanycteris and Pteronotus, with the medial edge of the trochlea located about halfway between the center and medial edge of the shaft. The distal articular surface is not noticeably offset from the shaft in Mormoops, with the medial edge of the trochlea in line with the medial edge of the shaft. However, the capitulum is offset from the shaft in the fossil and Mormoops, but is less strongly offset in Pteronotus. The distal articular surface of the humerus in Koopmanycteris lacks any evidence of a groove separating the capitulum into medial and lateral portions or ridges that is typical of all species of Pteronotus and many other bats. In this character, the fossils are more similar to Mormoops, which also lacks the groove separating the medial and lateral portions of the capitulum. However, the capitulum of the fossils is broader than in Mormoops, in which the medial portion of the capitulum is reduced and truncated by a broad and very deep groove between the capitulum and trochlea. This groove is shallow and of medium breadth in the fossils and shallow and very narrow in Pteronotus. The distal surface of the capitulum is weakly convex in the fossils, more strongly convex in Pteronotus, and straight and angled proximally toward the groove between the capitulum and trochlea in Mormoops. The epitrochlea or medial epicon- 


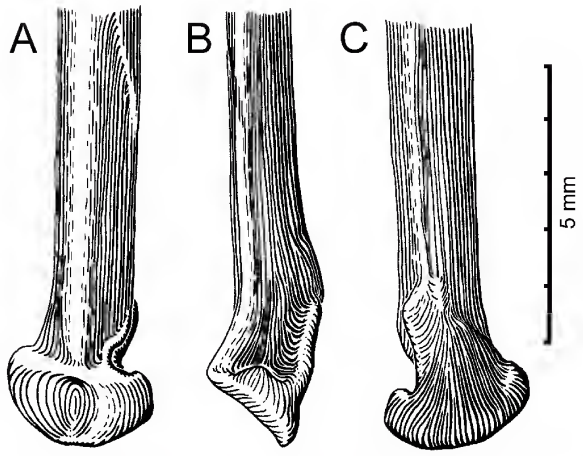

FIGURE 11. Left proximal radius of Koopmanycteris palaeomormoops (UF 179922, paratype) in A, anterior, $\mathbf{B}$, ventral, and $\mathbf{C}$, posterior views.

dyle shows significant variation in the various taxa of mormoopids. In Mormoops, the epitrochlea is narrow and directly connected to the medial edge of the trochlea, not separated by a groove or notch. The epitrochlea is of medium breadth in the fossils, broader than in Mormoops, similar to members of the $P$. davyi complex and $P$. gymnonotus, and narrower than seen in the $P$. parnellii complex. The fossil has a deep notch separating the spinous process and epitrochlea from the trochlea, as do all species of Pteronotus. The medial edge of the epitrochlea in Koopmanycteris is rounded; there is a slight indentation or notch distolateral to it, and between it and the spinous process. The spinous process extends well distal to the distal edge of the trochlea in Koopmanycteris, similar in length to members of the P. parnellii complex, but is not as long as the spinous process in Mormoops and most other species of Pteronotus. The proximomedial edge of the epitrochlea has a distinct rounded concavity in Koopmanycteris and in some species of Pteronotus, including members of the $P$. davyi complex and P. gymnonotus. This concavity, and the medial expansion of the epitrochlea in general, are absent in Mormoops. In the $P$. parnellii complex, this proximomedial corner of the epitrochlea has a rounded convex process. In medial view in the fossils and most Pteronotus, the spinous process together with the shaft of the humerus angles posteriorly. In the fossils, the anterior surface of the spinous process is espe- cially angled. The spinous process is essentially straight and parallel to the humeral shaft in Mormoops and in the P. parnellii complex. On the posterior surface of the distal humeral shaft in Koopmanycteris there is a well-developed ridge extending from the articular surface onto the medial third of the shaft. This ridge is located about halfway between the center and lateral edge of the shaft. In side view, this ridge forms a low convexity. This ridge is also very prominent on the distal humerus in Mormoops, forming a triangular winglike process with a rounded triangular tip. In Koopmanycteris and Mormoops this ridge is continuous with the posterolateral edge of the articular surface. This distolateral humeral ridge is either absent or very weak in Pteronotus. Pteronotus has a low ridge along the medial edge of the posterior distal humeral shaft, which gives this portion of the shaft a flattened appearance. This medial ridge on the distal humerus is absent in the fossils and Mormoops and the distal portion of the humeral shaft is rounded in cross section.

RADIUS: The proximal end of the radius (table 5 ) is the most abundant postcranial element in the sample of Koopmanycteris palaeomormoops from Brooksville 2, with 15 specimens representing at least 11 individuals (4 right, 11 left). A left proximal radius (UF 179922, paratype) is illustrated in figure 11. The triangular process on the proximal end of the radius that is typical of most bats is absent or truncated in Koopmanycteris, 
TABLE 5

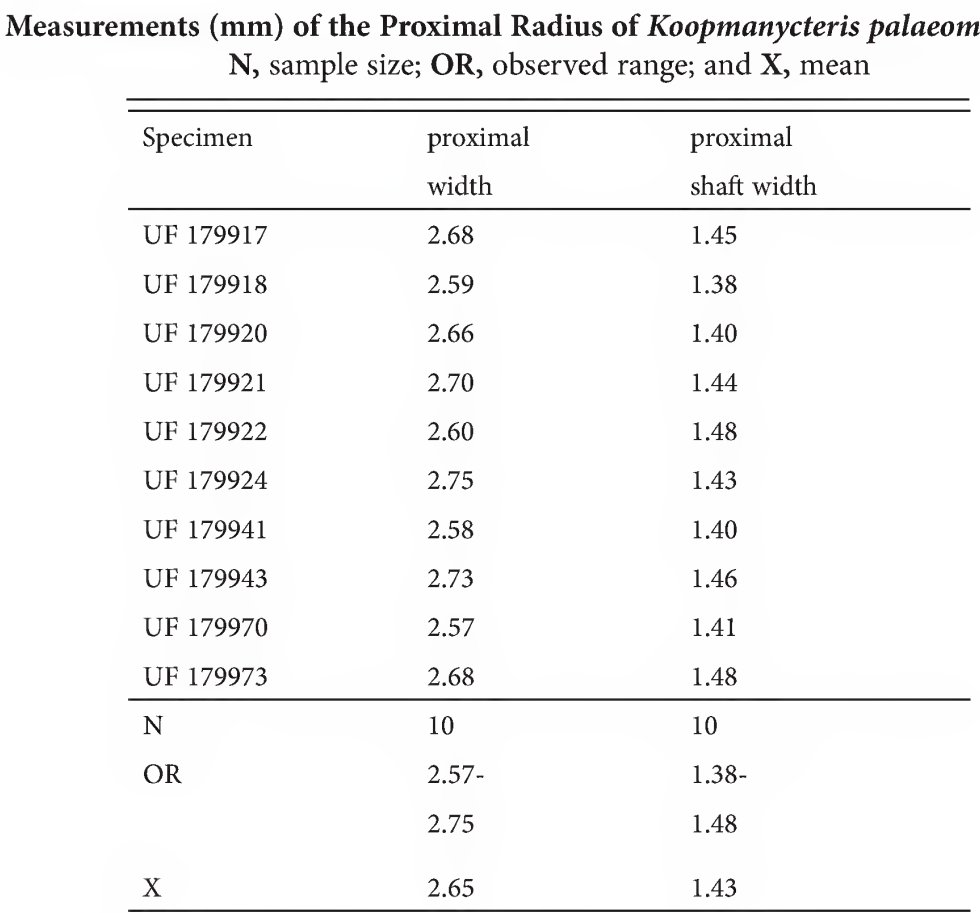

giving the proximal radius a more rounded shape. The proximal articular surface of the radius reflects the morphology of the distal end of the humerus. Only two articular facets are present, representing the articular surfaces for the capitulum (not separated by a groove into medial and lateral portions) and the trochlea on the distal end of the humerus. The articular facet for the capitulum is a large round concavity occupying about two-thirds the breadth of the articular surface, whereas the facet for the trochlea is much smaller. There is a moderately welldeveloped ridge separating the articular facets for the capitulum and trochlea of the humerus.

The proximal end of the radius in Koopmanycteris is more similar to the radius of Mormoops. The triangular process is absent or truncated in Mormoops and Koopmanycteris, giving the proximal end a more rounded or flattened shape. The proximal extremity of the radius is gently rounded in Koopmanycteris, but is flatter with a small concave notch in Mormoops. This portion of the proximal radius is distinctly triangular in Pteronotus, as is typical for most bats. There are three distinct concavities or facets on the proximal articular surface in Pteronotus, where it articulates with the three articular facets of the distal humerus, consisting of the lateral and medial ridges of the capitulum, and the trochlea. Only two facets or concavities are present on the proximal articular surface of the radius in Koopmanycteris and Mormoops, the capitulum (not separated into medial and lateral portions) and the trochlea. However, there are differences in the proximal radius between Mormoops and Koopmanycteris, reflecting the differences between these two genera in the morphology of the distal humerus. In Pteronotus and Koopmanycteris, the articular surface for the trochlea of the humerus is similar in size, whereas the trochlear facet is much more expanded in Mormoops because of the considerably greater size of the trochlea. This facet for reception of the trochlea is not only much larger in Mormoops than in Koopmanycteris, it is also deflected posteriorly. The characters on the prox- 


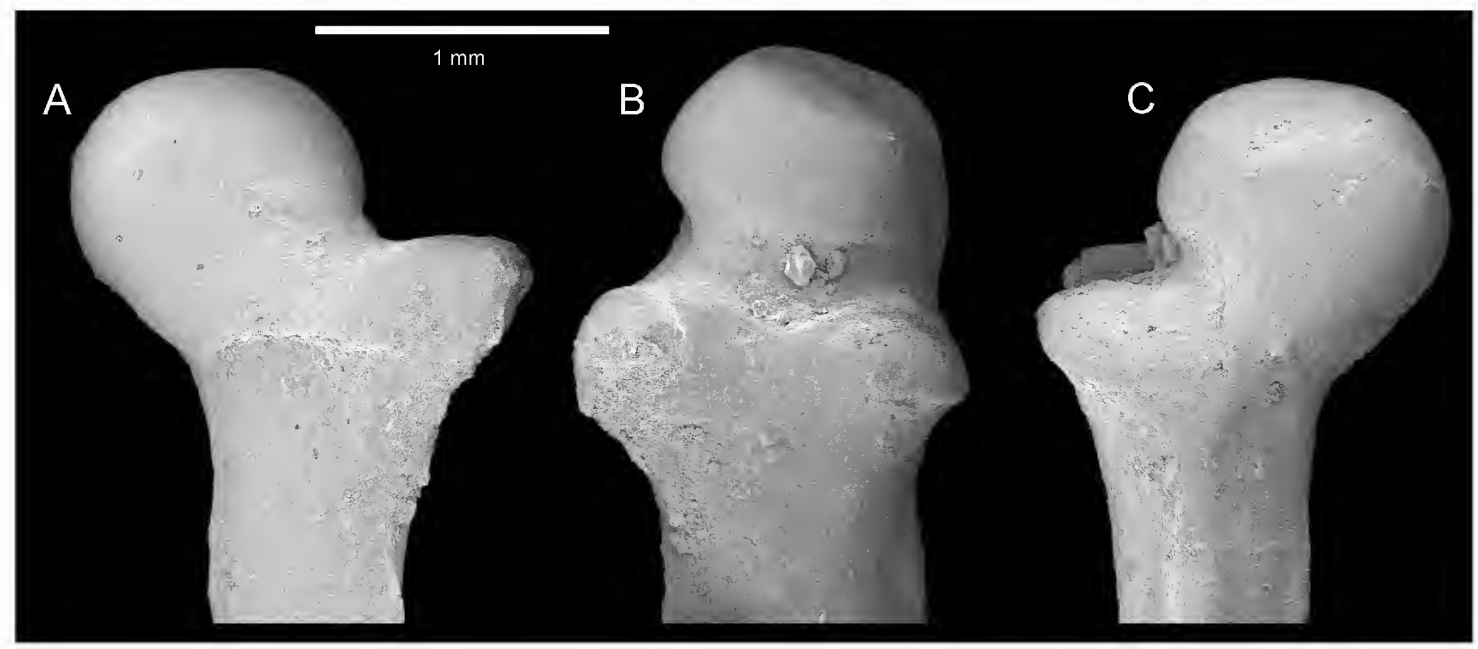

FIGURE 12. Left proximal femur of Koopmanycteris palaeomormoops (UF 179948, paratype) in A, lateral, B, posterior, and $\mathbf{C}$, medial views.

imal radius reflect the highly modified morphology of the distal humerus in Mormoops. The facet for the capitulum is a large round concavity in Koopmanycteris and Mormoops, but is deeper in Mormoops. The facet for the capitulum in Pteronotus is shallow and divided into two facets, separated by a groove into medial and lateral portions. There is a strong, broad ridge between the trochlear and capitular facets in Mormoops, signifying the deep groove between the capitulum and trochlea on the distal humerus. This ridge is not as well developed in Koopmanycteris and is much weaker in Pteronotus. The radius of Speonycteris is unknown, precluding comparisons with that genus.

FEMUR: The presence of mormoopids in the I-75 and Brooksville 2 faunas was first indicated by discovery of the highly distinctive proximal femur (fig. 12, table 6). As pointed out by Smith (1972), members of the Mormoopidae can be distinguished from most other bats by the extreme reduction of the greater trochanter and lesser trochanter on the proximal end of the femur. Unlike most other bats, the trochanters are so reduced on the proximal femur in mormoopids that they barely extend laterally or medially beyond the edges of the femoral head. The proximal femora referred to Koopmanycteris are identified as mormoopids on the basis of their greatly reduced greater and lesser trochanters compared with the femoral head. Among other New World bats, only members of Natalidae and Furipteridae also have greatly reduced trochanters on the proximal femur (see Smith, 1972, fig. 8). In natalids and furipterids, the shaft of the femur is extremely thin, the proximal end is sharply bent relative to the shaft, and there is a well-developed ridge on the proximomedial edge of the shaft. The proximal portion of the femoral shaft is more robust and less strongly bent in mormoopids, and the ridge on the medial edge of the shaft, although present, is less pronounced than in natalids and furipterids.

There are four proximal femora of Koopmanycteris, two from Brooksville 2 (UF 179948, paratype, fig. 11; SCSM 2004.35.6) and two from I-75 (UF 121721, UF 121722). These femora are all essentially identical in morphology. The femoral head in Koopmanycteris is squarish to rectangular with a distinct but shallow fovea capitis. The head is not positioned in the center of the femoral shaft, but is shifted toward the medial edge. The medial edge of the head is aligned with the medial edge of the shaft and is confluent with it, not separated by a groove. The lateral edge of the head is separated from the greater trochanter 


\section{TABLE 6}

Measurements of the Femur of Koopmanycteris palaeomormoops

$\mathbf{N}$, sample size; $\mathbf{O R}$, observed range; and $\mathbf{X}$, mean

\begin{tabular}{lllll}
\hline \hline $\begin{array}{l}\text { Locality and } \\
\text { Specimen }\end{array}$ & $\begin{array}{l}\text { proximal } \\
\text { width }\end{array}$ & $\begin{array}{l}\text { width of } \\
\text { head }\end{array}$ & $\begin{array}{l}\text { shaft } \\
\text { width }\end{array}$ & $\begin{array}{l}\text { distal } \\
\text { width }\end{array}$ \\
\hline $\begin{array}{rlll}\text { Brooksville 2 } \\
\text { UF 179948 }\end{array}$ & 1.65 & 1.23 & 1.13 & - \\
UF 179947 & - & - & 1.15 & 1.98 \\
I-75 & & & & \\
UF 121721 & 1.61 & 1.25 & 0.95 & - \\
UF 121722 & 1.58 & 1.28 & 1.03 & - \\
\hline N & 3 & 3 & 4 & 1 \\
OR & $1.58-$ & $1.23-$ & $0.95-$ & - \\
& 1.65 & 1.28 & 1.15 & \\
X & 1.61 & 1.25 & 1.07 & 1.9 \\
\hline
\end{tabular}

by a distinct groove. The fossils have a short, low, but distinct ridge extending distally about $1 \mathrm{~mm}$ from the head in the middle of the anterior face of the shaft. The greater and lesser trochanters are located on the posterior surface of the proximal femur, are positioned close together, and are greatly reduced compared to the head. Neither trochanter extends proximally beyond the base of the head. The two trochanters are connected to one another by a weak horizontal ridge across the posterior surface of the femur just distal to the head. The greater trochanter is somewhat larger than the lesser trochanter and extends slightly farther proximally, is triangular in shape with a short, blunt tip, and extends laterally beyond the head and lateral edge of the shaft. The lesser trochanter is smaller and more ridgelike, oriented horizontally, and does not extend beyond the medial edge of the head or shaft. The proximal quarter of the shaft and the head of the femur are distinctly bent laterally. There is a ridge along the medial edge of the shaft extending distally from the lesser trochanter to the point where the shaft is bent.

The head of the femur is somewhat larger in Mormoops than in Koopmanycteris, as broad as or broader than the shaft. The head is narrower than the shaft in Koopmanycteris. The head appears to be comparatively larger and more bulbous in Pteronotus than the fossils, but this is due at least in part to the even more highly reduced trochanters and more delicate femoral shaft in Pteronotus. The greater trochanter is reduced to a rounded tuberosity in Pteronotus. In Mormoops and Koopmanycteris, the greater trochanter is a larger, more triangular, laterally oriented process. The lesser trochanter is horizontal and ridgelike in Koopmanycteris and Pteronotus, but is somewhat more reduced in Mormoops. The femoral shaft is thinner just distal to the head in Pteronotus but is more robust in Koopmanycteris and Mormoops. All three genera have a low ridge along the proximomedial edge of the shaft, although this ridge is most prominent in Koopmanycteris.

The most obvious difference between the proximal femora of Koopmanycteris and Speonycteris is size, with the later genus nearly twice the size in most dimensions. Compared to Koopmanycteris, the head of the femur of Speonycteris has a more flattened proximal surface that is more strongly inclined medially, and has a more developed fovea capitis. The greater trochanter of Speonycteris extends farther laterally and the lesser trochanter extends farther medially than in Koopmanycteris in which both trochanters have 

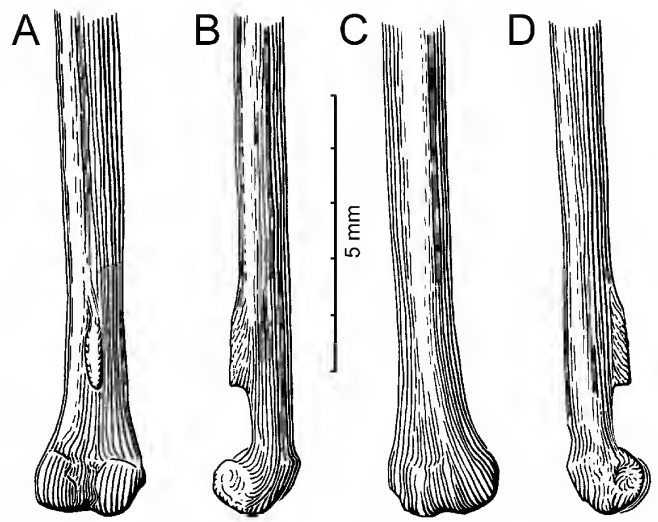

FIGURE 13. Distal femur of Koopmanycteris palaeomormoops (UF 179947, paratype) in A, posterior, B, lateral, $\mathrm{C}$, anterior, and $\mathrm{D}$, medial views.

a more posterior orientation and are located closer to one another. The longitudinal ridge on the anterior surface of the femoral shaft just distal to the head is more prominent in Speonycteris than Koopmanycteris.

The distal two-thirds to three-quarters of a mormoopid femur from Brooksville 2 (UF 179947, paratype, fig. 13) has a short but distinct ridge or tubercle in the middle of the posterodistal surface of the shaft. Mormoops has a weaker tubercle in this same position, and Pteronotus either lacks this tubercle/ridge or it is very weak. The femora of Koopmanycteris and Mormoops are comparatively longer than the femur of Pteronotus. As preserved, UF 179947 is nearly as long as the entire femur of $P$. gymnonotus and bats of the Pteronotus parnellii complex, even though those two species are larger than Koopmanycteris in most other dental and postcranial dimensions. Moreover, the proximal end of the fossil femur is missing, comprising as much as one-third of its length. Koopmanycteris has a longer and more robust femur than comparable-sized or larger species of Pteronotus. Compared to the femur of M. megalophylla, UF 179947 is similar in shape, breadth of shaft, and overall length, even though M. megalophylla is otherwise a larger animal.

Overall, the four partial femora of Koopmanycteris are most similar to the femur of Mormoops, and differ more significantly from
Pteronotus. The shape and size of the head and greater and lesser trochanters, length and thickness of the shaft, and distal ridge on the shaft are all more similar to Mormoops than to Pteronotus. The femur of Pteronotus differs from that of the fossils and Mormoops in its shorter length, reduced greater trochanter, thin shaft distal to the head, and absence of the ridge or tubercle on the distal portion of the shaft. Although the distal portion of the femur is unknown in Speonycteris, the proximal femur, including the head and trochanters, is more similar to Koopmanycteris than to Mormoops or Pteronotus.

Completeness: Although Koopmanycteris palaeomormoops is known only from a limited number of elements, it should be emphasized that the hypodigm for this species, which includes 50 specimens, is much larger than the samples for most other named species of North American Tertiary bats. Two early Eocene bats from the Green River Formation of Wyoming, Icaronycteris index (Jepsen, 1966, 1970) and the more recently described Onychonycteris finneyi (Simmons et al., 2008), are known from complete skeletons but these are extremely rare. Only a few named taxa of Tertiary bats from North America have been described from samples of 10 or more fossils, including the vespertilionid Anzanycteris anzensis from the Pliocene of California (White, 1969) and four species from Flor- 
ida: the large vespertilionid Karstala silva (Czaplewski and Morgan, 2000) and the natalid Primonatalus prattae (Morgan and Czaplewski, 2003) from the early Miocene (Hemingfordian) Thomas Farm LF, and Koopmanycteris palaeomormoops and Speonycteris aurantiadens from the Oligocene I-75 and Brooksville 2 faunas (Czaplewski and Morgan, 2012). More than half the known taxa of North American Tertiary bats were described from a single fossil, usually a partial dentary or maxilla, or in several cases isolated teeth or complete or partial humeri (Czaplewski et al., 2008).

\section{CHARACTER DESCRIPTIONS AND STATE DISTRIBUTIONS}

The characters used in our phylogenetic analyses are described below along with information concerning the taxonomic distribution of the states, use of characters in previous studies and, in the case of multistate characters, whether or not we treated them as ordered characters. Many of these characters were illustrated by Simmons and Geisler (1998), Wetterer et al. (2000), and/or Simmons and Conway (2001), and readers are referred to those publications for additional information and illustrations. We were able to score Koopmanycteris palaeomormoops for 61 of the 245 characters, about $25 \%$ of the total, including characters of the dentition, dentary, petrosal, humerus, radius, and femur.

\section{Dentition}

ChaRACter 1: Inner upper incisors (I1) taper to blunt point (0); or bilobed (1). Most bats have two pairs of upper incisor teeth. The inner pair, in which the teeth are adjacent to each other in the midsagittal plane, are typically interpreted as homologous to I1 in other mammals, while the outer pair are thought to represent I2 (Thomas, 1908; Andersen, 1912; Slaughter, 1970; Giannini and Simmons, 2007a). All extant mormoopids have bilobed inner upper incisors (I1). Among the outgroups, both species of Macrotus also have similar bilobed inner upper incisors. In contrast, the remaining outgroups have inner upper incisors that taper to a blunt point. Data are not available for Pteronotus pristinus, Speonycteris, or Koopmanycteris because the upper incisors are unknown for these taxa. This character corresponds to character 29 of Simmons and Conway (2001).

CHARACTER 2: Two pairs of upper incisors (II and I2) present (0); or only one pair of upper incisors (I1) present, I2 absent (1). All members of Pteronotus and Mormoops have two pairs of upper incisors. Among the outgroups, Thyroptera tricolor, Furipterus horrens, both species of Noctilio, both species of Macrotus, and Artibeus jamaicensis also have two pairs of upper incisors. In contrast, both species of Mystacina have only one pair of upper incisors, which correspond in shape and position to I1 of other bats; I 2 appears to be absent in this genus (Simmons and Conway, 2001). Saccopteryx bilineata also has only a single pair of upper incisors, which Simmons and Conway (2001) interpreted as homologous to I1 based on comparisons with other emballonurids that retain two pairs of upper incisors (e.g., Emballonura). Speonycteris and Koopmanycteris could not be scored for this character, which corresponds to character 16 of Simmons and Geisler (1998), character 48 of Wetterer et al. (2000), and character 28 of Simmons and Conway (2001).

CHARACTER 3: Height of outer upper incisors (I2) less than one-half that of inner incisors (I1) (0); or I2 and II subequal in height (1). The relative proportions of I1 and I2 vary considerably among bats that possess both of these teeth (Simmons and Conway, 2001). The height of the outer upper incisors (I2) is less than one-half that of the inner incisors (I1) in all species of Pteronotus and Mormoops. This condition is also seen in both species of Noctilio and both species of Macrotus. In contrast, I2 and I1 are subequal in height in Artibeus jamaicensis, Thyroptera tricolor, and Furipterus horrens. Taxa lacking I2 (Saccopteryx bilineata and both species of Mystacina; see character 2) could not be evaluated 
for this character, and so were scored "_" in our data set. Data were not available for Pteronotus pristinus, Speonycteris, or Koopmanycteris for this character, which corresponds to character 49 of Wetterer et al. (2000) and character 30 of Simmons and Conway (2001).

Character 4: Lingual cingulum present on upper incisors (I1 and I2) (0); or absent (1). Each upper incisor has a distinct lingual cingulum at its base in all extant Pteronotus (Simmons and Conway, 2001). In contrast, lingual cingulae are absent from these teeth in both species of Mormoops. Saccopteryx bilineata, Thyroptera tricolor, and Furipterus horrens similarly lack a lingual cingulum on the upper incisors, but the remaining outgroups have a lingual cingulum on the base of each upper incisor. Data were not available for Pteronotus pristinus, Speonycteris, or Koopmanycteris for this character, which corresponds to character 31 of Simmons and Conway (2001).

Character 5: Diastema absent between outer upper incisor (I2) and canine (0); or present (1). Diastemata are variously present between many tooth loci in bats (Wetterer et al., 2000; Simmons and Conway, 2001). There is no diastema between the outer upper incisor (I2) and canine tooth (C) in bats of the Pteronotus parnellii complex. In contrast, a distinct diastema is present between these teeth in all the remaining extant mormoopids and Pteronotus pristinus. Among the outgroups, Artibeus jamaicensis and both species of Macrotus lack a diastema between I2 and $\mathrm{C}$, while such a diastema is present in both species of Noctilio, Thyroptera tricolor, and Furipterus horrens. Saccopteryx bilineata and both species of Mystacina have a diastema present anterior to the canine, but these taxa lack I2, so the condition is not comparable to that seen in other taxa. Accordingly, we scored these species "-" for this character. Speonycteris and Koopmanycteris could not be scored for this character, which corresponds to character 32 of Simmons and Conway (2001).

Character 6: Three pairs of lower incisors (i1, i2, i3) present (0); or two pairs (i1 and i2) present (1); or only one pair (i1) present (2). The maximum number of lower incisors found in any bat is three pairs (Miller, 1907; Simmons and Geisler, 1998; Simmons and Conway, 2001). All extant mormoopids have two pairs of lower incisors, which we presume to be homologous to i1 and i2 following Miller (1907) and Simmons and Conway (2001). As in these taxa, Koopmanycteris had two lower incisors, presumably the i1 and i2, preserved as empty alveoli in the available specimens. Artibeus jamaicensis and both species of Macrotus also have two pairs of lower incisors, again presumed to represent il and i2. In contrast, Saccopteryx bilineata, Thyroptera tricolor, and Furipterus horrens each retain three pairs of lower incisors. Both species of Noctilio and both species of Mystacina have only one pair of lower incisors that seem to correspond in shape and position to il of other bats; i2 and i3 appear to be absent in these forms (Miller, 1907). Speonycteris aurantiadens probably had a similar morphology (a single enlarged lower incisor), but presence of a small i 2 cannot be ruled out due to damage of existing specimens (Czaplewski and Morgan, 2012). Regardless, i3 was clearly absent in this form. We scored Speonycteris " $1 / 2$ " for this character to reflect this uncertainty.

As noted by Simmons and Conway (2001), although the number of upper and lower incisors is correlated in many species (e.g., mormoopids), this is not true in all taxa. For example, both species of Noctilio have two pairs of upper incisors but only one pair of lower incisors; Saccopteryx bilineata has three pairs of lower incisors but only one pair of upper incisors. Even closely related genera within families (e.g., Phyllostomidae, Pteropodidae) may show different patterns of reduction of incisors in the upper and lower dentition (Wetterer et al., 2000; Giannini and Simmons, 2007a). The number of upper versus lower incisors therefore appears to be decoupled, and is clearly so among the taxa in our study. Accordingly, we followed Simmons and Geisler (1998) and Simmons and Conway (2001) in treating these as separate characters. This character corresponds to character 17 of Simmons and Geisler (1998), characters 53 and 54 of Wet- 
terer et al. (2000), character 33 of Simmons and Conway (2001), and character 28 of Czaplewski and Morgan (2012). We followed Simmons and Conway (2001) in ordering this character.

CHARACTER 7: Inner lower incisors (i1) trilobed (0); or bilobed (1). All extant mormoopids have trilobed inner lower incisors (i1). Among the outgroups, Saccopteryx bilineata, both species of Mystacina, Thyroptera tricolor, Furipterus horrens, and Noctilio albiventris similarly have a trilobed il. In contrast, il is bilobed in Noctilio leporinus, both species of Macrotus, and Artibeus jamaicensis. Data were not available for Pteronotus pristinus, Speonycteris, or Koopmanycteris for this character, which corresponds to character 34 of Simmons and Conway (2001).

Character 8: Second lower incisors (i2) trilobed (0); or bilobed (1). Although crown morphology of $i 1$ and $i 2$ is frequently similar within any given taxon, this is not uniformly true in mormoopids; for example, members of the Pteronotus parnellii complex have a trilobed i1, but the i2 is bilobed. Accordingly, we followed Simmons and Conway (2001) in treating these as separate characters. The second lower incisors (i2) are trilobed in Pteronotus macleayii, $P$. quadridens, members of the $P$. personatus and $P$. davyi complexes, $P$. gymnonotus, and both species of Mormoops. In contrast, bats of the Pteronotus parnellii complex have bilobed outer lower incisors. Among the outgroups, Saccopteryx bilineata, Thyroptera tricolor, and Furipterus horrens have trilobed outer lower incisors, while these teeth are bilobed in both species of Macrotus and Artibeus jamaicensis. Both species of Noctilio and both species of Mystacina cannot be scored for this character because they lack i2 (see char. 6 above); these taxa were scored "_" for this character in our analysis. Data were not available for Pteronotus pristinus, Speonycteris, or Koopmanycteris for this character, which corresponds to character 35 of Simmons and Conway (2001).

CHARACTER 9: Three upper premolars present $(P 1, P 3, P 4)$ present (0); or two premolars present $(P 3, P 4)$ present $(0)$; or only one (P4) present (1).
We follow Simmons and Conway (2001) in recognizing the three upper premolars in bats as $\mathrm{P} 1$, $\mathrm{P} 3$, and P4. The only taxon in our study that retains three upper premolars is Thyroptera tricolor. Two upper premolars are present in all mormoopids. These apparently correspond to P3 and $\mathrm{P} 4 ; \mathrm{P} 1$ is seemingly absent in these taxa (Miller, 1907; Simmons and Conway, 2001). This also seems to be the case in Mystacina robusta, Mystacina tuberculata, Furipterus horrens, Artibeus jamaicensis, Macrotus waterhousii, and Macrotus californicus (Simmons and Conway, 2001). Both species of Noctilio have only a single premolar that is thought to be P4 (Miller, 1907; Simmons and Conway, 2001).

There is controversy regarding the homologies of dental loci in emballonurids including Saccopteryx, all of which retain only two upper premolars. Simmons and Handley (1998) argued that the missing premolar in emballonurids is P3; the anterior premolar in Saccopteryx would therefore be homologous to P1. Simmons and Conway (2001) followed this assessment and scored Saccopteryx bilineata as having P1 present and P3 absent. In retrospect, we do not believe that this hypothesis is supported by the data at hand, and instead tentatively treat the two premolars in Saccopteryx as homologous to the loci of the other taxa in our study that retain only two premolars. In this respect our scoring is similar to that of Simmons and Geisler (1998: char. 20).

Koopmanycteris and Speonycteris could not be scored for this character. The present multistate character corresponds to character 18 of Simmons and Geisler (1998), character 56 of Wetterer et al. (2000), and characters 36 and 37 of Simmons and Conway (2001). Transformations in this character were ordered to reflect the hypothesis that changes in the number of premolar teeth occurred in a progressive fashion.

Character 10: Diastema absent between P3 and $P 4(0)$; or present (1). As noted by Simmons and Conway (2001), there is no diastema present between P3 and P4 in any species of Pteronotus. In contrast, a distinct diastema is present between these teeth in both species of Mormoops. Among 
the outgroups, a diastema between $\mathrm{P} 3$ and $\mathrm{P} 4$ is lacking in Artibeus jamaicensis, Thyroptera tricolor, Furipterus horrens, and both species Mystacina, while such a diastema is present in Saccopteryx bilineata and both species Macrotus. P3 is absent in both species of Noctilio, so these taxa were scored "_" for this character. Speonycteris and Koopmanycteris could not be scored for this character, which corresponds to character 71 of Wetterer et al. (2000) and character 38 of Simmons and Conway (2001).

Character 11: Crown height of P3 subequal to that of P4 (0); or height of P3 less than one-half height of P4 (1). As noted by Simmons and Conway (2001), the relative crown height of P3 and $\mathrm{P} 4$ varies among bats. $\mathrm{P} 4$ is typically a large tooth with a crown height equal to or greater than that of the molars; P3 may be of similar size, or reduced relative to the other cheekteeth. The crown height of $\mathrm{P} 3$ is reduced to less than onehalf the height of P4 in all extant mormoopids (Simmons and Conway, 2001). The anterior premolar in Saccopteryx bilineata, which we tentatively identify as P3, is also very small, less than half the height of $\mathrm{P} 4$. In contrast, crown height of $\mathrm{P} 3$ is subequal to that of $\mathrm{P} 4$ in both species of Mystacina, Thyroptera tricolor, Furipterus horrens, both species of Macrotus, and Artibeus jamaicensis. Both species of Noctilio cannot be scored for this character because they lack P3 (see char. 9 above); these taxa were scored "_-" for this character in our analysis. Data were not available for Pteronotus pristinus, Speonycteris, or Koopmanycteris. This character corresponds to character 39 of Simmons and Conway (2001).

Character 12: Protocone on P4 high, narrow, and sharply pointed (0); or protocone lower, broader, and more blunt (1). The central or main cusp on $\mathrm{P} 4$, which is often considered homologous to the protocone of the succeeding molars, varies in form among bats. Koopmanycteris and Mormoops have a protocone on $\mathrm{P} 4$ that is high, sharply pointed, and appears narrow in lateral view. The protocone on $\mathrm{P} 4$ is distinctly lower in all species of Pteronotus, and is blunt and not sharply pointed. Furipterus horrens and Saccop- teryx bilineata have a sharp conical cusp on P4, whereas this cusp is lower and more blunt in both species of Macrotus, Artibeus jamaicensis, both species of Noctilio, both species of Mystacina, Thyroptera tricolor, and Speonycteris aurantiadens. Shape of the protocone of P4 (scored in this character) varies independently of relative height of $\mathrm{P} 4$ compared with $\mathrm{P} 3$ (preceding character)-Thyroptera tricolor, for example, has P3 and P4 subequal in height but has high, sharply pointed P4, whereas Furipterus horrens, also with P3 and P4 subequal in height, has a lower, broader, more blunt P4. Similarly, taxa with a relatively small P3 can have either condition of this character. Accordingly, we include both characters in our analysis. Pteronotus pristinus could not be scored for this character. This is a new character that was not employed by Simmons and Conway (2001).

Character 13: Anterolabial cingulum on P4 absent (0); or cingulum present but narrow (1); or well-developed anterolabial basin present (2). Koopmanycteris has a large anterolabial basin on P4, consisting of low, broadly rounded basin. The anterolabial basin is also well developed in both species of Mormoops, although it is somewhat narrower and more elongated than in Koopmanycteris, especially in $M$. megalophylla. In contrast, only a narrow cingular shelf is present along the anterior margin of P4 in all extant species of Pteronotus, both species of Mystacina, Furipterus horrens, Thyroptera tricolor, Saccopteryx bilineata, and Speonycteris aurantiadens. Among the remaining outgroup taxa, both species of Macrotus, Artibeus jamaicensis, and both species of Noctilio lack an anterolabial basin or cingulum on P4. A tiny anterolabial cusp may be present, but there is no cingular shelf in these taxa. Pteronotus pristinus could not be scored for this character. Transformations in this character were ordered to reflect the hypothesis that the narrow cingulum represents an intermediate condition between absence of a cingulum and presence of a well-developed anterolabial basin (i.e., that the basin is really an enlarged cingulum). This is a new character that was not employed by Simmons and Conway (2001). 
ChARACTER 14: Three lower premolars ( $p 1, p 3$, p4) present (0); or two premolars present $(p 1, p 4)$ present (0); or only one ( 44$)$ present (1). As with the upper dentition, there has been considerable debate regarding the identity of the lower premolar teeth in bats, which never number more than three. Many authors have identified the bat premolars as p2, p3, and p4 (e.g., Miller, 1907; Slaughter, 1970), but the anteriormost tooth is more likely homologous with $\mathrm{p} 1$ of other mammals based on morphology and specimens with anomalous additional teeth (Thomas, 1908; Handley, 1959; Giannini and Simmons, 2007a). Three lower premolars (which we presume to be p1, p3, and p4) are present in all extant mormoopids and Koopmanycteris. Thyroptera tricolor, Furipterus horrens, both species of Macrotus, and Speonycteris aurantiadens also retain three lower premolars. In contrast, only two lower premolars are present in Saccopteryx bilineata, both species of Noctilio, both species of Mystacina, and Artibeus jamaicensis.

Simmons and Conway (2001) identified the anteriormost premolar as $\mathrm{p} 1$ in Saccopteryx (with which we concur), but identified the tiny anterior premolar in Noctilio, Mystacina, and Artibeus jamaicensis as the p3. In noctilionoids that demonstrate a reduction of the lower premolars (e.g., Pteronotus and some taxa of phyllostomines), the $\mathrm{p} 3$ is always the first premolar to become reduced in size, and is lost in several genera of phyllostomines (e.g., Phyllostomus and Mimon; Wetterer et al., 2000). There is no evidence for reduction in size of $\mathrm{pl}$ in taxa with three premolars. Based on this evidence, it seems most likely that in noctilionoids and other closely related taxa that lose a lower premolar, it is probably the $\mathrm{p} 3$ that is lost first, not the $\mathrm{p} 1$ (Wetterer et al., 2000). Therefore, we consider the missing lower premolar to be the $\mathrm{p} 3$ in all the outgroup taxa with two lower premolars, contra Simmons and Conway (2001). The present multistate character corresponds to character 20 of Simmons and Geisler (1998) and characters 40 and 41 of Simmons and Conway (2001). Transformations in this character were ordered to reflect the hypothesis that changes in the number of premolar teeth occurred in a progressive fashion with p3 lost first, followed by $\mathrm{p} 1$.

CHARACTER 15: Lower $p 3$ with elongate crown, $p 3$ length between $90 \%$ and $100 \%$ that of $p 4(0)$; or $p 3$ with very small crown, length less than or equal to $50 \%$ of the crown length of $p 4$ (1). The $\mathrm{p} 3$ is a relatively large tooth in Koopmanycteris and both species of Mormoops. In Mormoops the crown of $\mathrm{p} 3$ is approximately the same length as p4, whereas in Koopmanycteris it is roughly $90 \%$ the length of $\mathrm{p} 4$. Shape of the crown in these taxa differs (see characters below), but $\mathrm{p} 3$ is large in both genera. In contrast, the $\mathrm{p} 3$ in all species of Pteronotus is reduced to a tiny, single-rooted tooth that is blunt and circular or peglike in form. Crown length of $\mathrm{p} 3$ in Pteronotus is less than or equal to $50 \%$ of the length of $\mathrm{p} 4$. Among the outgroup taxa, Thyroptera tricolor and both species of Macrotus have a relatively large p3. In contrast p3 is very small in Furipterus horrens and Speonycteris aurantiadens, but in these forms it differs from the p3 of Pteronotus in having a sharply conical cusp. Taxa having only two lower premolars, and thus lacking p3 under our homology assessment, were coded "-" for this character (i.e., Saccopteryx bilineata, both species of Noctilio, both species of Mystacina, and Artibeus jamaicensis). This character corresponds to character 58 of Wetterer et al. (2000) and character 43 of Simmons and Conway (2001).

CHARACTER 16: Lower $p 3$ with two roots (0); or $p 3$ with only one root (1). The p3 is double rooted in Koopmanycteris and both species of Mormoops. In contrast, the p3 in all species of Pteronotus has only one root. Among the outgroup taxa, Thyroptera tricolor, both species of Macrotus, and Speonycteris aurantiadens have a p3 with two roots. The p3 is single rooted in Furipterus horrens. Although relative crown size (char. 15) and number of roots (this character) are correlated in most taxa (with small size correlated with a reduced number of roots), these features are not linked in Speonycteris, a taxon that has a very small yet double-rooted p3 (Czaplewski and Morgan, 2012). Accordingly, 
we follow Simmons and Conway (2001) in treating these as separate characters. Taxa having only two lower premolars, and thus lacking p3 under our homology assessment, were coded "-" for this character (i.e., Saccopteryx bilineata, both species of Noctilio, both species of Mystacina, and Artibeus jamaicensis). This character corresponds to character 42 of Simmons and Conway (2001).

Character 17: Large $p 3$ with crown that is narrow and rectangular in occlusal view (0); or broad and diamond shaped in occlusal view (1). Crown morphology of $\mathrm{p} 3$ varies among taxa in which this is a relatively large, double-rooted tooth (i.e., those taxa scored with state 0 for chars. 15 and 16). The morphology of the p3 in Koopmanycteris is unique among mormoopids; it is a broad, diamond-shaped tooth, with the anterior portion of the diamond rounded and the posterior portion pointed. In Mormoops this tooth is comparatively narrow, rectangular in shape, and elongated anteroposteriorly. Among the outgroup taxa with a large p3, Macrotus and Thyroptera tricolor have a relatively rectangular $\mathrm{p} 3$. Taxa with a small p3 (i.e., those scored with state 1 for char. 15) were scored "_" for this character, as were taxa having only two lower premolars (and lacking p3). This is a new character that was not employed by Simmons and Conway (2001).

Character 18: Small $p 3$ with crown that is circular and peglike or blunt (0); or with a single sharp, conical cusp (1). Morphology of $\mathrm{p} 3$ varies among taxa in which this tooth is a relatively small tooth (i.e., those taxa scored with state 1 for character 15). All species of Pteronotus have p3 that is circular in occlusal outline and peglike or blunt. In contrast, p3 in Furipterus horrens and Speonycteris aurantiadens is also circular in occlusal outline, but has a sharp, conical cusp reminiscent of the cusps on other premolars. Taxa with a large, double-rooted $\mathrm{p} 3$ (i.e., those scored with state 0 for characters 15 and 16) were scored "-" for this character, as were taxa having only two lower premolars (and lacking p3). This is a new character that was not employed by Simmons and Conway (2001).
ChARACTER 19: Alveoli of adjacent lower premolars not separated by diastemata (0); or narrow but distinct diastemata present between alveoli of adjacent teeth (1). All species of Pteronotus and Koopmanycteris lack diastemata, or gaps, between the alveoli of adjacent lower premolars. In these forms, only a thin wall of bone generally separates the alveoli of p1, p3, and p4. The p 3 and $\mathrm{p} 4$ are so closely appressed in Koopmanycteris that the posterior alveolus of $\mathrm{p} 3$ actually encroaches upon the anterior alveolus of $\mathrm{p} 4$. In contrast, both species of Mormoops have a distinct gap between the posterior alveolus of $\mathrm{p} 3$ and the anterior alveolus of $\mathrm{p} 4$, although this diastema is better developed in $M$. megalophylla than in M. blainvillei. M. megalophylla also has a short diastema between $\mathrm{p} 1$ and p3 that is more reduced in M. blainvillei. Among the outgroup taxa, Furipterus horrens, Thyroptera tricolor, and Artibeus jamaicensis have diastemata between the alveoli of the lower premolars. Both species of Macrotus, both species of Mystacina, both species of Noctilio, Saccopteryx bilineata, and Speonycteris aurantiadens lack diastemata between the lower premolars. This is a new character that was not employed by Simmons and Conway (2001).

Character 20: Lower $p 4$ with straight anterior margin, no indentation or notch for $p 3(0)$; or anterolingual margin of $p 4$ with distinct notch or indentation where it contacts the posterior edge of $p 3$ (1). The anterior margin of $\mathrm{p} 4$ is straight and lacks any kind of indentation for $\mathrm{p} 3$ in both Koopmanycteris and Mormoops. In contrast, the anterolingual margin of $\mathrm{p} 4$ has a distinct notch or indentation where it contacts the posterior edge of p3 in all species of Pteronotus. A notch for $\mathrm{p} 3$ is also present on the $\mathrm{p} 4$ of both species of Noctilio, both species of Macrotus, and Artibeus jamaicensis, although the form of $\mathrm{p} 4$ is different in each of these taxa. A notch or indentation is absent in Speonycteris aurantiadens, Saccopteryx bilineata, both species of Mystacina, Thyroptera tricolor, and Furipterus horrens. Presencel absence of a notch or indentation in the anterior margin of $\mathrm{p} 4$ (this character) is decoupled from 
presence/absence of a diastema between the alveoli for $\mathrm{p} 3$ and $\mathrm{p} 4$ (preceding character) because the crowns of adjacent teeth may impinge upon one another even if there is a significant diastema between the alveoli, and absence of a diastema does not necessarily imply that a notch must be present in the crown of $\mathrm{p} 4$. Some taxa lacking a diastema also lack a notch (e.g., Koopmanycteris) and some taxa having a diastema also have a notch or indentation (e.g., Artibeus). Accordingly, we treat these as separate characters. This is a new character not employed by Simmons and Conway (2001).

Character 21: Alveolus of $p 3$ lies in line with axis of toothrow and alveoli of preceding and following teeth (0); or alveolus of $p 3$ offset from toothrow axis, located more lingually than alveoli of adjacent teeth (1). In taxa possessing a p3, the alveolus for this tooth may be located either in line in the toothrow (directly in line between those of adjacent teeth both preceding and following this locus) or may be offset lingually. The alveolus of p3 is in line with other alveoli in the toothrow in Koopmanycteris and both species of Mormoops. In contrast, the alveolus of p3 is offset lingually in all species of Pteronotus. Among the outgroups, the alveolus of $\mathrm{p} 3$ is in line with other alveoli in the toothrow in Thyroptera tricolor, Furipterus horrens, both species of Macrotus, and Speonycteris aurantiadens. Taxa having only two lower premolars, and thus lacking p3 under our homology assessment, were coded "--" for this character (i.e., Saccopteryx bilineata, both species of Noctilio, both species of Mystacina, and Artibeus jamaicensis). This character, which was not employed by Simmons and Conway (2001), corresponds to character 58 of Czaplewski and Morgan (2012).

CHARACTER 22: Crowns of lower premolars parallel to the long axis of the toothrow (0); or crowns of lower premolars oriented slightly obliquely to the long axis of the toothrow (1). The crowns of the lower premolars are oriented parallel to the long axis of the toothrow in most mormoopids including both species of Mormoops, most Pteronotus, and Koopmanycteris. In contrast, the lower pre- molar crowns are oriented slightly obliquely relatively to the toothrow axis in Pteronotus gymnonotus. A similar condition is seen among the outgroups in both species of Noctilio. The remaining outgroups all have lower premolar crowns that are oriented parallel to the long axis of the toothrow (e.g., Saccopteryx bilineata, both species of Mystacina, Thyroptera tricolor, Furipterus horrens, Artibeus jamaicensis, both species of Macrotus, and Speonycteris aurantiadens). This character, which was not employed by Simmons and Conway (2001), corresponds to character 23 of Czaplewski and Morgan (2012).

Character 23: Upper M1 and M2 premetacrista without cuspule (0); or small cuspule present on labial premetacrista (1). The premetacrista is a crestlike ridge that connects the mesostyle and metacone on the upper molars in many tribosphenic taxa. A small cuspule is present on the labial premetacrista in Pteronotus personatus. In contrast, no cuspule is present in either species of Mormoops or any other species of Pteronotus. A cuspule is similarly lacking on the premetacrista in Saccopteryx bilineata, Thyroptera tricolor, Furipterus horrens, both species of Noctilio, both species of Mystacina, both species of Macrotus, and both species of Speonycteris. Artibeus jamaicensis cannot be scored for this character due to modification of the molar teeth for frugivory, so this taxon is scored "." for this character. Upper molars of Koopmanycteris are unknown, so this taxon is scored "NPA" for this character. This character corresponds to character 44 of Simmons and Conway (2001).

Character 24: Upper M3 present (0); or absent (1). The upper third molar (M3) is present in all Pteronotus and Mormoops. M3 is also present in most of the outgroups. In contrast, M3 is absent in Artibeus jamaicensis. This character corresponds to characters 63 of Wetterer et al. (2000) and part of character 45 of Simmons and Conway (2001). The latter authors treated absence of the upper and lower third molars together as single character, but we treat these as separate characters since they are decoupled in some noctilionoid taxa (Wetterer et al., 2000). 
Data were not available for Koopmanycteris or Speonycteris for this character.

CHARACTER 25: Lower first and second molars ( $m 1$ and $m 2$ ) myotodont (0); or nyctalodont (1); or modified for fruit feeding, cusps and cristids not distinct (2). Morphology of the posterior talonid basin-articularly the connections among cusps and cristids-varies among bats (Menu and Sigé, 1971). In taxa with the nyctalodont condition, the postcristid connects the hypoconid with the hypoconulid, so that the latter cusp forms part of the distal wall of the talonid. Koopmanycteris, Speonycteris aurantiadens, both species of Mormoops, and three lineages of Pteronotus ( $P$. macleayii, $P$. quadridens, and members of the $P$. personatus complex) have a nyctalodont $\mathrm{m} 1$ and $\mathrm{m} 2$. In bats with the myotodont condition, the postcristid connects the hypoconid with the entoconid, leaving the hypoconulid as a separate cusp that is excluded from the talonid. Several species of Pteronotus (P. gymnonotus, P. pristinus, and members of the P. parnellii and $P$. davyi complexes) have a myotodont $\mathrm{m} 1$ and $\mathrm{m} 2$. Among the outgroups, Saccopteryx bilineata and Furipterus horrens are nyctalodont, but Thyroptera tricolor, both species of Mystacina, both species of Noctilio, and both species of Macrotus have myotodont lower molars. Artibeus jamaicensis has molar teeth that have been modified for frugivory in such a way that the cusps and cristids are no longer distinct. This character corresponds to a modified version of character 21 of Simmons and Geisler (1998), character 46 of Simmons and Conway (2001), and character 1 of Czaplewski and Morgan (2012). We followed previous authors in not ordering this character.

CHARACTer 26: Cristid obliqua on lower first and second molars ( $m 1$ and $m 2$ ) extends from hypoconid to posterior wall of protocristid and contacts it closer to protoconid than to metaconid: (0); or cristid obliqua extends to contact posterior wall of protocristid approximately midway between protoconid and metaconid (1); or cristid obliqua extends from hypoconid to metaconid (2). In mormoopids, as in most bats, the cristid obliqua extends from the hypoconid to join the pos- terior wall of the postcristid between the protoconid and metaconid. There is variability with respect to exactly where the cristid obliqua contacts the posterior wall of the postcristid. In all species of Pteronotus, the cristid obliqua on $\mathrm{m} 1$ and $\mathrm{m} 2$ contacts the protocristid near the midpoint between the protoconid and metaconid. In contrast, the point of contact is distinctly closer to the protoconid than the metaconid in both species of Mormoops and in Koopmanycteris. This is most noticeable on $\mathrm{ml}$, and the labial shift of the contact point is more pronounced in Koopmanycteris than in Mormoops. The cristid obliqua on $\mathrm{ml}$ in Koopmanycteris connects closer to the protoconid than in the other two genera of mormoopids. Among the outgroups, Speonycteris aurantiadens resembles Koopmanycteris in the position of the contact of the cristid obliqua. In contrast, in Furipterus horrens, Thyroptera tricolor, and both species of Mystacina, the cristid obliqua contacts the protocristid near the midpoint between the protoconid and metaconid. Saccopteryx bilineata, both species of $\mathrm{Mac}$ rotus, and both species of Noctilio exhibit a distinctive third condition in which the cristid obliqua is instead directed toward the metaconid, forming a much more acute angle than in the other taxa. As noted under character 25, Artibeus jamaicensis has molar teeth that have been modified for frugivory in such a way that the cusps and cristids are no longer distinct. To avoid scoring this condition twice in our analysis, Artibeus jamaicensis was scored “-” for the present character. This character represents a modified version of character 47 of Simmons and Conway (2001), and we followed those authors in treating this as an ordered character.

Character 27: Lower molars cristids thick, slightly inflated, and not deeply notched (0); or thin, sharp edged, and deeply notched (1). The crests ( $=$ cristids) on the lower molars (paracristid, protocristid, entocristid) in both species of Mormoops are thin with sharp edges and deep notches separating the major cusps. The deep, $\mathrm{V}$-shaped notches in the lower molar crests in Mormoops have the overall effect of making the 
major cusps appear taller and more sharply conical compared to Pteronotus and Koopmanycteris, as well as most other insectivorous bats. Even the cristid obliqua has a deep notch in Mormoops, causing it to be connected to the protocristid in a more ventral position on the distal wall of the trigonid than in the other two genera of mormoopids. The molar crests are thicker, more inflated, and not as deeply notched in Koopmanycteris and Pteronotus, particularly the latter genus. The more inflated and less deeply notched cristids give the individual cusps a shorter and more inflated aspect in Pteronotus compared to Mormoops. Most of the outgroup taxa including Speonycteris aurantiadens are similar to Pteronotus in having thicker molar crests, but Saccopteryx bilineata has thinner and more deeply notched molar crests that resemble those of Mormoops. As noted above, Artibeus jamaicensis has molar teeth that have been modified for frugivory in such a way that the cusps and cristids are no longer distinct. To avoid scoring this condition twice in our analysis, Artibeus jamaicensis was scored "-" for the present character. This is a new character that was not employed by Simmons and Conway (2001).

Character 28: Entocristid on $m 1$ and $m 2$ curved, concave lingually (0); or entocristid straight (1). The entocristid on the lower $\mathrm{ml}$ and $\mathrm{m} 2$ is straight in all members of Mormoops, Pteronotus, and Koopmanycteris. This condition is seen among the outgroups in both species of Mystacina, both species of Noctilio, both species of Macrotus, and Speonycteris aurantiadens. In contrast, the entocristid on $\mathrm{m} 1$ and $\mathrm{m} 2$ is curved so it is concave lingually in Saccopteryx bilineata, Thyroptera tricolor, and Furipterus horrens. As noted above, Artibeus jamaicensis has molar teeth that have been modified for frugivory in such a way that the cusps and cristids are no longer distinct. To avoid scoring this condition twice in our analysis, Artibeus jamaicensis was scored "-" for the present character. This character, which was not employed by Simmons and Conway (2001), corresponds to character 11 of Czaplewski and Morgan (2012).
Character 29: Paraconid on $m 1$ located on lingual margin of tooth directly in line with metaconid and entoconid (0); or paraconid displaced slightly labially (1); or paraconid strongly displaced labially (2). In all species of Pteronotus, the paraconid on $\mathrm{m} 1$ is positioned on the lingual margin of the tooth and is directly anterior to the entoconid and metaconid. In contrast, in Koopmanycteris and both species of Mormoops, the paraconid is displaced labially and is not in line with the entoconid and metaconid. The paraconid is only slightly displaced labially in Mormoops, whereas the paraconid in Koopmanycteris is displaced farther labially than in any other mormoopid, essentially midway between the metaconid and protoconid. As in Pteronotus, the paraconid is located in line with the metaconid and entoconid in Furipterus horrens, Thyroptera tricolor, Mystacina robusta, Noctilio albiventris, Saccopteryx bilineata, and Speonycteris aurantiadens, whereas the paraconid is displaced slightly labially in Mystacina tuberculata and Noctilio leporinus. The paraconid is strongly displaced labially in both species of Macrotus. As noted previously, Artibeus jamaicensis has molar teeth that have been modified for frugivory in such a way that the cusps and cristids are no longer distinct. To avoid scoring this condition twice in our analysis, Artibeus jamaicensis was scored "_" for the present character. Transformations in this character were ordered to reflect the hypothesis that shifts in the position of the paraconid occur in a progressive fashion from lingual to labial. This is a new character that was not employed by Simmons and Conway (2001).

Character 30: Paraconid on $m 1$ approximately the same height as metaconid (0); or paraconid approximately three-quarters of the height of metaconid (1); or paraconid about half height of metaconid (2); or paraconid very low, forms a shelf barely one-quarter height of metaconid (3). The paraconid on $\mathrm{m} 1$ is highly reduced in Koopmanycteris, forming a low, flat shelf at almost the same level as the trigonid valley. The paraconid is also low in both species of Mormoops, about half the height of the metaconid (as measured 
from the base of the crown), but is not so highly reduced as in Koopmanycteris. The paraconid in all species of Pteronotus is approximately threequarters the height of the metaconid. In these forms, comparisons with the other tooth cusps (e.g., protoconid and hypoconid) suggest that it is the metaconid that has been reduced in height; the paraconid appears to be roughly the same size as in Mormoops, although the relative proportions of the two cusps are different. Saccopteryx bilineata and Noctilio leporinus resemble Pteronotus in cusp proportions, while Noctilio albiventris, both species of Mystacina, both species of Macrotus, and Speonycteris aurantiadens resemble Mormoops. In contrast, the paraconid and metaconid are subequal in height-both tall cusps-in Thyroptera tricolor and Furipterus horrens. As noted under character 23, Artibeus jamaicensis has molar teeth that have been modified for frugivory in such a way that the cusps and cristids are no longer distinct, and so was scored "-" for the present character. Transformations in this character were ordered to reflect the hypothesis that changes in the relative height of the paraconid occur in a progressive fashion. This is a new character that was not employed by Simmons and Conway (2001).

Character 31: Distance between paraconid and metaconid on $m 1$ less than or equal to distance between metaconid and entoconid (0); or greater than distance between metaconid and entoconid (1). The relative positions of the paraconid, metaconid, and entoconid vary among mormoopids, apparently because the paraconid has shifted its position relative to the other two cusps. Like most other bats, all species of Pteronotus have the cusps on $\mathrm{m} 1$ arranged so that the distance between the paraconid and metaconid is either slightly less than the distance between the metaconid and entoconid or is a similar distance, making the two outlying cusps (paraconid and entoconid) equidistant from the metaconid. In contrast, the paraconid on $\mathrm{ml}$ is located proportionately much further anteriorly in Mormoops, so that the distance between the paraconid and metaconid is considerably greater than the distance between the metaconid and entoconid. The paraconid on the $\mathrm{ml}$ in Koopmanycteris is not located quite as far anteriorly as in Mormoops, but the distance between this cusp and the metaconid is somewhat greater than the distance between the metaconid and entoconid. All the outgroup taxa are similar to Pteronotus in having a more distally located paraconid that is either closer to the metaconid than the metaconid and entoconid are to one another or an equal distance. Artibeus jamaicensis was scored “-” for this character. This is a new character that was not employed by Simmons and Conway (2001).

Character 32: Metaconid on $m 1$ taller than entoconid (0); or metaconid and entoconid subequal in height (1); or metaconid shorter than entoconid (2). In lingual view, the metaconid on $\mathrm{ml}$ is noticeably taller than the entoconid in Koopmanycteris. In contrast, the metaconid and entoconid are approximately equal in height in both species of Mormoops, and the metaconid is shorter than the entoconid in all species of Pteronotus. Among the outgroups, Noctilio albiventris, Macrotus californicus, Mystacina tuberculata, and Speonycteris aurantiadens are similar to Koopmanycteris in having the metaconid on $\mathrm{ml}$ taller than the entoconid. In the remaining outgroup taxa, these two cusps are subequal in height. Transformations in this character were ordered to reflect the hypothesis that changes in the relative height of the metaconid occur in a progressive fashion. Artibeus jamaicensis was scored "_" for this character, which is a new character that was not employed by Simmons and Conway (2001).

Character 33: Lower third molar (m3) present (0); or absent (1). The lower third molar (m3) is present in Koopmanycteris and all other mormoopids. These teeth are also present in most of the outgroups. In contrast, $\mathrm{m} 3$ is absent in Artibeus jamaicensis. This character corresponds to character 66 of Wetterer et al. (2000) and part of character 45 of Simmons and Conway (2001). As noted above, the latter authors treated absence of the upper and lower third molars as a single character, but we treat these as separate charac- 
ters since they are decoupled in some noctilionoid taxa (Wetterer et al., 2000).

Character 34 Lower $m 3$ talonid with distal cingulum present (0); or absent (1). Among mormoopids, Koopmanycteris, Mormoops blainvillei, and all species of Pteronotus have a distal cingulum on $\mathrm{m} 3$, although it is only weakly to moderately developed in most species. $M$. megalophylla completely lacks a distal cingulum on $\mathrm{m} 3$, as do both species of Macrotus and both species of Noctilio. In contrast, both species of Mystacina, Furipterus horrens, Thyroptera tricolor, Saccopteryx bilineata, and Speonycteris aurantiadens have a distal cingulum on m3. Artibeus jamaicensis, which lacks $\mathrm{m} 3$, was scored “_" for this character. This is a new character that was not employed by Simmons and Conway (2001).

Character 35: Lower m3 with hypoconulid present (0); or absent (1). A hypoconulid, the tiny rounded cusp directly posterior to the entoconid, is present on the $\mathrm{m} 3$ in Koopmanycteris and both species of Mormoops but is absent in all species of Pteronotus. Among the outgroups, both species of Mystacina, Furipterus horrens, and Thyroptera tricolor have a hypoconulid on $\mathrm{m} 3$, while both species of Macrotus, both species of Noctilio, Speonycteris aurantiadens, and Saccopteryx bilineata lack this cusp. Artibeus jamaicensis, which lacks m3, was scored “_” for this character. This character corresponds to part of character 2 of Czaplewski and Morgan (2012).

\section{SKULL}

Character 36: Premaxillary body reduced, left and right counterparts not in contact, separated by a space in the midsagittal line (0); or body well developed, left and right premaxillary bodies in contact medially but partially separated by a notch anteriorly (1); or left and right bodies well developed and fused medially (2). The premaxillary body is that portion of the premaxilla that bears the incisor teeth (Giannini and Simmons, 2007b). The right and left premaxillary bodies are well developed and fused to one another medially in all species of Pteronotus and
Mormoops, and in most of the outgroups (Artibeus jamaicensis, Macrotus waterhousii, Macrotus californicus, Mystacina tuberculata, Mystacina robusta, Noctilio leporinus, Noctilio albiventris). An alternative condition occurs in Thyroptera tricolor and Furipterus horrens. In these taxa, the right and left premaxillary bodies are well developed and in contact with one another medially, but they are partially separated by a notch anteriorly. A third condition is seen in Saccopteryx bilineata. In this species, the body of the premaxilla bears teeth but is reduced in size, with the left and right bodies completely separated by a space in the midsagittal line. This character corresponds to character 1 of Giannini and Simmons (2007b) and is a modified version of character 2 of Simmons and Conway (2001) and characters 12 and 13 of Simmons and Geisler (1998). We followed Giannini and Simmons (2007b) in treating this character as ordered, although noting that they recognized additional character states not observed among the taxa in our study. This character could not be scored in Koopmanycteris or Speonycteris.

CHARACTER 37: Nasal process of the premaxilla well developed, fused to the rostral process of the maxilla (0); or nasal process caudally reduced, attached to the maxilla via ligaments (1). The nasal process (= facial branch) of the premaxilla varies among bats in terms of degree of development and the nature of its articulation to the maxilla (Simmons and Geisler, 1998; Giannini and Simmons, 2007b). In the majority of the taxa in our study, the nasal process of the premaxilla is well developed and is fused to the rostral process of the maxilla. In contrast, the nasal process in Saccopteryx bilineata is reduced caudally and is attached to the maxilla via ligaments. The latter condition corresponds to the "freely movable" premaxilla discussed by Simmons and Geisler (1998) and others. This character corresponds to character 9 of Simmons and Geisler, character 1 of Simmons and Conway (2001), and character 2 of Giannini and Simmons (2007b). This character could not be scored in Koopmanycteris or Speonycteris. 
Character 38: Nasoincisive suture long, nasal-premaxilla contact broad (0); or contact of intermediate breadth (1); or nasoincisive contact consists of a point contact (2). Length of the nasoincisive suture (the suture between the premaxilla and the nasal) varies considerably among bats and typically reflects the degree of development of the dorsal portion of the nasal process of the premaxilla (Giannini and Simmons, 2007b). In many bats the suture becomes fused in adults, but traces remain visible that allow determination of the breadth of the nasal-premaxilla contact. The nasal process is broad dorsally and the nasoincisive suture is correspondingly long in all species of Pteronotus, both species of Mormoops, Artibeus jamaicensis, and both species of Macrotus. The nasoincisive suture is relatively shorter in Saccopteryx bilineata, both species of Noctilio, and Furipterus horrens. Finally, the nasal process of the premaxilla forms only a point contact with the nasal in both species of Mystacina. We followed Giannini and Simmons (2007b: char. 8) in treating this character as ordered. This character could not be scored Thyroptera tricolor because no appropriately preserved specimens of young individuals were available to us, and extensive fusions of the skull bones made it difficult to determine the shape of the nasoincisive contact. This character could not be scored in Koopmanycteris or Speonycteris because we lack skulls for these taxa.

Character 39: Palatine process of the premaxilla complete, with medial and lateral flanges enclosing paired incisive foramina (0); or palatine process complete, incisive foramina closed by a process of the maxilla (1); or both lateral and medial flanges of premaxilla absent, wide incisive fissure present (2). We follow Giannini and Simmons (2007b) in treating the premaxillary contribution to the hard palate and the degree of development of the incisive fissure/foramina in a single character because these features are intimately associated. In a majority of the taxa in our study, the anterior palate resembles that of most mammals: the palatine process of the premaxilla consists of two flanges (medial and lateral) that enclose paired incisive foramina. Other bats not sampled in this analysis exhibit a slightly different condition in which the lateral and medial branches of the premaxilla form the lateral, anterior, and medial margins of paired incisive foramina, but a portion of the maxilla forms the posterior edge of each foramen (Giannini and Simmons, 2007b). In Noctilio albiventris and $N$. leporinus, an anterior growth of the maxilla completely fills in the space between the lateral and medial flanges of the palatine process, so that no incisive foramina or fissure are present in adults (Giannini and Simmons, 2007b). Saccopteryx bilineata exhibits a very different condition in which the lateral and medial flanges of the premaxilla are both absent. Rather than paired incisive foramina, a single, wide incisive fissure is present (Giannini and Simmons, 2007b). Simmons and Conway (2001: char. 3) scored presence/absence of incisive foramina as a character in their analysis, but scored Saccopteryx as inapplicable given construction of the palate in this species. We prefer the Giannini and Simmons' (2007b) treatment of anterior palate structures, and followed them in treating this character as unordered since different bones participate in different taxa. This character could not be scored in Koopmanycteris or Speonycteris.

ChARACTER 40: Hard palate extends posteriorly into interorbital region (0); or terminates at the level of the zygomatic roots (1). The hard palate, which forms a bony separation between the oral and nasal passages, terminates posteriorly at the mesopterygoid fossae. As noted by Simmons and Conway (2001), the position of the posterior edge of the hard palate varies independently of the posterior extent of the molar toothrow, and is apparently linked to the structure of the nasal passages and soft tissues of the pharyngeal region. The hard palate extends posteriorly into the interorbital region in mormoopids and most of the outgroups (Artibeus jamaicensis, Macrotus waterhousii, Macrotus californicus, Mystacina tuberculata, Mystacina robusta, Noctilio leporinus, Noctilio albiventris, Thyroptera tricolor). In contrast, the hard palate 
terminates at the level of the zygomatic roots in Saccopteryx bilineata and Furipterus horrens. This character, which corresponds to character 15 of Simmons and Geisler (1998), character 44 of Wetterer et al. (2000), and character 4 of Simmons and Conway (2001), could not be scored in Koopmanycteris or Speonycteris.

CHARACTER 41: Basisphenoid with shallow longitudinal furrows (0); or with deep furrows (1); or with very deep pits (2). In most noctilionoids the basisphenoid is trapezoid shaped, wider anteriorly than posteriorly, and has two parallel furrows along its entire length (Simmons and Conway, 2001). In part owing to the shape of the basisphenoid, the furrows are less well defined anteriorly than posteriorly. Pteronotus macleayii, $P$. quadridens, $P$. gymnonotus, members of the $P$. personatus and $P$. davyi complexes, and both species of Mormoops have basisphenoid furrows that are wide and shallow, covering the entire width of the basisphenoid. In contrast, members of the Pteronotus parnellii complex and P. pristinus have deeper furrows down the center of the basisphenoid. Both species of Macrotus have similar deep furrows, while Artibeus jamaicensis, both species of Noctilio, and both species of Mystacina have furrows that are wide and shallow. Saccopteryx bilineata and Furipterus horrens share an alternative condition in which the basisphenoid is dominated by a pair of large, very deep pits. These pits are clearly distinct from the deep furrows of the Pteronotus parnellii complex because the pits are circumscribed anteriorly and posteriorly as well as along the sides, while the furrows are open both anteriorly and posteriorly. This character, which corresponds to character 24 of Simmons and Conway (2001), could not be scored in Koopmanycteris or Speonycteris. We followed Simmons and Conway (2001) in treating this as an unordered character.

CHARACTER 42: Epitympanic recess shallow and broad (0); or deep, constricted in area (1). The epitympanic recess in bats lies in the dorsolateral roof of the middle-ear space, where it houses the incus and the joint between the malleus and incus (Simmons and Geisler, 1998). The epitym- panic recess is deep and constricted in area in all species of Pteronotus and Mormoops (Simmons and Conway, 2001). Among the outgroups, a similar condition is seen in Saccopteryx bilineata, both species of Noctilio, and both species of Mystacina. In contrast, the epitympanic recess is shallow and broad in Artibeus jamaicensis, both species of Macrotus, Thyroptera tricolor, and Furipterus horrens. This character, which corresponds to character 30 of Simmons and Geisler (1998) and character 16 of Simmons and Conway (2001), could not be scored in Koopmanycteris or Speonycteris.

CHARACTER 43: Fossa for $m$. stapedius broad (0); or constricted in area, forms a crescent-shaped fissure (1). The fossa for the origin of $\mathrm{m}$. stapedius is located in the posterior roof of the middle-ear space, and when it is well defined it occupies a cavity behind (medial to) the crista parotica (Simmons and Geisler, 1998). The fossa for m. stapedius in all species of Pteronotus and Mormoops was treated as "indistinct" by Simmons and Conway (2001), but upon reexamination we found it to be distinct and broad in all except the P. parnellii complex. A similar condition (broad and distinct) occurs in Koopmanycteris and among the outgroups in both species of Macrotus, Artibeus jamaicensis, both species of Noctilio, both species of Mystacina, and Furipterus horrens. In contrast, this fossa is constricted in area in Pteronotus parnellii complex, Thyroptera tricolor, and Saccopteryx bilineata. This character could not be scored in Speonycteris. Simmons and Conway (2001: char. 17) included a version of this character in their analysis, but we have modified it as noted above.

Character 44: Fenestra cochleae small or of moderate size, maximum diameter $<20 \%$ of the external width of the first half turn of the cochlea (0); or enlarged, maximum diameter $>25 \%$ of the external width of the first half turn of the cochlea (1). The fenestra cochleae (= fenestra rotundum) is a membrane-covered opening in the tympanic wall of the petrosal. It faces posteriorly or posterolaterally, and separates the scala tympani (at the base of the cochlear labyrinth) from the mid- 
dle-ear cavity (Simmons and Geisler, 1998). The fenestra cochleae appears relatively large in Koopmanycteris and in all species of Pteronotus and Mormoops, where it has a maximum diameter $>25 \%$ of the external width of the first half turn of the cochlea (Simmons and Conway, 2001). A similar condition is seen in most of the outgroups. In contrast, the fenestra cochleae is smaller (maximum diameter $<20 \%$ of the external width of the first half turn) in Artibeus jamaicensis and Furipterus horrens. Data were not available for Pteronotus pristinus or Speonycteris. This character corresponds to character 32 of Simmons and Geisler (1998) and character 18 of Simmons and Conway (2001).

Character 45: Pars cochlearis of petrosal broadly sutured to basisphenoid (0); or loosely attached to edge of basisphenoid via ligaments and/or thin splints of bone (1). The pars cochlearis of the petrosal (which in echolocating bats consists principally of the bone enclosing the enlarged cochlea) is loosely attached to the basisphenoid via ligaments and/or thin splints of bone in all species of Mormoops, and all extant species of Pteronotus (Simmons and Conway, 2001), and Koopmanycteris. A similar condition is seen in most of the outgroups. In contrast, the pars cochlearis of the petrosal has a broad contact with a flange of the basisphenoid in emballonurids including Saccopteryx bilineata. Data were not available for Pteronotus pristinus or Speonycteris for this character, which corresponds to character 25 of Simmons and Geisler (1998) and character 19 of Simmons and Conway (2001).

Character 46: Cochlea phanerocochlear (0); or cryptocochlear (1). Cochlear structure varies among bats and Novacek (1985a, 1991) described two distinct patterns of petrosal ossification. The "phanerocochlear" state occurs when the petrosal wall is thin and poorly ossified, resulting in a condition where the cochlear labyrinth is clearly visible externally in the adult (Novacek, 1985a, 1991). In contrast, a "cryptocochlear" condition occurs when strong petrosal ossification produces a thicker encasement of bone around the cochlea, hiding the cochlear labyrinth from external view in adults (Novacek, 1985a, 1991). Members of the Pteronotus parnellii complex have a cryptocochlear condition, while all other extant mormoopids exhibit the phanerocochlear condition. The cochlea is phanerocochlear also in Koopmanycteris. Among the outgroups, the phanerocochlear condition occurs in Saccopteryx bilineata, Thyroptera tricolor, Furipterus horrens, both species of Macrotus, both species of Noctilio, and both species of Mystacina. Artibeus jamaicensis has a cryptocochlear cochlea. Data were not available for Pteronotus pristinus or Speonycteris for this character, which corresponds to character 27 of Simmons and Geisler (1998) and character 20 of Simmons and Conway (2001).

Character 47: Cochlea greatly enlarged (0); or moderately enlarged (1). As discussed by Simmons and Conway (2001), numerous authors have discussed the degree of enlargement of the cochlea in echolocating bats, a feature that appears to be correlated with echolocation and foraging habits (Novacek, 1985b, 1987, 1991; Habersetzer and Storch, 1992; Simmons and Geisler, 1998). Habersetzer and Storch (1992) plotted cochlear width (measured from the end of the first half turn of the cochlea to the end of the second half turn) versus basicranial width, and found a small zone of overlap between nonecholocating and echolocating bats. Simmons and Geisler (1998) added additional data points to this plot, and formalized these data in phylogenetic characters that they used in an assessment of interfamilial relationships. Based on their data plot (Simmons and Geisler, 1998: fig. 29), they recognized three character states: (A) cochlea not enlarged (taxa that fall below the zone of overlap between echolocating and nonecholocating [i.e., Pteropodidae] bats); (B) cochlea moderately enlarged (taxa that fall in the zone of overlap between echolocating and nonecholocating bats); and (C) cochlea greatly enlarged (taxa that fall above the zone of overlap between echolocating and nonecholocating bats). Simmons and Conway (2001) scored taxa using Simmons and Geisler's (1998: fig. 29) methods and data, adding new observations only for the 
species not explicitly scored in that study. Based on that work, all extant mormoopids have a greatly enlarged cochlea (Pteronotus pristinus, although lacking preserved cochleae, can be scored based on the size of the spaces for the cochlea preserved in the skull of ROM 59132). Among the outgroups, a similar condition is seen in Saccopteryx bilineata, Thyroptera tricolor, Furipterus horrens, both species of Noctilio, Mystacina tuberculata, and Artibeus jamaicensis. In contrast, Mystacina robusta and both species of Macrotus have a moderately enlarged cochlea. This character could not be scored in Koopmanycteris (because the basicranial width is unknown; however, the cochlea itself is comparable in its absolute size to that of $P$. personatus complex and $P$. davyi complex, and a little smaller than that of $M$. megalophylla) or Speonycteris (for which the cochlea is unknown). This character corresponds to character 26 of Simmons and Geisler (1998) and character 21 of Simmons and Conway (2001).

Character 48: Cochlear canaliculus smaller than fenestra vestibuli (0); or about the same size as the fenestra vestibuli (1); or larger than the fenestra vestibuli (2). The cochlear canaliculus is about the same size as the fenestra vestibuli in Koopmanycteris and in Mormoops. In contrast, the cochlear canaliculus is larger than the fenestra vestibuli in all species of Pteronotus. Both species of Macrotus and Artibeus jamaicensis also have a cochlear canaliculus that is larger than the fenestra vestibuli. A third condition is seen among the outgroups in which the cochlear canaliculus is smaller than the fenestra vestibuli, including both species of Noctilio, Furipterus, Mystacina, and Saccopteryx. In Thyroptera tricolor the cochlear canaliculus is a tiny pore that is much smaller than the fenestra vestibuli and visible only at high magnification; we scored this condition with state " 0 " for the purposes of our analyses. Data were not available for Pteronotus pristinus or Speonycteris for this character. We treated this as an ordered character.

CHARACTER 49: Region between the semicircular canals covered by a complete bony lamina (0); or by one or more partial laminae (1); or laminae absent between semicircular canals (2). In some bat families (e.g., Emballonuridae, Rhinolophidae, some Molossidae) a thin bony lamina mostly or completely covers the area between the three semicircular canals, closing off the subarcuate fossa to enclose the lobus petrosus of the paraflocculus of the brain, and forming a closed mastoid exposure of the pars canalicularis of the petrosal in the sidewall of the braincase. In other bats there are no laminae, or there may be small flanges of bone along the lateral semicircular canal where two of the semicircular canals meet; these flanges do not completely enclose the subarcuate fossa. In Koopmanycteris, the semicircular canals all are open and lack lamina caps or flanges. This condition is also seen in members of the Pteronotus davyi complex, P. macleayii, $P$. quadridens, and P. gymnonotus. In contrast, Mormoops blainvillei and M. megalophylla both exhibit small laminar flanges at the anterior and posterior ends of the lateral semicircular canal that extend partway up the bases of the adjacent anterior and posterior semicircular canals. Members of the Pteronotus personatus and P. parnellii complexes have a small flange of bone on the lateral semicircular canal that rises to a point before descending slightly to contact the anterior semicircular canal; the posterior flange is small or absent in these taxa. Among the outgroups, Macrotus and Artibeus jamaicensis have small partial laminae at either end of the lateral semicircular canal. Furipterus has a small flange at the middle of the lateral semicircular canal above the posterior petrosal process. Both species of Noctilio lack flanges of bone on the semicircular canals, as does Thyroptera tricolor. Mystacina has a well-developed flange all along the top of the lateral semicircular canal, as well as another flange at the junction of the anterior and posterior semicircular canals above the common crus. In contrast to all these bats, Saccopteryx bilineata has a complete bony lamina between the semicircular canals, completely closing the subarcuate fossa. Data were not available for Pteronotus pristinus, Speonycteris, or Mystacina tuberculata for 
this character. This character was treated as an ordered character in our analyses.

Character 50: Fossa incudis on crista parotica present as a small shallow recess (0); or recess rudimentary or absent (1). The fossa incudis is formed laterally by the squamosal bone and medially by the crista parotica of the petrosal. It accommodates the crus breve of the incus adjacent to the base of the processus petrosus anterior. In Mormoops and Koopmanycteris, the medial wall of the fossa incudis on the crista parotica occurs as a small, shallow hollow. In contrast, in species of Pteronotus the fossa incudis is barely visible as a minuscule depression or it is completely absent. In the outgroups the fossa incudis is similar to that in Mormoops and Koopmanycteris. Data were not available for Pteronotus pristinus or Speonycteris for this character.

Character 51: Processus petrosus anterior of the crista parotica is present as a delicate spine or short pointed projection, not connected to the cochlea (0); or as a pointed projection connected by a bony flange to the cochlea (1); or as a rounded knob merged into the bone of the cochlea (2). The processus petrosus anterior is a thin, spinelike projection in many bats. It is two to four times as long as it is wide and as a result, it is easily broken off and may be missing on many specimens. In Koopmanycteris, the process is broken off the fossil but the remaining base indicates that the spine was present in life. In Mormoops and most species of Pteronotus (except P. parnellii complex) the processus petrosus anterior is a long, free-standing spine as described above. In P. parnellii complex, the process is reduced to a rounded knob fused onto the bone encircling the canalis facialis. In Macrotus the process is long but connected via a strong bony flange to the bone encircling the canalis facialis. In Artibeus jamaicensis the process is about 1.5 times as long as wide and is free standing (i.e., without the bony flange seen in Macrotus). In Noctilio the process is a short, pointed projection, wider than long. In Furipterus and Thyroptera the process is long and pointed but confluent via a bony flange to the bone encircling the canalis facialis, similar to Macrotus. In
Mystacina the process is longer than wide but connected medially via bony flange to the cochlear portion of the petrosal. In Saccopteryx the process is a long free spine (without flanges) much longer than wide, similar to that in the mormoopids. Data were not available for Pteronotus pristinus or Speonycteris for this character. We treated this as an unordered character.

Character 52: Ectotympanic bulla extends medially across two-thirds or more of cochlea (0); or extends across one-half of cochlea (1); or extends across no more than one-third of cochlea (2). The auditory bulla of bats is poorly developed, consisting of a single ectotympanic element that typically covers only part of the ventral exposure of the cochlea (Simmons and Conway, 2001). The ectotympanic bulla extends medially across two-thirds or more of the cochlea in both species of Mormoops and all extant species of Pteronotus, with the exception of members of the $P$. parnellii complex. In the latter bats, the ectotympanic bulla extends across no more than onethird of the cochlea. Among the outgroups, the ectotympanic bulla extends medially across twothirds or more of the cochlea in Artibeus jamaicensis, both species of Macrotus, and both species of Mystacina. In contrast, the ectotympanic bulla extends across one-half of the cochlea in Saccopteryx bilineata and both species of Noctilio. The ectotympanic bulla extends across no more than one-third of the cochlea in Thyroptera tricolor and Furipterus horrens. Data were not available for Pteronotus pristinus, Koopmanycteris, or Speonycteris. This character corresponds to character 22 of Simmons and Conway (2001), and we followed those authors in treating this as an ordered character.

Character 53: Tympanic annulus inclined, lies at an angle of $35^{\circ}-55^{\circ}$ relative to the basicranial plane (0); or semivertical, lies at an angle of $75^{\circ}-90^{\circ}$ relative to basicranial plane (1). The tympanic annulus is that part of the ectotympanic that forms the ring that supports the tympanic membrane. In bats the annulus is typically composed of relatively dense bone (as opposed to the thinner medial portion of the ectotympanic, 
which forms the bulla), and it lies in a plane that defines the orientation of the tympanic membrane (Simmons and Conway, 2001). The tympanic annulus is semivertical (plane of annulus lies at an angle of $35^{\circ}-55^{\circ}$ relative to the basicranial plane) in all extant species of Pteronotus and Mormoops. A similar condition is found among the outgroups in Furipterus horrens, Artibeus jamaicensis, and both species of Macrotus. In contrast, the tympanic annulus is inclined at an angle of $35^{\circ}-55^{\circ}$ relative to the basicranial plane in Saccopteryx bilineata, Thyroptera tricolor, both species of Noctilio, and both species of Mystacina. Data were not available for Pteronotus pristinus, Koopmanycteris, or Speonycteris for this character, which corresponds to character 29 of Simmons and Geisler (1998) and character 23 of Simmons and Conway (2001).

Character 54: Basioccipital not constricted (0); or constricted (1). In bats the basioccipital forms the posterior floor of the braincase, typically extending anteriorly between the cochlea (Simmons and Conway, 2001). In members of the Pteronotus parnellii complex, the basioccipital is markedly constricted anteriorly, so that the width of the anterior portion of this element is approximately one-third the width of the foramen magnum. In contrast, the basioccipital is not so constricted in Mormoops and the remaining species of Pteronotus. In these forms, the width of the anterior basioccipital is approximately one-half the width of the foramen magnum. The basioccipital is similarly unconstricted in both species of Noctilio, both species of Mystacina, both species of Macrotus, Artibeus jamaicensis, and Thyroptera tricolor. The basioccipital is constricted in Saccopteryx bilineata and Furipterus horrens. Data were not available for Pteronotus pristinus, Koopmanycteris, or Speonycteris for this character, which corresponds to character 25 of Simmons and Conway (2001).

Character 55: Parietals not inflated (0); or inflated in area encasing cerebellum (1). The parietal bones, which cover the brain in the region of the cerebellum, are not notably inflated with respect to the bones of the anterior braincase (i.e., the frontals) in most bats. In contrast, the parietal bones are markedly inflated over the cerebellum in both species of Mormoops (Simmons and Conway, 2001). All species of Pteronotus lack inflated parietals, as do all of the outgroups. This character could not be scored in Koopmanycteris or Speonycteris. This character corresponds to character 15 of Simmons and Conway (2001).

CHARACTER 56: Zygomatic breadth greater than or equal to mastoid breadth (0); or less than mastoid breadth (1). The maximum breadth of the skull in bats may occur in either the zygomatic region anterior to the braincase or in the mastoid region at the posterior end of the braincase (Simmons and Conway, 2001). Zygomatic breadth (the maximum breadth of the skull measured across the zygomatic arches) is greater than or equal to mastoid breadth (maximum breadth of the skull measured across the mastoid region) in both species of Mormoops, Pteronotus gymnonotus, $P$. pristinus, and members of the $P$. parnellii and $P$. davyi complexes. In contrast, mastoid breadth is greater than zygomatic breadth in Pteronotus quadridens, $P$. macleayii, and members of the $P$. personatus complex. Zygomatic breadth is greater than mastoid breadth in all the outgroups. This character could not be scored in Koopmanycteris or Speonycteris. This character corresponds to character 43 of Wetterer et al. (2000) and character 14 of Simmons and Conway (2001).

Character 57: Postorbital process present (0); or absent (1). A postorbital process is absent in all Pteronotus, Mormoops, and most of the outgroups (Simmons and Conway, 2001). In contrast, a well-developed, elongate postorbital process is present in Saccopteryx bilineata. This character could not be scored in Koopmanycteris or Speonycteris. This character corresponds to character 24 of Simmons and Geisler (1998) and character 13 of Simmons and Conway (2001).

Character 58: Infraorbital foramen not enlarged, diameter less than one-eighth the height of the rostrum (0); or enlarged, diameter onequarter to one-half the height of the rostrum (1). The size of the infraorbital foramen can be evalu- 
ated by comparing the diameter of the foramen to the height of the rostrum above M1 (Simmons and Conway, 2001). The infraorbital foramen is not enlarged (i.e., foramen diameter less than one-eighth the height of the rostrum) in all extant mormoopids. In contrast, the infraorbital canal is enlarged and its diameter is approximately one-quarter to one-third the height of the rostrum in Pteronotus pristinus. Among the outgroups, the infraorbital foramen is not enlarged in Artibeus jamaicensis, Macrotus waterhousii, Macrotus californicus, Noctilio leporinus, Noctilio albiventris, Thyroptera tricolor, Furipterus horrens, and Saccopteryx bilineata, but this foramen is enlarged (one-half the height of the rostrum) in both species of Mystacina. This character could not be scored in Koopmanycteris or Speonycteris. This character corresponds to character 10 of Simmons and Conway (2001).

Character 59: Infraorbital foramen located above anterior half of $\mathrm{P} 4(0)$; or above posterior half of P4 (1); or above anterior half of M1 (2); or above posterior half of $M 1$ (3); or anterior half of M2 (4). As noted by Simmons and Conway (2001), the position of the infraorbital foramen on the rostrum varies among mormoopids, and it can be described in terms of position of this foramen relative to the upper toothrow. The infraorbital foramen in the Pteronotus personatus complex is located directly above (dorsal to) the anterior half of $\mathrm{M} 2$, roughly above the parastyle. In contrast, the infraorbital foramen is located above the posterior half of M1 (above the metacone) in the P. davyi complex and P. gymnonotus. The infraorbital foramen is located above the anterior half of M1 (above the paracone) in members of the $P$. parnellii complex, $P$. macleayii, $P$. quadridens, and P. pristinus. Both species of Mormoops exhibit a fourth condition in which the infraorbital foramen occurs above the posterior half of P4. Among the outgroups, both species of Mystacina have an infraorbital foramen that opens above the posterior half of M1. Both species of Noctilio and both species of Macrotus have the foramen above the anterior half of M1, and the infraorbital foramen opens above the poste- rior half of P4 in Artibeus jamaicensis, Thyroptera tricolor, and Saccopteryx bilineata. Finally, the infraorbital foramen lies above the anterior half of P4 in Furipterus horrens. This character could not be scored in Koopmanycteris or Speonycteris. This character represents a modified version of character 11 of Simmons and Conway (2001) that includes an additional state for Furipterus horrens. We followed Simmons and Conway (2001) in treating this as an ordered character.

Character 60: Anterior rim of orbit terminates above P4 (0); or above the anterior half of $M 1$ (1); or above the posterior half of $M 1$ (2); or above anterior half of $M 2$ (3); or above posterior half of $M 2$ (4). The anterior terminus of the orbit, which in most bats is marked by a sharply demarcated rim, may occur in different positions relative to the toothrow (Simmons and Conway, 2001). This variation affects both the relative position of the eye, which typically occupies the anteriormost portion of the orbit, and the length of the infraorbital canal, which begins in the anterior orbit and terminates on the face at the infraorbital foramen (see char. 49). The anterior rim of the orbit terminates above (dorsal to) the posterior half of M2 in all species of Pteronotus. In contrast, the anterior orbital rim terminates above the posterior half of M1 in both species of Mormoops. Among the outgroups, the anterior rim of the orbit terminates above P4 in Saccopteryx bilineata, above the anterior half of M1 in Furipterus horrens and Thyroptera tricolor, above the posterior half $\mathrm{M} 1$ in both species of Noctilio, above the anterior half of M2 in Artibeus jamaicensis and both species of Macrotus, and above the posterior half of M2 in both species of $M y s-$ tacina. This character could not be scored in Koopmanycteris or Speonycteris. This character represents a modified version of character 12 of Simmons and Conway (2001) that includes an additional state for Furipterus horrens and Thyroptera tricolor. We followed those authors in treating this as an ordered character.

Character 61: Nasals flat or convex (0); or nasals concave (1). As noted by Simmons and Conway (2001), the nasal bones in most bats are 
either flat or convex upward when seen in lateral view. In contrast, all species of Pteronotus and Mormoops have nasals that are concave upward. This condition is also seen in Furipterus horrens, but the remaining outgroups all have nasals that are flat or convex, suggesting that concave nasals represent a derived condition. This character appears to be correlated with the presence of an upturned rostrum in mormoopids (see below), but these features are decoupled in the outgroups. Artibeus jamaicensis, Macrotus waterhousii, Macrotus californicus, Noctilio leporinus, and Noctilio albiventris each have a slightly upturned rostrum, but lack concave nasals. Accordingly, we follow Simmons and Conway (2001) in treating shape of the nasals and rostral upturning as separate characters in our analysis. This character, which corresponds to character 6 of Simmons and Conway (2001), could not be scored in Koopmanycteris or Speonycteris.

CHARACTER 62: Nasal foramina small or absent (0); or pair of large foramina present in posterior nasal region below forehead (1). The nasal bones of most bats are imperforate or include only a few small foramina (Simmons and Conway, 2001). This condition is seen in Pteronotus, Mormoops, and most of the outgroups (Artibeus jamaicensis, Macrotus waterhousii, Macrotus californicus, Mystacina tuberculata, Mystacina robusta, Thyroptera tricolor, Furipterus horrens, Saccopteryx bilineata). In contrast, both species of Noctilio are characterized by presence of a pair of large foramina in the posterior portion of the nasals just below the forehead. This character, which corresponds to character 7 of Simmons and Conway (2001), could not be scored in Koopmanycteris or Speonycteris.

CHARACTER 63: Maximum rostral breadth less than or equal to length of maxillary toothrow (0); or greater than length of maxillary toothrow (1). The shape of the rostrum in dorsal view can be described by comparing maximum breadth of the rostrum (which usually occurs at the level of the last premolar or first molar) with the length of the maxillary toothrow (Simmons and Conway, 2001). Pteronotus macleayii, $P$. quadridens, mem- bers of the $P$. parnellii and $P$. personatus complexes, $P$. pristinus, and both species of Mormoops have a rostral breadth that is less than or equal to the length of the maxillary toothrow. In contrast, Pteronotus gymnonotus and members of the $P$. davyi complex have a rostral breadth that is greater than the length of the maxillary toothrow. Similar variation is seen among the outgroups. Saccopteryx bilineata, both species of Mystacina, Thyroptera tricolor, Furipterus horrens, and both species of Macrotus have a rostral breadth that is less than or equal to the length of the maxillary toothrow, while Artibeus jamaicensis and both species of Noctilio have a rostral breadth that is greater than the length of the maxillary toothrow. This character, which corresponds to character 8 of Simmons and Conway (2001), could not be scored in Koopmanycteris or Speonycteris.

CHARACTER 64: Rostrum length less than 42\% of total length of skull (0); or 44\%-55\% of length of skull (1). The relative length of the rostrum in bats varies independently of rostral breadth. Following Simmons and Conway (2001), we defined rostral length as the distance between the anteriormost point on the skull (excluding teeth) and the interorbital constriction (the point of minimum skull breadth in the orbital region). Skull length was defined as the greatest length of the skull excluding teeth. Pteronotus pristinus, members of the $P$. parnellii, $P$. personatus, and $P$. davyi complexes, $P$. gymnonotus, and both species of Mormoops are characterized by having a rostral length that is less than $42 \%$ the length of the skull. In contrast, the rostrum is noticeably longer in Pteronotus quadridens and P. macleayii, where rostral length (as defined above) is $44 \%-$ $55 \%$ the total length of the skull. All of the outgroups have a rostrum length that is less than $42 \%$ the length of the skull. This character could not be scored in Koopmanycteris or Speonycteris. This character represents a modified version of character 9 of Simmons and Conway (2001), who used $50 \%$ of total skull length as a cutoff value between the two states.

Character 65: Rostrum not upturned, angle between long axis of anterior half of zygomatic 
arch and occlusal surface of molar toothrow less than $10^{\circ}$, ventral margin of dentary between canine and $m 1$ straight, margin between $m 1$ and $m 3$ straight to slightly curved ventrally $(0)$; or rostrum slightly upturned, angle $10^{\circ}-26^{\circ}$, ventral margin of dentary between canine and $m 1$ straight, margin between $m 1$ and $m 3$ straight to slightly curved ventrally (1); or rostrum slightly upturned, at an angle of $10^{\circ}-26^{\circ}$, ventral margin of dentary between canine and $m 1$ straight, margin between $m 1$ and $m 3$ dentary more strongly curved ventrally, reaching maximum curvature below $m 2$ (2); or rostrum strongly upturned, at an angle of $28^{\circ}-34^{\circ}$, ventral margin of dentary between canine and $m 1$ curved dorsally, margin between $m 1$ and $m 3$ dentary highly curved ventrally reaching maximum curvature below $m 3$ (3). The long axis of the rostrum lies roughly parallel to the long axis of the zygomatic arch in many bats, resulting in a skull morphology that lacks any obvious "upturning" of the rostrum relative to the braincase (Simmons and Conway, 2001). These forms similarly lack any bowing or curvature of the body of the dentary. At the other end of the spectrum is Mormoops, which is characterized by extreme dorsiflexion of both the rostral portion of the skull and the dentary. Measuring the degree of upturning of the rostrum is complicated by numerous factors, including modifications of the zygomatic arch (e.g., dorsoventral curvature) and modifications of the rostrum (e.g., foreshortening and dorsal curvature), and, in fossils like Koopmanycteris, by the absence of cranial specimens altogether. However, comparisons of skull and dentary morphology in mormoopids and the outgroups allows recognition of a series of character states that describes a progression in relative cranial flexion of both the skull and the dentary. This character corresponds in part to character 5 of Simmons and Conway (2001), but has been expanded here to include dentary features.

In most bats, the anterior half of the zygomatic arch usually appears straight in lateral view, and the occlusal surface of the first and second molar teeth (M1 and M2) describe a plane with which zygomatic arch orientation may be compared. Saccopteryx bilineata, both species of Mystacina, and Artibeus jamaicensis are characterized by a condition in which the rostrum is not upturned and the occlusal plane of molar teeth lies at an angle of less than $10^{\circ}$ to the long axis of the anterior half of the zygomatic arch. The ventral margin of dentary between the canine and $\mathrm{ml}$ is straight, and the margin between $\mathrm{m} 1$ and $\mathrm{m} 3$ straight to slightly curved ventrally. This "no upturn" condition (state 0) probably represents the ancestral condition of the rostral area in bats.

In contrast, the occlusal plane of molar teeth lies at an angle of $10^{\circ}-26^{\circ}$ to the long axis of the anterior half of the zygomatic arch in all species of Pteronotus, giving these bats the appearance of having a slightly upturned rostrum (Simmons and Conway, 2001). In members of the Pteronotus personatus and $P$. parnellii complexes, and $P$. pristinus, the ventral margin of the dentary between the canine and $\mathrm{ml}$ is straight, and the margin between $\mathrm{m} 1$ and $\mathrm{m} 3$ straight to slightly curved ventrally. However, the remaining species of Pteronotus are characterized by a more strongly curved dentary. In these forms, the ventral margin of the dentary between the canine and $\mathrm{ml}$ is straight, but the margin between $\mathrm{ml}$ and $\mathrm{m} 3$ is more strongly curved ventrally, reaching maximum curvature below $\mathrm{m} 2$. The former condition of both skull and dentary (i.e., slight upturn, state 1 , seen in the Pteronotus parnellii complex) is also seen among the outgroups in Thyroptera tricolor, both species of Noctilio, and both species of Macrotus. The moderately upturned condition (i.e., state 2, as seen in Pteronotus gymnonotus) occurs among the outgroups only in Furipterus horrens.

Finally, a more extreme condition is seen in Mormoops, in which both species have a strongly upturned rostrum, characterized by an angle of $28^{\circ}-34^{\circ}$ between the zygomatic arch and molar occlusal plane. In both species the ventral margin of the dentary between canine and $\mathrm{m} 1$ is curved dorsally (so that it appears concave downward under the premolar region) 
while the margin between $\mathrm{m} 1$ and $\mathrm{m} 3$ is highly curved ventrally, reaching maximum curvature below $\mathrm{m} 3$. This condition (state 3 ) is not seen in any of the outgroups.

As noted previously, Koopmanycteris is not presently known from cranial material. However, morphology of the dentary allows unambiguous assessment of its degree of rostral flexion. Like Pteronotus gymnonotus, members of the $P$. davyi complex, P. macleayii, P. quadridens, and Furipterus horrens, the ventral margin of the dentary in Koopmanycteris is straight between the canine and $\mathrm{ml}$, but the margin between $\mathrm{ml}$ and $\mathrm{m} 3$ is more strongly curved ventrally, reaching maximum curvature below $\mathrm{m} 2$. On this basis, we scored Koopmanycteris as having state 2 of this character. Speonycteris also lacks cranial material, but the form of the dentary is quite different in that taxon. Speonycteris has a dentary with a ventral margin that is nearly perfectly straight below the entire toothrow, so we scored it with state 0 of this character.

As noted previously, this character represents an expanded version of character 5 of Simmons and Conway (2001). We followed those authors in treating this as an ordered character.

Character 66: Depth of body of dentary moderate, approximately equal to height of crowns of cheekteeth (0); or dentary depth noticeably greater than height of cheekteeth (1). Relative dentary depth in bats can be estimated by comparing the depth of the dentary to the height of the crowns of the cheekteeth imbedded in it. The depth of the dentary is moderate-approximately equal to the height of the cheekteeth-in both species of Mormoops. In contrast, the dentary is deep in all Pteronotus and Koopmanycteris. Among the outgroups, a moderately deep dentary is seen in Saccopteryx bilineata, Thyroptera tricolor, Furipterus horrens, and both species of Macrotus. A deep dentary occurs in both species of Mystacina, both species of Noctilio, Artibeus jamaicensis, and Speonycteris. This character, which was not employed by Simmons and Conway (2001), corresponds to character 43 of Czaplewski and Morgan (2012).
CHARACTER 67: Coronoid process of dentary two times the height of the condyloid process, angle between leading edge of coronoid process and alveolar margin of toothrow greater than $90^{\circ}(0)$; or coronoid process 1.5 times the height of the condyloid process, angle between leading edge of coronoid process and alveolar line greater than $90^{\circ}(1)$; or coronoid extends dorsally to the level of condyloid process, angle between leading edge of coronoid process and alveolar line greater than $90^{\circ}$ (2); or coronoid process does not extend dorsally as far as the condyloid process, angle between leading edge of coronoid process and alveolar line $80^{\circ}-90^{\circ}$ (3). The coronoid process of the dentary varies in both its height (in relationship to the condyloid process) and in the angle formed by the leading (anterior) edge of the coronoid process relative to the alveolar margin of the toothrow. These features are partially correlated with rostral flexion, but we have structured the character states to avoid duplicating conditions already scored in character 65 above.

The coronoid process of the lower jaw does not extend as far dorsally as the level of the condyloid process (articular condyle) in Koopmanycteris or in any species of Pteronotus or Mormoops. In all these taxa, the leading edge of the coronoid process forms an angle of $80^{\circ}-90^{\circ}$ with the alveolar margin of the toothrow. In Koopmanycteris and Pteronotus, the leading edge forms an essentially right angle $\left(90^{\circ}\right)$ with respect to the alveolar line. Apparently due to the extreme rostral flexion in Mormoops, this angle is smaller and therefore acute $\left(\sim 80^{\circ}\right)$ in both species of Mormoops. To avoid counting rostral flexion more than once in our analysis, however, we have not scored this as a separate state here, and treat with a single state all taxa with either an acute or right angle between the leading edge of the coronoid and the alveolar line. This condition is seen in all mormoopids and in Thyroptera tricolor and Furipterus horrens among the outgroups. Both of the latter taxa have an angle of approximately $90^{\circ}$ between the leading edge of the coronoid process and the alveolar line.

In contrast, all other extant taxa in our study (including forms with some rostral flexion, e.g., 
Noctilio) have an angle between the leading edge of the coronoid process and the alveolar margin of the toothrow that is greater than $90^{\circ}$ and thus noticeably obtuse. In these forms the coronoid process extends at least as far dorsally as the condyloid process. However, relative height of these processes (as measured from the lower border of the body of the mandible) varies considerably. Saccopteryx bilineata and both species of Noctilio have coronoid and condyloid processes are subequal in height. The coronoid process is 1.5 times the height of the condyloid process in both species of Mystacina and Artibeus jamaicensis, while it is two times the height of the condyloid process in both species of Macrotus.

Although the posterior dentary is missing in all known specimens of Speonycteris, the base of the coronoid process is preserved in the holotype of S. aurantiadens (Czaplewski and Morgan, 2012). It appears from this specimen that the angle between the alveolar margin of the toothrow and the coronoid process was greater than $90^{\circ}$ in this taxon. However, we cannot assess the relative height of the coronoid process due to breakage. Accordingly, we score Speonycteris aurantiadens with " $0 / 1 / 2$ " for this character to accommodate uncertainty about coronoid height.

This character represents a modified version of character 27 of Simmons and Conway (2001), which considered only height of the coronoid process and recognized only three states. We have expanded this character to take into account additional variation, but we followed Simmons and Conway (2001) in treating this as an ordered character. Pteronotus pristinus, for which the posterior dentary is not known, could not be scored for this character.

Character 68: Angular process of dentary projects at or below the level of the occlusal plane of the molar toothrow (0); or projects above the level of the occlusal plane but below the level of the coronoid process (1); or projects well above the level of the occlusal plane, roughly at the same level as the coronoid process (2). The angular process of the dentary extends from the posteroventral "corner" of the lower jaw in bats (Simmons and Geisler, 1998). This process projects above the level of the occlusal plane of the molar toothrow, but below the level of the coronoid process, in Koopmanycteris and all species of Pteronotus and Mormoops. A similar condition is seen in Saccopteryx bilineata and both species of Noctilio. Dorsal curvature of the posteroventral edge of the dentary is even greater in Thyroptera tricolor and Furipterus horrens, so that the angular process projects at the same level (with respect to the occlusal plane of the molar toothrow) as the coronoid process. In contrast, the angular process lies either at or entirely below the level of the occlusal plane in both species of Mystacina, Artibeus jamaicensis, and both species of Macrotus. This also seems to be the case in Speonycteris-although the angular process is missing, part of its base is preserved in the holotype of $S$. aurantiadens and it seems clear that it must have projected below the level of the occlusal plane. Data were not available for Pteronotus pristinus for this character. This character represents a modified version of character 26 of Simmons and Conway (2001), expanded here to accommodate an additional state for Furipterus horrens and Thyroptera tricolor. Transformations in this character were ordered to reflect our hypothesis that changes in relative level of projection of the angular process occur in a progressive fashion.

Although, conceivably, the relative position of the angular process and curvature of the posteroventral edge of the dentary might be linked to the rostral flexion (character 55) and morphology of the coronoid process (character 56), the distribution of states suggests that, at least in our sample, these features vary independently. For example, Saccopteryx bilineata, which lacks rostral flexion entirely, exhibits a similar condition for the current character as does Mormoops, which is characterized by the most extreme rostral flexion seen in our study. Thyroptera tricolor and Furipterus horrens, which have a more dorsally placed angular process than other bats, have a coronoid process whose form and angle is similar to that of all mormoopids. Accordingly, 
we have chosen to treat these features as separate characters in our analysis.

Character 69: Mandibular symphysis with posteroventral projection absent to weak (0); or relatively strong, pronglike (1). Some bats have a pronglike posteroventral projection from the mandibular symphysis that serves as a robust attachment site for $\mathrm{m}$. geniohyoideus (Simmons and Geisler, 1998: char. 51). Such a projection is strongly developed in Koopmanycteris and all species of Pteronotus. In contrast, Mormoops lacks a projection on the posteroventral surface of the mandibular symphysis. Among the outgroups a posteroventral projection from the symphysis is absent in Saccopteryx bilineata, both species of Mystacina, Thyroptera tricolor, both species of Noctilio, both species of Macrotus, and Artibeus jamaicensis. In contrast, a well-developed pronglike projection from the posteroventral symphysis is present in Furipterus horrens and Speonycteris. This is a new character was not included in Simmons and Conway (2001).

\section{Vomeronasal Complex and Brain}

Character 70: Vomeronasal epithelial tube absent (0); or rudimentary, lacking a neuroepithelial medial lining (1); or well-developed, neuroepithelial medial lining present (2). Wible and Bhatnagar (1996) described morphology of nine of the taxa in our study. They found that the vomeronasal epithelial tube is well developed, with a neuroepithelial medial lining, in the Pteronotus parnellii complex. The vomeronasal tube is rudimentary (lacking a neuroepithelial lining) in Mormoops megalophylla, and the tube is entirely absent in the Pteronotus personatus group. Among the outgroups, Furipterus horrens, Noctilio leporinus, and Mystacina tuberculata lack a vomeronasal epithelial tube, while this structure is rudimentary in Thyroptera tricolor. In contrast, the vomeronasal epithelial tube is well developed in Macrotus californicus and Artibeus jamaicensis (Wible and Bhatnagar, 1996). Data were not available for Koopmanycteris, Pteronotus macleayii, $P$. quadridens, members of the $P$. davyi complex, P. gymnonotus, $P$. pristinus, Mormoops blainvillei, Saccopteryx bilineata, Noctilio albiventris, Mystacina robusta, Macrotus waterhousii, or Speonycteris. This character corresponds to character 7 of Simmons and Geisler (1998), character 39 of Wetterer et al. (2000), and character 48 of Simmons and Conway (2001), and we followed the last-named authors in treating this as an ordered character

Character 71: Vomeronasal cartilage curved in cross section (J-, C-, U-, or O-shaped) (0); or bar shaped in cross section (1); or cartilage absent (2). The vomeronasal cartilage lies ventrolateral to the anterior nasal septum and supports the vomeronasal epithelial tube (Wible and Bhatnagar, 1996). Mormoops megalophylla has a vomeronasal cartilage that is curved in cross section. In contrast, members of the Pteronotus parnellii and $P$. personatus complexes have bar-shaped vomeronasal cartilage. Noctilio leporinus and Furipterus horrens also have a bar-shaped cartilage, while Thyroptera tricolor, Macrotus californicus, and Artibeus jamaicensis have a curved vomeronasal cartilage. Mystacina tuberculata lacks the vomeronasal cartilage entirely (Wible and Bhatnagar, 1996). Data were not available for Koopmanycteris, Pteronotus macleayii, $P$. quadridens, members of the $P$. davyi complex, $P$. gymnonotus, $P$. pristinus, Mormoops blainvillei, Saccopteryx bilineata, Noctilio albiventris, Mystacina robusta, Macrotus waterhousii, or Speonycteris. This character corresponds to character 6 of Simmons and Geisler (1998), character 40 of Wetterer et al. (2000), and character 49 of Simmons and Conway (2001), and we followed the last-named authors in treating this as an unordered character.

Character 72: Nasopalatine duct absent (0); or present (1). The nasopalatine duct connects the nasal cavity to the oral cavity through the incisive foramen (Wible and Bhatnagar, 1996). This duct is absent in the Pteronotus parnellii complex, but is present in the $P$. personatus complex and Mormoops megalophylla. Among the outgroups, the nasopalatine duct is present in Artibeus jamaicensis but is absent in Macrotus 
californicus, Noctilio leporinus, Furipterus horrens, Thyroptera tricolor, and Mystacina tuberculata. Data were not available for Koopmanycteris, Pteronotus macleayii, P. quadridens, members of the $P$. davyi complex, P. gymnonotus, P. pristinus, Mormoops blainvillei, Saccopteryx bilineata, Noctilio albiventris, Mystacina robusta, Macrotus waterhousii, or Speonycteris. This character corresponds to character 5 of Simmons and Geisler (1998), character 41 of Wetterer et al. (2000), and character 50 of Simmons and Conway (2001).

Character 73: Accessory olfactory bulb absent (0); or present (1). The accessory olfactory bulb (AOB) is an anatomically distinct portion of the forebrain that receives sensory information from the vomeronasal nerve (Wible and Bhatnagar, 1996). Although presence of an AOB is correlated with degree of development of the vomeronasal epithelial tube (char. 60), we follow Wible and Bhatnagar (1996) and Simmons and Conway (2001) in treating these as separate characters pending further research on the connections of these structures. An AOB is present in the Pteronotus parnellii complex but is absent in the $P$. personatus complex and Mormoops megalophylla (Wible and Bhatnagar, 1996). Among the outgroups, an $\mathrm{AOB}$ is present in Artibeus jamaicensis but is absent in Noctilio leporinus, Thyroptera tricolor, and Furipterus horrens. Data were not available for Koopmanycteris, Pteronotus macleayii, $P$. quadridens, members of the $P$. davyi complex, P. gymnonotus, P. pristinus, Mormoops blainvillei, Saccopteryx bilineata, Noctilio albiventris, Mystacina robusta, both species of Macrotus, both species of Mystacina, or Speonycteris. This character corresponds to character 135 of Wetterer et al. (2000) and character 51 of Simmons and Conway (2001).

CHARACTER 74: Inferior colliculi fully exposed on dorsal surface of brain, not covered by cerebellar vermis or cerebral hemispheres (0); or inferior colliculi partially exposed, medial longitudinal fissure and medial portions of colliculi covered by rostral extension of cerebellar vermis (1); or inferior colliculi not exposed, completely covered by cerebellar vermis and cerebral hemispheres (2). As noted by Wetterer et al. (2000) and Simmons and Conway (2001), there is significant variation among noctilionoids in the degree of exposure of the inferior colliculi on the dorsal surface of the brain. The inferior colliculi are partially exposed on the dorsal surface of the brain in the Pteronotus parnellii complex, P. gymnonotus, and Mormoops megalophylla (Schneider, 1957, 1972; Henson, 1970b; Stephan, 1977). In these forms, a rostral extension of the cerebellar vermis covers the medial portion of each colliculus and the longitudinal fissure between them, but the lateral portion of each inferior colliculus is clearly visible along the edges of the cerebellar vermis. Among the outgroups, a similar condition is seen in Noctilio leporinus (Baron et al., 1996). In contrast, the inferior colliculi are entirely visible (no portion is covered by the cerebellum) in Macrotus californicus (McDaniel, 1976). A third condition is seen in Artibeus jamaicensis, in which the inferior colliculi are completely covered by the cerebellar vermis and cerebral hemispheres (McDaniel, 1976; Bhatnagar and Kallen, 1974). No portion of the inferior colliculi are visible on the brain surface in dorsal view. Data were not available for Koopmanycteris, Pteronotus macleayii, $P$. quadridens, members of the $P$. personatus and $P$. davyi complexes, $P$. pristinus, Mormoops blainvillei, Saccopteryx bilineata, Thyroptera tricolor, Furipterus horrens, Noctilio albiventris, Mystacina robusta, Macrotus waterhousii, or Speonycteris. This character corresponds to character 136 of Wetterer et al. (2000) and character 52 of Simmons and Conway (2001), and we followed the latter authors in treating it as an ordered character.

\section{Trachea and Hyoid Apparatus}

As noted by Simmons and Conway (2001), bones, cartilages, and muscles of the hyoid apparatus of bats have been discussed extensively by Sprague (1943), Griffiths (1982, 1983, 1994), Griffiths and Smith (1991) and Griffiths et al. (1992). Griffiths' terminology is identical to that used by Sprague (1943) with two exceptions: (1) 
the element termed the hypohyal by Sprague (1943) is identified as the ceratohyal by Griffiths (1982, 1983, 1994), and (2) the element termed the ceratohyal by Sprague (1943) is identified as the epihyal by Griffiths $(1982,1983,1994)$. We follow Simmons and Geisler (1998) and Simmons and Conway (2001) in employing Griffith's (1982, 1983, 1994) terminology.

CHARACTER 75: Tracheal rings subequal in diameter throughout length of trachea (0); or first 5-8 rings enlarged to form tracheal expansion posterior to larynx (1). In most mammals, including most bats, the cartilaginous rings that support the trachea are of roughly uniform diameter throughout the length of the postlaryngeal trachea. However, some bats have "tracheal expansions" posterior to the larynx (Griffiths, 1983, 1994; Griffiths and Smith, 1991; Griffiths et al., 1992; Simmons, 1998; Simmons and Geisler, 1998; Simmons and Conway, 2001). These expansions consist of balloonlike spaces supported by tracheal rings that have a diameter greater than that of the "normal" tracheal rings composing the remainder of the trachea (Griffiths, 1983, 1994; Griffiths and Smith, 1991; Griffiths et al., 1992). All extant species of Pteronotus and Mormoops have a tracheal expansion that involves the first 5-8 tracheal rings. No tracheal expansion is seen in any of the outgroups. Data were not available for Mystacina tuberculata, Koopmanycteris, Speonycteris, or Pteronotus pristinus for this character, which corresponds to character 40 of Simmons and Geisler (1998) and character 53 of Simmons and Conway (2001).

Character 76: Basihyal without entoglossal process (0); or with small entoglossal process (1); or with very large entoglossal process, resulting in a T-shaped basihyal (2). The basihyal of many bats includes a medial entoglossal process that provides an attachment site for several hyoid muscles (Griffiths 1982, 1983, 1994; Griffiths and Smith, 1991; Griffiths et al. 1992; Simmons and Geisler, 1998). A small entoglossal process is present in Pteronotus personatus and P. parnellii (Griffiths, 1982, 1983). Similarly, a small entoglossal process is present on the basihyal in Noc- tilio leporinus, Mystacina robusta, Macrotus waterhousii, and Artibeus jamaicensis (Sprague, 1943; Griffiths, 1982, personal commun.). A very large entoglossal process is present in Thyroptera tricolor and Furipterus horrens, resulting in a basihyal that is T-shaped (Griffiths, personal commun.; Simmons and Geisler, 1998: char. 71). In contrast, the basihyal element lacks an entoglossal process in Saccopteryx bilineata (Griffiths and Smith, 1991). Data were not available for Koopmanycteris, Pteronotus macleayii, $P$. quadridens, $P$. gymnonotus, members of the $P$. davyi complex, $P$. pristinus, Mormoops megalophylla, M. blainvillei, Noctilio albiventris, Mystacina tuberculata, Macrotus californicus, or Speonycteris. This represents a modified version of character 54 of Simmons and Conway (2001) and mirrors character 71 of Simmons and Geisler (1998). We treated this as an ordered character.

ChARACTER 77: Ceratohyal unreduced, approximately equal in length to epihyal (0); or ceratohyal reduced to half the length of epihyal (1); or ceratohyal reduced to tiny cartilaginous element (2). The ceratohyal and epihyal (sensu Griffiths) are rodlike elements that are approximately the same length in the Pteronotus personatus complex (Griffiths, 1982, 1983). A similar "unreduced" condition is seen in Thyroptera tricolor and Furipterus horrens (Griffiths, personal commun.; Simmons and Geisler, 1998). In contrast, the ceratohyal is reduced in length to a short, stubby element that is roughly half the length of epihyal in the Pteronotus parnellii complex (Griffiths, 1983). Among the outgroups, Saccopteryx bilineata, Mystacina robusta, and Macrotus waterhousii also have a ceratohyal that is roughly half the length of the epihyal (Griffiths, 1982, personal commun.). The ceratohyal is reduced to a tiny cartilaginous element in Noctilio leporinus (Sprague, 1943). Data were not available for Koopmanycteris, Pteronotus macleayii, $P$. quadridens, P. gymnonotus, members of the $P$. davyi complex, $P$. pristinus, Mormoops megalophylla, M. blainvillei, Noctilio albiventris, Mystacina tuberculata, Macrotus californicus, Artibeus jamaicensis, or Speonycteris. This character corresponds to character 72 of Simmons and 
Geisler (1998) and character 55 of Simmons and Conway (2001), and we followed the latter authors in treating this as an ordered character.

Character 78: M. mylohyoideus undivided sheet of muscle with no aponeurosis (0); or undivided but with anterior aponeurosis (1); or with a pronounced break, clearly divided into distinct anterior and posterior muscular parts by a fleshy aponeurosis (2). M. mylohyoideus in bats originates from the medial surface of the mandible and inserts into the elements of the hyoid and/or other muscles of the hyoid region (Griffiths, 1982, 1983, 1994; Griffiths and Smith, 1991; Griffiths et al., 1992). M. mylohyoideus consists of an undivided sheet of muscle with an aponeurotic anterior portion in the Pteronotus parnellii complex (Sprague, 1943). Among the outgroups, Thyroptera tricolor and Furipterus horrens exhibit a similar condition (Griffiths, personal commun.; Simmons and Geisler, 1998). Saccopteryx bilineata, Noctilio leporinus, and Mystacina robusta have an undivided $\mathrm{m}$. mylohyoideus that lacks an anterior aponeurosis (Sprague, 1943; Griffiths, personal commun.; Griffiths and Smith, 1991). In contrast, m. mylohyoideus exhibits a pronounced break and is clearly divided into distinct anterior and posterior parts by a fleshy aponeurosis in Macrotus waterhousii and Artibeus jamaicensis (Griffiths, 1982). Data were not available for Koopmanycteris, Pteronotus macleayii, $P$. quadridens, members of the $P$. personatus complex, $P$. gymnonotus, members of the $P$. davyi complex, $P$. pristinus, Mormoops megalophylla, M. blainvillei, Noctilio albiventris, Mystacina tuberculata, Macrotus californicus, or Speonycteris for this character, which corresponds to character 90 of Wetterer et al. (2000) and character 56 of Simmons and Conway (2001). We treated this as an unordered character.

Character 79: M. mylohyoideus inserts on basihyal, basihyal raphe, and thyrohyal (0); or on basihyal and basihyal raphe only (1). M. mylohyoideus runs ventral to the midline strap muscles and inserts on the basihyal and basihyal raphe in the Pteronotus parnellii complex, Artibeus jamaicensis, Macrotus waterhousii, Mystacina robusta,
Thyroptera tricolor, Furipterus horrens, and Noctilio leporinus (Sprague, 1943; Griffiths, 1982, personal commun.; Simmons and Geisler, 1998). In contrast, m. mylohyoideus in Saccopteryx bilineata inserts on the basihyal raphe and basihyal, but also onto the thyrohyal (Griffiths and Smith, 1991). Data were not available for Koopmanycteris, Pteronotus macleayii, $P$. quadridens, members of the $P$. personatus complex, $P$. gymnonotus, members of the $P$. davyi complex, $P$. pristinus, Mormoops megalophylla, M. blainvillei, Noctilio albiventris, Mystacina tuberculata, Macrotus californicus, Speonycteris for this character, which corresponds to character 44 of Simmons and Geisler (1998) and character 57 of Simmons and Conway (2001).

Character 80: M. mandibulo-hyoideus absent (0); or present (1). M. mandibulo-hyoideus, which represents the medial portion of the anterior digastric muscle, is absent (or not differentiated) in the Pteronotus parnellii complex, Artibeus jamaicensis, Macrotus waterhousii, Noctilio leporinus, Thyroptera tricolor, and Saccopteryx bilineata (Sprague, 1943; Griffiths, 1982, Griffiths and Smith, 1991; Griffiths, personal commun.; Simmons and Geisler, 1998). In contrast, a small $\mathrm{m}$. mandibulo-hyoideus with a tendon is present in Mystacina robusta and Furipterus horrens (Griffiths, personal commun.; Simmons and Geisler, 1998). Data were not available for Koopmanycteris, Pteronotus macleayii, $P$. quadridens, members of the $P$. personatus complex, $P$. gymnonotus, members of the $P$. davyi complex, $P$. pristinus, Mormoops megalophylla, M. blainvillei, Noctilio albiventris, Mystacina tuberculata, Macrotus californicus, or Speonycteris for this character, which corresponds to character 46 of Simmons and Geisler (1998) and character 58 of Simmons and Conway (2001).

Character 81: M. stylohyoideus present, passes superficial to digastric muscles (0); or superficial slip absent (1). M. stylohyoideus in bats originates from the medial stylohyal and inserts into the anterior cornu of the hyoid (Sprague, 1943; Griffiths, 1982, 1983, 1994; 
Griffiths and Smith, 1991; Griffiths et al., 1992). Slips may pass either superficial to the digastric muscles or deep to the digastric. M. stylohyoideus is absent (or is reduced to a few fibers fused with $\mathrm{m}$. stylopharyngeus, deep to the digastric muscles) in the Pteronotus parnellii complex, Artibeus jamaicensis, Macrotus waterhousii, Mystacina robusta, Thyroptera tricolor, Furipterus horrens, and Noctilio leporinus (Sprague, 1943; Griffiths, 1982, 1983, personal commun.; Simmons and Geisler, 1998). In contrast, $\mathrm{m}$. stylohyoideus is present as a distinct muscle that runs superficial to the digastric muscles in Saccopteryx bilineata (Griffiths and Smith, 1991). Data were not available for Koopmanycteris, Pteronotus macleayii, P. quadridens, members of the $P$. personatus complex, P. gymnonotus, members of the $P$. davyi complex, $P$. pristinus, Mormoops megalophylla, M. blainvillei, Noctilio albiventris, Mystacina tuberculata, Macrotus californicus, or Speonycteris for this character, which corresponds to character 49 of Simmons and Geisler (1998), character 102 of Wetterer et al. (2000), and character 59 of Simmons and Conway (2001).

CHARACTER 82: M. geniohyoideus originates by fleshy fibers directly from the bone of the mandible (0); or originates by a short tendon from the mandible (1); or originates by a long tendon from the mandible (2). M. geniohyoideus originates from the inner surface of the anterior mandible and inserts into the tongue (Griffiths, 1982, 1983, 1994; Griffiths and Smith, 1991; Griffiths et al., 1992). In the Pteronotus parnellii complex, $\mathrm{m}$. geniohyoideus originates by means of a long tendon from the mandible (Griffiths, personal commun.; Simmons and Conway, 2001). A similar condition is seen in Saccopteryx bilineata (Griffiths and Smith, 1991). In Furipterus horrens, the origin of $\mathrm{m}$. geniohyoideus is by tendon, but length of the tendon-in comparison to length of the fleshy part of the muscle-is much shorter (Griffiths, personal commun.; Simmons and Geisler, 1998). In contrast, m. geniohyoideus originates by fleshy fibers directly from the bone of the mandible in
Artibeus jamaicensis, Macrotus waterhousii, Mystacina robusta, Thyroptera tricolor, and Noctilio leporinus (Sprague, 1943; Griffiths, 1982, personal commun.; Simmons and Geisler, 1998). Data were not available for Koopmanycteris, Pteronotus macleayii, P. quadridens, members of the $P$. personatus complex, $P$. gymnonotus, members of the $P$. davyi complex, $P$. pristinus, Mormoops megalophylla, M. blainvillei, Noctilio albiventris, Mystacina tuberculata, Macrotus californicus, or Speonycteris. This character is a revised version of character 60 of Simmons and Conway (2001) and mirrors character 52 of Simmons and Geisler (1998). Transformations in this character were ordered to reflect the hypothesis that a short tendon represents an intermediate condition between direct connection of fleshy fibers to the bone and a long tendinous connection.

Character 83: Paired m. geniohyoideus muscles partially or completely fused across midline (0); or muscles not fused (1). M. geniohyoideus is partially or completely fused with its counterpart across the midline in the Pteronotus parnellii complex (Sprague, 1943). Among the outgroups, a similar condition is seen in Artibeus jamaicensis, Thyroptera tricolor, and Furipterus horrens (Sprague, 1943). In contrast, the right and left m. geniohyoideus are not fused in Noctilio leporinus (Sprague, 1943). Data were not available for Koopmanycteris, Pteronotus macleayi, $P$. quadridens, members of the $P$. personatus complex, P. gymnonotus, members of the P. davyi complex, P. pristinus, Mormoops megalophylla, M. blainvillei, Saccopteryx bilineata Noctilio albiventris, Mystacina tuberculata, M. robusta, Macrotus waterhousii, $M$. californicus, and Speonycteris for this character, which corresponds to character 99 of Wetterer et al. (2000) and character 61 of Simmons and Conway (2001).

Character 84: $M$. sternohyoideus origin includes entire anterodorsal surface of manubrium and medial tip of clavicle (0); or origin includes entire anterodorsal surface of manubrium but does not include clavicle (1); or origin restricted to medialmost surface manubrium in vicinity of 
anterior process (2). M. sternohyoideus in bats extends between the sternum and the hyoid region (Sprague, 1943; Griffiths, 1978; 1982, 1983, 1994; Griffiths and Smith, 1991; Griffiths et al., 1992). The origin of this muscle includes the entire anterodorsal surface of the manubrium and the medial tip of the clavicle in the Pteronotus parnellii complex (Sprague, 1943). A similar condition is seen in Macrotus waterhousii, Artibeus jamaicensis, Noctilio leporinus, and Saccopteryx bilineata (Sprague, 1943; Griffiths, 1982; Griffiths and Smith, 1991). In contrast, the origin of $\mathrm{m}$. sternohyoideus is restricted to the anterodorsal surface of the manubrium and the clavicular origin is lacking in the Pteronotus davyi complex, $M$. megalophylla, and Thyroptera tricolor (Griffiths, 1978; Griffiths, personal commun.; Simmons and Geisler, 1998). Mystacina robusta and Furipterus horrens exhibit a different condition in which the origin of this muscle is restricted to the medialmost surface of the manubrium in the vicinity of the anterior process (Griffiths, personal commun.; Simmons and Geisler, 1998). Data were not available for Koopmanycteris, Pteronotus macleayii, $P$. quadridens, members of the $P$. personatus complex, $P$. gymnonotus, $P$. pristinus, Mormoops blainvillei, Noctilio albiventris, Mystacina tuberculata, Macrotus californicus, or Speonycteris. This multistate character corresponds to characters 63 and 64 of Simmons and Geisler (1998), characters 91 and 92 of Wetterer et al. (2000), and to character 62 of Simmons and Conway (2001). We followed the last-named authors in treating this as an ordered character.

Character 85: Midline hyoid strap musculature with $m$. geniohyoideus and $m$. hyoglossus directly attached to basihyal via fleshy fibers (0); or muscles attached indirectly to basihyal via basihyal tendon (1). The midline hyoid strap musculature of bats includes $\mathrm{m}$. geniohyoideus and $\mathrm{m}$. hyoglossus (Sprague, 1943; Griffiths, 1982, 1983, 1994; Griffiths and Smith, 1991; Griffiths et al., 1992). In many bats, these muscles are attached indirectly to the basihyal via the basihyal tendon, resulting in a condition that has been described as a "free-floating" strap muscle (Griffiths, 1982, 1983, 1994; Griffiths and Smith, 1991; Griffiths et al., 1992). This condition is seen in the Pteronotus parnellii complex, Artibeus jamaicensis, Macrotus waterhousii, Mystacina robusta, Thyroptera tricolor, Furipterus horrens, and Noctilio leporinus (Sprague, 1943; Griffiths, 1978, 1982, personal commun.; Simmons and Geisler, 1998). In contrast, $\mathrm{m}$. geniohyoideus and $\mathrm{m}$. hyoglossus attach directly to the basihyal via fleshy fibers in Saccopteryx bilineata (Griffiths and Smith, 1991). Data were not available for Koopmanycteris, Pteronotus macleayii, $P$. quadridens, members of the $P$. personatus complex, $P$. gymnonotus, members of the $P$. davyi complex, $P$. pristinus, Mormoops megalophylla, M. blainvillei, Noctilio albiventris, Mystacina tuberculata, Macrotus californicus, or Speonycteris for this character, which corresponds to character 41 of Simmons and Geisler (1998), characters 96 and 97 of Wetterer et al. (2000), and character 63 of Simmons and Conway (2001).

Character 86: M. styloglossus with one belly (0); or with two bellies separated by lateral portion of $m$. hyoglossus (1). M. styloglossus in bats originates from the stylohyoid process and/or the adjacent surface of the skull and inserts into the tongue (Sprague, 1943; Griffiths, 1982, 1983, 1994; Griffiths and Smith, 1991; Griffiths et al., 1992). In the Pteronotus parnellii complex this muscle has two bellies that are separated by the lateral portion of m. hyoglossus (Griffiths, 1983). Among the outgroups, m. styloglossus has two bellies in Mystacina robusta, Thyroptera tricolor, and Furipterus horrens, but this muscle has only one belly in Saccopteryx bilineata, Noctilio leporinus, Macrotus waterhousii, and Artibeus jamaicensis (Sprague, 1943; Griffiths, 1982; Griffiths and Smith, 1991; Griffiths, personal commun.; Simmons and Geisler, 1998). Data were not available for Koopmanycteris, Pteronotus macleayii, $P$. quadridens, members of the $P$. personatus complex, $P$. gymnonotus, members of the $P$. davyi complex, $P$. pristinus, Mormoops megalophylla, M. blainvillei, Noctilio albiventris, Mystacina tuberculata, Macrotus californicus, or 
Speonycteris for this character, which corresponds to character 57 of Simmons and Geisler (1998) and character 64 of Simmons and Conway (2001).

Character 87. Origin of $m$. ceratohyoideus includes ceratohyal (0); or origin does not include ceratohyal (1). M. ceratohyoideus in bats originates from the anterior cornu of the hyoid and inserts on the thyrohyal (Sprague, 1943 ; Griffiths, 1982, 1983, 1994; Griffiths and Smith, 1991; Griffiths et al., 1992). The origin of $\mathrm{m}$. ceratohyoideus includes the epihyal element in all of the taxa in our study that have been investigated thus far (Sprague, 1943; Griffiths, 1982, personal commun.; Griffiths and Smith, 1991; Simmons and Geisler, 1998). In the Pteronotus parnellii complex, an adjacent portion of this muscle originates from the ceratohyal (Griffiths, 1978). A similar origin occurs in Saccopteryx bilineata, Noctilio leporinus, Thyroptera tricolor, Furipterus horrens, and Artibeus jamaicensis (Sprague, 1943; Griffiths, 1982; Griffiths and Smith, 1991; Simmons and Geisler, 1998; Griffiths, personal commun.). In contrast, m. ceratohyoideus lacks a ceratohyal origin in Macrotus waterhousii and Mystacina robusta (Griffiths, 1982, personal commun.). Data were not available for Koopmanycteris, Pteronotus macleayii, $P$. quadridens, members of the $P$. personatus complex, $P$. gymnonotus, members of the $P$. davyi complex, $P$. pristinus, Mormoops megalophylla, M. blainvillei, Noctilio albiventris, Mystacina tuberculata, Macrotus californicus, or Speonycteris for this character, which corresponds to character 59 of Simmons and Geisler (1998), character 94 of Wetterer et al. (2000) and character 65 of Simmons and Conway (2001).

Character 88: Origin of $m$. ceratohyoideus does not include stylohyal (0); or origin does include stylohyal (1). M ceratohyoideus lacks a stylohyal origin in the Pteronotus parnellii complex, Saccopteryx bilineata, Noctilio leporinus, Mystacina robusta, Furipterus horrens, and Artibeus jamaicensis (Sprague, 1943; Griffiths, 1978, 1982, personal commun.; Griffiths and Smith, 1991). In contrast, the origin of $\mathrm{m}$. ceratohyoideus does include the stylohyal element in Macrotus waterhousii (Griffiths, 1982). Data were not available for Koopmanycteris, Pteronotus macleayii, $P$. quadridens, members of the $P$. personatus complex, $P$. gymnonotus, members of the $P$. davyi complex, $P$. pristinus, Mormoops megalophylla, M. blainvillei, Noctilio albiventris, Thyroptera tricolor, Mystacina tuberculata, Macrotus californicus, or Speonycteris for this character, which corresponds to character 61 of Simmons and Geisler (1998), character 95 of Wetterer et al. (2000), and character 66 of Simmons and Conway (2001).

CHARACTER 89: $M$. sternothyroideus originates from clavicle (0); or from manubrium of sternum (1). M. sternothyroideus in bats originates from the sternal region and inserts onto the thyroid cartilage (Sprague, 1943 ; Griffiths, 1982, 1983, 1994; Griffiths and Smith, 1991; Griffiths et al., 1992). M. sternothyroideus originates from the medial tip of the clavicle (not from any part of the sternum) in the Pteronotus parnellii complex (Sprague, 1943; Griffiths, 1978). A similar condition is seen in Artibeus jamaicensis, Macrotus waterhousii, Noctilio leporinus, and Saccopteryx bilineata (Sprague, 1943; Griffiths, 1982; Griffiths and Smith, 1991). In contrast, m. sternothyroideus originates from the lateral manubrium (not the clavicle) in Mystacina robusta, Thyroptera tricolor, and Furipterus horrens (Sprague, 1943; Simmons and Geisler, 1998; Griffiths, personal commun.). Data were not available for Koopmanycteris, Pteronotus macleayii, $P$. quadridens, members of the $P$. personatus complex, $P$. gymnonotus, members of the $P$. davyi complex, $P$. pristinus, Mormoops megalophylla, M. blainvillei, Noctilio albiventris, Mystacina tuberculata, Macrotus californicus, or Speonycteris for this character, which corresponds to character 66 of Simmons and Geisler (1998) and character 67 of Simmons and Conway (2001).

Character 90: M. omohyoideus originates from clavicle (0); or originates from scapula (1); or muscle absent (2). M. omohyoideus connects the shoulder girdle with the hyoid apparatus, and the origin of this muscle may be from either the scapula or the clavicle (Sprague, 1943 ; Griffiths, 
1982, 1983, 1994; Griffiths and Smith, 1991; Griffiths et al., 1992). M. omohyoideus is present and originates from the scapula in the Pteronotus parnellii complex (Sprague, 1943). Among the outgroups, $\mathrm{m}$. omohyoideus similarly originates from the scapula in Noctilio leporinus, Furipterus horrens, and Artibeus jamaicensis (Sprague, 1943). In contrast, m. omohyoideus originates from the clavicle in Saccopteryx bilineata (Griffiths and Smith, 1991). M. omohyoideus is absent in Mystacina robusta and Thyroptera tricolor (Sprague, 1943; Griffiths, personal commun.). Data were not available for Koopmanycteris, Pteronotus macleayii, P. quadridens, members of the $P$. personatus complex, $P$. gymnonotus, members of the $P$. davyi complex, P. pristinus, Mormoops megalophylla, M. blainvillei, Noctilio albiventris, Mystacina tuberculata, Macrotus californicus, M. waterhousii, and Speonycteris for this character, which corresponds to character 67 of Simmons and Geisler (1998) and character 68 of Simmons and Conway (2001).

Character 91: M. sphincter colli profundus present (0); or absent (1). In bats $\mathrm{m}$. sphincter colli profundus originates from the fascia of the mylohyoid region, forms a variable number of slips, and inserts on the inner surface of the skin of the cervical region (Sprague, 1943; Griffiths, 1982). M. sphincter colli profundus is absent in the Pteronotus parnellii complex (Sprague, 1943). In contrast, this muscle is present in Macrotus waterhousii, Artibeus jamaicensis, Thyroptera tricolor, and Noctilio leporinus (Sprague, 1943; Griffiths, 1982). Data were not available for Koopmanycteris, Pteronotus macleayii, $P$. quadridens, members of the $P$. personatus complex, $P$. gymnonotus, members of the $P$. davyi complex, P. pristinus, Mormoops megalophylla, M. blainvillei, Furipterus horrens, Noctilio albiventris, Mystacina tuberculata, M. robusta, Saccopteryx bilineata, Macrotus californicus, and Speonycteris for this character, which corresponds to character 103 of Wetterer et al. (2000) and character 69 of Simmons and Conway (2001).

CHARACTER 92: $M$. cricopharyngeus consists of a single large slip (0); or three or more slips (1). M. cricopharyngeus in bats originates from the cricoid cartilage and inserts into the dorsal wall of the pharynx (Griffiths, 1978; Griffiths and Smith, 1991). M. cricopharyngeus consists of a single large slip in members of the Pteronotus parnellii and $P$. davyi complexes, and in Mormoops megalophylla (Griffiths, 1978). A similar condition is seen in Noctilio leporinus and Saccopteryx bilineata, but $\mathrm{m}$. cricopharyngeus consists of three or more slips in Macrotus waterhousii and Artibeus jamaicensis (Sprague, 1943; Griffiths, 1978, 1982; Griffiths and Smith, 1991). Data were not available for Koopmanycteris, Pteronotus macleayii, P. quadridens, members of the $P$. personatus complex, $P$. gymnonotus, $P$. pristinus, Mormoops megalophylla, $M$. blainvillei, Thyroptera tricolor, Furipterus horrens, Noctilio albiventris, Mystacina tuberculata, $M$. robusta, Macrotus californicus, and Speonycteris for this character, which corresponds to character 106 of Wetterer et al. (2000) and character 70 of Simmons and Conway (2001).

ChARACTER 93: $M$. cricothyroideus consists of a single undivided muscle sheet (0); or two muscles present, $m$. cricothyroideus anterior and $m$. cricothyroideus posterior (1). Two cricothyroid muscles are present on each side of the larynx in members of the Pteronotus parnellii and P. davyi complexes, and in Mormoops megalophylla: m. cricothyroideus anterior originates from the wide, calcified anterior portion of the cartilage and inserts on the ventrolateral thyroid cartilage, while $\mathrm{m}$. cricothyroideus posterior originates from the soft, uncalcified lateral walls of the cricoid cartilage and inserts on the medial surface of the thyroid cornu (Griffiths, 1978). Both muscles are innervated by branches of $\mathrm{n}$. laryngeus cranialis, the nerve that innervates the single $\mathrm{m}$. cricothyroideus found in other mammals (Griffiths, 1978). In contrast, Saccopteryx bilineata, Noctilio leporinus, Macrotus waterhousii, and Artibeus jamaicensis have a m. cricothyroideus that consists of a single, undivided sheet of muscle on each side of the larynx (Griffiths, 1978; Griffiths and Smith, 1991). Data were not available for Koopmanycteris, Pteronotus macleayii, $P$. quadridens, members of the $P$. per- 
sonatus complex, $P$. gymnonotus, $P$. pristinus, $M$. blainvillei, Noctilio albiventris, Thyroptera tricolor, Furipterus horrens, Mystacina tuberculata, M. robusta, Macrotus californicus, and Speonycteris for this character, which corresponds to character 71 of Simmons and Conway (2001).

\section{Tongue and Oral Cavity}

As noted by Simmons and Conway (2001), terminology for describing structure and distribution of tongue papillae is complex and often confusing. We follow Park and Hall (1951), Greenbaum and Phillips (1974), Griffiths (1982), Gimenez (1993), Gimenez et al. (1996), Wetterer et al. (2000), and Simmons and Conway (2001) in recognizing groups of presumably homologous tongue papillae based on morphology of individual papillae and position of papillae on the tongue.

Character 94: Horny papillae of different sizes, largest near midline (0); or all horny papillae of uniform size (1); or horny papillae absent (2). Horny papillae are a cluster of enlarged, bifid papillae located at the midline near the tip of the tongue (Park and Hall, 1951). The horny papillae are all of roughly uniform size in all extant species of Pteronotus (Simmons and Conway, 2001). In contrast, the horny papillae are of different sizes in both species of Mormoops. In these species, the posteromedial horny papillae are much larger than others in the cluster. A similar condition is seen in Mystacina tuberculata, Artibeus jamaicensis, and both species of Macrotus. In contrast, the horny papillae are of uniform size in Saccopteryx bilineata and both species of Noctilio. Mystacina robusta, Furripterus horrens, and Thyroptera tricolor lack horny papillae entirely. Data were not available for Koopmanycteris, Speonycteris, and Pteronotus pristinus for this character, which corresponds to a modified version character 122 of Wetterer et al. (2000) and character 72 of Simmons and Conway (2001). We treated this as an unordered character.

CHARACTER 95: Lateral circumvallate papillae absent (0); or present (1). Many bats have paired circumvallate papillae (one lateral and one medial) located near the base of the tongue (Park and Hall, 1951; Greenbaum and Phillips, 1974; Griffiths, 1982; Gimenez, 1993; Gimenez et al, 1996; Wetterer et al., 2000). Lateral vallate papillae are present in all extant mormoopids and are also present in Thyroptera tricolor, Furipterus horrens, both species of Mystacina, Artibeus jamaicensis, and both species of Macrotus. In contrast, lateral vallate papillae are absent in Saccopteryx bilineata and both species of Noctilio. Data were not available for Koopmanycteris, Speonycteris, Pteronotus pristinus, Mystacina robusta for this character, which corresponds to character 109 of Wetterer et al. (2000) and character 73 of Simmons and Conway (2001).

Character 96: Distal tips of medial-posterior mechanical papillae directed toward midline of tongue (0); or directed toward pharyngeal region (1); or directed toward anterior tip of tongue (2); or papillae basin shaped with no clear inclination (3). The medial-posterior mechanical papillae are those papillae located anterior to the circumvallate papillae in roughly the middle one-third of the tongue (Gimenez, 1993; Wetterer et al., 2000). Most medial-posterior mechanical papillae are thick, fleshy, and terminate in one or more rounded points (Wetterer et al., 2000). The distal tips of the medial posterior mechanical papillae are directed toward the pharyngeal region in both species of Mormoops (Simmons and Conway, 2001). In contrast, these papillae are somewhat basin shaped and show no clear inclination in any direction in extant species of Pteronotus (Simmons and Conway, 2001). Among the outgroups, the tips of the medial posterior mechanical papillae are directed toward the pharyngeal region in both species of Mystacina, Thyroptera tricolor, and both species of Macrotus, and in the opposite direction (toward the tip of the tongue) in Furipterus horrens and Artibeus jamaicensis (Wetterer et al., 2000). A fourth condition, in which the medial posterior mechanical papillae are directed medially toward the midline of the tongue, is seen in Saccopteryx bilineata and both species of Noc- 
tilio (Simmons and Conway, 2001). Data were not available for Koopmanycteris, Speonycteris, and Pteronotus pristinus. This character corresponds to character 116 of Wetterer et al. (2000) and character 74 of Simmons and Conway (2001), and we followed those authors in treating this as an unordered transformation.

CHARACTER 97: Basketlike medial-posterior mechanical papillae present (0); or absent (1). Basketlike papillae are medial-posterior mechanical papillae that have central concavities and fleshy, cylindrical bases (Park and Hall, 1951; Wetterer et al., 2000; Simmons and Conway, 2001). Basketlike papillae are present in all extant mormoopids (Simmons and Conway, 2001). Among the outgroups, they are also present in Saccopteryx bilineata, both species of Mystacina, and both species of Macrotus. In contrast, basketlike papillae are absent in Thyroptera tricolor, Furipterus horrens, both species of Noctilio and Artibeus jamaicensis. Data were not available for Koopmanycteris, Speonycteris, Pteronotus pristinus, and Mystacina robusta for this character, which corresponds to character 119 of Wetterer et al. (2000) and character 75 of Simmons and Conway (2001).

ChARACTER 98: Pharyngeal region of tongue totally bare, papillae absent along lateral edges (0); or with medial bare patch, papillae present along lateral edges (1). The pharyngeal region of the tongue is defined as that part of the tongue that lies proximal to the circumvallate papillae (Sonntag, 1925). The pharyngeal region of the tongue is completely bare of papillae in all extant mormoopids. A similar condition is seen in Saccopteryx bilineata. In contrast, only the medial portion of the pharyngeal region of the tongue is bare in Thyroptera tricolor, both species of Mystacina, both species of Macrotus, Artibeus jamaicensis, and both species of Noctilio. In these forms, mechanical papillae are present along the lateral edges of the tongue in the pharyngeal region. Data were not available for Koopmanycteris, Speonycteris, and Pteronotus pristinus for this character, which corresponds to character
111 of Wetterer et al. (2000) and character 76 of Simmons and Conway (2001). We treated this as an ordered character.

CHARACTER 99: Internal labial papillae absent (0); or present (1). Internal labial papillae are small, fleshy projections that occur in patches inside the lips and cheeks of some bats (Silva Taboada and Pine, 1969; Wetterer et al., 2000). Internal labial papillae are absent in all extant mormoopids (Simmons and Conway, 2001). A similar condition is seen in most of the outgroups. In contrast, internal labial papillae are present along the lingual edge of the lower lip in Artibeus jamaicensis (Simmons and Conway, 2001). Data were not available for Koopmanycteris, Speonycteris, and Pteronotus pristinus for this character, which corresponds to character 77 of Simmons and Conway (2001).

Character 100: Cheek pouches absent (0); or present (1). Cheek pouches are epithelium-lined pockets in the cheeks that open inside the mouth. These are absent in most bats, including all extant mormoopids (Simmons and Conway, 2001). Among the outgroups, cheek pouches are absent in most of our sample but are present in both species of Noctilio (Murray and Strickler, 1975; Simmons and Conway, 2001). Data were not available for Koopmanycteris, Speonycteris, and Pteronotus pristinus for this character, which corresponds to character 78 of Simmons and Conway (2001).

\section{Face, Ears, ANd Vibrissae}

Character 101: Lower lip and chin without multiple dermal papillae (0); or with multiple dermal papillae (1). As described by Simmons and Conway (2001), multiple dermal papillae are present on the lower lip and chin in all extant mormoopids. Among the outgroups, similar multiple papillae are present in Artibeus jamaicensis. Multiple papillae are absent in both species of Macrotus, both species of Noctilio, both species of Mystacina, Thyroptera tricolor, Furipterus horrens, and Saccopteryx bilineata. Data were not available for Koopmanycteris, Speonycteris, and Pteronotus pristinus for this char- 
acter, which corresponds to character 79 of Simmons and Conway (2001).

CHARACTER 102: Lower lip of small or moderate size, dorsoventral height less than height of nostrils (0); or lip large and platelike, dorsoventral height equal or greater than the nostrils (1). Both species of Mormoops have a lower lip of moderate size, characterized by dorsoventral height less than the height of the nostril. In contrast, all extant species of Pteronotus have a large, platelike lower lip that has a height equal to or greater than height of the nostrils (Simmons and Conway, 2001). The outgroups all have a small or moderate lower lip whose dorsoventral height is less than the height of the nostrils. Data were not available for Koopmanycteris, Speonycteris, and Pteronotus pristinus for this character, which corresponds to character 80 of Simmons and Conway (2001).

CHARACTER 103: Lower lip without small horseshoe-shaped pad at midline (0); or pad present (1). The lower lip of both species of Mormoops is characterized by a horseshoe-shaped dermal pad that is centered above the chin and extends perpendicular to the nostrils when the mouth is closed. This horseshoe-shaped pad is tiny; that is, the height of the pad is approximately one-fourth the width of the lower lip (Simmons and Conway, 2001). A similar horseshoe-shaped lip pad is absent in extant members of the genus Pteronotus and all the outgroups. Data were not available for Koopmanycteris, Speonycteris, and Pteronotus pristinus for this character, which corresponds to character 81 of Simmons and Conway (2001).

Character 104: No transverse flap below lower lip (0); or one transverse flap present below lower lip (1); or two transverse rows of flaps present (2). Most bats do not have transverse flaps below the lower lip. In contrast, extant mormoopids have one or more transverse flaps of skin that project from the lower lip. Extant species of Pteronotus have a single transverse flap on the lower lip, while both species of Mormoops have two rows of transverse flaps. Among the outgroups, both species of Noctilio have two rows of transverse flaps below the lower lip. Saccopteryx bilineata, both species of Mystacina, Thyroptera tricolor, Furipterus horrens, Artibeus jamaicensis, and both species of Macrotus lack transverse flaps entirely. Data were not available for Koopmanycteris, Speonycteris, and Pteronotus pristinus for this character, which corresponds to character 82 of Simmons and Conway (2001) and part of character 30 of Wetterer et al. (2000). We treated this as an unordered character.

Character 105: Anterior edge of labio-nasal region protrudes anteriorly beyond edge of lower lip, muzzle appears pointed (0); or edge does not protrude anteriorly, muzzle appears blunt (1). The anterior edge of the labio-nasal region does not protrude anteriorly beyond the edge of the lower lip in any extant species of Pteronotus or Mormoops. As a result, the muzzle in these taxa appears to be relatively blunt (i.e., not pointed). A similar condition is seen among the outgroups in Thyroptera tricolor, Furipterus horrens, Artibeus jamaicensis, and both species of Macrotus. In contrast, the anterior edge of the labio-nasal region does protrude anteriorly beyond edge of lower lip in Saccopteryx bilineata, both species of Noctilio, and both species of Mystacina, giving the muzzle a pointed appearance. Data were not available for Koopmanycteris, Speonycteris, and Pteronotus pristinus for this character, which corresponds to character 83 of Simmons and Conway (2001).

Character 106: Nostrils tubelike, openings face slightly laterally and are not adjacent (0); or nostrils open directly adjacent to each other and face anteriorly (1). The nostrils open adjacent to each other and face anteriorly in all extant species of Pteronotus. In contrast, both species of Mormoops have tubelike nostrils that open slightly laterally. Saccopteryx bilineata, both species of Noctilio, and both species of Mystacina also have tubelike nostrils, while Thyroptera tricolor, Furipterus horrens, both species of Macrotus, and Artibeus jamaicensis have nostrils that are adjacent and open anteriorly. Data were not available for Koopmanycteris, Speonycteris, and Pteronotus pristinus for this character, which corresponds to character 84 of Simmons and Conway (2001). 
Character 107: Narial pad with V-shaped notch present between nostrils (0); or narial pad with narrow, papillated vertical ridge between nostrils (1); or narial pad with wide, smooth-sided vertical ridge between nostrils (2); or narial pad flat, with no notch or ridge between nostrils (3). The narial pad in bats is highly variable in form and ornamentation (Wetterer et al., 2000; Simmons and Conway, 2001). There is no notch or ridge between the nostrils on the narial pad in Pteronotus quadridens, members of the $P$. personatus and $P$. davyi complexes, and P. gymnonotus. In these forms, the narial pad is flat and unornamented. Another condition is seen in the Pteronotus parnellii complex and P. macleayii, which have a V-shaped notch in the narial pad between the nostrils. In contrast, both species of Mormoops have a narrow, papillated vertical ridge between the nostrils. This structure is quite prominent and has smooth lateral edges, but the anterior face of the ridge gives the impression of being composed of a series of indistinct dermal papillae. Among the outgroups, Thyroptera tricolor, Furipterus horrens, and both species of Mystacina have a flat narial pad, while there is a notch in the narial pad between the nostrils in Saccopteryx bilineata and both species of Noctilio. Artibeus jamaicensis and both species of Macrotus and have a ridge between the nostrils, but this ridge is wider and flatter than that seen in Mormoops and it lacks a papillated surface, instead having a smooth anterior face. Data were not available for Koopmanycteris, Speonycteris, and Pteronotus pristinus for this character, which corresponds to character 22 of Wetterer et al. (2000) and character 85 of Simmons and Conway (2001). Like those authors, we treated this as an unordered character.

Character 108: Anterodorsal edge of narial pad unadorned, without ridge of skin or noseleaf (0); or with papillated ridge of skin present (1); or with noseleaf present (2). As noted by Simmons and Conway (2001), both species of Mormoops lack a noseleaf or ridge of skin on the anterodorsal edge of the narial pad. In contrast, all extant species of Pteronotus have a ridge of skin on the anterodorsal edge of the narial pad. This ridge has an uneven, papillated dorsal edge that gives the impression of being composed of a series of indistinct dermal papillae. Among the outgroups, the anterodorsal edge of the narial pad is unadorned and lacks a ridge or noseleaf in Saccopteryx bilineata, Thyroptera tricolor, Furipterus horrens, both species of Mystacina, and both species of Noctilio. Artibeus jamaicensis and both species of Macrotus have a well-developed noseleaf that projects from the anterodorsal edge of the narial pad. Data were not available for Koopmanycteris, Speonycteris, and Pteronotus pristinus for this character, which corresponds to character 3 of Simmons and Geisler (1998) and character 86 of Simmons and Conway (2001). We followed those authors in treating this as an ordered character.

Character 109: No dermal papillae on dorsal surface of nostril (0); or one dermal papilla present on dorsal surface of each nostril (1). All extant members of the genus Pteronotus lack dermal papillae on the dorsal surface of the nostrils. In contrast, both species of Mormoops have one dermal papilla on the dorsal surface of each nostril. This papilla is not located on the anterodorsal edge of the narial pad (as are the ridges and noseleaves described in character 99), but the papilla is instead set back approximately midway along the tubelike dorsal aspect of the nostril. All of the outgroups lack dermal papillae on the dorsal surface of the nostrils. Data were not available for Koopmanycteris, Speonycteris, and Pteronotus pristinus for this character, which corresponds to character 87 of Simmons and Conway (2001).

Character 110: No dermal projection present lateral to the nostrils (0); or dermal projection present, rounded distally, lateral side of projection continuous with the lip (1); or projection triangular and pointed distally, lateral side not continuous with lip (2). Most bats lack dermal projections lateral to the nostrils, but such structures are present in all extant mormoopids. In these taxa, a single dermal projection of variable form extends anterodorsally from a position lateral to the nostrils. This projection is rounded distally in 
members of the Pteronotus parnellii and P. personatus complexes, and its lateral side is continuous with the lip. This arrangement makes the upper lip appear swollen on either side of the narial pad. In contrast, the dermal projection in both species of Mormoops, members of the $P$. davyi complex, P. gymnonotus, $P$. macleayii, and $P$. quadridens is triangular in shape and tapers distally to a point. The projections have welldefined lateral sides that are not continuous with the lip. As a result, the lip does not appear swollen in these taxa. Dermal projections lateral to the nostrils are absent in all the outgroups. Data were not available for Koopmanycteris, Speonycteris, and Pteronotus pristinus for this character, which corresponds to character 88 of Simmons and Conway (2001). We followed those authors in treating this as an unordered character.

Character 111: No dermal tubercle on midline of muzzle posterodorsal to nostrils (0); or prominent dermal tubercle present (1). Pteronotus macleayii, $P$. quadridens, members of the $P$. davyi complex, and P. gymnonotus lack a conspicuous dermal tubercle on the dorsal aspect of the muzzle. In contrast, members of the Pteronotus parnellii and P. personatus complexes and both members of the genus Mormoops have a prominent dermal tubercle located on the midline of the muzzle above the nostrils. The dermal tubercle is absent in all the outgroups. Data were not available for Koopmanycteris, Speonycteris, and Pteronotus pristinus for this character, which corresponds to character 89 of Simmons and Conway (2001).

CHARACTER 112: Interauricular band absent (0); or prominent interauricular band present (1). Both species of Mormoops have a prominent, $\mathrm{V}$-shaped interauricular band of skin that connects the pinnae across the top of the head. In contrast, all extant species of Pteronotus lack an interauricular band. In these taxa, a very low, inconspicuous ridge may be seen to extend medially from the base of each pinna. The degree of prominence of these ridges varies among individuals and perhaps among species (see Smith, 1972), and appears to be significantly affected by preservation in museum specimens (e.g., degree of desiccation in fluid-preserved material; Simmons and Conway, 2001). Simmons and Conway (2001) concluded that these ridges represent skin-covered auricular muscles. Due to difficulties associated with interpreting the degree of development of these low ridges in preserved specimens, we follow Simmons and Conway (2001) in choosing not to score their presence as a separate character state. Among the outgroups, Artibeus jamaicensis, Thyroptera tricolor, Furipterus horrens, both species of Noctilio, both species of Mystacina, and Saccopteryx bilineata lack an interauricular band, while a prominent interauricular band is present in both species of Macrotus. Data were not available for Koopmanycteris, Speonycteris, and Pteronotus pristinus for this character, which corresponds to character 36 of Wetterer et al. (2000) and character 90 of Simmons and Conway (2001).

Character 113: Pinna not funnel shaped, base of pinna located well above the level of the mouth (0); or pinna funnel shaped, lateral base of pinna extends to or below the level of the mouth (1). All extant mormoopids have funnel-shaped pinnae in which the lateral base of the pinnae extends below the level of the mouth. Among the outgroups, Thyroptera tricolor, Furipterus horrens, and both species of Noctilio also have pinnae in which the lateral edge of the pinna extends to or below the level of the mouth. In contrast, the remaining outgroups lack funnel-shaped pinnae, the lateral edge of each pinna instead joining the head well above the level of the mouth. Data were not available for Koopmanycteris, Speonycteris, and Pteronotus pristinus for this character, which corresponds to character 1 of Simmons and Geisler (1998) and character 91 of Simmons and Conway (2001).

Our scoring of this feature is identical to that of Simmons and Conway (2001) and agrees with the descriptions of Smith (1972) and Hall (1981), but differs from some accounts in the literature that have contrasted the "funnel-shaped" ears in Mormoops with "narrow" ears in Pteronotus (e.g., Koopman, 1994). The latter distinction refers to 
the form of the distal pinna, which we treat as a separate character below.

Character 114: Distal pinna lanceolate, tapers to blunt point (0); or distal pinna squared, pinna height relatively uniform across the entire width of the pinna (1); or distal pinna rounded (2). All extant species of Pteronotus have pinnae that are lanceolate and taper to a blunt point. In contrast, both species of Mormoops have pinnae that are squared distally with an edge that is of equal height across most of the breadth of the pinna. The distal edge of the pinnae is rounded in both species of Macrotus and tapers to a blunt point in the remaining outgroups. Data were not available for Koopmanycteris, Speonycteris, and Pteronotus pristinus for this character, which corresponds to character 92 of Simmons and Conway (2001). We follow those authors in treating this as an unordered character.

Character 115: Lateral edge of distal pinna smooth (0); or serrated (1). As in most bats, members of the Pteronotus parnellii and $P$. davyi complexes, $P$. gymnonotus, and both species of Mormoops have pinnae with smooth edges. In contrast, $P$. macleayii, $P$. quadridens, and members of the $P$. personatus complex have several serrations on the lateral edge of the distal pinna. The outgroups all have pinnae with a smooth lateral edge. Data were not available for Koopmanycteris, Speonycteris, and Pteronotus pristinus for this character, which corresponds to character 93 of Simmons and Conway (2001).

Character 116: Distal tip of tragus rounded (0); or tapers to point (1); or bifurcate (2). As noted by Simmons and Conway (2001), the distal tip of the tragus is rounded in all extant species of Pteronotus and Mormoops. Among the outgroups, a similar condition is seen in Saccopteryx bilineata. In contrast, the distal tragus tapers to a point in Thyroptera tricolor, Furipterus horrens, Artibeus jamaicensis, both species of Macrotus, and both species of Mystacina. An alternative state is seen in both species of Noctilio, which have a tragus with a bifurcate tip. Data were not available for Koopmanycteris, Speonycteris, and Pteronotus pristinus for this char- acter, which corresponds to character 94 of Simmons and Conway (2001). This character was treated as unordered.

Character 117: Tragus thin, of uniform thickness throughout (0); or tragus with distinctly thickened area at base (1); or tragus with a thickened central area that extends from midpoint to tip of tragus; lateral and medial edges of tragus thin (2); or tragus uniformly thick (3). All members of the genus Pteronotus have a tragus that is relatively thin and of roughly uniform thickness throughout. In contrast, the base of the tragus is thickened in both species of Mormoops. Among the outgroups, Saccopteryx bilineata, Furipterus horrens, both species of Noctilio, and both species of Mystacina have a uniformly thin tragus that resembles that of Pteronotus. Thyroptera tricolor has a tragus that is thickened at the base. Both species of Macrotus are characterized by a tragus with a vertically oriented, thickened central area that extends up the posterior face of the tragus from its midpoint to its tip. The lateral and medial edges of the tragus are thin in this taxon. In contrast, Artibeus jamaicensis has a tragus that is uniformly thick. Data were not available for Koopmanycteris, Speonycteris, and Pteronotus pristinus for this character, which corresponds to character 95 of Simmons and Conway (2001). This character was treated as unordered.

Character 118: Secondary fold on tragus absent (0); or fold present, smaller than body of tragus (1); or fold present, equal to or larger than body of tragus (2). The secondary fold is a distally rounded fold of skin that extends from the ventromedial aspect of the tragus, lying roughly at a right angle to the main longitudinal axis of that structure (Smith, 1972; Simmons and Conway, 2001). The thickness of the fold is related to its size; when the fold is approximately the same size as the body of the tragus, it is approximately the same thickness, while smaller folds are relatively thinner. Most bats, including all the outgroups, lack a secondary fold on the tragus. In contrast, all extant species of the genus Pteronotus have a secondary fold that is smaller than the body of the tragus, while both species of Mor- 
moops have a secondary fold that is equal to or larger than the body of the tragus. Data were not available for Koopmanycteris, Speonycteris, and Pteronotus pristinus for this character, which corresponds to character 96 of Simmons and Conway (2001). We followed those authors in treating this as an ordered character.

ChARACTER 119: Five interramal vibrissae present (0) or two interramal vibrissae present (1); or one interramal vibrissa present (2); or interramal vibrissae absent (3). Interramal vibrissae are found under the chin between the rami of the lower jaws, posterior to the mandibular symphysis (Pocock, 1914; Brown, 1971). All extant species of Pteronotus are characterized by the presence of a single interramal vibrissa. In contrast, both species of Mormoops have two interramal vibrissae that emerge from a single papilla. Among the outgroups, Saccopteryx bilineata, both species of Noctilio, and Artibeus jamaicensis have two interramal vibrissae. Mystacina tuberculata and Thyroptera tricolor each have one interramal vibrissa, and Mystacina robusta and both species of Macrotus lack interramal vibrissae entirely. Furipterus horrens has a unique condition in which five interramal papillae are present, widely separated and each emerging from a separate papilla. Data were not available for Koopmanycteris, Speonycteris, and Pteronotus pristinus for this character, which corresponds to a modified version of character 13 of Wetterer et al. (2000) and character 97 of Simmons and Conway (2001). We treated this as an unordered character because the condition in Furipterus is very different from those in the other taxa.

CHARACTER 120: Interramal tubercle well developed (0); or absent (1). The interramal tubercle (= ventral sinus-hair tubercle of Dalquest and Werner, 1954) is a swelling associated with the interramal vibrissae in some bats including all extant mormoopids (Simmons and Conway, 2001). Among the outgroups, this tubercle is similarly well developed in Saccopteryx bilineata, Mystacina tuberculata, both species of Noctilio, and both species of Macrotus. Furipterus horrens has several interramal tubercles, all well developed. In contrast, the interramal tubercle is absent in Mystacina robusta and Artibeus jamaicensis. The interramal vibrissae in these taxa originate from a tiny pitlike perforation in the skin. Absence of interramal vibrissae does not preclude presence of an interramal tubercle (e.g., Macrotus lacks interramal vibrissae but has a tubercle), so we treat these as separate characters. Data were not available for Koopmanycteris, Speonycteris, or Pteronotus pristinus for this character corresponds to character 98 of Simmons and Conway (2001).

Character 121: Two genal vibrissae present on each cheek (0); or one genal vibrissa present on each cheek (1); or genal vibrissae absent (2). Genal vibrissae are located on the cheek ventral to the eye and subocular vibrissae (Pocock, 1914; Brown, 1971). All extant species of Pteronotus have a single genal vibrissa on each cheek while both species of Mormoops lack genal vibrissae. Among the outgroups, Saccopteryx bilineata, both species of Noctilio, and both species of Mystacina have a pair of genal vibrissae on each cheek. Both species of Macrotus have a single genal vibrissa on each cheek. Thyroptera tricolor, Furipterus horrens, and Artibeus jamaicensis lacks genal vibrissae entirely. Data were not available for Koopmanycteris, Speonycteris, and Pteronotus pristinus for this character, which corresponds to character 12 of Wetterer et al. (2000) and character 99 of Simmons and Conway (2001). We followed the latter authors in treating this as an ordered character.

ChARACTER 122: Superciliary vibrissae present (0); or absent (1). Superciliary (= supraorbital) vibrissae are located dorsal to the eye in many mammals including many bats (Pocock, 1914; Brown, 1971). All extant mormoopids lack superciliary vibrissae. A similar condition is seen among the outgroups in both species of Mystacina, Thyroptera tricolor, Furipterus horrens, and Artibeus jamaicensis. In contrast, a single superciliary vibrissa is present above each eye in Saccopteryx bilineata, both species of Noctilio, and both species of Macrotus. Data were not available for Koopmanycteris, Speonyc- 
teris, and Pteronotus pristinus for this character, which corresponds to character 11 of Wetterer et al. (2000) and character 100 of Simmons and Conway (2001).

CHARACTER 123: Vibrissae on face posterior and lateral to narial pad arranged in a single vertical column (0); or arranged in two roughly parallel vertical columns (1). Wetterer et al. (2000) noted that there is variation in the arrangement of the vibrissae on the face posterior and lateral to the narial pad. There are two vertical columns of vibrissae in this region in all extant mormoopids: an anteromedial column located adjacent to the narial pad, and a posterolateral column located posterior to the anteromedial column. These columns are roughly parallel in orientation, and each contains at least two vibrissae. A similar arrangement is seen among the outgroups in both species of Macrotus, Mystacina robusta, Thyroptera tricolor, Furipterus horrens and both species of Noctilio. In contrast, the posterolateral column is absent in Saccopteryx bilineata, Mystacina tuberculata, and Artibeus jamaicensis. Data were not available for Koopmanycteris, Speonycteris, and Pteronotus pristinus for this character, which corresponds to character 14 of Wetterer et al. (2000) and character 101 of Simmons and Conway (2001).

Character 124: Four vibrissae present in anteromedial column (0); or three vibrissae (1); or two vibrissae (2). The anteromedial column of vibrissae on the face includes only two vibrissae in all extant mormoopids. Among the outgroups, a similar condition occurs in Furipterus horrens and both species of Noctilio. In contrast, this column consists of four vibrissae in Saccopteryx bilineata and three vibrissae in both species of Mystacina, Thyroptera tricolor, both species of Macrotus, and Artibeus jamaicensis. Data were not available for Koopmanycteris, Speonycteris, and Pteronotus pristinus for this character, which corresponds to character 15 of Wetterer et al. (2000) and character 102 of Simmons and Conway (2001). We followed the latter authors in treating this as an ordered character.

\section{Pelage and Patagia}

Character 125: Facial stripes absent (0); or paired stripes present (1). Facial stripes are absent in all extant mormoopids. The fur appears to be of uniform color between the narial pad and ears in these taxa. A similar condition is seen in Saccopteryx bilineata, Thyroptera tricolor, Furipterus horrens, both species of Noctilio, both species of Mystacina, and both species of Macrotus. In contrast, Artibeus jamaicensis is characterized by a pair of pale facial stripes that run from the anterior rostrum to near the base of the ear. These stripes are roughly parallel, with one dorsal to and one ventral to the eye. Data were not available for Koopmanycteris, Speonycteris, or Pteronotus pristinus for this character, which corresponds to character 6 of Wetterer et al. (2000) and character 103 of Simmons and Conway (2001).

Character 126: Dorsal fur unicolored (0); or polymorphic, either unicolored or bicolored (1); or bicolored (2); or polymorphic, either bicolored or tricolored (3); or tricolored (4); or with four bands of color (5). The fur of adult bats consists of hairs that may have alternating bands of dark and pale colors along the shaft. Hairs may be unicolored (of uniform color along the shaft), bicolored (two bands of color), tricolored (three bands), or have four distinct bands of color. Because the pattern of color banding may vary over the surface of the body (e.g., fur over the rump may have fewer color bands than does fur over the shoulders), we follow Simmons and Conway (2001) in restricting comparisons to the dorsal fur on the upper back over the scapulae. Members of the Pteronotus davyi complex and P. gymnonotus have unicolored fur in this region. In contrast, members of the $P$. personatus complex and Mormoops blainvillei have bicolored dorsal fur, and Pteronotus macleayii and $P$. quadridens have tricolored fur. The $P$. parnellii complex is polymorphic for this feature, with either bicolored or tricolored fur (see discussion in Smith, 1972); it is possible that this trait varies among species in this complex, but resolving that issue is beyond the scope of the present study. Mormoops megalophylla has fur with four color 
bands. Among the outgroups, Saccopteryx bilineata, Mystacina robusta, Thyroptera tricolor, Furipterus horrens, and both species of Noctilio have unicolored fur, and bicolored fur occurs in Mystacina tuberculata (Dwyer, 1960) and both species of Macrotus. Artibeus jamaicensis is polymorphic, with either unicolored or bicolored dorsal fur. Data were not available for Koopmanycteris, Speonycteris, and Pteronotus pristinus for this character, which corresponds to character 5 of Wetterer et al. (2000) and character 104 of Simmons and Conway (2001). We followed the latter authors in treating this as an ordered character.

CHARACTER 127: Ventral fur unicolored (0); or polymorphic, either unicolored or bicolored (1); or bicolored (2); or polymorphic, either bicolored or tricolored (3). While dorsal and ventral banding patterns in some species are identical, they are often different; accordingly, we followed Simmons and Conway (2001) and scored these as separate characters. Pteronotus gymnonotus has unicolored ventral fur, while $P$. macleayii, $P$. quadridens, members of the $P$. parnellii, $P$. personatus, and $P$. davyi complexes, and Mormoops blainvillei have bicolored ventral fur. Mormoops megalophylla is polymorphic for this feature, with either bicolored or tricolored ventral fur. Among the outgroups, Mystacina robusta, Thyroptera tricolor, Furipterus horrens, and both species of Noctilio have unicolored ventral fur, while bicolored fur occurs in Saccopteryx bilineata, Mystacina tuberculata (Dwyer, 1960), and both species of Macrotus. Artibeus jamaicensis is polymorphic, with either unicolored or bicolored ventral fur. Data were not available for Koopmanycteris, Speonycteris, and Pteronotus pristinus for this character, which corresponds to character 105 of Simmons and Conway (2001). We followed those authors in treating this as an ordered character.

Character 128: Dorsal fur short, $4-7 \mathrm{~mm}$ in length (0); or long, 8-10 $\mathrm{mm}$ in length (1). Hair length varies considerably among bats. All extant species of Pteronotus have relatively short hair, approximately 4-7 $\mathrm{mm}$ in length. In contrast, both species of Mormoops have longer hair, approximately $8-10 \mathrm{~mm}$ in length. Among the outgroups, both species of Macrotus, Artibeus jamaicensis, and Mystacina tuberculata have long hair, while Saccopteryx bilineata, Mystacina robusta, Thyroptera tricolor, Furipterus horrens, and both species of Noctilio have short hair. Data were not available for Koopmanycteris, Speonycteris, and Pteronotus pristinus for this character, which corresponds to character 106 of Simmons and Conway (2001).

Character 129: Dorsal stripes always absent (0); pair of pale dorsal stripes always present (1); or single pale middorsal stripe often present (2). All extant mormoopids lack dorsal stripes, as do both species of Mystacina, Thyroptera tricolor, Furipterus horrens, both species of Macrotus, and Artibeus jamaicensis. A single, dark middorsal stripe is often (but not always) present in both species of Noctilio. Saccopteryx bilineata is characterized by a pair of pale dorsal stripes. Data were not available for Koopmanycteris, Speonycteris, or Pteronotus pristinus for this character, which corresponds to character 7 of Wetterer et al. (2000) and character 107 of Simmons and Conway (2001). This character was treated as unordered.

Character 130: Underhair and overhair not differentiated in dorsal pelage (0); or clearly differentiated (1). Benedict (1957) documented clearly differentiated overhair and underhair in the dorsal pelage of many bats including all extant mormoopids. Individual overhairs are straighter (and may thus appear longer) and are coarser than individual underhairs. In contrast, all hairs in the dorsal pelage are of similar waviness and coarseness in species that lack differentiated overhair and underhair (Benedict, 1957). Among the outgroups, clearly differentiated overhair and underhair is seen in Thyroptera tricolor and both species of Noctilio (Benedict, 1957). The dorsal pelage in Saccopteryx bilineata, Furipterus horrens, both species of Mystacina, both species of Macrotus, and Artibeus jamaicensis is not differentiated into overhair and underhair (Benedict, 1957). Data were not available for Koopmanycteris, Speonycteris, Pteronotus pristinus, or Mystacina robusta for this character, 
which corresponds to character 1 of Wetterer et al. (2000) and character 108 of Simmons and Conway (2001).

Character 131: Midshaft scales on dorsal hair filaments all entire coronal (0); or scales exhibit a continuous range of variation from entire coronal to repand coronal (1); or alternating entire coronal and hastate coronal scales (2); or all scales dentate coronal (3); or alternating dentate coronal and hastate coronal scales (4); or all scales denticulate coronal (5). Benedict (1957) described hair scale morphology in bats and recognized two principal types of scales on the dorsal hairs: "imbricate," which overlap laterally, and "coronal," which encircle the filament like a ring. Seen in lateral view, coronal scales on a hair filament look like cups. "Entire" coronal scales are rings with uniformly level edges, so that each individual scale appears approximately the same height in all views (Benedict, 1957). "Repand" coronal scales are the same shape as entire coronal scales, but have a slightly uneven edge on one side, a feature not seen in entire coronal scales (Benedict, 1957). "Hastate" coronal scales are characterized by having one part of the distal ring edge that is significantly lower than the rest of the edge (Benedict, 1957). The low point on any given scale is not necessarily in the same position as the low points on the surrounding scales. "Dentate" and "denticulate" coronal scales are characterized by presence of serrations along the edges of the scale (Benedict, 1957). These serrations are small and close together in denticulate scales, and are somewhat larger and farther apart in dentate scales (Benedict, 1957). Among mormoopids, the Pteronotus davyi complex and $P$. gymnonotus have entire coronal scales (Benedict, 1957). Members of the P. parnellii complex have scales that exhibit a continuous range of variation from entire coronal to repand coronal (Benedict, 1957). Denticulate coronal scales are present in Pteronotus macleayii, P. quadridens, and the P. personatus complex (Benedict, 1957). Dentate coronal scales are present in both species of Mormoops (Benedict, 1957). Among the outgroups, Saccopteryx bilineata and Furipterus horrens are characterized by denticulate coronal hair scales, and Thyroptera tricolor and both species of Noctilio have scales that range from entire coronal to repand coronal (Benedict, 1957). Mystacina tuberculata has only entire coronal scales, and both species of Macrotus have alternating entire coronal and hastate coronal scales (Benedict, 1957). Artibeus jamaicensis has alternating dentate coronal and hastate coronal scales (Benedict, 1957). Data were not available for Koopmanycteris, Speonycteris, Pteronotus pristinus, or Mystacina robusta for this character, which corresponds to characters 3 and 4 of Wetterer et al. (2000) and character 109 of Simmons and Conway (2001). We followed the latter authors in treating this character as unordered.

Character 132: Midshaft scales on dorsal hair filaments divaricate from hair shaft (0); or scales divergent from hair shaft (1); or appressed to hair shaft (2). The degree to which hair scales diverge from the shaft of the filament varies among bats (Benedict, 1957). Scales that are "appressed" lie flat against the filament, so that the sides of the scale are parallel with the long axis of the hair shaft, forming a smooth surface with adjacent scales up and down the shaft (Benedict, 1957). In contrast, "divergent scales" are flared distally. The proximal portion of each scale has sides that are parallel with each other and the long axis of the hair shaft, much like those of appressed scales, but the distal portion of each scale flares outward, away from the axis of the shaft (Benedict, 1957). "Divaricate" scales flare even more markedly, with no portion of the side of the scale remaining parallel to the long axis of the hair shaft (Benedict, 1957). Each divaricate scale increases in diameter continuously from its proximal border (where it is narrowest) to its distal edge (where it is widest). All extant species of Pteronotus have midshaft hair scales that are appressed to the hair shaft (Benedict, 1957). In contrast, both species of Mormoops have divergent hair scales (Benedict, 1957). Among the outgroups, Mystacina tuberculata, Thyroptera tricolor, and both species of Noctilio have appressed hair scales, Artibeus 
jamaicensis and Furipterus horrens have divergent scales, and Saccopteryx bilineata and both species of Macrotus have divaricate scales (Benedict, 1957). Data were not available for Koopmanycteris, Speonycteris, Pteronotus pristinus, or Mystacina robusta for this character, which corresponds to character 110 of Simmons and Conway (2001). We followed those authors in treading this as an ordered character.

Character 133: Plagiopatagium attaches to the side of the body, dorsal fur exposed on back between right and left wing membranes (0); or plagiopatagium attaches at the middorsal line, right and left membranes meet over spine and cover dorsal fur entirely (1). The plagiopatagium, which makes up most of the wing membrane, extends between the body and the fifth digit of the hand. The medial attachment of the plagiopatagium is on the side of the body in most bats, with dorsal fur exposed on the back between the right and left membranes. This condition is seen in Pteronotus macleayii, $P$. quadridens, members of the $P$. parnellii and $P$. personatus complexes, and both species of Mormoops. In contrast, the plagiopatagium attaches at the middorsal line in the Pteronotus davyi complex and P. gymnonotus. The right and left membranes in these species meet over the spine and cover the dorsal fur, which is present but not visible in dorsal view. This arrangement gives these bats a "nakedbacked" appearance. The plagiopatagium attaches on the side of the body in all of the outgroups. Data were not available for Koopmanycteris, Speonycteris, or Pteronotus pristinus for this character, which corresponds to character 111 of Simmons and Conway (2001).

CHARACTER 134: Wings folded by flexing proximal phalanx of digits III and IV posteriorly (toward dorsal surface of wing), distal phalanges folded anteriorly (toward underside of wing) (0); or distal phalanges of digits III and IV folded anteriorly, proximal phalanges not folded (1); or all phalanges in digits III, IV, and V folded anteriorly toward the underside of the wing (2). Bats at rest fold their wings in a number of different ways that are constrained by anatomy of the joints in the hand and fingers. All extant mormoopids fold their wings by flexing all phalanges in digits III, IV, and V anteriorly toward the underside of the wing. A similar pattern is seen in Thyroptera tricolor, Furipterus horrens, both species of Macrotus, and Artibeus jamaicensis. In contrast, both species of Noctilio fold their wings by flexing the distal phalanges of digits III and IV anteriorly without folding the proximal phalanges of those digits. A third pattern is seen in both species of Mystacina and Saccopteryx bilineata, which flex the proximal phalanx of digits III and IV posteriorly while folding the distal phalanges anteriorly. Data were not available for Koopmanycteris, Speonycteris, or Pteronotus pristinus for this character, which corresponds to character 153 of Simmons and Geisler (1998) and character 112 of Simmons and Conway (2001).This character was treated as unordered.

ChARACter 135: Antebrachial wing sac absent (0); or present (1). All extant mormoopids and most of the outgroups lack an antebrachial wing sac. In contrast, Saccopteryx bilineata is characterized by presence of an antebrachial wing sac. This structure, which is larger in males than in females, is located in the propatagium anterior to the elbow. Data were not available for Koopmanycteris, Speonycteris, or Pteronotus pristinus for this character, which corresponds to character 113 of Simmons and Conway (2001).

CHARACTER 136: Uropatagium broad (0); or with V-shaped cutout (1); or rudimentary (2). The extent of the uropatagium varies significantly both among and within families of bats (Schutt and Simmons, 1998; Simmons and Conway, 2001). The uropatagium is broad and the trailing edge of the membrane extends between the tips of the calcars (with no notchlike cutout) in all extant mormoopids. A similar condition is seen among the outgroups in Saccopteryx bilineata, Thyroptera tricolor, Furipterus horrens, both species of Noctilio, and both species of Macrotus. In contrast, the uropatagium in Artibeus jamaicensis is less extensive and is characterized by a large, anteriorly directed $\mathrm{V}$-shaped notch in the trailing edge between the calcars. Even more 
extreme reduction in the uropatagium is seen in both species of Mystacina, which have a rudimentary uropatagium that is restricted to narrow strips of membranes along the legs. Data were not available for Koopmanycteris, Speonycteris, or Pteronotus pristinus for this character, which corresponds to character 114 of Simmons and Conway (2001). We followed those authors in treating this as an ordered character.

CHARACTER 137: Uropatagium attaches to calcar, plagiopatagium does not (0); or both plagiopatagium and uropatagium attach to calcar (1). In most bats, including all the outgroups in our study, the uropatagium attaches to the calcar while the plagiopatagium attaches directly to the lateral surface of the leg and sometimes the foot. In contrast, both the plagiopatagium and the uropatagium attach to the calcar in all extant species of Pteronotus and Mormoops. Data were not available for Koopmanycteris, Speonycteris, or Pteronotus pristinus for this character, which corresponds to character 115 of Simmons and Conway (2001).

Character 138: Calcar not bound to tibia (0); or caudal half of calcar bound to tibia, calcar restricted to position parallel to tibia (1). Members of the Pteronotus davyi complex, P. gymnonotus, and both species of Mormoops have a calcar that is not bound to the tibia. In contrast, the caudal half of the calcar in members of the $P$. parnellii complex, $P$. macleayii, $P$. quadridens, and members of the $P$. personatus complex is bound to the tibia by connective tissue, thus restricting the possible range of motion of the calcar. All of the outgroups have a calcar that is not bound to the tibia. Data were not available for Koopmanycteris, Speonycteris, or Pteronotus pristinus for this character, which corresponds to character 116 of Simmons and Conway (2001).

\section{Postcranial Skeleton}

Character 139: Ventral processes of sixth cervical vertebra (C6) approximately the same width as those of $\mathrm{C} 2-\mathrm{C5}(0)$; or C6 ventral processes enlarged to twice the width of $\mathrm{C} 2-\mathrm{C} 5$ ven- tral processes (1). The cervical vertebrae of most bats are characterized by a pair of longitudinal, ventrally directed processes located on the centrum (Simmons and Geisler, 1998). The ventral processes of the sixth cervical vertebra (C6) are twice as wide as those of the other cervical vertebrae in all extant mormoopids, both species of Mystacina, Furipterus horrens, and both species of Noctilio. In contrast, the ventral processes of C6 are similar in width to the ventral processes of C2-C5 in Saccopteryx bilineata, both species of Macrotus, and Artibeus jamaicensis. Data were not available for Koopmanycteris, Speonycteris, or Pteronotus pristinus for this character, which corresponds to character 117 of Simmons and Conway (2001).

Character 140: Seventh cervical vertebra (C7) not fused to first thoracic vertebrae (T1) (0); or C7 fused to T1 (1). The centrum, zygapophyses, and transverse processes of the seventh cervical vertebra (C7) are partially to fully fused with those of first thoracic vertebrae (T1) in members of several bat families (Simmons and Geisler, 1998). C7 and T1 are fused in both species of Mormoops. In contrast, there is no evidence of C7/T1 fusion in any extant species of Pteronotus. C7 and T1 are not fused in Saccopteryx bilineata, both species of Noctilio, Mystacina robusta, both species of Macrotus, and Artibeus jamaicensis. C7 and T1 are fused in Thyroptera tricolor and Furipterus horrens. Data were not available for Koopmanycteris, Speonycteris, Pteronotus pristinus, or Mystacina tuberculata for this character, which corresponds to character 78 of Simmons and Geisler (1998) and character 118 of Simmons and Conway (2001).

Character 141: Number of thoracic vertebrae present: 14 (0); or 13 (1); or 12 (2); or 11 (3). All bats have between 11 and 14 thoracic (rib-bearing) vertebrae (Walton and Walton, 1970). Both species of Mormoops have 13 thoracic vertebrae, while all extant species of Pteronotus have only 12 thoracic vertebrae. Among the outgroups, both species of Noctilio have 11 thoracic vertebrae, Saccopteryx bilineata, Thyroptera tricolor, Furipterus horrens, and both species of Macrotus 
have 12 thoracic vertebrae, Mystacina robusta and Artibeus jamaicensis have 13 thoracic vertebrae, and Mystacina tuberculata has 14 thoracic vertebrae. This character was ordered to reflect the presumed progressive sequence of changes in vertebral counts. Data were not available for Koopmanycteris, Speonycteris, or Pteronotus pristinus for this character, which corresponds to character 119 of Simmons and Conway (2001).

Character 142: Neural spines absent from first four thoracic vertebrae (T1-T4) (0); or spines present on T1-T4 (1). Neural spines are absent from the first four thoracic vertebrae (T1-T4) in both species of Mormoops. In contrast, neural spines are present on T1-T4 in all extant species of Pteronotus. Among the outgroups, Artibeus jamaicensis has neural spines on T1-T4, while neural spines are absent from these vertebrae in both species of Macrotus, Saccopteryx bilineata, Thyroptera tricolor, Furipterus horrens, both species of Noctilio, and both species of Mystacina. Data were not available for Koopmanycteris, Speonycteris, or Pteronotus pristinus for this character, which corresponds to character 120 of Simmons and Conway (2001).

Character 143: Height of neural spines decreases from T1-T4 (0); or neural spines on T1T4 of equal height (1). The relative height of the neural spines on $\mathrm{T} 1-\mathrm{T} 4$ varies among bats in which these spines are present. The height of the neural spines progressively decreases from $\mathrm{T} 1$ through T4 in Pteronotus macleayii, P. quadridens, $P$. gymnonotus, and members of the $P$. davyi, and $P$. personatus complexes. In contrast, the neural spines on T1-T4 are of equal height in the P. parnellii complex. Among the outgroups, the height of the neural spines decreases from $\mathrm{T} 1$ through $\mathrm{T} 4$ in Artibeus jamaicensis. The remaining outgroups, which lack neural spines on T1-T4 (see char. 120), were scored "-" for this character. Data were not available for Koopmanycteris, Speonycteris, Pteronotus pristinus, or Mystacina tuberculata for this character, which corresponds to character 121 of Simmons and Conway (2001).

CHARACTER 144: Ridges on ventral surface of T4 absent (0); or two parallel ridges present on ventral surface of T4 (1). A pair of parallel ridges are present on the ventral surface of $\mathrm{T} 4$ in all extant mormoopids. A similar condition is seen in Macrotus californicus and Mystacina robusta. In contrast, these ridges are absent in Macrotus waterhousii, Artibeus jamaicensis, both species of Noctilio, Thyroptera tricolor, Furipterus horrens, and Saccopteryx bilineata. Data were not available for Koopmanycteris, Speonycteris, Pteronotus pristinus, or Mystacina tuberculata for this character, which corresponds to character 122 of Simmons and Conway (2001).

CHARACTER 145: Neural spines absent from posterior thoracic vertebrae (T8 and above) (0); or spines present on posterior thoracic vertebrae (1). Neural spines are absent from the posterior thoracic vertebrae (T8 and above) in the Pteronotus personatus complex, $P$. quadridens, and both species of Mormoops. In contrast, neural spines are present on the posterior thoracic vertebrae in members of the Pteronotus parnellii complex, $P$. macleayii, $P$. gymnonotus, and members of the $P$. davyi complex. Among the outgroups, neural spines are present on the posterior thoracic vertebrae in Artibeus jamaicensis, Thyroptera tricolor, and both species of Mystacina. Neural spines are absent from the posterior thoracic vertebrae in both species of Macrotus, Saccopteryx bilineata, Furipterus horrens, and both species of Noctilio. Data were not available for Koopmanycteris, Speonycteris, or Pteronotus pristinus for this character, which corresponds to character 123 of Simmons and Conway (2001).

Character 146: No fusion between posterior thoracic and anterior lumbar vertebrae (0); or two posteriormost thoracic vertebrae and two anteriormost lumbar vertebrae fused (1); or three posteriormost thoracic vertebrae and three to five lumbar vertebrae fused (2). Vertebral fusion is absent in the lower back of most bats. However, the last two thoracic and first two lumbar vertebrae are fused together in all extant mormoopids. Even more extensive fusion is seen in Furipterus horrens, where the last three thoracic and three to five lumbar vertebrae are fused. The remaining outgroups show no evidence of thoracic-lumbar fusion. This 
character was ordered to reflect the presumed progressive sequence of increasing vertebral fusion. Data were not available for Koopmanycteris, Speonycteris, Pteronotus pristinus, or Mystacina tuberculata for this character, which corresponds to character 124 of Simmons and Conway (2001) and represents an expanded version of character 158 of Simmons and Geisler (1998). We treated this as an ordered character.

CHARACTER 147: Ridges on ventral surface of third lumbar vertebra (L3) absent (0); or two parallel ridges present on ventral surface of $L 3$ (1). The third lumbar vertebra (L3) lacks ridges on its ventral surface in Mormoops megalophylla. In contrast, $M$. blainvillei and all extant species of Pteronotus have two parallel ridges present in this location. Among the outgroups, Saccopteryx bilineata, Thyroptera tricolor, Furipterus horrens, Mystacina robusta, and Artibeus jamaicensis have similar ventral ridges on L3, but both species of Macrotus and both species of Noctilio lack these ridges. Data were not available for Koopmanycteris, Speonycteris, Pteronotus pristinus, or Mystacina tuberculata for this character, which corresponds to character 125 of Simmons and Conway (2001).

CHARACTER 148: Ridges on ventral surface of fourth and fifth lumbar vertebra (L4 and L5) absent (0); or two parallel ridges present on ventral surface of both L4 and L5 (1). The fourth and fifth lumbar vertebrae (L4 and L5) lack ridges on the ventral surface in both species of Mormoops. In contrast, all extant species of Pteronotus have two parallel ventral ridges on the ventral surface of both L4 and L5. Among the outgroups, paired ventral ridges are present on L4 and L5 in Artibeus jamaicensis, both species of Macrotus, Thyroptera tricolor, Furipterus horrens, and Mystacina robusta, but are absent in Saccopteryx bilineata and both species of Noctilio. Data were not available for Koopmanycteris, Speonycteris, Pteronotus pristinus, or Mystacina tuberculata for this character, which corresponds to character 126 of Simmons and Conway (2001).

Character 149: Anterior face of manubrium small (0); or broad, defined by elevated ridges (1).
The anterior face of the manubrium of the sternum is the site of origin for the anterior division of $\mathrm{m}$. pectoralis (Vaughan, 1959, 1970a; Strickler, 1978; Hermanson and Altenbach, 1983, 1985). The anterior face of the manubrium is relatively small and poorly defined in all extant mormoopids. A similar condition is seen in both species of Macrotus, both species of Noctilio, Mystacina tuberculata, Thyroptera tricolor, Furipterus horrens, and Saccopteryx bilineata. In contrast, the anterior face of the manubrium is a broad, triangular surface that extends onto the lateral processes and is defined by three elevated ridges in Artibeus jamaicensis and Mystacina robusta. Data were not available for Koopmanycteris, Speonycteris, Pteronotus pristinus, or Mystacina tuberculata for this character, which corresponds to character 90 of Simmons and Geisler (1998) and character 127 of Simmons and Conway (2001).

Character 150: Angle between axis of ventral process of manubrium and body of manubrium approximately $90^{\circ}(0)$; or greater than $90^{\circ}(1)$. The ventral process is a bony projection from the midline of the manubrium that provides an attachment point for a series of ligamentous sheets that together with the ventral process form the origin for the $\mathrm{m}$. pectoralis complex (Vaughan, 1959, 1970a; Strickler, 1975; Hermanson and Altenbach, 1983, 1985). The angle between the axis of the ventral process (defined as the long axis of the thickened base and central body of the process) and the body of the manubrium varies among bats (Simmons and Geisler, 1998). All extant species of Pteronotus have an angle of more than $90^{\circ}$ between the axis of ventral process and the body of the manubrium. As a result, the ventral process appears to project anteroventrally in these species. In contrast, the angle between the axis of the ventral process and the body of the manubrium is approximately $90^{\circ}$ and the ventral process projects ventrally in both species of Mormoops. Among the outgroups, the angle between the axis of the ventral process and the body of the manubrium is approximately $90^{\circ}$ in Saccopteryx bilineata, Thyroptera tricolor, both species of Macrotus, and Artibeus jamaicensis, 
but this angle is greater than $90^{\circ}$ in both species of Noctilio, Furipterus horrens, and both species of Mystacina. Data were not available for Koopmanycteris, Speonycteris, or Pteronotus pristinus for this character, which corresponds to character 92 of Simmons and Geisler (1998) and character 128 of Simmons and Conway (2001).

Character 151: Distal tip of ventral process of manubrium laterally compressed, keellike (0); or blunt and rounded (1). The distal tip of the ventral process of the manubrium is laterally compressed and keellike in all extant mormoopids. Among the outgroups, a laterally compressed, keellike ventral process is also seen in Artibeus jamaicensis, both species of Macrotus, Thyroptera tricolor, Furipterus horrens, both species of Noctilio, and Saccopteryx bilineata. In contrast, the distal tip of the ventral process is blunt and rounded in both species of Mystacina. Data were not available for Koopmanycteris, Speonycteris, or Pteronotus pristinus for this character, which corresponds to character 91 of Simmons and Geisler (1998) and character 129 of Simmons and Conway (2001).

Character 152: Length of manubrium approximately equal to maximum width (0); or less than maximum width (1). The length of the manubrium posterior to the lateral processes is less than the transverse width of this portion of the manubrium in all extant mormoopids. A similar condition is seen in both species of Mystacina, Thyroptera tricolor, Furipterus horrens, both species of Noctilio, Artibeus jamaicensis, and both species of Macrotus. In contrast, the length of the manubrium posterior to the lateral processes is approximately equal to its width in Saccopteryx bilineata. Data were not available for Koopmanycteris, Speonycteris, or Pteronotus pristinus for this character, which corresponds to character 93 of Simmons and Geisler (1998) and character 130 of Simmons and Conway (2001).

Character 153: Mesosternum with medial keel low or absent (0); or with high keel (1). The mesosternum has a low median keel, or lacks the keel altogether, in all extant species of Pteronotus and Mormoops. A similar condition is seen in
Artibeus jamaicensis, both species of Mystacina, Thyroptera tricolor, Furipterus horrens, both species of Noctilio, and Saccopteryx bilineata. In contrast, a high keel (maximum keel height greater than the width of mesosternum) is present in both species of Macrotus. Data were not available for Koopmanycteris, Speonycteris, or Pteronotus pristinus for this character, which corresponds to character 131 of Simmons and Conway (2001).

Character 154: Xiphisternum with prominent median keel (0); or without keel (1). The xiphisternum has a prominent median keel in all extant species of Pteronotus and Mormoops. Among the outgroups, this condition is also seen in Thyroptera tricolor, Furipterus horrens, both species of Mystacina, and Saccopteryx bilineata. In contrast, the xiphisternum lacks a keel in both species of Noctilio, both species of Macrotus, and Artibeus jamaicensis. Data were not available for Koopmanycteris, Speonycteris, or Pteronotus pristinus for this character, which corresponds to character 95 of Simmons and Geisler (1998) and character 132 of Simmons and Conway (2001).

CHARACTER 155: Second costal cartilage articulates with sternum at manubrium-mesosternum joint (0); or second rib articulates with manubrium only (1). The second costal cartilage articulates with the sternum at the manubrium-mesosternum joint in all extant species of Pteronotus and Mormoops. A similar condition is seen among the outgroups in Saccopteryx bilineata, Thyroptera tricolor, Furipterus horrens, and Mystacina robusta. In contrast, the second rib articulates with the manubrium and there is no contact between the rib (or costal cartilage) and the mesosternum in Artibeus jamaicensis, both species of Macrotus, Mystacina robusta, and both species of Noctilio. Data were not available for Koopmanycteris, Speonycteris, or Pteronotus pristinus for this character, which corresponds to character 83 of Simmons and Geisler and character 133 of Simmons and Conway (2001).

Character 156: Mesosternum articulates with six costal cartilages posterior to second rib (0); or with five costal cartilages (1); or with four 
costal cartilages (2). Variable numbers of costal cartilages connect the mesosternum with the bony ribs in bats (Simmons and Geisler, 1998). On each side of the body, the mesosternum articulates with six costal cartilages posterior to the second rib in all extant species of Pteronotus and Mormoops. A similar condition is seen in Mystacina tuberculata and both species of Macrotus. In contrast, the mesosternum articulates with five costal cartilages posterior to the second rib in Artibeus jamaicensis, both species of Noctilio, Mystacina robusta, and Saccopteryx bilineata. Thyroptera tricolor and Furipterus horrens exhibit even greater reduction, with the mesosternum articulating with only four costal cartilages posterior to the second rib. This character was ordered to reflect the presumed progressive sequence of changes in the number of costal cartilages that articulate with the mesosternum. Data were not available for Koopmanycteris, Speonycteris, or Pteronotus pristinus for this character, which corresponds to character 134 of Simmons and Conway (2001) and is an expanded version of character 85 of Simmons and Geisler (1998). We treated this as an ordered character.

CHARACTER 157: Ribs with no anterior laminae (0); or narrow anterior laminae present (1); or wide anterior laminae present (2). Anterior laminae are thin plates of bone that run along the leading edges of ribs anterior to the main body of the rib (Simmons and Geisler, 1998). These structures, which are often nearly transparent, appear to provide an increased area for muscle attachment (Simmons and Geisler, 1998). The anterior laminae are relatively narrow (lamina width less than that of the main body of the rib) in Pteronotus macleayii, $P$. quadridens, members of the $P$. personatus and $P$. davyi complexes, $P$. gymnonotus, and Mormoops blainvillei. In contrast, the anterior laminae are relatively wide (lamina width equal to or greater than that of the main body of the rib) in the Pteronotus parnellii complex and Mormoops megalophylla. Among the outgroups, wide anterior laminae are seen in Thyroptera tricolor, Furipterus horrens, and both species of Noctilio.
Narrow laminae occur in Saccopteryx bilineata, and anterior laminae are entirely absent in both species of Mystacina, both species of Macrotus, and Artibeus jamaicensis. Data were not available for Koopmanycteris, Speonycteris, or Pteronotus pristinus for this character, which corresponds to characters 86 and 87 of Simmons and Geisler (1998) and character 135 of Simmons and Conway (2001). We followed the latter authors in treating this as an ordered character.

ChARACTER 158: Ribs with no posterior laminae (0); or narrow posterior laminae present (1); or wide posterior laminae present (2). Posterior laminae are thin plates of bone that run along the trailing edges of ribs posterior to the main body of the rib (Simmons and Geisler, 1998). Wide posterior laminae (lamina width equal to or greater than that of the main body of the rib) are seen in all extant species of Pteronotus and Mormoops megalophylla. In contrast, the posterior laminae are relatively narrow (lamina width less than that of the main body of the rib) in Mormoops blainvillei. Narrow posterior laminae are present among the outgroups in Saccopteryx bilineata, Mystacina tuberculata, both species of Noctilio, Artibeus jamaicensis, and both species of Macrotus. Wide posterior laminae occur in Thyroptera tricolor and Furipterus horrens. The posterior laminae are entirely absent in $M y s-$ tacina robusta. Data were not available for Koopmanycteris, Speonycteris, or Pteronotus pristinus for this character, which corresponds to characters 88 and 89 of Simmons and Geisler (1998) and character 136 of Simmons and Conway (2001). We followed the latter authors in treating this as an ordered character.

Character 159: Distal clavicle articulates with or lies in contact with coracoid process (0); or clavicle suspended by ligaments between acromion and coracoid processes of scapula (1). The distal (dorsolateral) clavicle articulates with the scapula in the region between the tip of the acromion process and the base of the coracoid process. The articulation can be accomplished in several ways, depending on whether the clavicle is associated principally with the acromion, principally with 
the coracoid, or is suspended between these two processes by a series of ligaments (Strickler, 1978; Simmons and Geisler, 1998). The clavicle articulates with or lies in contact with the coracoid process in all extant species of Pteronotus and Mormoops. A similar condition is seen among the outgroups in Saccopteryx bilineata, both species of Macrotus, and Artibeus jamaicensis. In contrast, the clavicle is suspended by ligaments between the acromion and coracoid processes in both species of Noctilio and Mystacina robusta. Data were not available for Koopmanycteris, Speonycteris, Pteronotus pristinus, or Mystacina tuberculata for this character, which corresponds to character 113 of Simmons and Geisler (1998), character 74 of Wetterer et al. (2000), and character 137 of Simmons and Conway (2001).

Character 160: Pit for attachment of clavicular ligament absent from scapula (0); or present anterior and medial to glenoid fossa (1). The clavicular ligament extends between the base of the coracoid process and the clavicle (Strickler, 1978). A distinct pit for the attachment of the clavicular ligament is present anterior and medial to the glenoid fossa in all extant species of Pteronotus and Mormoops. In contrast, there is no evidence of a pit for attachment of the clavicular ligament in any of the outgroups. Data were not available for Koopmanycteris, Speonycteris, or Pteronotus pristinus for this character, which corresponds to character 107 of Simmons and Geisler (1998) and character 138 of Simmons and Conway (2001).

Character 161: Coracoid process elongate, tip approximately the same width as the shaft (0); or coracoid process elongate, tip distinctly flared (1); or coracoid process reduced to a small triangular process (2). The coracoid process of the scapula in most bats is an elongate bar of bone with a distinct shaft and tip (Simmons and Geisler, 1998). The tip of the coracoid process is blunt and approximately the same width as the shaft of the coracoid in both species of Mormoops. In contrast, the tip of the coracoid process is distinctly flared (wider than the shaft) in all extant species of Pteronotus. Among the outgroups, Thyroptera tricolor, Artibeus jamaicensis, and both species of Macrotus have a coracoid process with a flared tip, while the tip of the coracoid in Saccopteryx bilineata, Furipterus horrens, and both species of Noctilio is not flared. In contrast to these conditions (all of which involve a relatively elongate coracoid), the coracoid process of both species of Mystacina is reduced to a small triangular process that lacks a definable shaft. Data were not available for Koopmanycteris, Speonycteris, or Pteronotus pristinus for this character, which corresponds to character 139 of Simmons and Conway (2001) and is modified from characters 109 and 111 of Simmons and Geisler (1998). We treated this as an unordered character.

Character 162: Distal acromion process without anteromedial projection (0); or with triangular anteromedial projection that does not contact rim of scapula (1); with elongate projection that extends anteriorly and medially to fuse with anteromedial rim of scapula (2). A triangular anteromedial projection is present just ventral and medial to the tip of the acromion process of the scapula in all extant species of Pteronotus and Mormoops. This projection is directed toward (but does not contact) the anteromedial rim of the scapula. Among the outgroups, a similar process is present in Thyroptera tricolor, Furipterus horrens, and both species of Noctilio. A different condition is seen in both species of Mystacina, which have a very long anterior projection that extends anteriorly and medially to contact and fuse with the anteromedial rim of the scapula medial to the suprascapular notch. The resulting bar of bone forms a complete bridge over the supraspinous fossa. A secondary sutural contact is also present between the lateral surface of the bony bridge and the tip of the suprascapular process, enclosing the suprascapular notch to form a small canal. In contrast, the distal acromion process lacks an anterior projection entirely in Saccopteryx bilineata, Artibeus jamaicensis, and both species of Macrotus. Data were not available for Koopmanycteris, Speonycteris, or Pteronotus 
pristinus for this character, which corresponds to character 140 of Simmons and Conway (2001) and represents an expanded version character 98 of Simmons and Geisler (1998). We followed Simmons and Conway (2001) in treating this as an ordered character.

Character 163: Distal acromion process without posterolateral projection (0); or with triangular posterolateral projection (1). A triangular projection from the distal acromion process is present in members of the Pteronotus davyi complex and P. gymnonotus. In contrast, this process is absent in the Pteronotus personatus complex, $P$. quadridens, $P$. macleayii, members of the $P$. parnellii complex, and both species of Mormoops. Among the outgroups, a posterolateral projection is present in both species of Noctilio, but this projection is absent in Saccopteryx bilineata, Thyroptera tricolor, Furipterus horrens, both species of Mystacina, both species of Macrotus, and Artibeus jamaicensis. Data were not available for Koopmanycteris, Speonycteris, or Pteronotus pristinus for this character, which corresponds to character 99 of Simmons and Geisler (1998) and character 141 of Simmons and Conway (2001).

CHARACTER 164: Suprascapular process absent (0); or present (1). The suprascapular process is a projection that extends medially and somewhat anteriorly from the anterolateral border of the suprascapular notch at the base of the coracoid process, just medial to the anterior edge of the glenoid fossa and just anterior to the pit for the clavicular ligament (in those forms that have this pit; Simmons and Geisler, 1998). A suprascapular process is present in all extant species of Pteronotus and Mormoops. Among the outgroups, this process is similarly present in both species of Mystacina and both species of Noctilio. In contrast, the suprascapular process is absent in Saccopteryx bilineata, Thyroptera tricolor, Furipterus horrens, Artibeus jamaicensis, and both species of Macrotus. Data were not available for Koopmanycteris, Speonycteris, or Pteronotus pristinus for this character, which corresponds to character 112 of Simmons and Geisler (1998) and character 142 of Simmons and Conway (2001).
Character 165: Dorsal articular facet on scapula absent (0); or dorsal articular facet faces dorsolaterally, consists of a small groove on the anteromedial rim of the glenoid fossa (1); or faces dorsolaterally, consists of oval facet on anteromedial rim of glenoid fossa (2); or faces dorsally, consists of a large, flat facet clearly separated from the glenoid fossa (3). A secondary articulation between the humerus and scapula occurs in many bats when the humerus is abducted and the trochiter (= greater tuberosity) contacts a dorsal articular facet on the scapula (Vaughan, 1959, 1970b; Hill, 1974; Strickler, 1978; Altenbach and Hermanson, 1987; Schlosser-Strum and Schliemann, 1995; Simmons and Geisler, 1998). The dorsal articular facet faces dorsolaterally and consists of an oval facet on the anteromedial rim of the glenoid fossa in all extant mormoopids. The same condition is seen in Thyroptera tricolor, Furipterus horrens, Artibeus jamaicensis and both species of Macrotus. Dorsal articular facet in Saccopteryx bilineata also faces dorsolaterally, but consists of a small groove on the anteromedial rim of the glenoid fossa. In contrast, the dorsal articular facet faces dorsally and consists of a large, flat facet clearly separated from the glenoid fossa in both species of Mystacina. Both species of Noctilio lack a dorsal articular facet. Data were not available for Koopmanycteris, Speonycteris, or Pteronotus pristinus for this character, which corresponds to characters 100 and 101 of Simmons and Geisler (1998) and character 143 of Simmons and Conway (2001). We treated this as an unordered character.

CHARACTER 166: Infraspinous fossa of scapula wide, maximum width greater than $50 \%$ of maximum length (0); or infraspinous fossa narrow, maximum width less than or equal to $50 \%$ of maximum length (1). The infraspinous fossa, located on the dorsal aspect of the scapula posterolateral to the scapular spine, is the site of origin for $\mathrm{m}$. infraspinatus and $\mathrm{m}$. teres major, muscles that act to flex, rotate, and (in the case of $\mathrm{m}$. infraspinatus) abduct the humerus (Vaughan, 1959, 1970a; Nor- 
berg, 1970; Strickler, 1978; Hermanson and Altenbach, 1983, 1985). The infraspinous fossa is relatively wide in Mormoops blainvillei and all extant species of Pteronotus. In these taxa, the maximum width of the fossa is greater than $50 \%$ of its maximum length. In contrast, $M$. megalophylla has an infraspinous fossa that is relatively narrow, with maximum width less than $50 \%$ of length. Among the outgroups, a wide infraspinous fossa is seen in Saccopteryx bilineata, Furipterus horrens, Mystacina robusta, both species of Noctilio, and Artibeus jamaicensis. Both species of Macrotus and Thyroptera tricolor have a narrow infraspinous fossa. Data were not available for Koopmanycteris, Speonycteris, Pteronotus pristinus, or Mystacina tuberculata for this character, which corresponds to character 102 of Simmons and Geisler (1998) and character 144 of Simmons and Conway (2001).

ChARACTER 167: Intermediate infraspinous facet narrower than posterolateral facet $(0)$; or facets subequal (1). The infraspinous fossa of the scapula has three facets in all the taxa in our study: an anteromedial facet (located adjacent to the spine of the scapula), an intermediate facet, and a posterolateral facet (adjacent to the axillary border of the scapula). The intermediate infraspinous facet is narrower than the posterolateral facet in the Pteronotus personatus complex and Mormoops megalophylla. In contrast, these facets are subequal in members of the Pteronotus parnellii complex, $P$. macleayii, $P$. quadridens, members of the $P$. davyi complex, $P$. gymnonotus, and Mormoops blainvillei. A similar condition is seen in Saccopteryx bilineata. The intermediate facet is narrower than the posterolateral facet in Thyroptera tricolor, Furipterus horrens, both species of Noctilio, both species of Mystacina, Artibeus jamaicensis, and both species of Macrotus. Data were not available for Koopmanycteris, Speonycteris, or Pteronotus pristinus for this character, which corresponds to character 104 of Simmons and Geisler (1998) and character 145 of Simmons and Conway (2001).

Character 168: Axillary border of scapula flat, level within dorsoventral plane (0); or axil- lary border curved in dorsoventral plane, concave ventrally (1). The axillary border of the scapula is that edge that faces the axilla or armpit. The axillary border of the scapula is flat and lies level within the dorsoventral plane in all extant species of Pteronotus. In contrast, both species of Mormoops have a scapula with a curved axillary border that is concave ventrally. All the outgroups have a scapula with a flat axillary border that is level within the dorsoventral plane. Data were not available for Koopmanycteris, Speonycteris, Pteronotus pristinus, or Mystacina tuberculata for this character, which corresponds to character 146 of Simmons and Conway (2001).

CHARACTER 169: Anterior portion of axillary border of scapula rounded (0); or flattened (1). The anterior portion of the axillary border of the scapula is flattened to form a sharp edge in both species of Mormoops and all extant species of Pteronotus. The anterior portion is similarly flattened in both species of Macrotus. In contrast, the anterior portion is rounded with no definitive sharp edge in Artibeus jamaicensis, both species of Noctilio, Thyroptera tricolor, Furipterus horrens, Mystacina robusta, and Saccopteryx bilineata. Data were not available for Koopmanycteris, Speonycteris, Pteronotus pristinus, or Mystacina tuberculata for this character, which corresponds to character 147 of Simmons and Conway (2001).

ChARACTER 170: Head of humerus round (0); or symmetrically oval or elliptical (1); or oval but flattened transversely and narrowed to a pointed process proximally (2). The shape of the head of the humerus varies among bats and among mormoopids. In all species it is globular medially, but the outline of the head varies significantly. The humeral head is oval in shape in Koopmanycteris but is somewhat flattened transversely, especially its proximalmost portion, which is narrowed to form a pointed process proximally. The head of the humerus is similarly shaped and slightly more transversely flattened in both species of Mormoops. In contrast, the head of the humerus is a symmetrically oval or elliptical in the extant 
species of Pteronotus, having a more rounded aspect than in Koopmanycteris or Mormoops. It shows no evidence of lateral flattening, and the proximalmost extremity of the head in Pteronotus is gently rounded, not flattened and sharply pointed as in the other two genera of mormoopids. Among the outgroups, the humeral head is flattened transversely and narrowed to a pointed process proximally in Saccopteryx bilineata, Thyroptera tricolor, and both species of Noctilio. In contrast, both species of Mystacina, Artibeus jamaicensis, both species of Macrotus, and Furipterus horrens have a humeral head that is rounded and more spherical, not oval or flattened. Data were not available for Speonycteris and Pteronotus pristinus for this character, which corresponds to a modified version of character 140 of Simmons and Geisler (1998) and character 148 of Simmons and Conway (2001). We treated this as an unordered character.

ChARACTER 171: Humeral head angled toward lesser tuberosity (0); or head not obviously oriented toward either greater or lesser tuberosity (1); or head angled toward greater tuberosity (2). Differences in orientation of the humeral head are apparent among taxa in which the humeral head is oval or flattened, so that there is an obvious long axis to the head. The humeral head is strongly angled or canted in the direction of the lesser tuberosity in Koopmanycteris and both species of Mormoops. In contrast, the humeral head in Pteronotus angles noticeably toward the greater tuberosity, opposite the orientation of the head in Koopmanycteris and Mormoops. Among the outgroups, the humeral head in both species of Noctilio is angled toward the lesser tuberosity, while in Saccopteryx bilineata and Thyroptera tricolor the head is not obviously oriented in either the direction of the greater tuberosity or lesser tuberosity, instead falling somewhere in between. Those taxa with a rounded humeral head (both species of Mystacina, Furipterus horrens, Artibeus jamaicensis, and Macrotus) were scored "_" for this character. We chose to treat this as an unordered character because of the variation in humeral head shape among taxa in our study (see character 166). Data were not available for Speonycteris and Pteronotus pristinus for this character. This is a new character not employed in Simmons and Conway (2001).

Character 172: Humeral head separated from greater tuberosity by distinct groove or notch $(0)$; or head not well separated from greater tuberosity, notch or groove absent (1). The head of the humerus is separated from the greater tuberosity by a distinct notch in Koopmanycteris and both species of Mormoops. In contrast, there is no groove or notch, and the head is not well separated from the greater tuberosity in the extant species of Pteronotus. While examination of mormoopids only might suggest that this feature is correlated with the shape and orientation of the head of the humerus, this does not seem to be the case in bats more generally. All the outgroup taxa have a groove or notch between the humeral head and greater tuberosity. Data were not available for Speonycteris or Pteronotus pristinus for this character. This is a new character not employed in Simmons and Conway (2001).

CHARACTER 173: Greater tuberosity of humerus extends proximally just to the level of the proximal edge of the humeral head (0); or extends proximally well beyond the level of the head (1). The greater tuberosity (= trochiter) of the humerus in bats extends varying distances proximally relative to the head of the humerus (Simmons and Geisler, 1998). The greater tuberosity extends proximally just to the level of the proximal edge of the head in Koopmanycteris and all extant species of Pteronotus and Mormoops. Among the outgroups, a similar condition is seen in Saccopteryx bilineata and both species of Noctilio. In contrast, the greater tuberosity extends proximally well beyond the level of the humeral head in Thyroptera tricolor, Furipterus horrens, both species of Mystacina, Macrotus waterhousii, and Artibeus jamaicensis. Data were not available for Speonycteris, Pteronotus pristinus, and Macrotus californicus for this character, which corresponds to character 139 of Simmons and Geisler (1998) and character 149 of Simmons and Conway (2001). 
CHARACTER 174: Greater tuberosity of humerus with lateral surface lacking a groove (0); or groove present (1). Mormoops possesses a rather deep groove on the lateral surface of the greater tuberosity on the proximal humerus. This groove is present but somewhat less well developed (more shallow) in Koopmanycteris. In contrast, extant species of Pteronotus and all the outgroup taxa lack a groove on the lateral surface of the greater tuberosity. Data were not available for Speonycteris or Pteronotus pristinus for this character, which is a new character not employed by Simmons and Conway (2001).

CHARACTER 175: Lesser tuberosity of humerus lacking concavity on proximal edge (0); or with distinct elliptically shaped concavity present (1). At its posteriormost extremity, the proximal edge of the lesser tuberosity bears a distinct elliptical concavity or pit in extant species of Pteronotus. In contrast, the proximal edge of the lesser tuberosity forms a high, sharp ridge in Koopmanycteris and Mormoops and there is no trace of a concavity. A concavity is similarly absent in the outgroup taxa. Data were not available for Speonycteris or Pteronotus pristinus for this character, which is a new character not employed by Simmons and Conway (2001).

Character 176: Proximal humerus with a broad, continuous flange extending distally from lesser tuberosity along medial edge of shaft (0); or flange continuous and narrow (1); or flange reduced and represented by a tuberosity at distal extremity (2); or flange very poorly developed or absent (3). The entire proximal end of the humerus of extant species of Pteronotus appears to be wider than that of the other mormoopids due to the presence of a broad flange of bone that runs distally from the lesser tuberosity along the medial edge of the shaft. This flange extends along about $20 \%$ of the total length of the humeral shaft. A flange is not developed similarly in Mormoops, which instead has an elevated ridge or tuberosity at the distal extremity of the lesser tuberosity. The proximal humeri of Koopmanycteris show some variation in this character. On the paratype humerus there is little evidence of a flange, whereas a referred proximal humerus has a narrow but continuous flange in this position. The outgroup taxa vary widely in this character. Mystacina robusta and Furipterus horrens have a broad flange similar to that of Pteronotus; Macrotus waterhousii, Thyroptera tricolor, Noctilio albiventris, and Mystacina tuberculata have a narrow but continuous flange; and Noctilio leporinus and Saccopteryx bilineata lack the flange. Data were not available for Speonycteris, Pteronotus pristinus, and Macrotus californicus for this character, which is a new character not employed by Simmons and Conway (2001). We treated this as an unordered character.

Character 177: Pectoral ridge on proximal humerus short and narrow (0); or long and broad (1); or short and broad (2). In Koopmanycteris and both species Mormoops, the pectoral ridge on the proximal humerus is rather short and narrow, and its anterior edge is essentially parallel to the shaft. The pectoral ridge is comparatively longer and broader in extant species of Pteronotus. The anterior edge of the pectoral ridge is not parallel to the humeral shaft, but the ridge itself is much broader proximally. The pectoral ridge in both species of Macrotus, Artibeus jamaicensis, Noctilio albiventris, and Thyroptera tricolor is short and narrow, similar to Mormoops, whereas the pectoral ridge in both species of Mystacina and Noctilio leporinus is long and broad, especially proximally, like Pteronotus. The pectoral ridge in Furipterus horrens and Saccopteryx bilineata is short but comparatively broad, unlike the condition in any mormoopid. Data were not available for Speonycteris and Pteronotus pristinus for this character, which is a new character not employed by Simmons and Conway (2001). We treated this feature as unordered in our analyses.

Character 178: Humerus with distal articular facets in line with shaft, not displaced laterally (0); or articular facets displaced laterally from line of shaft (1). The articular facets of the distal humerus include the trochlea, capitulum, and lateral surface of the capitulum, which together typically form a spool-shaped structure (Vaughan 
and Bateman, 1970; Smith, 1972). This structural unit lies in line with the shaft of the humerus in both species of Mormoops. The medial edge of the trochlea minimally lies in line with the medial surface of the humeral shaft and may extend medially beyond this level. In contrast, the distal articular facet complex is laterally displaced from the line of the humeral shaft in Koopmanycteris and all extant species of Pteronotus. In these forms, the edge of the trochlea does not extend medially as far as the medial surface of the humeral shaft. Among the outgroups, the distal articular facets are in line with the shaft in Saccopteryx bilineata, both species of Noctilio, and both species of Mystacina. These facets are displaced laterally in Thyroptera tricolor, Furipterus horrens, Artibeus jamaicensis and both species of Macrotus. Data were not available for Speonycteris and Pteronotus pristinus for this character, which corresponds to character 141 of Simmons and Geisler (1998) and character 150 of Simmons and Conway (2001).

CHARACTER 179: Central surface of capitulum of humerus not reduced, height equal to that of trochlea, groove between capitulum and trochlea narrow and shallow (0); or central surface of the capitulum reduced, height less than that of trochlea, groove between capitulum and trochlea wide and deep (1). The capitulum on the distal end of the humerus is an articular surface comprised of two ridges that typically have a groove between them (though see next character below). The central surface of the capitulum (= medial ridge) is the more medial of the two capitular articular surfaces, lying adjacent to a third articular ridge, the trochlea (Vaughan, 1959; Vaughan and Bateman, 1970; Smith, 1972). The central capitulum surface is the same height as the trochlea in Koopmanycteris and all extant species of Pteronotus. In these forms the groove between the central capitulum is narrow and shallow. In contrast, both species of Mormoops have a reduced central capitulum whose height is considerably less than that of the trochlea, and the groove between the capitulum and trochlea is wide and deep. All of the outgroups have an unreduced central capitu- lum surface that is equal in height to the trochlea and separated from it by a narrow, shallow groove. Data were not available for Speonycteris and Pteronotus pristinus for this character, which corresponds to character 151 of Simmons and Conway (2001).

Character 180: Capitulum with groove present between central surface and lateral ridge (0); or groove absent (1). The capitulum of the humerus is characterized by the presence of a deep groove between the central surface and lateral ridge in all extant species of Pteronotus as well as in all our outgroups. In contrast, a groove is lacking in Koopmanycteris and both species of Mormoops, and the capitulum forms a single articular surface that is not divided into medial and lateral portions. Data were not available for Speonycteris and Pteronotus pristinus for this character, which was not used by Simmons and Conway (2001).

The morphology of the capitulum of the humerus is reflected in the morphology of the proximal radius, which articulates with this structure as well as the trochlea. Most batsincluding all those in our study that have a groove between the central surface and lateral ridge of the capitulum-have a proximal radius with three articular facets. The three facets articulate with the trochlea, the central surface of the capitulum, and the lateral ridge of the capitulum. In contrast, Koopmanycteris and Mormoops, which lack a groove between the central surface and lateral ridge, have a proximal radius with only two facets (one for the trochlea and one for the entire capitulum). Because the facets of the radius are clearly correlated with one another and with the morphology of the distal humerus, we did not treat them as separate characters in our analysis.

Character 181: Distal spinous process of humerus separated from trochlea by a deep notch (0); or process located directly adjacent to trochlea, notch very shallow or absent (1). The distal spinous process of the humerus is a bony projection that extends distally from the medial epicondyle of the humerus (Vaughan and Bateman, 1970; 
Smith, 1972). The distal spinous process is separated from the trochlea by a deep notch in Koopmanycteris and all extant species of Pteronotus. In contrast, this process lies directly adjacent to the trochlea (and the notch is absent) in both species of Mormoops. Among the outgroups, the distal spinous process is separated from the trochlea by a deep notch in Saccopteryx bilineata, Thyroptera tricolor, both species of Noctilio, and both species of Macrotus. Both species of Mystacina and Furipterus horrens have the distal spinous process located adjacent to the trochlea, and the notch is very shallow or absent. Artibeus jamaicensis lacks a distal spinous process (see next character) and hence was scored "_" for this character. Data were not available for Speonycteris or Pteronotus pristinus for this character, which corresponds to character 152 of Simmons and Conway (2001).

Character 182: Height of distal spinous process of humerus greater than height of trochlea (0); or process present but height less than or equal to height of trochlea (1); or process absent (2). The height of the distal spinous process of the humerus (measured along the long axis of the spinous process, which runs roughly parallel to the long axis of the humeral shaft) is greater than the height of the trochlea in Koopmanycteris and all extant mormoopids. A similar condition is seen in Furipterus horrens and both species of Mystacina. In contrast, the distal spinous process is present, but its height is less than or equal to the height of the trochlea in both species of Macrotus, both species of Noctilio, Thyroptera tricolor, and Saccopteryx bilineata. Artibeus jamaicensis lacks a distal spinous process altogether; the distal aspect of the epitrochlea is smoothly rounded and no part of it extends beyond the body of the epitrochlea. Data were not available for Speonycteris or Pteronotus pristinus for this character, which is a modified version of character 153 of Simmons and Conway (2001). We treated this as an ordered character in our analyses.

Character 183: Distal spinous process of humerus oriented vertically and parallel with shaft when seen in medial view (0); or spinous process angled posteriorly (1). In medial view, the distal spinous process is essentially straight and parallel to the humeral shaft in both species of Mormoops and the Pteronotus parnellii complex. In contrast, the distal spinous process forms a distinct posteriorly oriented angle with the shaft in all other extant species of Pteronotus and in Koopmanycteris. This is especially noticeable in the orientation of the anterior surface of the spinous process, but also affects the posterior aspect of the process, which clearly projects out of the plane of the long axis of the distal shaft. The spinous process is vertical and parallel to the shaft in most of the outgroup taxa, except Saccopteryx bilineata in which this process is oriented posteriorly. The distal spinous process in Thyroptera tricolor is reduced to a small knob that has no discernable axis; accordingly we scored this taxon with "_" for this character. Artibeus jamaicensis, which lacks a distal spinous process, was similarly scored “-." Data were not available for Speonycteris or Pteronotus pristinus for this character, which was not used by Simmons and Conway (2001).

Character 184: Epitrochlea of distal humerus broad (0); or epitrochlea narrow (1). As in most bats, the epitrochlea (= medial epicondyle) on the distal end of the humerus is moderately broad (wider than the trochlea) and rounded in Koopmanycteris and extant species of Pteronotus. In contrast, the epitrochlea is narrow (not as wide as the trochlea) in both species of Mormoops. All the outgroups in our study have a broad trochlea with the exception of both species of Mystacina, which have a narrow epitrochlea similar to that seen in Mormoops. Data were not available for Speonycteris or Pteronotus pristinus for this character, which was not used by Simmons and Conway (2001).

Character 185: Epitrochlea of distal humerus lacking a concavity on its proximomedial corner (0); or with concavity present (1). The epitrochlea has a distinct concavity at its proximomedial corner in Koopmanycteris and in all extant species of Pteronotus except members of the P. parnellii 
complex. The proximomedial corner lacks such a concavity in both species of Mormoops and the Pteronotus parnellii complex. A concavity is absent on the proximomedial corner of the epitrochlea in all our outgroup taxa except both species of Mystacina, which have a well-defined concavity despite having a reduced epitrochlea. Data were not available for Pteronotus pristinus for this character, which was not used by Simmons and Conway (2001).

CHARACTER 186: Ridge or flange on posterolateral surface of distal humeral shaft absent (0); or ridge present (1). In Koopmanycteris there is a distinct ridge or flange located about halfway between the center of the shaft and its lateral edge on the posterior surface of the humeral shaft just proximal to the distal articulation. This ridge, which is continuous with the articular surface, is somewhat variable in height in the sample of distal humeri of Koopmanycteris, but it is always present. This ridge is present and even better developed in Mormoops, forming a high, winglike process with a triangular to rounded outline in lateral view. In contrast, the ridge on the posterolateral surface of the distal humeral shaft is either very poorly developed or entirely absent in extant species of Pteronotus. Among the outgroups, a ridge on the posterolateral surface of the distal humerus is present in both species of Mystacina but absent in the other outgroup taxa. Data were not available for Speonycteris or Pteronotus pristinus for this character, which was not used by Simmons and Conway (2001).

CHARACTER 187: Ridge on posteromedial edge of distal humeral shaft absent (0); or present (1). Extant species of Pteronotus have a low but distinct ridge along the posteromedial edge of the distal humeral shaft proximal to the articular surface. This ridge, which runs parallel to the long axis of the humeral shaft, is located on the opposite side of the shaft from the ridge described in the preceding character, and it is not nearly as well developed. Rather than forming a crest or flange, in many specimens it appears as the sharp edge formed by the juncture of the posterior and medial faces of the humeral shaft, which are rela- tively flat in this area. In part due to this arrangement, the distal humeral shaft appears somewhat flattened in Pteronotus, especially the posterior surface. Koopmanycteris and both species of Mormoops lack a posteromedial ridge and the distal portion of the humeral shaft appears rounded in cross section, not flattened. A medial ridge is present on the posterodistal humeral shaft in Thyroptera tricolor, and Saccopteryx bilineata, but is absent in both species of Mystacina, both species of Noctilio, both species of Macrotus, Artibeus jamaicensis, and Furipterus horrens. Data were not available for Speonycteris or Pteronotus pristinus for this character, which was not used by Simmons and Conway (2001).

Character 188: Olecranon process of ulna well developed, extending proximally beyond end of radius (0); or reduced, not extending beyond end of radius (1). Both species of Mormoops have a well-developed olecranon process that extends proximally beyond the end of the radius. In contrast, all extant species of Pteronotus have a reduced olecranon process that does not extend beyond the end of the radius. The olecranon process is reduced in all the outgroup species. Data were not available for Koopmanycteris, Speonycteris, and Pteronotus pristinus for this character, which corresponds to character 155 of Simmons and Conway (2001).

Character 189: Radius with triangular proximal extremity (0); proximal extremity truncated and somewhat flattened or rounded (1). Most bats-including all extant members of the genus Pteronotus and all the outgroups in our studyhave a proximal radius with a triangular proximal extremity. In contrast, Koopmanycteris and Mormoops have a proximal radius with a proximal extremity that is truncated and somewhat flattened or rounded. Data were not available for Speonycteris and Pteronotus pristinus for this character, which was not used by Simmons and Conway (2001).

Character 190: Pisiform bone rodlike, of uniform width throughout (0); or dumbbell shaped, enlarged at ends (1). All extant species of Pteronotus have a pisiform bone that is rodlike in 
form, roughly uniform in width throughout its length. In contrast, both species of Mormoops have a pisiform that is enlarged at both ends giving it a dumbbell shape. A similar condition is seen among the outgroups in Saccopteryx bilineata, both species of Mystacina, Thyroptera tricolor, and both species of Macrotus. Both species of Noctilio, and Artibeus jamaicensis have rodlike pisiform bone. The relative sizes of the two ends of the pisiform vary among these taxa, and the proximal end is typically more greatly enlarged than the distal end; however, the pisiform is not rodlike in any of these taxa. Data were not available for Koopmanycteris, Speonycteris, Pteronotus pristinus, and Furipterus horrens for this character, which corresponds to character 156 of Simmons and Conway (2001).

ChARACTER 191: Metacarpal formula $5<4<3$ (0); or $5<4=3$ (1); or $3=4=5$ (2); or $3=5<4$ (3); or $3<4<5$ (4). Metacarpal formulae in bats describe the relative length of the metacarpals of the third, fourth and fifth digits, and proportions of these elements vary enormously among taxa (Wetterer et al., 2000; Simmons and Conway, 2001). Both species of Mormoops have a metacarpal formula of $5<4=3$ in which metacarpals 4 and 3 are much longer than 5 . In contrast, all extant species of Pteronotus have a metacarpal formula of $5<4<3$ in which metacarpals 4 and 3 are only slightly longer than 5 . Saccopteryx bilineata, Thyroptera tricolor, and Furipterus horrens have a metacarpal formula of $5<4<3$, similar to Pteronotus. Both species of Mystacina have a formula of $5<4=3$, with the relative lengths similar to Mormoops. Different metacarpal formulae occur in other groups. Both species of Noctilio have a metacarpal formula of $3=5<4$ in which metacarpal 4 is only slightly longer than 3 and 5 . Both species of Macrotus have a metacarpal formula of $3<4<5$ in which each metacarpal is only slightly longer than the preceding. All three metacarpals are subequal in length $(3=4=5)$ in Artibeus jamaicensis. Data were not available for Koopmanycteris, Speonycteris, and Pteronotus pristinus for this character, which corresponds to character 84 of Wetterer et al. (2000) and char- acter 157 of Simmons and Conway (2001). We followed those authors in treating this as an unordered character because changes in different metacarpals can produce similar formulae in different, nonhomologous ways.

CHARACTER 192: Wing digit I with first phalanx longer than metacarpal (0); or first phalanx and metacarpal subequal in length (1). The relative proportions of the metacarpal and first phalanx of the thumb (wing digit I) vary among mormoopids. The first phalanx in wing digit $\mathrm{I}$ is longer than the metacarpal in both species of Mormoops. In contrast, all extant species of Pteronotus are characterized by a wing digit I in which the first phalanx and metacarpal are subequal in length. These elements are similarly subequal in length in both species of Noctilio and Artibeus jamaicensis, but the first phalanx is markedly longer than the metacarpal in Saccopteryx bilineata, Thyroptera tricolor, Furipterus horrens, both species of Mystacina, and both species of Macrotus. Data were not available for Koopmanycteris, Speonycteris, and Pteronotus pristinus for this character, which corresponds to character 158 of Simmons and Conway (2001).

Character 193: Wing digit II with long, ossified first phalanx (0); or first phalanx absent or tiny and unossified (1). The first phalanx in wing digit II is relatively long-length more than four times the diameter of the shaft-and ossified in all extant mormoopids. A similar condition is seen among the outgroups in both species of Artibeus jamaicensis, both species of Macrotus, and both species of Noctilio. In contrast, the first phalanx is apparently absent in both species of Mystacina, Thyroptera tricolor, Furipterus horrens, and Saccopteryx bilineata. As noted by Simmons and Conway (2001), it is possible that a minute, unossified remnant of the first phalanx remains in these species, but we were unable to detect it in standard museum skeletal preparations. Data were not available for Koopmanycteris, Speonycteris, and Pteronotus pristinus for this character, which corresponds to character 149 of Simmons and Geisler (1998) and character 159 of Simmons and Conway (2001). 
Character 194: Wing digit III with long, completely ossified third phalanx (0); or with long third phalanx that is ossified at the base and unossified at the tip (1); or with long but completely unossified third phalanx (2); or with minute, unossified third phalanx (3). The third phalanx of wing digit III is long (length more than four times the diameter of the shaft) and fully ossified in all extant mormoopids, and a similar condition is seen in Thyroptera tricolor, Artibeus jamaicensis, and both species of Macrotus. In contrast, the third phalanx is long but ossified only at its base in Furipterus horrens and both species of Mystacina, and completely unossified in both species of Noctilio. The third phalanx of wing digit III is a very tiny, unossified element in Saccopteryx bilineata. Data were not available for Koopmanycteris, Speonycteris, and Pteronotus pristinus for this character, which corresponds to character 152 of Simmons and Geisler (1998) and character 160 of Simmons and Conway (2001). We followed the latter authors in treating this as an ordered character.

Character 195: Second phalanx of wing digit IV longer than first phalanx (0); or phalanges subequal in length (1); or second phalanx shorter than first phalanx (2). The second phalanx of wing digit IV is longer than the first phalanx of that digit in all extant species of Pteronotus. In contrast, the first and second phalanges of digit IV are subequal in both species of Mormoops. Among the outgroups, the second phalanx is longer than the first phalanx in Artibeus jamaicensis, both species of Noctilio, Furipterus horrens, and Saccopteryx bilineata. These phalanges are subequal in both species of Mystacina, and the second phalanx is shorter than the first phalanx in Thyroptera tricolor and both species of Macrotus. We followed Simmons and Conway (2001) in ordering this character. Data were not available for Koopmanycteris, Speonycteris, and Pteronotus pristinus for this character, which corresponds to character 161 of Simmons and Conway (2001).

ChARACTER 196: Sacral vertebrae do not contact ischium (0); or posterior sacral vertebrae fused with posterior ischium (1). As noted by Simmons and Conway (2001), a secondary articulation between the vertebral column and pelvis occurs between the posterior sacral vertebrae and the posterior portion of the ischium in some bats. This secondary articulation is separated from the main iliosacral articulation by a gap across which there is no contact between the pelvis and vertebral column. All extant species of Pteronotus have such an articulation in which the posterior sacral vertebrae are fused with the ischium. In contrast, the ischium does not contact the vertebral column in either species of Mormoops. A similar condition (no contact or fusion) is seen among the outgroups in Saccopteryx bilineata, Thyroptera tricolor, Furipterus horrens, both species of Mystacina, Artibeus jamaicensis, and both species of Macrotus. Both species of Noctilio are characterized by the presence of contact and fusion between the ischium and posterior sacral vertebrae. Data were not available for Koopmanycteris, Speonycteris, Pteronotus pristinus, and Mystacina tuberculata for this character, which corresponds to character 162 of Simmons and Conway (2001).

Character 197: Dorsomedial edge of ascending process of ilium not upturned, does not extend dorsally beyond the level of the iliosacral articulation, iliac fossa not large or well defined (0); or dorsomedial edge upturned, flares dorsally above the level of the iliosacral articulation, iliac fossa large and well defined (1). The dorsomedial edge of the ascending process of the ilium is strongly upturned and flares dorsally above the level of the iliosacral articulation in Mormoops megalophylla and members of the Pteronotus parnellii and $P$. personatus complexes. As a result, the iliac fossa is large and well defined in these species. In contrast, the dorsomedial edge of the ascending process of ilium is not upturned, does not extend dorsally beyond the level of the iliosacral articulation, and the iliac fossa is not large or well defined in Mormoops blainvillei, Pteronotus macleayii, $P$. quadridens, members of the $P$. davyi complex, and P. gymnonotus. Among the outgroups Saccopteryx bilineata, Thyroptera tricolor, 
Furipterus horrens, both species of Mystacina, Artibeus jamaicensis, and both species of Macrotus are characterized by a low ascending process and small, poorly defined iliac fossa. An upturned, flared ascending process with a large, well-defined iliac fossa occurs in both species of Noctilio. Data were not available for Koopmanycteris, Speonycteris, and Pteronotus pristinus for this character, which corresponds to character 161 of Simmons and Geisler (1998) and character 163 of Simmons and Conway (2001).

CHARACTER 198: Ischium with ischial tuberosity small or absent, does not project dorsally beyond level of ramus (0); or with large ischial tuberosity that projects dorsally from posterior horizontal ramus (1). No extant mormoopid has a large, dorsally projecting ischial tuberosity, and the same is true of Artibeus jamaicensis, both species of Macrotus, Thyroptera tricolor, Furipterus horrens, and Saccopteryx bilineata. In contrast, a large, dorsally projecting ischial tuberosity is present in both species of Mystacina and both species of Noctilio. Data were not available for Koopmanycteris, Speonycteris, and Pteronotus pristinus for this character, which corresponds to character 162 of Simmons and Geisler (1998) and character 165 of Simmons and Conway (2001).

CHARACTER 199: Length of pubic spine less than or equal to one-third the length of the ilium (0); or equal to or greater than one-half the length of the ilium (1). All extant mormoopids have a long pubic spine (length equal to or greater than onehalf the length of the ilium). A similar condition is seen among the outgroups in Artibeus jamaicensis and both species of Macrotus. In contrast, the length of the pubic spine is less than or equal to one-third the length of the ilium in Saccopteryx bilineata, Thyroptera tricolor, Furipterus horrens, both species of Noctilio, and both species of Mystacina. Data were not available for Koopmanycteris, Speonycteris, and Pteronotus pristinus for this character, which corresponds to character 165 of Simmons and Conway (2001).

Character 200: Articulation between right and left pubes in male restricted to a small area, consisting of an ossified interpubic ligament (0); or articulation between pubes broad, consisting of a symphysis that is long in an anteroposterior dimension (1). Members of the Pteronotus parnellii, $P$. personatus, and $P$. davyi complexes, $P$. gymnonotus, and both species of Mormoops are characterized by a broad pubic symphysis that is long in an anteroposterior dimension. A similar condition is seen among the outgroups in Artibeus jamaicensis, both species of Macrotus, and both species of Noctilio. In contrast, the articulation between the pubes in male Saccopteryx bilineata, Thyroptera tricolor, and Furipterus horrens is restricted to a small area. The right and left pubes are not in direct contact, but are joined by a short, ossified interpubic ligament. Data were not available for Koopmanycteris, Speonycteris, Pteronotus pristinus, P. macleayii, P. quadridens, and both species of Mystacina for this character, which corresponds to character 166 of Simmons and Geisler (1998) and character 148 of Simmons and Conway (2001).

CHARACTER 201: Femur of normal length (0); or femur relatively elongated (1). In Koopmanycteris and Mormoops the femur is relatively longer than in comparable-sized species of Pteronotus. The femur of Mormoops blainvillei is $30 \%$ longer than that of members of the Pteronotus davyi complex that are of similar body size, and the femur of Mormoops megalophylla is $22 \%$ longer than the femur of the similar-sized Pteronotus gymnonotus. The single incomplete distal portion of a femur of Koopmanycteris (two-thirds to three-quarters complete) is almost as long as the entire femur of members of the Pteronotus parnellii complex even though the latter taxa are considerably larger than Koopmanycteris in almost all other dental and postcranial dimensions. This incomplete femur of Koopmanycteris is most similar in size and length and robustness of the shaft to Mormoops megalophylla, even though the latter species is otherwise larger in most other measurements.

A general comparison of femur length to a standard indicator of overall size, the length of the mandibular toothrow, demonstrates that the 
femur in the two species of Mormoops is more than three times longer than the lower toothrow, whereas the femur in the various species of Pteronotus ranges from two to 2.5 times longer than the lower toothrow, with most species having the femur barely twice the length of the lower toothrow. We consider species with the femur more than three times longer than the length of the lower toothrow (e.g., Mormoops and presumably Koopmanycteris) to have the "femur relatively elongated." Species in which the femur is less than three times as long as the lower toothrow (e.g., Pteronotus) are considered to have a "femur of normal length." Among the outgroups, only Furipterus has an elongated femur using this definition: It is extremely elongated with a very thin, delicate shaft compared with almost all other bats, including Mormoops. Moreover, it is almost four times longer than the lower toothrow length. The other outgroup taxa are similar to extant Pteronotus in having the femur of normal length, about twice the length of the mandibular toothrow. Data were not available for Speonycteris or Pteronotus pristinus for this character, which is a new character not used by Simmons and Conway (2001).

CHARACTER 202: Shaft of femur straight (0); or with bend that directs the distal shaft dorsally (1). The shaft of the femur is relatively straight in Koopmanycteris and all extant mormoopids. While the head of the femur is somewhat canted laterally, the shaft itself is relatively straight, so that the distal articular facets lie in line with most of the proximal shaft. A similar state is seen in Artibeus jamaicensis, both species of Mystacina, both species of Noctilio, Thyroptera tricolor, Furipterus horrens, and Saccopteryx bilineata. In contrast, in both species of Macrotus the shaft of the femur is bent somewhat, so that the entire distal end of the bone is directed more dorsally (the equivalent of a lateral bend were the femur in the position typical of nonvolant mammals). Data were not available for Speonycteris or Pteronotus pristinus for this character, which corresponds to character 169 of Simmons and Geisler (1998) and character 169 of Simmons and Conway (2001).
Character 203: Greater and lesser trochanters of femur well developed, flanges extending well beyond sides of femoral head in anterior view (0); or greater and lesser trochanters somewhat reduced, extending somewhat beyond the sides of the femoral head or just to the edge of the head, greater trochanter distinctly larger than lesser trochanter (1) or greater and lesser trochanters highly reduced, neither extending beyond the sides of the femoral head, greater trochanter remaining distinctly larger than lesser trochanter (2); or greater and lesser trochanters even more highly reduced, neither extending beyond femoral head, greater trochanter reduced to a rounded tuberosity similar in size to lesser trochanter (3). Most bats have femora with welldeveloped greater and lesser trochanters that extend well beyond the sides of the head of the femur. In contrast, Koopmanycteris and all extant mormoopids have reduced trochanters that are more closely appressed to the shaft and do not extend much beyond the sides of the femoral head. In Koopmanycteris and Mormoops, both the greater and lesser trochanters are highly reduced compared to most other bats, but the triangularshaped greater trochanter is somewhat less reduced, remaining distinctly larger than the lesser trochanter. Both trochanters are even more highly reduced in Pteronotus than in the other two genera of mormoopids, especially the greater trochanter, which is reduced to a rounded tuberosity similar in size to the lesser trochanter. Among the outgroups, Furipterus horrens has a similar condition to that of Mormoops and Koopmanycteris. Speonycteris exhibits an intermediate condition in which greater and lesser trochanters are somewhat reduced, but not as greatly as in Furipterus and mormoopids. In Speonycteris, the trochanters extend either somewhat beyond the side of the femoral head (lesser trochanter) or just to the edge of the head (greater trochanter), but the greater trochanter remains distinctly larger than the lesser trochanter. In contrast, the remaining outgroups all have well-developed trochanters that extend far beyond the femoral head. Data were not available for Pteronotus pristinus for this character, which represents an expanded version 
of character 167 of Simmons and Conway (2001) and character 104 of Czaplewski and Morgan (2012). We treated this as an ordered character.

Character 204: Femur with well-developed ridge present distal to lesser trochanter (0); or with well-developed ridge present dorsal to lesser trochanter (1); or ridge absent from femoral shaft (2). As noted by Simmons and Conway (2001), a high, longitudinally oriented ridge is present on the shaft of the femur distal to the lesser trochanter in all extant species of Mormoops and Pteronotus, and is also found in Koopmanycteris. A similar ridge is present in Artibeus jamaicensis, Thyroptera tricolor, and Saccopteryx bilineata. In contrast, Furipterus horrens and both species of Macrotus have a ridge present dorsal to the lesser trochanter. The femoral shaft lacks any such ridges in both species of Noctilio and both species of Mystacina. Data were not available for Pteronotus pristinus or Speonycteris for this character, which corresponds to character 168 of Simmons and Conway (2001). We treated this as an unordered character.

Character 205: Posterior shaft of distal femur lacking a ridge or tubercle just proximal to distal articular surface (0); or well-defined tubercle or short ridge present (1). Koopmanycteris has a short but distinct ridge in the middle of the posterodistal surface of the femoral shaft just proximal to the distal articulation. Mormoops also has a tubercle or short ridge in this same position, although it is less well developed than in Koopmanycteris. Extant species of Pteronotus and of the outgroups all lack a tubercle or ridge in this position. Data were not available for Pteronotus pristinus or Speonycteris for this character, which was not used by Simmons and Conway (2001).

Character 206: Fibula well developed and fully ossified (0); or thin and threadlike, often only partly ossified (1); or absent or entirely unossified (2). The fibula in most mammals is robust, complete, and ossified from knee to ankle. In contrast, the fibula in all extant mormoopids is relatively much thinner, almost threadlike. It is often only partially ossified, which makes it appear incomplete in dried skeleton prepara- tions. A similar condition is seen in Artibeus jamaicensis, both species of Macrotus, Thyroptera tricolor, Furipterus horrens, and both species of Noctilio. The fibula is either absent or entirely unossified (with no remnant present in dried skeletons) in Saccopteryx bilineata. In contrast, the fibula is well developed and fully ossified in both species of Mystacina. Data were not available for Koopmanycteris, Speonycteris, and Pteronotus pristinus for this character, which corresponds to character 170 of Simmons and Geisler (1998) and character 170 of Simmons and Conway (2001). We followed the latter authors in treating this as an ordered character.

ChARACTER 207: Tail absent (0); or tail length approximately one-half the length of the tibia (1); or approximately three-fourths the length of the tibia (2); or approximately the same length as the tibia (3); 1.5 times the length of the tibia (4); or roughly two times the length of the tibia (5). The tail of all extant mormoopids is approximately the same length as the tibia. Among the outgroups, a similar condition is seen in Mystacina tuberculata. In contrast, the tail is roughly twice the length of the tibia in Furipterus horrens, 1.5 times the length of the tibia in Thyroptera tricolor and both species of Macrotus, three-fourths the length of the tibia in Mystacina robusta and Saccopteryx bilineata, one-half the length of the tibia in both species of Noctilio, and the tail is absent in Artibeus jamaicensis. Data were not available for Koopmanycteris, Speonycteris, and Pteronotus pristinus for this character, which corresponds to character 89 of Wetterer et al. (2000) and character 171 of Simmons and Conway (2001). We followed the latter authors in treating this as an ordered character.

Character 208: Calcaneum not expanded or flattened (0); or expanded and flattened (1). The calcaneum of all extant mormoopids is a rectangular bone that is not noticeably flattened or expanded. A similar condition is seen among the outgroups in Artibeus jamaicensis, both species of Macrotus, both species of Mystacina, and Saccopteryx bilineata. In contrast, the calcaneum in Thyroptera tricolor, Furipterus horrens, and both 
species of Noctilio is flattened and expanded into a nearly triangular bone when seen in anterior view. The portion of this element that extends from the plantar aspect of the ankle is nearly as wide as the distal articular surface of the tibia in these species. Data were not available for Koopmanycteris, Speonycteris, and Pteronotus pristinus for this character, which corresponds to character 172 of Simmons and Conway (2001).

CHARACTER 209: Calcar entirely cartilaginous (0); or cartilaginous distally, with clearly demarcated calcified base (1); or calcar entirely calcified (2). The degree of calcification of the calcar varies among and within families of bats (Schutt and Simmons, 1998). The calcar is apparently entirely calcified in all extant species of Pteronotus, although it is thin and distally flexible in these taxa (Schutt and Simmons, 1998; Schutt, personal commun.). In contrast, the base of the calcar is calcified, but the distal portion of this element is cartilaginous in both species of Mormoops (Schutt and Simmons, 1998; Schutt, personal commun.). A transitional zone is clearly visible between the calcified and cartilaginous portions of the calcar in these species. Among the outgroups, both species of Macrotus, Furipterus horrens, and both species of Noctilio also have a calcar that is cartilaginous distally with a clearly demarcated calcified base (Schutt and Simmons, 1998). The calcar in Saccopteryx bilineata is entirely calcified (Schutt and Simmons, 1998). Thyroptera tricolor, both species of Mystacina, and Artibeus jamaicensis exhibit a third condition in which the calcar is entirely cartilaginous (Schutt and Simmons, 1998; N.B.S., personal obs.). Data were not available for Koopmanycteris, Speonycteris, and Pteronotus pristinus for this character, which corresponds to character 173 of Simmons and Conway (2001). We followed these authors in treating this as an ordered character.

Character 210: Calcar length less than or approximately equal to one-half the length of the hind foot (0); or approximately the same length as hind foot (1); or 1.5 times the length of the hind foot (2); or two times the length of the hind foot
(3). Calcar length varies enormously both within and among families of bats. Following Simmons and Conway (2001), we assessed relative length of the calcar by comparing its length (from base to tip) with the length of the hind foot including the claws. Several conditions are seen among extant mormoopids. The calcar is approximately the same length as the hind foot in the Pteronotus parnellii complex, $P$. quadridens, and members of the P. personatus complex. In contrast, the calcar is approximately 1.5 times the length of the hind foot in Pteronotus macleayii, P. gymnonotus, and members of the $P$. davyi complex. The calcar is even longer, approximately twice the length of the hind foot, in both species of Mormoops. Among the outgroups, the calcar is less than or equal to one-half the length of the hind foot in both species of Mystacina, Thyroptera tricolor, and Artibeus jamaicensis, approximately 1.5 times the length of the hind foot in Saccopteryx bilineata and both species of Macro$t u s$, and it is twice the length of the hind foot in Furipterus horrens and both species of Noctilio. Data were not available for Koopmanycteris, Speonycteris, and Pteronotus pristinus for this character, which corresponds to character 87 of Wetterer et al. (2000) and character 174 of Simmons and Conway (2001). We followed these authors in treating this as an ordered character.

Character 211: Length of foot less than or equal to one-half the length of the tibia (0); or greater than three-fourths the length of the tibia (1). The length of the foot (including claws) is less than or equal to one-half the length of the tibia in all extant mormoopids. A similar condition is seen in Saccopteryx bilineata, Furipterus horrens, Thyroptera tricolor, and both species of Macrotus. In contrast, the hind foot is at least three-fourths the length of the tibia in Artibeus jamaicensis, both species of Noctilio, and both species of Mystacina. Data were not available for Koopmanycteris, Speonycteris, and Pteronotus pristinus for this character, which corresponds to character 175 of Simmons and Conway (2001).

Character 212: Claws without basal talons (0); or with basal talons (1). The claws on the 
thumb and hind feet lack basal talons or spurs in most extant bats including all extant mormoopids. A similar condition is seen among the outgroups in both species of Macrotus, Artibeus jamaicensis, both species of Noctilio, Thyroptera tricolor, Furipterus horrens, and Saccopteryx bilineata. In contrast, the claws of both species of Mystacina are characterized by well-developed basal talons. Data were not available for Koopmanycteris, Speonycteris, and Pteronotus pristinus for this character, which corresponds to character 176 of Simmons and Conway (2001).

\section{Postcranial Myology}

Character 213: $M$. humeropatagialis present (0); or absent (1). M. humeropatagialis is present in all extant mormoopids. Among the outgroups m. humeropatagialis is present in Saccopteryx bilineata and both species of Noctilio (Strickler, 1978). In contrast, this muscle is absent in Thyroptera tricolor and both species of Macrotus (Vaughan, 1959; Strickler, 1978). Data were not available for Koopmanycteris, Speonycteris, Pteronotus pristinus, both species of Mystacina, Furipterus horrens, and Artibeus jamaicensis for this character, which corresponds to character 117 of Simmons and Geisler (1998) and character 177 of Simmons and Conway (2001).

Character 214: M. occipitopollicalis with tendinous attachments to the anterior division of $m$. pectoralis profundus (0); or with no tendinous attachment to the anterior division of $m$. pectoralis profundus (1). M. occipitopollicalis has a tendinous attachment to the anterior division of $\mathrm{m}$. pectoralis profundus in members of the Pteronotus parnellii and P. davyi complexes, and in Mormoops megalophylla (Strickler, 1978). Among the outgroups, a similar tendinous attachment is seen in Saccopteryx bilineata and both species of Macrotus, but no such attachment is present in Thyroptera tricolor or either species of Noctilio (Vaughan, 1959; Strickler, 1978). Data were not available for Koopmanycteris, Speonycteris, Pteronotus macleayii, $P$. quadridens, members of the $P$. personatus complex, $P$. gymnonotus, $P$. pristi- nus, Mormoops blainvillei, Artibeus jamaicensis, Furipterus horrens, and both species of Mystacina for this character, which corresponds to character 119 of Simmons and Geisler (1998), character 76 of Wetterer et al. (2000), and character 178 of Simmons and Conway (2001).

Character 215: M. occipitopollicalis insertional complex including muscle fibers distal to band of elastic tissue (0); or entirely tendinous distal to band of elastic tissue (1). The insertional complex of $\mathrm{m}$. occipitopollicalis is entirely tendinous distal to band of elastic tissue in the Pteronotus parnellii and $P$. davyi complexes, and in Mormoops megalophylla (Strickler, 1978). Among the outgroups, a similar arrangement is seen in Thyroptera tricolor and both species of Macrotus, but the insertional complex includes muscle fibers distal to the band of elastic tissue in Saccopteryx bilineata and both species of Noctilio (Vaughan, 1959; Strickler, 1978). Data were not available for Koopmanycteris, Speonycteris, Pteronotus macleayii, $P$. quadridens, the P. personatus complex, $P$. gymnonotus, $P$. pristinus, Mormoops blainvillei, Artibeus jamaicensis, Furipterus horrens, and both species of Mystacina for this character, which corresponds to character 122 of Simmons and Geisler (1998), character 75 of Wetterer et al. (2000), and character 179 of Simmons and Conway (2001).

CHARACTER 216: $M$. spinodeltoideus originates from vertebral border of scapula only (0); or from vertebral border of scapula plus one-half to twothirds of the transverse scapular ligament (1); or from vertebral border of scapula plus more than three-fourths of the transverse scapular ligament (2). M. spinodeltoideus originates from the vertebral border of scapula plus one-half to two-thirds of the transverse scapular ligament in the Pteronotus parnellii and $P$. davyi complexes (Strickler, 1978). The origin of this muscle is more extensive in $M$. megalophylla, originating from the vertebral border of the scapula plus more than threefourths of the transverse scapular ligament (Strickler, 1978). Among the outgroups, m. spinodeltoideus originates from the vertebral border of the scapula plus one-half to two-thirds of the 
transverse scapular ligament in Thyroptera tricolor, Artibeus jamaicensis, and both species of Macrotus, but the origin is restricted to the vertebral border of the scapula in Saccopteryx bilineata and both species of Noctilio (Vaughan, 1959; Strickler, 1978; Hermanson and Altenbach, 1985). Data were not available for Koopmanycteris, Speonycteris, Pteronotus macleayii, P. quadridens, the $P$. personatus complex, $P$. gymnonotus, $P$. pristinus, Mormoops blainvillei, Furipterus horrens, and both species of Mystacina for this character, which corresponds to character 137 of Simmons and Geisler (1998), character 77 of Wetterer et al. (2000), and character 180 of Simmons and Conway (2001). We followed the last-named authors in ordering this character.

Character 217: Origin of $m$. teres major from one-half to three-fourths of the axillary border of the scapula (0); or from one-fourth to twofifths of the axillary border (1); or restricted to the ventral tip of the axillary border (2). The origin of $\mathrm{m}$. teres major includes approximately onefourth to two-fifths of the total axillary border of the scapula in the Pteronotus parnellii and $P$. davyi complexes (Strickler, 1978). In contrast, the origin of this muscle is restricted to just the tip of the axillary border in M. megalophylla (Strickler, 1978). Among the outgroups, the origin of $\mathrm{m}$. teres major includes approximately one-fourth to two-fifths of the axillary border in Artibeus jamaicensis, both species of Macrotus, Thyroptera tricolor, and Saccopteryx bilineata. The origin is even more extensive in both species of Noctilio, where it extends from one-half to three-fourths of the axillary border (Vaughan, 1959; Strickler, 1978; Hermanson and Altenbach, 1985). Data were not available for Koopmanycteris, Speonycteris, Pteronotus macleayii, P. quadridens, the P. personatus complex, P. gymnonotus, P. pristinus, Mormoops blainvillei, Furipterus horrens, and both species of Mystacina for this character, which corresponds to character 181 of Simmons and Conway (2001). We followed those authors in ordering this character.

Character 218: $M$. teres major inserts into ventral ridge of humerus (0); or into ventral base of pectoral crest (1). M. teres major inserts into the ventral base of the pectoral crest of the humerus in the Pteronotus parnellii and $P$. davyi complexes, and in Mormoops megalophylla (Strickler, 1978). A similar condition is seen in Artibeus jamaicensis and both species of Macrotus (Vaughan, 1959; Hermanson and Altenbach, 1985). In contrast, m. teres major inserts into the ventral ridge of the humerus in Saccopteryx bilineata, Thyroptera tricolor, and both species of Noctilio (Strickler, 1978). Data were not available for Koopmanycteris, Speonycteris, Pteronotus macleayii, $P$. quadridens, members of the $P$. personatus complex, P. gymnonotus, P. pristinus, Mormoops blainvillei, Furipterus horrens, and both species of Mystacina for this character, which corresponds to character 135 of Simmons and Geisler (1998) and character 182 of Simmons and Conway (2001).

Character 219: $M$. triceps brachii caput medialis present (0); or absent (1). M. triceps caput medialis is present in all extant species of Pteronotus, but is absent in both species of Mormoops (Vaughan and Bateman, 1970). This muscle is present in Saccopteryx bilineata, Thyroptera tricolor, both species of Noctilio, and both species of Macrotus (Vaughan, 1959; Strickler, 1978). Data were not available for Koopmanycteris, Speonycteris, Pteronotus pristinus, Furipterus horrens, both species of Mystacina, and Artibeus jamaicensis for this character, which corresponds to character 183 of Simmons and Conway (2001).

ChARACTER 220: $M$. coracobrachialis the same size or smaller than coracoid head of $m$. biceps brachii, originates from tip of coracoid process (0); or approximately twice the size of coracoid head of biceps, originates proximal to tip of coracoid process (1). M. coracobrachialis originates from the tip of the coracoid process and is roughly the same size or smaller than the coracoid head (caput breve) of the biceps in the Pteronotus parnellii complex and both species of Mormoops (Vaughan and Bateman, 1970). In contrast, $\mathrm{m}$. coracobrachialis is twice the size of the coracoid head of the biceps in P. macleayii, $P$. quadridens, members of the P. personatus and 
P. davyi complexes, and P. gymnonotus, and its origin is proximal to the tip of the coracoid process (Vaughan and Bateman, 1970). A similar condition is seen in both species of Noctilio (Strickler, 1978). M. coracobrachialis originates at the tip of the coracoid process and is the same size or smaller than the coracoid head of the biceps in Saccopteryx bilineata, Thyroptera tricolor, and both species of Macrotus (Vaughan, 1959; Strickler, 1978). Data were not available for Koopmanycteris, Speonycteris, Pteronotus pristinus, both species of Mystacina, Furipterus horrens, and Artibeus jamaicensis for this character, which corresponds to character 184 of Simmons and Conway (2001).

Character 221: $M$. biceps brachii insertional tendons not encased in sling (0); or encased in sling (1). In both species of Mormoops, the insertional tendons of $\mathrm{m}$. biceps brachii are encased in an unusual connective tissue sling attached to the dorsal surface of the humerus (Vaughan and Bateman, 1970). Extant species of Pteronotus lack such a sling around the biceps tendons (Vaughan and Bateman, 1970). A sling is similarly lacking in Artibeus jamaicensis, both species of Macrotus, Thyroptera tricolor, and both species of Noctilio (Vaughan, 1959; Strickler, 1978; Hermanson and Altenbach, 1985). Data were not available for Koopmanycteris, Speonycteris, Pteronotus pristinus, Saccopteryx bilineata, Furipterus horrens, and both species of Mystacina for this character, which corresponds to character 185 of Simmons and Conway (2001).

ChARACTER 222: $M$. brachialis present (0); or absent (1). M. brachialis is present in all extant species of Pteronotus but is absent in both species of Mormoops (Vaughan and Bateman, 1970). M. brachialis is present in Saccopteryx bilineata, both species of Macrotus, and both species of Noctilio, but is absent in Thyroptera tricolor (Vaughan, 1959; Strickler, 1978. Data were not available for Koopmanycteris, Speonycteris, Pteronotus pristinus, both species of Mystacina, Furipterus horrens, and Artibeus jamaicensis for this character, which corresponds to character 186 of Simmons and Conway (2001).
Character 223: No sesamoid present in tendon of $m$. extensor carpi radialis longus (0); or sesamoid present (1). The tendon of $\mathrm{m}$. extensor carpi radialis longus lacks a sesamoid in all extant Pteronotus (Vaughan and Bateman, 1970). In contrast, a sesamoid is associated with the tendon of this muscle in both species of Mormoops (Vaughan and Bateman, 1970). Among the outgroups, a sesamoid is absent from the tendon of $m$. extensor carpi radialis longus in both species of Macrotus (Vaughan, 1959). Data were not available for the other outgroups or for Koopmanycteris, Speonycteris, Pteronotus pristinus for this character, which corresponds to character 187 of Simmons and Conway (2001).

Character 224: $M$. extensor pollicis brevis originates from ulna (0); or from both ulna and radius (1). M. extensor pollicis brevis originates from the dorsal surface of the ulna in both species of Mormoops (Vaughan and Bateman, 1970). In contrast, this muscle originates from the dorsal surface of the ulna and the adjacent surface of the radius in all extant Pteronotus (Vaughan and Bateman, 1970). In both species of Macrotus the origin of this muscle is restricted to the dorsal surface of the ulna (Vaughan, 1959). Data were not available for the other outgroups, Koopmanycteris, Speonycteris, or Pteronotus pristinus for this character, which corresponds to character 188 of Simmons and Conway (2001).

Character 225: $M$. extensor digitorum communis originates from radius, ulna, and humerus (0); or from radius and ulna only (1). M. extensor digitorum communis originates from the proximal half of the radius and ulna in all extant mormoopids (Vaughan and Bateman, 1970). In contrast, in both species of Macrotus, m. extensor digitorum communis has a more extensive origin that includes the proximal radius, proximal ulna, and the lateral epicondyle of the humerus (Vaughan, 1959). Data were not available for the other outgroups, Koopmanycteris, Speonycteris, or Pteronotus pristinus for this character, which corresponds to character 189 of Simmons and Conway (2001). 
CHARACTER 226: Tendon from $m$. extensor digitorum communis to fifth digit inserts on second phalanx (0); or on shaft of metacarpal (1). M. extensor digitorum communis in bats typically has two bellies and multiple insertions onto bones of the manus (Vaughn, 1959; Vaughn and Bateman, 1970). The tendon of $m$. extensor digitorum communis that runs to the fifth digit inserts on the second phalanx of that digit in the Pteronotus parnellii and $P$. davyi complexes, $P$. gymnonotus, and both species of Mormoops (Vaughan and Bateman, 1970). A similar condition is seen in both species of Macrotus (Vaughan, 1959). In contrast, this tendon inserts on the shaft of the metacarpal of the fifth digit in Pteronotus macleayii, $P$. quadridens, and members of the $P$. personatus complex (Vaughan and Bateman, 1970). Data were not available for the other outgroups, Koopmanycteris, Speonycteris, or Pteronotus pristinus for this character, which corresponds to character 190 of Simmons and Conway (2001).

Character 227: M. extensor digiti quinti proprius originates from lateral epicondyle of humerus and dorsal base of ulna (0); or from lateral epicondyle only (1); or from second division of m. extensor digitorum communis and posterodorsal base of radius (2). $M$. extensor digiti quinti proprius originates from the lateral epicondyle of humerus and the dorsal base of the ulna in Pteronotus macleayii, $P$. quadridens, members of the $P$. davyi complex, and P. gymnonotus (Vaughan and Bateman, 1970). A similar condition is seen in both species of Macrotus (Vaughan, 1959). In contrast, this muscle originates from only the lateral epicondyle of the humerus (and an ulnar origin is lacking) in members of the $P$. personatus complex and both species of Mormoops (Vaughan and Bateman, 1970). A third condition is seen in the Pteronotus parnellii complex, in which $\mathrm{m}$. extensor digiti quinti proprius originates from the second division of $\mathrm{m}$. extensor digitorum communis and the posterodorsal base of the radius (Vaughan and Bateman, 1970). Data were not available for the other outgroups, Koopmanycteris, Speonycteris, or Pteronotus pristinus for this character, which corresponds to charac- ter 191 of Simmons and Conway (2001). We treated this as an unordered character.

Character 228: $M$. flexor digitorum profundus inserts via tendon onto second phalanx of digit IV of wing (0); or does not insert onto digit IV (1). M. flexor digitorum profundus inserts onto the second phalanx of digit IV of the wing in all extant mormoopids (Vaughan and Bateman, 1970). In contrast, $m$. flexor digitorum profundus does not insert on digit IV in either species of Macrotus (Vaughan, 1959). Data were not available for the other outgroups, Koopmanycteris, Speonycteris, or Pteronotus pristinus for this character, which corresponds to character 155 of Simmons and Geisler (1998), character 83 of Wetterer et al. (2000), and character 190 of Simmons and Conway (2001).

Character 229: $M$. flexor digitorum profundus inserts via tendon onto second phalanx of digit $V$ of wing (0); or does not insert onto digit $V$ (1). M. flexor digitorum profundus inserts onto the second phalanx of digit $\mathrm{V}$ of the wing in all extant mormoopids (Vaughan and Bateman, 1970). In contrast, m. flexor digitorum profundus does not insert on digit $\mathrm{V}$ in either species of Macrotus (Vaughan, 1959). Data were not available for the other outgroups, Koopmanycteris, Speonycteris, or Pteronotus pristinus for this character, which corresponds to character 156 of Simmons and Geisler (1998) and character 193 of Simmons and Conway (2001). We follow the latter authors in treating this as a separate character from character 218 because the taxonomic distribution of these two features is not always identical. For example, m. flexor digitorum profundus inserts on digit IV but not on digit $\mathrm{V}$ in Phyllostomus hastatus (Vaughan and Bateman, 1970), indicating that insertion on digit IV and digit $\mathrm{V}$ may vary independently.

Character 230: $M$. palmaris longus robust (0); or vestigial (1). M. palmaris longus is a vestigial muscle that is much narrower than $\mathrm{m}$. flexor digitorum profundus in all extant Pteronotus (Vaughan and Bateman, 1970). In contrast, this muscle is relatively robust (approximately the same size as $\mathrm{m}$. flexor digitorum profundus) in 
both species of Mormoops. A similar, relatively robust $\mathrm{m}$. palmaris longus is seen in both species of Macrotus, Artibeus jamaicensis, and both species of Noctilio (Vaughan, 1959; Vaughan and Bateman, 1970). Data were not available for the other outgroups, Koopmanycteris, Speonycteris, or Pteronotus pristinus for this character, which corresponds to character 194 of Simmons and Conway (2001).

Character 231: M. palmaris longus inserts onto metacarpal of digit II (0); or does not insert onto metacarpal of digit II (1). M. palmaris longus inserts onto the metacarpal of digit II of the wing in the Pteronotus parnellii complex, $P$. macleayii, $P$. gymnonotus, Mormoops megalophylla, and M. blainvillei (Vaughan and Bateman, 1970). A similar condition is seen in Artibeus jamaicensis (Vaughan and Bateman, 1970). In contrast, m. palmaris longus lacks an insertion onto the metacarpal of digit II in both species of Macrotus (Vaughan, 1959). Data were not available for the other outgroups, Koopmanycteris, Speonycteris, or Pteronotus pristinus for this character, which corresponds to character 79 of Wetterer et al. (2000) and character 195 of Simmons and Conway (2001). As noted by the latter authors, Vaughan and Bateman (1970) attempted to trace the insertion of $\mathrm{m}$. palmaris longus in the Pteronotus personatus complex, P. quadridens, and members of the $P$. davyi complex, but found that the tendons were too small to follow. We accordingly scored these taxa "_" for this character.

Character 232: M. palmaris longus inserts onto metacarpal of digit III (0); or does not insert onto metacarpal of digit III (1). M. palmaris longus inserts onto the metacarpal of digit III of the wing in the Pteronotus parnellii complex, $P$. macleayii, P. gymnonotus, Mormoops megalophylla, and M. blainvillei (Vaughan and Bateman, 1970). A similar insertion is seen in both species of Macrotus (Vaughan, 1959). In contrast, an insertion of $\mathrm{m}$. palmaris longus onto the metacarpal of digit III is lacking in Artibeus jamaicensis and both species of Noctilio (Vaughan and Bateman, 1970; Straney, 1980). Data were not available for the other outgroups, Koopmanycteris, Speonycteris, or Pteronotus pristinus for this character, which corresponds to character 80 of Wetterer et al. (2000) and character 196 of Simmons and Conway (2001). As noted above, Vaughan and Bateman (1970) attempted to trace the insertion of $\mathrm{m}$. palmaris longus in members of the Pteronotus personatus complex, $P$. quadridens, and the $P$. davyi complex, but found that the tendons were too small to follow. We accordingly followed Simmons and Conway (2001) in scoring these taxa "--" for this character.

Character 233: Digital tendon locking mechanism absent from digits of hind feet (0); or ratchetlike lock present, consists of tubercles on the proximal flexor tendon and plicae on the adjacent tendon sheath (1); or friction lock present, consists of retinaculum on flexor tendon sheath (2). All extant mormoopids lack a digital tendon locking mechanism (TLM) in the hind feet (Simmons and Quinn, 1994; Schutt, personal commun.). A TLM is similarly lacking in Thyroptera tricolor, Furipterus horrens, and Mystacina tuberculata (Simmons and Quinn, 1994). In contrast, a ratchetlike TLM, consisting of tubercles on the proximal flexor tendon and plicae on the adjacent tendon sheath, is present in Saccopteryx bilineata and both species of Noctilio (Simmons and Quinn, 1994; Schutt, personal commun.). Both species of Macrotus and Artibeus jamaicensis lack a ratchetlike TLM, instead of having a friction lock on the digital tendons that consists of a bandlike retinaculum in the tendon sheath (Schutt, 1993; Simmons and Quinn, 1994). Data were not available for Koopmanycteris, Speonycteris, Pteronotus pristinus, or Mystacina robusta for this character, which corresponds to character 173 of Simmons and Geisler (1998) and character 197 of Simmons and Conway (2001). We treated this as an unordered character.

\section{Reproductive Tract}

Character 234: Female external genitalia with transverse vulval opening (0); or vulval opening oriented anteroposteriorly (1). The vulval 
opening is oriented anteroposteriorly in all extant mormoopids. A similar condition is seen among the outgroups in Artibeus jamaicensis, both species of Macrotus, and Mystacina tuberculata. In contrast, the vulval opening is oriented transversely in Saccopteryx bilineata, Thyroptera tricolor, Furipterus horrens, and both species of Noctilio. Data were not available for Koopmanycteris, Speonycteris, Pteronotus pristinus, or Mystacina robusta for this character, which corresponds to character 177 of Simmons and Geisler (1998) and character 198 of Simmons and Conway (2001).

Character 235: Clitoris of moderate size, length approximately equal to width at base (0); or clitoris elongated, length approximately twice width at base (1). As noted by Simmons and Conway (2001), the clitoris of mormoopids varies in relative length. The clitoris is of moderate size (clitoris length approximately equal to width at base) in the Pteronotus parnellii and $P$. personatus complexes, $P$. quadridens, the $P$. davyi complex, P. gymnonotus, and both species of Mormoops. In contrast, the clitoris is elongated (clitoris length approximately twice width at base) in Pteronotus macleayii. Among the outgroups, the clitoris is of moderate size in Saccopteryx bilineata, Thyroptera tricolor, Furipterus horrens, both species of Macrotus, and Artibeus jamaicensis, but is elongated in both species of Noctilio. Data were not available for Koopmanycteris, Speonycteris, Pteronotus pristinus, and both species of Mystacina for this character, which corresponds to character 178 of Simmons and Geisler (1998) and character 199 of Simmons and Conway (2001).

CHARACTER 236: External uterine horns more than three-fourths the length of the external common uterine body (0); or one-half the length of the common uterine body (1); or one-fourth the length of the common uterine body (2); or uterus fully simplex, uterine horns not distinct from common uterine body (3). All mormoopids for which uterine structure has been described-Mormoops blainvillei, the Pteronotus parnellii complex, $P$. macleayii, and $P$. quadridens-are characterized by uterine horns approximately one-half the length of the common uterine body (Hood and Smith, 1982, 1983). Among the outgroups, a similar condition is seen in both species of Noctilio, Thyroptera tricolor, and Furipterus horrens. In contrast, Saccopteryx bilineata and Mystacina robusta have uterine horns that are more than three-fourths the length of the common uterine body, while Macrotus californicus has uterine horns that are one-fourth the length of the common uterine body, and Artibeus jamaicensis has a fully simplex uterus that lacks free uterine horns (Hood and Smith, 1982, 1983; N.B.S., personal obs.). Data were not available for Koopmanycteris, Speonycteris, members of the Pteronotus personatus and $P$. davyi complexes, $P$. gymnonotus, $P$. pristinus, Mormoops megalophylla, Mystacina tuberculata, and Macrotus waterhousii for this character, which corresponds to character 131 of Wetterer et al. (2000), character 179 of Simmons and Geisler (1998), and character 200 of Simmons and Conway (2001). We followed the last-named authors and Hood and Smith $(1982,1983)$ in treating this as an ordered character.

Character 237: Common uterine lumen relatively short, coronal lumina join well within common uterine body (0); or common uterine lumen large, coronal lumina join immediately within the common uterine body (1); or common uterine lumen very large, coronal lumina either reduced to a tubular intramural uterine cornua or entirely absent (2). As noted by Simmons and Conway (2001), internal uterine fusion in bats is broadly correlated with external uterine fusion but these two features are decoupled to some extent because the degree of external fusion is not always indicative of a similar degree of fusion of the coronal lumina within the common uterine body (Hood and Smith, 1982, 1983). In Mormoops blainvillei, the Pteronotus parnellii complex, $P$. macleayii, and $P$. quadridens, the common uterine lumen is relatively large and the coronal lumina join immediately upon their entry into the common uterine body (Hood and Smith, 1982, 1983). A 
similar condition is seen in Macrotus californicus. In contrast, the common uterine lumen is relatively short and the coronal lumina join well within the common uterine body in Saccopteryx bilineata, Mystacina robusta, Thyroptera tricolor, Furipterus horrens, and both species of Noctilio (Hood and Smith, 1982, 1983; N.B.S., personal obs.). Another condition is seen in Artibeus jamaicensis, which has a very large common uterine lumen and lacks any remnants of coronal lumina (Hood and Smith, 1982, 1983). As with the preceding character, we followed Hood and Smith $(1982,1983)$ and Simmons and Conway (2001) in ordering this character. No data were available for Koopmanycteris, Speonycteris, the Pteronotus personatus and $P$. davyi complexes, P. gymnonotus, $P$. pristinus, Mormoops megalophylla, Mystacina tuberculata, and Macrotus waterhousii for this character, which corresponds to character 181 of Simmons and Geisler (1998) and character 201 of Simmons and Conway (2001).

Character 238: Uterotubal junction with oviductal papilla (0); or oviductal papilla absent (1). Mormoops blainvillei, members of the Pteronotus parnellii complex, $P$. macleayii, and $P$. quadridens have a simple uterotubal junction and lack an oviductal papilla (Hood and Smith, 1982, 1983). Saccopteryx bilineata, both species of Noctilio, Thyroptera tricolor, Macrotus californicus, and Artibeus jamaicensis similarly have a simple uterotubal junction lacking an oviductal papilla (Hood and Smith, 1982, 1983). In contrast, an oviductal papilla projects into the lumen of the uterus in Mystacina robusta (Simmons and Conway, 2001). No data were available for Koopmanycteris, Speonycteris, members of the Pteronotus personatus and $P$. davyi complexes, $P$. gymnonotus, $P$. pristinus, Mormoops megalophylla, Mystacina tuberculata, Furipterus horrens, and Macrotus waterhousii for this character, which corresponds to character 182 of Simmons and Geisler (1998) and character 202 of Simmons and Conway (2001).

Character 239: Oviductal mucosal folds occur throughout the oviduct (0); or folds restricted to extramural oviduct (1). Oviductal mucosal folds occur throughout the oviduct including the intramural portion that is enclosed within the wall of the uterus in Mormoops blainvillei, the Pteronotus parnellii complex, $P$. macleayii, and $P$. quadridens (Hood and Smith, 1982, 1983). A similar condition occurs among in Saccopteryx bilineata, Thyroptera tricolor, both species of Noctilio, and Mystacina robusta (Hood and Smith, 1982, 1983). In contrast, Macrotus californicus and Artibeus jamaicensis are characterized by restriction of oviductal mucosal folds to the extramural oviduct; the intramural portion of the oviduct is smooth and lacks any such folds (Hood and Smith, 1982, 1983). No data were available for Koopmanycteris, Speonycteris, members of the Pteronotus personatus and $P$. davyi complexes, P. gymnonotus, P. pristinus, Mormoops megalophylla, Furipterus horrens, Mystacina tuberculata, and Macrotus waterhousii for this character, which corresponds to character 203 of Simmons and Conway (2001).

Character 240: Ovarian ligament extends from ovary to external entry of oviduct (0); or to lateral border of common uterine body (1). The ovarian ligament extends from the ovary to the external entry of the oviduct into the uterus in all mormoopids surveyed to date (Mormoops blainvillei, members of the Pteronotus parnellii complex, P. macleayii, and P. quadridens; Hood and Smith, 1982, 1983). This condition also occurs among the outgroups in Saccopteryx bilineata, Mystacina robusta, Thyroptera tricolor, both species of Noctilio, and Macrotus californicus (Hood and Smith, 1982, 1983). In contrast, the ovarian ligament extends from the ovary to the lateral border of the common uterine body in Artibeus jamaicensis (Hood and Smith, 1982, 1983). No data were available for Koopmanycteris, Speonycteris, members of the Pteronotus personatus and $P$. davyi complexes, $P$. gymnonotus, P. pristinus, Mormoops megalophylla, Furipterus horrens, Mystacina tuberculata, and Macrotus waterhousii for this character, which corresponds to character 134 of Wetterer et al. (2000) and character 204 of Simmons and Conway (2001). 


\section{Digestive Tract}

CHARACTER 241: Submaxillary glands of mucous type (0); or of serous type (1); or absent (2). Mucous-type submaxillary glands (which are nongranular, have an epithelial membrane, and secrete mucous) are found in members of the Pteronotus parnellii and $P$. davyi complexes (Dalquest and Werner, 1954). In contrast, Mormoops megalophylla is characterized by serous-type submaxillary glands (= albuminous glands), which are granular, have a layer of mesothelium, and secrete a watery fluid (Dalquest and Werner, 1954). Among the outgroups, mucous-type submaxillary glands are present in Saccopteryx bilineata, and submaxillary glands are absent in Artibeus jamaicensis (Dalquest and Werner, 1954). No data were available for Koopmanycteris, Speonycteris, members of the Pteronotus personatus complex, $P$. quadridens, $P$. macleayii, P. gymnonotus, $P$. pristinus, Mormoops blainvillei, both species of Noctilio, Thyroptera tricolor, Furipterus horrens, both species of Mystacina, and both species of Macrotus for this character, which corresponds to character 205 of Simmons and Conway (2001). We followed those authors in treating this as an unordered character.

Character 242: Cardiac vestibule of stomach very small or absent (0); or large (1). The cardiac vestibule, defined as that part of the stomach that is immediately adjacent to the esophageal opening, is very small or absent in the Pteronotus parnellii complex and Mormoops megalophylla (Foreman, 1971, 1972, 1973). A similar condition is seen among the outgroups in Saccopteryx bilineata, both species of Noctilio, and Macrotus waterhousii (Foreman, 1971, 1972, 1973, 1979). In contrast, the cardiac vestibule is large in Artibeus jamaicensis (Foreman, 1979). Data were not available for Koopmanycteris, Speonycteris, Pteronotus quadridens, $P$. macleayii, members of the $P$. personatus and $P$. davyi complexes, $P$. gymnonotus, P. pristinus, Mormoops blainvillei, both species of Mystacina, Thyroptera tricolor, Furipterus horrens, and Macrotus californicus for this character, which corresponds to character 206 of Simmons and Conway (2001).

Character 243: Mucous-producing pyloric glands distributed in extremely narrow zone immediately adjacent to pyloric sphincter (0); or distributed in broad zone (1). Mucous-producing pyloric glands are distributed in an extremely narrow zone immediately adjacent to pyloric sphincter in members of the Pteronotus parnellii complex and Mormoops megalophylla (Foreman, 1971, 1972, 1973). A similar condition is seen in Saccopteryx bilineata and both species of Noctilio (Foreman, 1971, 1972, 1973). In contrast, mucous-producing pyloric glands are distributed in a much broader zone of the stomach in Macrotus waterhousii and Artibeus jamaicensis (Foreman, 1979). Data were not available for Koopmanycteris, Speonycteris, Pteronotus quadridens, $P$. macleayii, members of the $P$. personatus and $P$. davyi complexes, $P$. gymnonotus, $P$. pristinus, Mormoops blainvillei, both species of Mystacina, Thyroptera tricolor, Furipterus horrens, and Macrotus californicus for this character, which corresponds to character 207 of Simmons and Conway (2001).

Character 244: Pyloric sphincter asymmetrical, valve in lesser curvature smaller than valve in greater curvature (0); or sphincter symmetrical, valves of similar size (1). The pyloric sphincter is asymmetrical, with the valve in the lesser curvature of the stomach smaller than the valve in the greater curvature, in members of the Pteronotus parnellii complex and Mormoops megalophylla (Foreman, 1971, 1972, 1973). A similar condition is seen in both species of Noctilio and Macrotus waterhousii (Foreman, 1971, 1972, 1973, 1979). In contrast, the pyloric sphincter has valves of similar size and is symmetrical in Saccopteryx bilineata and Artibeus jamaicensis (Foreman, 1973, 1979). Data were not available for Koopmanycteris, Speonycteris, Pteronotus quadridens, $P$. macleayii, members of the $P$. personatus and $P$. davyi complexes, $P$. gymnonotus, P. pristinus, Mormoops blainvillei, both 
species of Mystacina, Thyroptera tricolor, Furipterus horrens, and Macrotus californicus for this character, which corresponds to character 208 of Simmons and Conway (2001).

CHARACTER 245: Brunner's glands at gastroduodenal junction present in small to moderate numbers, with broad tubules and moderate to large cells with large, spherical nuclei that are juxtaposed to the basement membrane (0); or glands abundant, with tubules of moderate breadth and small cells with extremely small, spherical nuclei that are juxtaposed to the basement membrane (1); or glands unusually abundant, with narrow tubules and small cells with extremely small, flattened nuclei that are not juxtaposed to the basement membrane (2). Brunner's glands are unusually abundant in the Pteronotus parnellii complex and Mormoops megalophylla compared with other bats (Foreman, 1971, 1972, 1973). Brunner's glands in mormoopids are characterized by narrow tubules and small cells with extremely small, flattened nuclei that are not juxtaposed to the basement membrane (Foreman, $1971,1972,1973)$. A similar condition is seen in both species of Noctilio (Foreman, 1971, 1972, 1973). In contrast, Macrotus waterhousii and Artibeus jamaicensis have Brunner's glands present in small to moderate numbers, with broad tubules and moderate to large cells with large circular nuclei that are juxtaposed to the basement membrane (Foreman, 1979). Saccopteryx bilineata is characterized by an intermediate condition in which the Brunner's glands are abundant, with tubules of moderate breadth and small cells with extremely small, spherical nuclei that are juxtaposed to the basement membrane (Foreman, 1972, 1973). Data were not available for Koopmanycteris, Speonycteris, Pteronotus quadridens, $P$. macleayii, members of the $P$. personatus and $P$. davyi complexes, $P$. gymnonotus, P. pristinus, Mormoops blainvillei, both species of Mystacina, Thyroptera tricolor, Furipterus horrens, and Macrotus californicus for this character, which corresponds to character 209 of Simmons and Conway (2001). We followed those authors in ordering this character.

\section{PHYLOGENETIC ANALYSES}

\section{REsUlts}

A parsimony analysis of the complete morphological data set (all characters, no scaffold constraints) resulted in three equally most-parsimonious trees of 654 steps $(\mathrm{CI}=0.544$; $\mathrm{CI}$ excluding uninformative characters $=0.526$; $\mathrm{RI}=$ $0.702)$; a bootstrap consensus tree is shown in figure 14. Monophyly of all genera and families was strongly supported, including Mormoops, Pteronotus, and Mormoopidae. Within Mormoopidae, Koopmanycteris grouped within crown group as the sister taxon of Mormoops. Support for this grouping was high-it occurred in $99 \%$ of the bootstrap replicates (abbreviated hereafter as BS =99). Speonycteris aurantiadens was placed as the sister-group to the entire mormoopid clade with low support ( $B S=59$ ). The third fossil in our analysis, Pteronotus pristinus, was placed as the sister-taxon of the $P$. parnellii complex with moderate support $(B S=76)$. Support for relationships among outgroups representing different families was high for one pairing (Thyroptera + Furipterus, BS $=97$ ) but was moderate to low for all other interfamilial groupings. Phyllostomidae (represented by Artibeus + Macrotus) was placed as the sister group of Mormoopidae + Speonycteris with low support (BS = 54).

A parsimony analysis including only 145 osteological features of the dentition, skull, and postcranium (i.e., features that might be preserved in a fossil taxon; $59 \%$ of the total character set) resulted in a single most-parsimonious tree (not shown; 407 steps; $\mathrm{CI}=0.509$; $\mathrm{CI}$ excluding uninformative characters $=0.498$; $\mathrm{RI}=0.704$ ). Tree topology was similar to that recovered in the analysis of the complete data set, differing only in the relationships detected among the outgroups and in relationships among the Pteronotus personatus complex, $P$. macleayii, and $\mathrm{P}$. quadridens. Relationships of Koopmanycteris, Speonycteris, and Pteronotus pristinus to extant species were identical to the more comprehensive analysis including all characters. 


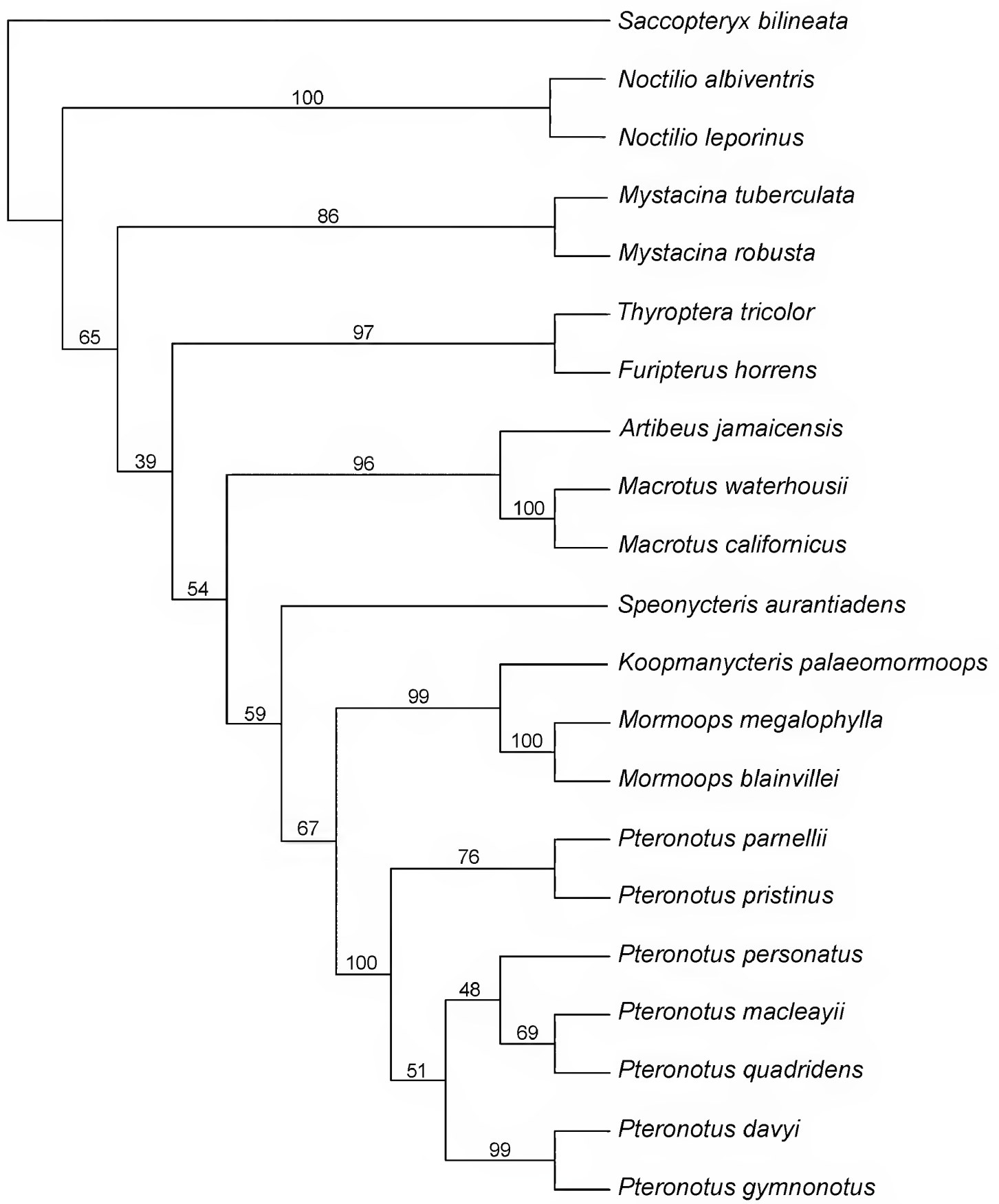

FIGURE 14. Relationships of mormoopids and selected outgroups based on unconstrained parsimony analyses (no molecular scaffold) of the complete 245 character morphological data set. The topology shown is a bootstrap consensus of the three equally most-parsimonious trees recovered (654 steps; $\mathrm{CI}=0.544$; $\mathrm{CI}$ excluding uninformative characters $=0.526$; $\mathrm{RI}=0.702)$; numbers above branches are bootstrap values. Note Koopmanycteris falls within the crown clade Mormoopidae as the sister taxon of Mormoops with very high support $(B S=99)$. See Materials and Methods for details of analysis. 
As described in "Materials and Methods" above, we constructed a scaffold constraint tree for the extant taxa in our study based on results of published analyses of molecular sequence data (i.e., Dávalos, 2006; Meredith et al., 2011; Rojas et al., 2016; Pavan and Marroig, 2016, 2017). With relationships of the extant taxa held constant, we ran a parsimony analysis to place the three fossil taxa in the tree. This analysis resulted in a single most-parsimonious tree (fig. 15) in which Koopmanycteris was placed as the sister taxon to Mormoops, and Pteronotus pristinus was placed as the sister taxon of the $P$. parnellii complex, just as in our unconstrained analyses. Support for the Koopmanycteris + Mormoops clade was very high (BS $=99$ ), and support for the Pteronotus parnellii complex + P. pristinus clade was moderate $(\mathrm{BS}=73)$. Speonycteris was placed in a slightly different position in the constrained analysis, appearing as sister taxon to the clade comprising Mormoopidae + Phyllostomidae (rather than as the sister group of Mormoopidae) but with only low support $(B S=48)$. Support for the sister-group relationship of Mormoopidae and Phyllostomidae was similarly low ( $B S=52$ ), apparently reflecting ambiguity regarding the placement of Speonycteris relative to the more completely known taxa in those families.

To test the effects of inclusion of various fossil taxa on perceived relationships and support values, we conducted a series of pruned analyses using the scaffold constraints. When Speonycteris was excluded from the analysis (fig. 16), perceived relationships remained unchanged, but support values for many nodes increased, most notably along the backbone of the tree. Support for the crown clade Mormoopidae (including Koopmanycteris) was very high ( $\mathrm{BS}=100)$, as was support for the Koopmanycteris + Mormoops clade (BS =99). In contrast, removal of Koopmanycteris (fig. 17) had a different effect: perceived relationships remained unchanged, but support values were significantly decreased along much of the backbone of the tree.

\section{Discussion AND Conclusions}

In his classic review of the Mormoopidae, Smith (1972) discussed a large suite of morphological characters that he convincingly argued established the distinctiveness of this family, which previously had been considered a subfamily (Chilonycterinae) of the Phyllostomidae. Subsequent classifications of the Chiroptera (e.g., Hill and Smith, 1984; Koopman, 1993, 1994; Nowak, 1994; McKenna and Bell, 1997; Simmons, 1998, 2005a, 2005b) have followed Smith in recognizing the Mormoopidae as a valid chiropteran family. Smith (1972) presented detailed systematic accounts of eight living species of mormoopids, including two species of Mormoops and six species of Pteronotus. He recognized three subgenera within Pteronotus: the subgenus Pteronotus including $P$. davyi and P. gymnonotus (= P. suapurensis of Smith, 1972, now considered a synonym of $P$. gymnonotus); the subgenus $C h i-$ lonycteris, including Pteronotus macleayii, $P$. personatus, and $P$. quadridens ( $=P$. fuliginosus of Smith, 1972, now considered a synonym of $P$. quadridens); and the subgenus Phyllodia, including only Pteronotus parnellii (Smith, 1972). Two years later Silva Taboada (1974) described two fossil mormoopids, which he named Mormoops magna and Pteronotus pristinus, from late Pleistocene/Holocene cave deposits in Cuba.

Recent analyses of the Mormoopidae have employed different but overlapping data sets that produced different results with respect to both species limits and phylogeny. To evaluate relationships among traditionally recognized species, Simmons and Conway (2001) used morphological characters, Lewis-Oritt et al. (2001) used molecular data, and Van Den Bussche et al. (2002) both conducted sequence analyses and employed a total-evidence approach that incorporated molecular and morphological data, the latter drawn from Simmons and Conway (2001). Hoofer et al. (2003) incorporated molecular data from the Mormoopidae into a larger molecular phylogeny of noctilionoid and vespertilionoid bats but did not have complete sam- 


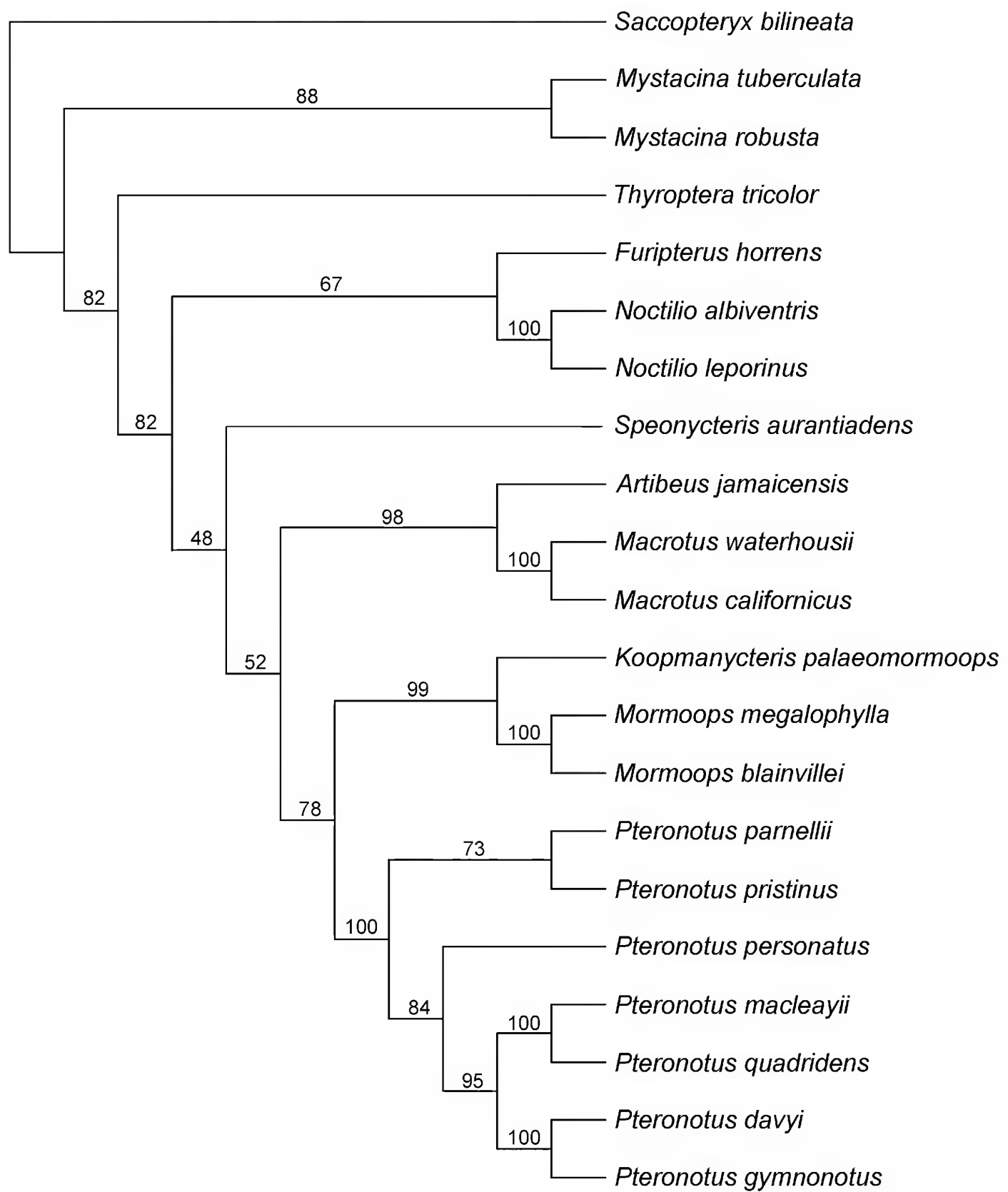

FIGURE 15. Results of parsimony analyses of the complete data set with relationships of extant taxa constrained by a molecular scaffold (see Materials and Methods for details). The topology shown is the single most-parsimonious tree recovered (689 steps; CI = 0.517; CI excluding uninformative characters $=0.499$; RI = 0.667); numbers above branches are bootstrap values. As in the unconstrained analyses (fig. 14), Koopmanycteris falls within the crown clade Mormoopidae as the sister taxon of Mormoops with very high support (BS =99). 


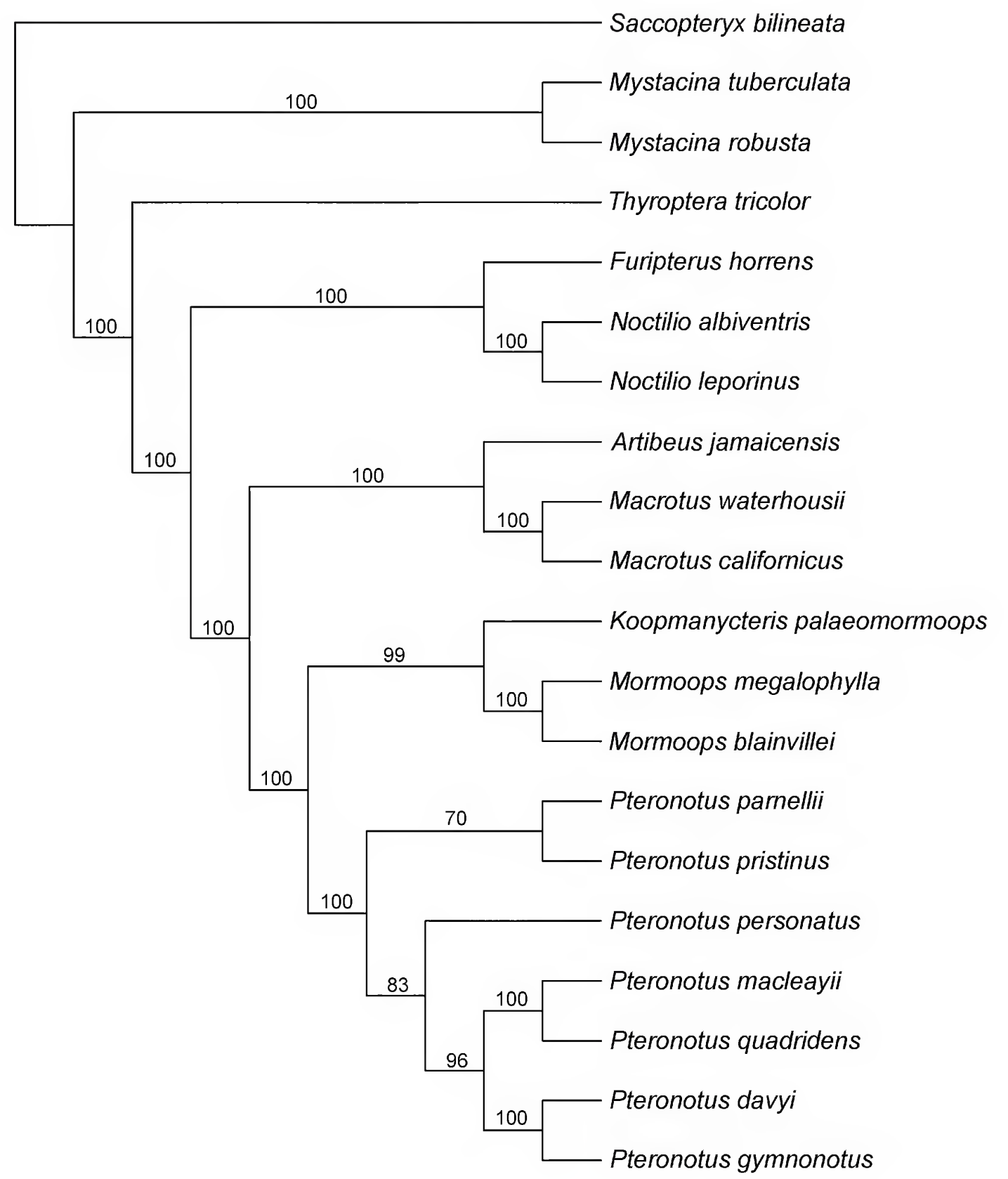

FIGURE 16. Results of parsimony analyses using a molecular scaffold but excluding Speonycteris aurantiadens from the data set. The topology shown is the single most-parsimonious tree recovered ( 683 steps; $\mathrm{CI}=0.521$; $\mathrm{CI}$ excluding uninformative characters $=0.502$; $\mathrm{RI}=0.669$ ); numbers above branches are bootstrap values. Comparison with figure 15 indicates that removal of Speonycteris aurantiadens from the analyses has no effect on tree topology, but results in much higher support values, particularly along the backbone of the tree. 


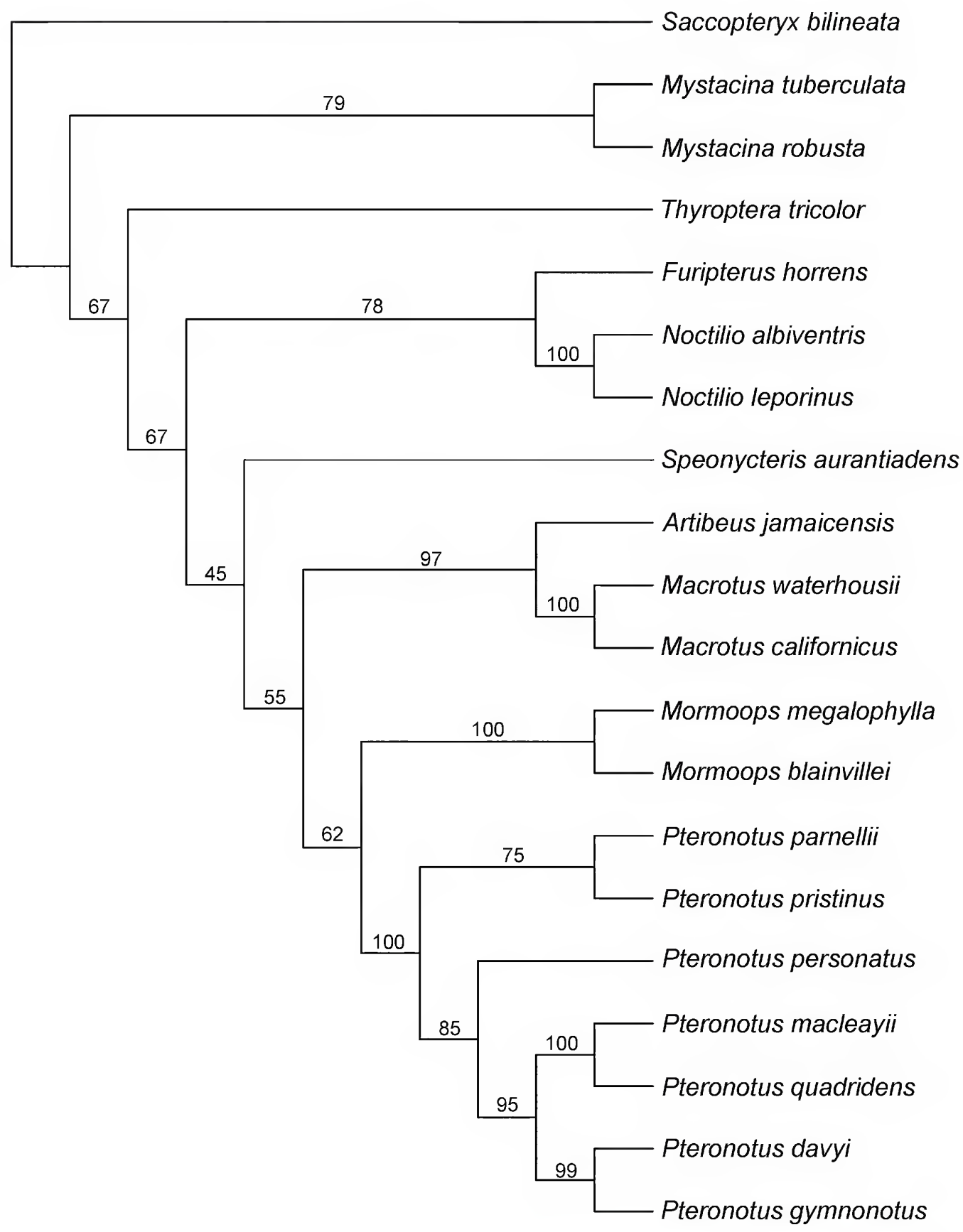

FIGURE 17. Results of parsimony analyses using a molecular scaffold but excluding Koopmanycteris palaeomormoops from the data set. The topology shown is a bootstrap consensus tree; numbers above branches are bootstrap values. Note that while topology of this tree is fully consistent with that shown in figure 15, support values are comparatively lower along the backbone of the tree. Perhaps by breaking up the long branch leading to Mormoops, inclusion of Koopmanycteris seems to have a stabilizing effect, particularly on analyses including the much less complete Oligocene noctilionoid Speonycteris aurantiadens (e.g., fig. 15). 
pling of extant mormoopid species. More recently, several teams of researchers have focused on simultaneously evaluating phylogenetic relationships and understanding hidden diversity within the traditionally recognized species. Dávalos (2006) was among the first to note that several lineages of Pteronotus (notably $P$. parnellii, $P$. davyi, and $P$. personatus) contained cryptic species, although she did not attempt a comprehensive analysis of any of these groups. Gutiérrez and Molinari (2008) and Clare et al. (2013) used molecular, morphological, and acoustic data to confirm that Pteronotus parnellii represents a species complex and to begin to tease apart relationships among various populations. Thoisy et al. (2014) built upon these findings using a more comprehensive sample of $P$. parnellii, and Rojas et al. (2016) reported similar results using a larger set of genes and noctilionoid taxa. The most comprehensive analyses of extant mormoopids to date are those of Pavan and Marroig $(2016,2017)$, who combined extensive nuclear and mitochondrial data with morphometric analyses to simultaneously reconstruct phylogeny and evaluate species limits across the nearly entire geographic ranges of various lineages. Their phylogenetic results mirror those of Dávalos (2006) while adding depth of resolution within each clade.

All phylogenetic analyses completed to dateregardless of data source-have provided strong support for monophyly of Mormoopidae, Mormoops, and Pteronotus (Simmons and Conway, 2001, Lewis-Oritt et al., 2001; Van Den Bussche et al., 2002; Hoofer et al., 2003; Dávalos, 2006; Thoisy et al., 2014; Rojas et al., 2016; Pavan and Marroig, 2016, 2017). Within Pteronotus, the morphology-based analyses of Simmons and Conway (2001) also supported the monophyly of the three subgenera of Pteronotus (Pteronotus, Phyllodia, and Chilonycteris), and placed the extinct Pleistocene species from Cuba, $P$. pristinus, in the subgenus Phyllodia. In contrast, however, molecular studies of the Mormoopidae have not supported the monophyly of all three subgenera of Pteronotus. Notably, the relationships of the P. personatus complex have been problematic, and several studies have suggested that the subgenus Chilonycteris may not be monophyletic as originally conceived (Lewis-Oritt et al., 2001; Van Den Bussche et al., 2002; Dávalos, 2006; Thoisy et al., 2014; Rojas et al., 2016; Pavan and Marroig, 2016, 2017).

Simmons and Conway's (2001) morphological analyses produced a single most-parsimonious tree, but support values for many of the clades within were low. Strong support was found for monophyly of Mormoopidae, Mormoops, Pteronotus, and a clade comprised of $P$. davyi and P. gymnonotus. However, the remaining groupings within Pteronotus had bootstrap support of $<70 \%$ and Bremer (1994) supports of 1 regardless of whether the fossil $P$. pristinus was included or excluded (Simmons and Conway, 2001). In recent molecular sequence analyses, strong support has been found for monophyly of Phyllodia (comprised of the Pteronotus parnellii complex), the subgenus Pteronotus ( $P$. davyi complex plus $P$. gymnonotus), and a sister-group relationship between $P$. quadridens and $P$. macleayii (Dávalos, 2006; Thoisy et al., 2014; Rojas et al., 2016; Pavan and Marroig, 2016, 2017), all of which were groupings recovered with low support in the most-parsimonious morphology-based trees of Simmons and Conway (2001). However, support for monophyly of Chilonycteris as conceived by Smith (1972) and Simmons and Conway (2001)-comprised of Pteronotus personatus and the $P$. quadridens $+P$. macleayii clade-has been lacking. Instead, several studies have found moderate support for a placement of the P. personatus complex as sister group to a larger clade additionally including the subgenus Pteronotus (Dávalos, 2006; Thoisy et al., 2014; Rojas et al., 2016; Pavan and Marroig, 2016, 2017). This topology was used as the molecular scaffold in our analyses (see Materials and Methods above).

One of the interesting aspects of the phylogenetic results of our study is that the topology of the trees recovered based on an unconstrained analysis of morphology alone (fig. 14) are more similar to the molecular scaffold for extant mor- 
moopid taxa than were the results of Simmons and Conway (2001). With the addition of three fossils, two additional outgroups, and 36 new characters, the unconstrained morphology-based tree we recovered for mormoopids matched the structure of the molecular scaffold with the exception of placement of only one taxon, the ever-problematic Pteronotus personatus lineage. In our morphology-based tree there is low support $(B S=48)$ for a sister-group relationship between the $P$. personatus complex and the $P$. quadridens $+P$. macleayii clade. Ironically, that mirrors the low support (BS $=62$ ) for placement of the $P$. personatus complex in a somewhat more basal position (as sister to a $P$. quadridens $+P$. macleayii $+P$. gymnonotus $+P$. davyi clade) found by Dávalos (2006) based on Rag2 data. Unlike Simmons and Conway (2001), our revised morphological data place the Pteronotus parnellii lineage (including $P$. pristinus) as the most basal branch within Pteronotus. This matches the placement supported by concatenated molecular data (Lewis-Oritt, 2001; Dávalos, 2006; Rojas et al., 2016, Pavan and Marroig, 2016, 2017).

The relationships detected among the outgroups based on morphology alone (fig. 14) matched those of the scaffold tree topology with one notable exception: the placement of Noctilionidae, represented by two species, Noctilio albiventris and $N$. leporinus. The Noctilio lineage was placed near the bottom of the tree as sister to all other New World noctilionoids in our unconstrained morphology analysis, but nested higher up the tree as the sister group of Furipterus in recent molecular studies (e.g., Miller-Butterworth et al., 2007; Meredith et al., 2011; Rojas et a., 2016). The placement of Noctilio in our morphology analysis may represent a case of longbranch attraction (sensu Bergsten, 2005); Noctilio is diagnosed by over 30 synapomorphies and the living taxa are clearly highly derived in terms of their morphology, exhibiting numerous conditions not seen in any other noctilionoid (Simmons and Conway, 2001).

Our analyses strongly support the placement of the Oligocene fossil Koopmanycteris palaeomor- moops within the mormoopid crown group. In both the morphology-only and scaffold analyses, Koopmanycteris was placed as the sister taxon to Mormoops with very high support $(\mathrm{BS}=99)$. Features that diagnose Mormoops + Koopmanycteris (and differentiate this clade from Pteronotus) include derived features of the dentition (e.g., P4 with large anterolabial basin and tall, sharp, conical protocone on P4), skull and lower jaw (e.g., moderate upturning of the rostrum and rounded, flangelike angular process oriented posteriorly), radius (e.g., rounded to flattened extremity of proximal radius), humerus (e.g., absence of groove separating capitulum into medial and lateral portions on distal humerus; presence of prominent ridge on posterolateral edge of distal humeral shaft), and femur (relatively elongated femur; presence of prominent ridge or tubercle on posterodistal shaft of femur). Koopmanycteris also shares relatively plesiomorphic features with Mormoops that are modified in Pteronotus (e.g., a large, double-rooted p3).

The premolar dentition of Koopmanycteris appears to be somewhat more derived than that of Mormoops, based on the presumption that premolar reduction and loss is a derived feature in most chiropteran families (see discussion in Simmons and Geisler, 1998, and Giannini and Simmons, 2007a). It is evident from the alveolar morphology that, compared with Mormoops, both the p1 and p3 are smaller in Koopmanycteris and there are no diastemata separating them, and the entire premolar region is more compressed anteroposteriorly. The morphology of the lower molars in Mormoops differs from Koopmanycteris in the sharp, narrow crests with deep notches, which causes the cusps to look more elongated, delicate, and spikelike. Also, the $\mathrm{m} 1$ of Mormoops has an elongated paraconid that overlaps p4. Although more similar to Mormoops than Pteronotus, the $\mathrm{m} 1$ of Koopmanycteris differs from all other mormoopids in its highly reduced paraconid that is strongly offset labially from the lingual margin of the tooth.

In several mandibular characters, Koopmanycteris more closely resembles Pteronotus than 
Mormoops, although most of these features can be considered plesiomorphic. These characters include: the overall shape of the mandibular symphysis; the more vertical orientation of the symphysis, which forms a more acute angle with the ventral edge of the mandible; a pronounced posteroventral process on the symphysis; and the lack of curvature of the ventral edge of the horizontal ramus between the posterior edge of the symphysis and $\mathrm{p} 4$. Posterior to $\mathrm{m} 3$, the ascending ramus of the mandible is sharply upturned dorsally in Mormoops, whereas the dentary in Koopmanycteris and Pteronotus, although strongly upturned compared to most other bats, is not as radically flexed dorsally as in Mormoops. The strong dorsal flexion of the posterior region of the mandible is a derived condition in mormoopids compared to most other bats, a feature reaching its most extreme development in Mormoops. The lesser degree of dorsal flexion of the ascending ramus in Pteronotus and Koopmanycteris represents the primitive condition for the Mormoopidae, but is derived compared to most other groups of bats.

When fossil species are discovered that clearly belong to living lineages, there is often a question as to whether or not they should be included within extant genera. In the case of Koopmanycteris, it is clear that this taxon preserves a mosaic of primitive and derived traits that sets it apart from both of these living genera, Mormoops and Pteronotus. While our analyses unambiguously place $K$. palaeomormoops as the sister group of living Mormoops, the fossil species is clearly different from $M$. megalophylla and M. blainvillei. Although it shares many synapomorphies with living Mormoops, Koopmanycteris minimally lacks at least 10 synapomorphies of Mormoops including lower molar cristids that are especially thin, sharp edged, and deeply notched; a proximal humerus with an elevated ridge or tuberosity at the distal extremity of the lesser tuberosity (rather than a continuous flange that runs along it); distal humerus with articular facets in line with shaft (rather than being offset); a reduced central capitulum whose height is considerably less than that of the trochlea; a distal spinous process whose height is greater than the trochlea, and that is directly adjacent to the trochlea and not separated from it by a notch. Mormoops is additionally diagnosed by other synapomorphies that cannot be scored in Koopmanycteris due to the absence of appropriately preserved specimens, including features of the dentition, skull, face, ears, pelage, vertebral column, scapula, ulna, metacarpals, phalanges, and forelimb musculature. What is more, Koopmanycteris is itself diagnosed by features not seen in Mormoops (see Description and Comparisons above). Redefining Mormoops to include palaeomormoops would be counterproductive because it would cause confusion with respect to historical use of the name Mormoops and would hinder communication about the genus, especially regarding unknowable features of soft anatomy, behavior, and ecology. The age of the fossil species and its placement decidedly outside the crown group of Mormoops also argue against it being considered just another type of Mormoops. Koopmanycteris was something different, and much older. Accordingly, we believe that naming a new genus for this taxon is clearly justifiable. In contrast to the case of Koopmanycteris, Pteronotus pristinus groups within the crown group Pteronotus, and differs in only a few features from the extant Pteronotus parnellii complex. Moreover, Pteronotus pristinus is Late Quaternary in age, and occurs in a cave fossil deposit with several extant species of mormoopids (Silva Taboada, 1974). In this case, placement of the fossil in Pteronotus is certainly warranted.

Our analyses also included Speonycteris, an enigmatic fossil noctilionoid from Florida. Speonycteris, which includes two species, comes from the same two Florida Oligocene localities, I-75 and Brooksville 2, that produced Koopmanycteris, but is easily distinguished from Koopmanycteris on the basis of size (Speonycteris is larger) and morphology. 
At the time they described Speonycteris, Czaplewski and Morgan (2012) conducted a phylogenetic analysis that produced somewhat ambiguous results. Depending on the subset of taxa and characters they used, Czaplewski and Morgan (2012) found that Speonycteris aurantiadens occupied various stem positions within Noctilionoidea, always closely related to Mormoopidae, Noctilionidae, Mystacinidae, and Phyllostomidae but never falling within any of those families. Given these results, Czaplewski and Morgan (2012) concluded that Speonycteris most likely represented a stem noctilionoid, and they named a new family (Speonycteridae) for this genus. Our more comprehensive analyses including both Speonycteris aurantiadens and Koopmanycteris provide considerable support for Czaplewski and Morgan's (2012) conclusion that Speonycteris represents an ancient noctilionoid not referable to any extant family. In our constrained analysis including all taxa, Speonycteris aurantiadens fell outside all extant families but nested high within the noctilionoid tree; support for placement of Speonycteris within the Mormoopidae + Phyllostomidae + Noctilionidae + Furipteridae clade was quite high $(\mathrm{BS}=82)$. Within that clade, our best guess is that Speonycteris represents the sister group of Mormoopidae + Phyllostomidae (BS $=48$ ), but more complete fossils will be needed to provide additional tests of this hypothesis. We suspect that part of our success in unambiguously placing Koopmanycteris in the tree, while placement of Speonycteris aurantiadens remains somewhat uncertain, stems from the greater completeness of Koopmanycteris (which can be scored for twice as many characters as Speonycteris aurantiadens) and the fact that inclusion of Koopmanycteris serves to break up the long branch leading to the highly derived Mormoops clade. The even less complete species Speonycteris naturalis-known only from a single M2 from the I-75 localitycan at best be hypothesized to group with $S$. aurantiadens based on overall similarity (Czaplewski and Morgan, 2012).

\section{BIOGEOGRAPHY AND EVOLUTIONARY HISTORY}

The discovery of fossils belonging to the Mormoopidae from the Oligocene of Florida adds an important new dimension to the evolutionary history and historical biogeography of this endemic New World chiropteran family. Koopmanycteris palaeomormoops from the early Oligocene I-75 LF and the late Oligocene Brooksville 2 LF is the oldest known Tertiary species of Mormoopidae. Prior to its discovery, the oldest known mormoopid fossil was a partial skeleton tentatively assigned to the extant species Pteronotus parnellii from the early Pleistocene (Irvingtonian) Barranca del Sisimico fauna in El Salvador, Central America (Webb and Perrigo, 1984). Late Quaternary fossils of mormoopids are known from cave deposits in Florida (Morgan, 1991, 2002), Mexico (Arroyo-Cabrales, 1992; ArroyoCabrales and Polaco, 2003, 2008), the West Indies (Silva Taboada, 1974, 1979; Morgan, 2001; Jiménez Vásquez et al., 2005; Orihuela and Tejedor, 2012; Velazco et al., 2013; Stoetzel et al., 2016), Venezuela (Rincón, 1999), and Brazil (Czaplewski and Cartelle; 1998; Lessa et al., 2005; Salles et al., 2005; Fracasso and Salles, 2005).

\section{BIogeography AND Fossil ReCord}

Extant mormoopid diversity includes two species of Mormoops and at least 16 species of Pteronotus (Pavan and Marroig, 2016, 2017; Pavan et al., 2018). All extant mormoopids are restricted to the Neotropical region, with the exception of Mormoops megalophylla as discussed below. Extant West Indian endemics include one species of Mormoops (Mormoops blainvillei), two species of Pteronotus long recognized to be island endemics (Pteronotus macleayii and $P$. quadridens), and three island populations recently identified as distinct species-level lineages from within the Pteronotus parnellii complex ( $P$. parnellii sensu stricto, $P$. pusillus, and $P$. portoricensis; Dávalos, 2006; Thoisy et al., 2014; Pavan and Marroig, 2016, 2017). Two extinct late 
Pleistocene species-Mormoops magna and Pteronotus pristinus-are also endemic to the West Indies (Varona, 1974; Silva Taboada, 1974, 1979; Morgan, 2001; Silva Taboada et al., 2007; Velaszco et al., 2013), although Morgan (1991, 2002) tentatively identified Pteronotus pristinus from a late Pleistocene site in southernmost Florida. The other extant mormoopid species occur on the Neotropical mainland with geographic ranges variously extending from Mexico to South America. Of these, Mormoops megalophylla (in Late Quaternary cave deposits), Pteronotus davyi, and P. fuscus also occur in the West Indies (Smith, 1972; Morgan, 2001; Kwiecinski et al., 2018). In South America, living mormoopids occur primarily in the northern half of the continent, especially the Caribbean coastal region of Venezuela and Colombia and the northwestern Pacific coast of Colombia, Ecuador, and Peru. With the exception of members of the Pteronotus parnellii complex, all are uncommon in the Amazon basin where caves are rare (Smith, 1972; Koopman, 1982; Simmons and Voss, 1998; Pavan et al., 2017; Pavan et al., 2018).

The Florida Oligocene fossils of Koopmanycteris and Speonycteris occur in what is now the Nearctic region, whereas extant mormoopids are almost exclusively restricted to the Neotropical region. The only exception in the modern fauna is Mormoops megalophylla, which reaches the southernmost portion of the Nearctic region in southern Texas and northern Mexico, with a single record in southern Arizona (Smith, 1972). There are numerous late Pleistocene records of $M$. megalophylla outside the current range of the species. In peninsular Florida, extralimital records of $M$. megalophylla include fossils from three late Pleistocene cave deposits, Rock Springs in Orange County in the central part of the state (Ray et al., 1963; Wilkins, 1983) and Cutler Hammock and Monkey Jungle Hammock from Dade County in the southernmost part of the peninsula (Morgan, 1991, 2002). Although some biogeographers place southern peninsular Florida in the Neotropics (e.g., Brown et al., 1998; Olson, et al. 2000), the mammalian fauna of this region is predominantly composed of temperate Nearctic species. The modern fauna includes just three mammals with Neotropical affinities, all of which are bats: Artibeus jamaicensis and Molossus molossus from the Florida Keys and Eumops floridanus from the southernmost portion of the peninsula (Koopman, 1971; Frank, 1997a, 1997b; Timm and Genoways, 2004; McDonough et al, 2008). However, the Neotropical influence among both birds and mammals was considerably stronger in the Florida peninsula during the late Pleistocene when Mormoops megalophylla occurred there (Morgan, 2002; Morgan and Emslie, 2010). M. megalophylla no longer occurs in the West Indies, but locally extinct or extirpated populations of this species are known from Late Quaternary cave deposits in Cuba (Silva Taboada, 1974), Hispaniola (Morgan, 2001), Jamaica (Morgan, 1993b), Abaco and Andros in the Bahamas (Morgan, 1989, 2001), MarieGalante in the Lesser Antilles (Stoetzel et al., 2016), and Tobago (Eshelman and Morgan, 1985). Czaplewski and Cartelle (1998) identified M. megalophylla from a cave in Bahia, northeastern Brazil, about $3000 \mathrm{~km}$ southeast of the closest modern occurrence of this species in eastern Venezuela (Smith, 1972; Koopman, 1982, 1993). Salles et al. (2014) recently reexamined this material and referred it instead to Mormoops cf. megalophylla, noting that it is somewhat more robust than typical $M$. megalophylla. Whether this material represents a distinct species of Mormoops remains to be determined.

Late Quaternary fossils of Mormoops blainvillei are known from several West Indian islands where this species no longer occurs, including Abaco, Exuma, and New Providence in the Bahamas, La Gonâve off the west coast of Haiti, and Anguilla, Antigua, Barbuda, and MarieGalante in the Lesser Antilles (Morgan, 2001; Stoetzel et al., 2016). Silva Taboada (1974) described the only extinct species of Mormoops, M. magna, based on two humeri from a Late Quaternary cave deposit in central Cuba. This same cave deposit also contained humeri of $M$. blainvillei and $M$. megalophylla, both of which 
are smaller than M. magna. Additional humeri from Hispaniola have also been referred to $M$. magna (Velazco et al., 2013), again from cave deposits also including fossils of $M$. blainvillei. Czaplewski and Cartelle (1998) noted that fossil humeri of $M$. megalophylla from Brazil and $M$. magna from Cuba are similar in size. Clarification of the taxonomy and relationships of $M$. magna and $M$. megalophylla will require additional study of fossil and modern specimens of M. megalophylla throughout the current and late Pleistocene range of this species.

Fossils of Pteronotus are not as widespread as those of Mormoops, with most records being from Late Quaternary cave deposits in the West Indies. With the exception of a partial skeleton of $P$. cf. parnellii from early Pleistocene lacustrine sediments in El Salvador (Webb and Perrigo, 1984), all other fossil records of Pteronotus are from Late Quaternary cave deposits. Morgan (1991) tentatively identified the extinct Cuban species $P$. pristinus from Monkey Jungle Hammock, a late Pleistocene sinkhole/cave deposit in southernmost peninsular Florida. This is the only record of the genus Pteronotus from the United States. Fossils representing the P. parnellii complex are known from several late Pleistocene cave deposits in Mexico that are within the current geographic range of this clade (ArroyoCabrales, 1992; Arroyo-Cabrales and Polaco, 2003, 2008). Czaplewski and Cartelle (1998) identified $P$. parnellii sensu lato and $P$. davyi from a late Pleistocene cave site in northeastern Brazil. These two taxa also were identified from late Pleistocene deposits in Goiás state, central Brazil (Lessa et al., 2005; Salles et al., 2005; Fracasso and Salles, 2005). Salles et al. (2014) additionally documented P. gymnonotus from a cave system in Bahia, Brazil. Members of the Pteronotus parnellii complex and P. gymnonotus still occur in these parts of Brazil, but the closest recent records of the $P$. davyi complex are from northwestern Venezuela (Smith, 1972; Koopman, 1993; Salles et al., 2014).

In addition to the extinct species Pteronotus pristinus from Cuba and southern Florida, Late
Quaternary fossils are known for all the living West Indian species complexes of Pteronotus (Morgan, 2001). Multiple species of Pteronotus currently inhabit the Greater Antilles. Pteronotus quadridens occurs in Cuba, Hispaniola, Puerto Rico, and Jamaica, while P. macleayii is restricted to Cuba and Jamaica (Simmons, 2005a; Pavan and Marroig, 2017). The Pteronotus parnellii complex is currently thought to be represented by three species in the Greater Antilles: the nominate form in Jamaica and Cuba, P. pusillus in Hispaniola, and P. portoricensis in Puerto Rico (Thoisy et al., 2014; Pavan and Marroig, 2016, 2017). Koopman (1955) described the extinct subspecies $P$. parnellii gonavensis from fossils collected in a cave on the island of La Gonâve off the western coast of Haiti. Koopman noted that gonavensis was the smallest known subspecies of $P$. parnellii, which suggests this form may represent an additional species of the Pteronotus parnellii complex. Two additional species of Pteronotus occur in the Lesser Antilles, $P$. davyi and $P$. fuscus (a member of the P. parnellii complex). Locally extinct populations representing the P. parnellii complex are known from Late Quaternary fossil deposits on Isla de Pinos off the southwestern coast of Cuba, La Gonâve (see above), Abaco and New Providence in the Bahamas, Grand Cayman, Antigua, and MarieGalante (Morgan, 2001; Stoetzel et al., 2016). It is not clear which of the extant Antillean species currently recognized ( $P$. parnellii sensu stricto, $P$. pusillus, or $P$. portoricensis) this fossil material represents, or if there are additional species among these extinct populations (e.g., gonavensis). There are three extinct populations of $P$. quadridens, from Abaco, Andros, and New Providence in the Bahamas, and two extinct populations of $P$. macleayii, from New Providence and Hispaniola (Morgan, 2001; Velazco et al., 2013). Stoetzel et al. (2016) reported Pteronotus macleayii and/or $P$. quadridens from a cave on the island of Marie-Galante in the Lesser Antilles. Although Stoetzel et al. (2016) were not able to distinguish fossil specimens of these two species, this is the first record of the subgenus 
Chilonycteris from the Lesser Antilles. Eshelman and Morgan (1985) identified five species of mormoopids, Mormoops megalophylla, Pteronotus davyi, $P$. gymnonotus, $P$. parnellii, and $P$. personatus, from a late Pleistocene cave deposit on the island of Tobago in the southeastern West Indies. While we cannot be sure which lineage(s) of the $P$. parnellii complex are present in this collection, it is remarkable that this assemblage represents essentially the entire modern mormoopid fauna from all of Middle and South America, not one of which is known to inhabit Tobago at the present time. Although located in the Caribbean Sea, Tobago lacks endemic Antillean bats and instead has a South American chiropteran fauna. Tobago's faunal affinities can be explained by its location on the South American continental shelf just north of Trinidad and Venezuela, and its direct connection to South America during the late Pleistocene low sea-level stand (Eshelman and Morgan, 1985).

\section{EVOLUTIONARY History}

The living species of Mormoopidae are primarily obligate cave dwellers (Rodríguez-Durán, 2009). In the West Indies, mormoopids generally roost deep within large caves characterized by a stable microenvironment with high temperature and humidity (Goodwin, 1970; Silva Taboada, 1979; Rivera-Marchand and Rodríguez-Durán, 2001; Rodríguez-Durán and Kunz, 2001; Rodríguez-Durán and Soto-Centeno, 2003; RodríguezDurán, 2009; Soto-Centeno et al., 2015). Their roost ecology strongly indicates that the present (and presumably past) distribution of most species is constrained by the availability of extensive cave systems (Morgan, 2001; Rodríguez-Durán and Kunz, 2001; Rodríguez-Durán and SotoCenteno, 2003; Rodríguez-Durán, 2009; SotoCenteno et al., 2015). Since the late Pleistocene, mormoopids underwent localized extinctions or extirpations throughout their range in tropical America. This trend is most obvious in the West Indies (Morgan, 1999, 2001; Soto-Centeno et al., 2015; Stoetzel et al., 2016), but is also well docu- mented in peninsular Florida (Morgan, 1991, 2002) and Brazil (Czaplewski and Cartelle, 1998; Fracasso and Salles, 2005). The present subtropical climate in southern Florida probably is suitable to support species of Mormoops or Pteronotus, but there are no dry caves in the southern half of the peninsula (Morgan, 1991). Morgan $(1999,2001)$ hypothesized that local extinctions of mormoopids on islands throughout the West Indies were related to changes in the occurrence and size of large cave systems, as well as climatic changes, which in turn affected cave microclimates. The disappearance of large cave systems that provided suitable roosting sites for mormoopids was in part related to rising sea levels in the late Pleistocene and early Holocene, and was particularly evident on small islands in the West Indies, most notably the Bahamas (Morgan, 1989, 2001), Cayman Islands (Morgan, 1994), Lesser Antilles (Pregill et al., 1994; Stoetzel et al., 2016), and Tobago (Eshelman and Morgan, 1985), as well as in southern Florida (Morgan, 1991, 2002).

A recent analysis of radiocarbon-dated bat fossils on Abaco in the northern Bahamas provided evidence that at least some of the local extinctions or extirpations of bats in the West Indies, including a member of the Pteronotus parnellii complex, occurred in the late Holocene $(\sim 3,000$ years B.P.) and thus probably were not related to climate change (Soto-Centeno and Steadman, 2015). Soto-Centeno et al. (2015) used ecological niche models to estimate the current, mid-Holocene, and Last Glacial Maximum distributions of Mormoops blainvillei, Pteronotus parnellii, and $P$. quadridens in order to assess whether suitable climatic habitat for these species has been stable across time in the Caribbean, and found that suitable climatic habitat had actually expanded from the late Pleistocene to Recent. Availability of karst formations (where hot caves typically form) was found to be a good predictor of mormoopid distributions when used either alone or combined as karst-climate environmental-niche models (Soto-Centeno et al., 2015). Stoetzel et al. (2016) identified several 
locally extinct species of mormoopids from radiocarbon-dated late Holocene deposits in a cave on Marie-Galante in the Lesser Antilles, indicating that climate-induced changes to the bat fauna on that island were less important than human impacts.

The fossil record as currently known suggests that the Mormoopidae may have evolved in North America, as the presence of Koopmanycteris indicates that this family was in Florida by the late early Oligocene (30-32 Ma). The fact that a fossil species of this age nests within the mormoopid crown group suggests that the family is potentially older, however, since the divergence of Pteronotus and the Koopmanycteris + Mormoops clade must have predated this time. On the basis of relaxed clock molecular dating methods applied across extant mammalian families, Meredith et al. (2011) postulated that the mormoopid lineage split from the phyllostomid lineage by about $36.4 \mathrm{Ma}$, a date that is consistent with an early Oligocene diversification of the crown group and a late Eocene origin for the lineage as a whole. More recently, Rojas et al. (2016), using Bayesian methods to estimate divergence times in a comprehensive study of noctilionoids, calculated that extant mormoopids began speciation $\sim 32.8 \mathrm{Ma}$ (95\% high-probability-density interval 30.8-36.2 Ma). In a separate analysis including more species of mormoopids, Pavan and Marroig (2017) obtained a remarkably similar date for this divergence, $\sim 32.71 \mathrm{Ma}$ (95\% HPD interval 31-36.7 Ma). Both sets of authors used Koopmanycteris as a calibration point (though obviously not by name) citing mention of its discovery by Czaplewski and Morgan (2003) and Morgan and Czaplewski (2012). Calibrations in these studies treated Koopmanycteris as a stem mormoopid (Rojas et al., 2016) or as an a priori specification of the minimum divergence time between Pteronotus and Mormoops (Pavan and Marroig, 2017).

Koopmanycteris occurs in two Oligocene paleokarst deposits in northern peninsular Florida, but thereafter mormoopids are unknown from Florida until late Pleistocene records of
Mormoops megalophylla and Pteronotus cf. pristinus. Of particular significance is the absence of mormoopids from the early Miocene (Hemingfordian) Thomas Farm LF in northern Florida, a paleokarst deposit that has an extensive chiropteran sample and documents the presence of the Natalidae and Emballonuridae, two other families of Neotropical bats now extinct in Florida (Morgan and Czaplewski, 2003, 2012). Mormoopids presumably survived in tropical Middle America and/or the West Indies between the early Miocene and their next known fossil occurrence in the early Pleistocene of El Salvador, but they have no fossil record during that time interval. Although mormoopids and other groups of bats have an excellent Late Quaternary record in the West Indies (Morgan, 2001), Tertiary bats are unknown from the Antillean islands. Nonetheless, the species richness of mormoopids in the West Indies, as well as the presence of multiple endemic species, indicates that the Mormoopidae probably reached the West Indies by overwater dispersal early in their history (Oligocene or Miocene).

Setting aside molecular data, the scenario for the evolutionary history of the Mormoopidae that is most consistent with the current evidence (e.g., Oligocene records from Florida, early Pleistocene record from El Salvador, high species richness and endemism in the West Indies) suggests that members of this family evolved in North America in the early Oligocene or earlier, dispersed to the West Indies in the Oligocene or Miocene, disappeared from Florida after the Oligocene (except for a brief reappearance in the late Pleistocene), and survived in tropical Middle America and the West Indies throughout the remainder of the Tertiary. Mormoopids are unknown from South America before the late Pleistocene, with the only fossil records consisting of several extant species from late Pleistocene cave deposits in Brazil. The evolutionary scenario for the Mormoopidae in South America that is most consistent with the current evidence (e.g., absence of a Tertiary fossil record, late Pleistocene records from Brazil, limited ende- 
mism, and marginal distribution) suggests that members of this family may not have arrived in South America until after the Great American Biotic Interchange in the Pliocene following the connection of North and South America at the Panamanian isthmus (O'Dea et al., 2016).

A biogeographic study of the Mormoopidae based on mitochondrial data provided independent support for certain aspects of our proposed evolutionary history of the family (Dávalos, 2006). Her data show greater divergences between Middle American and Antillean populations of mormoopids than between mormoopids in Middle and South America, suggesting that the family diversified in tropical North America (or Mesoamerica) before entering South America. More recently, comprehensive analyses by Pavan and Marroig (2017) of the timing and patterns of diversification in the genus Pteronotus have suggested a similar but slightly different scenario. Using an array of markers including mitochondrial, nuclear, and Y-linked genes, Pavan and Marroig (2017) reconstructed the evolutionary and biogeographic history of 15 species of Pteronotus and postulated that the genus originated approximately $16 \mathrm{Ma}$ with a basal split between the P. parnellii group and a lineage leading to all other species. While their model was not able to resolve the ancestral area for the genus with confidence, the latter clade (all non- $P$. parnellii group species) was unambiguously found to have originated in Central America in the early Miocene, with representatives of P. gymnonotus and P. personatus moving into South America no earlier than the late Pliocene (Pavan and Marroig, 2017). Biogeographic origins of the Pteronotus parnellii group were found to be ambiguous, but South American members of this clade ( $P$. rubiginosus and P. alitonus; Pavan et al., 2018) apparently arrived on that continent sometime between $6 \mathrm{Ma}$ and $1.5 \mathrm{Ma}$, and diverged in situ in the Quaternary (Pavan and Marroig, 2017). The DIVAj model employed by Pavan and Morroig (2017) proposed a widely distributed ancestor for the genus Pteronotus (with a range encompassing most of the current range of the genus including Amazonia), but those authors noted that ancestral range estimates by DIVA models seek to minimize dispersal-extinction costs and hence tend to reconstruct wide ancestral ranges at early nodes to explain distributional patterns of phylogeny tips. Inclusion of Koopmanycteris in future analyses of the historical biogeography of mormoopids may significantly affect results, given the age and location of this taxon. Minimally, a tropical North American [or tropical Nearctic] origin for the family and for basal diversification of the three genera (Pteronotus, Koopmanycteris, and Mormoops) seems most likely given the sum of evidence currently available.

The fossil record and historical biogeography of the Natalidae, another endemic family of Neotropical bats, is similar to the history of the Mormoopidae (Morgan and Czaplewski, 2003, 2012; Dávalos, 2005; A. Tejedor, 2006, 2011). Natalids reach their maximum species richness and endemism in the West Indies and have a marginal distribution in South America with only two endemic species (Morgan, 2001; Morgan and Czaplewski, 2003; A. Tejedor et al., 2005; A. Tejedor 2006, 2011). Like mormoopids, natalids have their earliest fossil record in the Oligocene (30$32 \mathrm{Ma}$ ) of Florida and lack a Tertiary record in South America (Morgan and Czaplewski, 2003; A. Tejedor et al., 2005; A. Tejedor, 2006, 2011). They are also known to be cave specialists and most species apparently require hot caves for roost sites (A. Tejedor et al., 2005; A. Tejedor, 2006, 2011). Karst deposits containing caves and vertebrate fossils are rare in North America prior to the Pleistocene, being primarily restricted to Florida (Morgan and Hulbert, 2008), which, together with a tropical climate during the mid Cenozoic, may help to explain why Tertiary mormoopids and natalids are currently known only from Florida.

Prior to the past two decades, the only New World noctilionoid family with a Tertiary fossil record was the Phyllostomidae, consisting of the extinct phyllostomine Notonycteris magdalenensis from the middle Miocene La Venta Fauna in 
Colombia (Savage, 1951). With the downward placement of the Pliocene-Pleistocene boundary to $2.6 \mathrm{Ma}$ (Gibbard et al., 2010), the Florida late Blancan record of the extinct desmodontine vampire bat Desmodus archaeodaptes from the Inglis 1A Local Fauna (Morgan et al., 1988) is now considered to be early Pleistocene in age, not late Pliocene. Since the mid-1990s, Tertiary fossils representing four of the five New World noctilionoid families (Noctilionidae, Phyllostomidae, Mormoopidae, and Thyropteridae) have been reported (fig. 18). Czaplewski (1996) described a new species of Noctilio, $N$. lacrimaelunaris, from the late Miocene of Peru. Czaplewski (1997) and Czaplewski et al. (2003b) identified from the middle Miocene La Venta Fauna of Colombia, the living species Noctilio albiventris, additional material of Notonycteris magdalenensis, named a second species of Notonycteris ( $N$. sucharadeus), reported a third phyllostomine (Tonatia sp.), described the earliest known nectar-feeding phyllostomid (Palynephyllum antimaster), and the earliest record of the Thyropteridae consisting of fossils referred to two living species, Thyroptera cf. tricolor and T. lavali. Czaplewski and Morgan (2012) named a new noctilionoid family (Speonycteridae), new genus (Speonycteris), and two new species ( $S$. aurantiadens and $S$. naturalis) of basal noctilionoids from the Oligocene I-75 and Brooksville 2 faunas in Florida. Czaplewski and Campbell (2017) recently described a new genus and species of thyropterid, Amazonycteris divisus, from a late Miocene site along the Juruá River, state of Acre, Brazil. Here we describe the oldest-known mormoopid, Koopmanycteris palaeomormoops, from the same two Oligocene faunas in Florida that produced the stem noctilionoid family Speonycteridae. With all of these recent discoveries, Furipteridae is now the only New World family in Noctilionoidea that lacks a Tertiary fossil record. Both living species of furipterids are known from the Pleistocene of South AmericaFuripterus horrens from late Pleistocene cave deposits in Brazil (Czaplewski and Cartelle, 1998; Lessa et al., 2005) and Amorphochilus schnablii from a Pleistocene deposit in Peru (Morgan and Czaplewski, 1999).

The ancestral region for the superfamily Noctilionoidea has been the source of considerable debate (Hand et al., 2005; Gunnell et al., 2014; Rojas et al., 2016). Five noctilionoid families (Phyllostomidae, Mormoopidae, Noctilionidae, Furipteridae, and Thyropteridae) are now primarily restricted to the Neotropical region (Simmons, 2005a). A sixth family, Mystacinidae (with two species of Mystacina endemic to the modern fauna of New Zealand) is the only extant member of the superfamily that occurs outside the Western Hemisphere (Simmons, 2005a). Mystacinidae appears as the basalmost member of Noctilionoidea in most phylogenies (Teeling et al., 2005; Meredith et al., 2011; Rojas et al., 2016). A Miocene fossil mystacinid is known from New Zealand, and late Oligocene and Miocene mystacinids are known from Australia (Hand et al., $2005,2015)$. Most previous hypotheses have proposed a southern Gondwanan origin for Noctilionoidea when Australia, Africa, and South America were connected through Antarctica, as recently as the late Eocene (Hand et al., 2005; Teeling et al., 2005; Lim, 2009; Gunnell et al., 2014). Gunnell et al. (2014) suggested that Neotropical noctilionids reached South America through a series of dispersal events from Australia across Antarctica.

Rojas et al. (2016) reconstructed the ancestral area for New World noctilionoids as South America, which is consistent with that hypothesis. However, one of the most surprising aspects of noctilionoid evolutionary history is that the earliest-known members of this superfamily, the mormoopid Koopmanycteris and the stem noctilionoid Speonycteris, are known from Florida and not South America, even though five families in this group are now endemic to the Neotropical region. As noted by Rojas et al. (2016: 444), "the geographic distribution of these fossils.... could upend the current narrative of noctilionoid dispersal via South America." Rojas et al. (2016) found that reconstructions of the biogeographic area for the most recent common ancestor of 


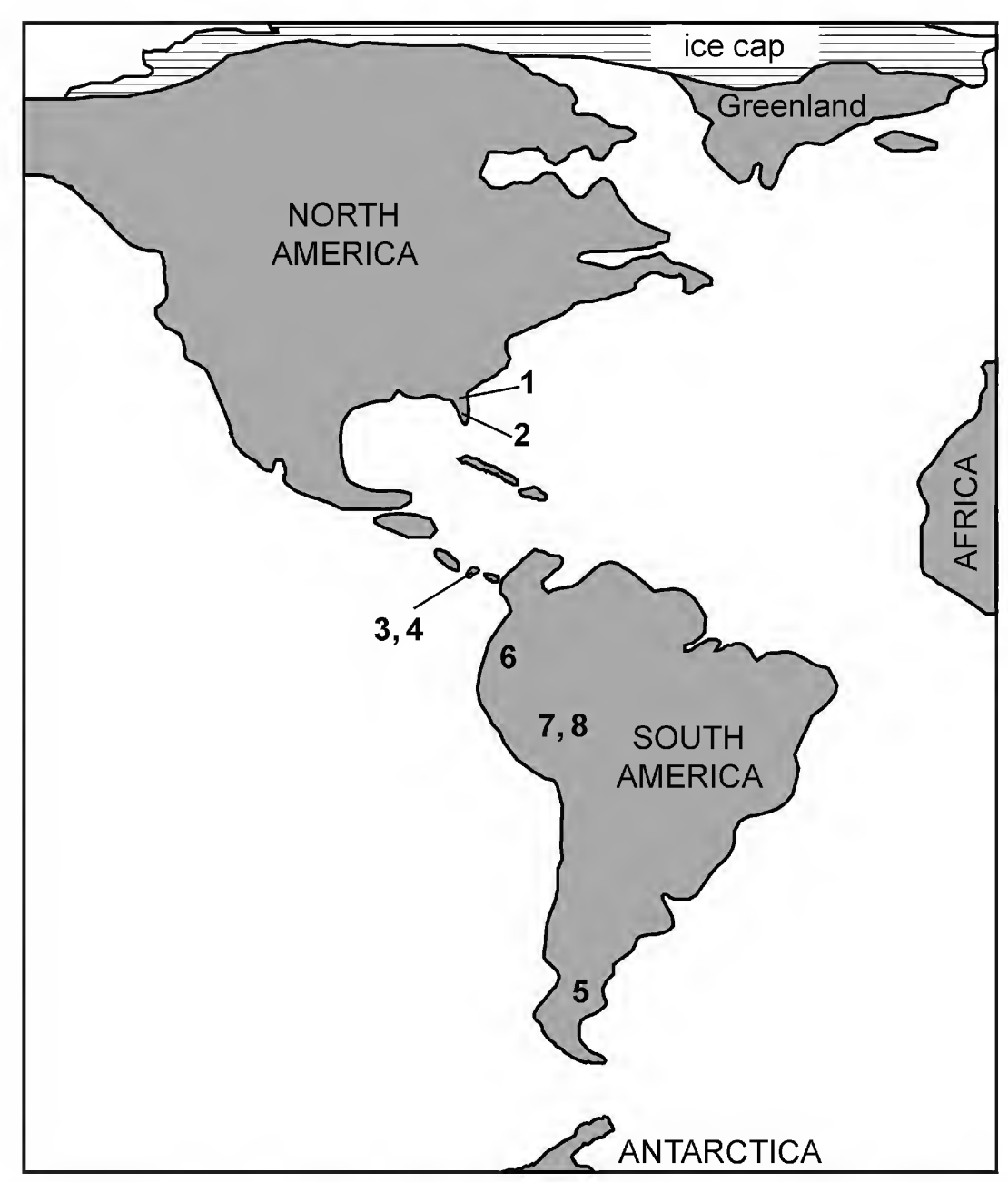

FIGURE 18. Oligocene and Miocene records of noctilionoid bats (Chiroptera: Noctilionoidea) from the Western Hemisphere, numbered in order from oldest to youngest. Oligocene: 1. I-75, Florida (early Oligocene, Whitneyan NALMA): Speonycteridae (Speonycteris aurantiadens, Speonycteris naturalis), Mormoopidae (Koopmanycteris palaeomormoops); 2. Brooksville 2, Florida (late Oligocene, early Arikareean NALMA): Speonycteridae (Speonycteris aurantiadens), Mormoopidae (Koopmanycteris palaeomormoops). Miocene: 3. Lirio Norte, Panama (early Miocene, late Arikareean NALMA): Phyllostomidae (undescribed genus and species of phyllostomine); 4. Centenario, Panama (early Miocene, early Hemingfordian NALMA): Phyllostomidae (undescribed genus and species of phyllostomine, same species as Lirio Norte); 5. Gran Barranca, Argentina (early Miocene, Colhuehuapian SALMA): Phyllostomidae (indeterminate phyllostomine); 6. La Venta, Colombia (medial Miocene, Laventan SALMA): Phyllostomidae (Notonycteris magdalenensis, ?N. sucharadeus, Palynephyllum antimaster, Tonatia or Lophostoma sp.), Noctilionidae (Noctilio albiventris), Thyropteridae (Thyroptera lavali, Thyroptera cf. T. tricolor); 7. Río Acre, Peru (late Miocene, Huayquerian SALMA): Noctilionidae (Noctilio lacrimaelunaris); 8. Juruá River, Brazil (late Miocene, Huayquerian SALMA): Thyropteridae (Amazonycteris divisus). Map modified from one by Ron Blakey, and represents approximate continental coastlines in the Western Hemisphere in the late Oligocene ( 25 Ma). 
Phyllostomidae + Mormoopidae, and for the Mormoopidae itself, were equivocal. For both clades, a combined South America + Central and North America had the highest support, followed by Central and North America (treated as a single area by Rojas et al., 2016). However, this assessment may be changed by the consideration of the Florida fossils. As noted by Dávalos (2006), phylogenetic and molecular divergence data, together with the Tertiary fossil record, suggest that mormoopids may have diversified in tropical North America before entering South America.

The two genera of noctilionoids from the early Oligocene of Florida (Koopmanycteris and Speonycteris; $~ 30-32 \mathrm{Ma}$ ) are about 10 million years older than the oldest-known noctilionoid from South America, an indeterminate phyllostomine phyllostomid from the early Miocene ( $20-21 \mathrm{Ma})$ of Argentina (Czaplewski, 2010), and about 5 million years older than the oldest previously reported noctilionoid, a late Oligocene ( $26 \mathrm{Ma}$ ) mystacinid from Australia (Hand et al.,, 2005). The occurrence of early Oligocene noctilionoids in Florida suggests the possibility that at least the Neotropical noctilionoid radiation may have had its origins in North America in the early Oligocene or before. Thereafter, an early noctilionoid may have dispersed from Central America to South America across the Central American Seaway, probably in the late Oligocene or early Miocene, as three other families in this group (Noctilionidae, Phyllostomidae, and Thyropteridae) appear in the South American fossil record by the early to middle Miocene. Just where and when the most recent common ancestor of the New World noctilionoids and the Old World Mystacinidae lived, and the directionality of dispersal of basal stocks of these two clades, remain open questions.

It is important to emphasize that the Paleogene fossil record of bats in South America is extremely poor, and as yet there are no known Tertiary paleokarst deposits from South America that contain bats. The only Paleogene bats known from South America are two teeth of an indeterminate family from Eocene volcaniclastics in northwestern Argentina (M. Tejedor et al., 2005), a tooth tentatively referred to the Chiroptera from the probable Eocene Santa Rosa LF in Amazonian Peru (Czaplewski and Campbell, 2004), two records of the molossid Mormopterus faustoi from Oligocene lacustrine deposits of the Tremembé Formation in Brazil (Paula Couto, 1956, 1983), and several records from the middle Eocene and late Oligocene of Contamana, Peru (Antoine et al., 2016). No bat fossils are known from Antarctica, which could have played a key role in early Tertiary evolution and dispersal of noctilionoids. As discussed above, the current distribution and molecular phylogeny of the New World members of the Noctilionoidea are consistent with a South American/Gondwanan origin for this group, whereas the fossil record of Mormoopidae and the extinct basal noctilionoid family Speonycteridae suggest the possibility of a North American origin. A Gondwanan origin for the Noctilionoidea would necessitate a late Eocene or earlier appearance of this group in South America (pre-Miocene records are currently unknown), and a subsequent northward dispersal of two families of noctilionoids (Speonycteridae, Mormoopidae) across the Central American Seaway to North America (Florida) by the early Oligocene. At present, the fossil record is not sufficient to determine whether a Southern Hemisphere or Northern Hemisphere origin for the Noctilionoidea is more likely. Only future fossil discoveries in Oligocene or older faunas in North America or South America, or perhaps Africa, Australia, New Zealand, or even Antarctica, will provide the evidence necessary to better understand the evolutionary and biogeographic history of the New World Noctilionoidea.

\section{ACKNOWLEDGMENTS}

We are honored to dedicate this paper to the memory of Karl F. Koopman, long-time curator and bat expert extraordinaire in the 
Department of Mammalogy at the American Museum of Natural History. Koopman had a major impact on our careers and was always extremely supportive and helpful in our various projects involving living and fossil bats. Our only regret is that we were not able to finish the description of Koopmanycteris during his lifetime. Ann Pratt, formerly of Georgia Southern University and Arthur Poyer of the Florida Museum of Natural History, screenwashed and sorted fossil bats from Brooksville 2, for which we are grateful, and Glynn Hayes provided helpful information on the Brooksville 2 fauna. James Knight, formerly of the South Carolina State Museum, loaned us several important specimens of fossil mormoopids from the Brooksville 2 fauna curated in the SCSM paleontology collection. Andrea Cirranello provided critical help with phylogenetic analysis software. Chris Bell provided an important rare literature reference on petrosals. We also thank Laurie Wilkins (UF/ FLMNH), Joe Cook, Jon Dunnum, and William Gannon (MSB), James Patton (MVZ), Judith Eger, Mark Engstrom, and Burton Lim (ROM), Linda Gordon, Charles Handley, and Helen Kafka (USNM), and Janet Braun and Brandi Coyner and (OMNH) for their help during our visits to their respective museums and/or arrangements of loans of comparative specimens. We also thank Darrin Lunde (formerly of the AMNH and now at the USNM), Eileen Westwig (formerly of the AMNH and now at the Oxford University Museum of Natural History) and Neil Duncan (AMNH) for their help in using the AMNH collections. Aldo Rincon kindly provided a base map used for our paleogeographic map. We benefitted greatly from many discussions of noctilionoid bat evolution with Andrea Cirranello, Beth Clare, Liliana Dávalos, Brock Fenton, Norberto Giannini, Gregg Gunnell, Ana Pavan, Angelo Soto-Centeno, and Paúl Velazco. This study was funded in part by National Science Foundation grants DEB 9981512 to N.J.C. and G.S.M., and DEB 0949859 to N.B.S.

\section{REFERENCES}

Albright, L.B., III. 1998. The Arikareean land mammal age in Texas and Florida: southern extension of Great Plains faunas and Gulf Coastal Plain endemism. In D.O. Terry, Jr., H.E. LaGarry, and R.M. Hunt, Jr. (editors), Depositional environments, lithostratigraphy, and biostratigraphy of the White River and Arikaree Groups (late Eocene to early Miocene, North America). Geological Society of America Special Paper 325: 167-183.

Albright L.B., III, et al. 2008. Revised chronostratigraphy and biostratigraphy of the John Day Formation (Turtle Cove and Kimberly members), Oregon, with implications for updated calibration of the Arikareean North American Land Mammal Age. Journal of Geology 116: 211-237.

Altenbach, J.S., and J.W. Hermanson. 1987. Bat flight muscle function and the scapula-humeral lock. In M.B. Fenton, P. Racey, and J.M. Rayner (editors), Recent advances in the study of bats: 100-118. Cambridge: Cambridge University Press.

Amador, L.I., R.L.M. Arévalo, F.C. Almeida, S.A. Catalano, and N.P. Giannini. 2018. Bat systematics in the light of unconstrained analyses of a comprehensive molecular supermatrix. Journal of Mammalian Evolution 25 (1): 37-70.

Andersen, K. 1912. Catalogue of the Chiroptera in the collection of the British Museum, 2nd ed., vol. 1: Megachiroptera. London: British Museum. [reprinted by Johnson Reprint Corporation, New York]

Antoine, P.-O. et al. 2016. A 60-million-year Cenozoic history of western Amazonian ecosystems in Contamana, eastern Peru. Gondwana Research 31: 30-59.

Arroyo-Cabrales, J. 1992. Sinopsis de los murciélagos fosiles de México. Revista de la Sociedad Mexicana de Paleontología 5 (1): 1-14.

Arroyo-Cabrales, J., and O.J. Polaco. 2003. Caves and the Pleistocene vertebrate paleontology of Mexico. In B.W Schubert, J.I. Mead, and R.W. Graham (editors), Ice Age cave faunas of North America: 273291. Bloomington, IN: Indiana University Press.

Arroyo-Cabrales, J., and O.J. Polaco. 2008. Fossil bats from Mesoamerica. Arquivos do Museu Nacional, Rio de Janeiro 66: 155-160.

Baron, G., H. Stephan, and H.D. Frahm. 1996. Comparative neurobiology in Chiroptera, vol. 2. Basel: Birkhäuser Verlag.

Benedict, F.A. 1957. Hair structure as a generic character in bats. University of California Publications in Zoology 59: 285-548. 
Bergsten, J. 2005. A review of long branch attraction. Cladistics 21 (2): 163-193.

Bhatnagar, K.P., and F.C. Kallen. 1974. Cribriform plate of ethmoid, olfactory bulb and olfactory acuity in forty species of bats. Journal of Morphology 142: 71-90.

Bremer, K. 1994. Branch support and tree stability. Cladistics 10: 295-304.

Brown, D.E., F. Reichenbacher, and S.E. Franson. 1998. A classification of North American biotic communities. Salt Lake City: University of Utah Press.

Brown, J.C. 1971. The description of mammals. 1. The external characters of the head. Mammal Review 1: 151-168.

Cartelle, C., and V.S. Abuhid. 1994. Chiroptera do Pleistoceno final-Holoceno da Bahia. Acta Geologica Leopoldensia 39: 429-440.

Clare, E.L., et al. 2013. Diversification and reproductive isolation: cryptic species in the only New World high-duty cycle bat, Pteronotus parnellii. BMC Evolutionary Biology 13: 1-26.

Czaplewski, N.J. 1996. Opossums (Didelphidae) and bats (Noctilionidae and Molossidae) from the late Miocene of the Amazon basin. Journal of Mammalogy 77: 84-94.

Czaplewski, N.J. 1997. Chiroptera. In R.F. Kay, R.H. Madden, R.L Cifelli, and J.J. Flynn (editors), Vertebrate paleontology in the Neotropics: the Miocene fauna of La Venta, Colombia: 410-431. Washington, DC: Smithsonian Institution Press.

Czaplewski, N.J. 2010. Colhuehuapian bats (Mammalia: Chiroptera) from the Gran Barranca, Chubut province, Argentina. In R.H. Madden, A.A. Carlini, M.G. Vucetich, and R.F. Kay (editors), The paleontology of Gran Barranca: evolution and environmental change through the Middle Cenozoic of Patagonia: 240-252. Cambridge, Cambridge University Press.

Czaplewski, N.J., and K.E. Campbell, Jr. 2004. A possible bat (Mammalia: Chiroptera) from the ?Eocene of Amazonian Perú. Natural History Museum of Los Angeles County, Science Series 40: 141-144.

Czaplewski, N.J., and K.E. Campbell, Jr. 2017. Late Miocene bats from the Juruá River, state of Acre, Brazil, with a description of a new genus of Thyropteridae (Chiroptera, Mammalia). Natural History Museum of Los Angeles County, Contributions in Science 525: 55-60.

Czaplewski, N.J., and C. Cartelle. 1998. Pleistocene bats from cave deposits in Bahia, Brazil. Journal of Mammalogy 79: 784-803.
Czaplewski, N.J., and G.S. Morgan. 2000. A new vespertilionid bat (Mammalia: Chiroptera) from the early Miocene (Hemingfordian) of Florida, USA. Journal of Vertebrate Paleontology 20: 736-742.

Czaplewski, N.J., and G.S. Morgan. 2003. Oligocene and early Miocene noctilionoid bats from Florida, USA. Bat Research News 44: 133.

Czaplewski, N.J., and G.S. Morgan. 2012. New basal noctilionoid bats (Mammalia: Chiroptera) from the Oligocene of subtropical North America. In G.F. Gunnell and N.B. Simmons (editors), Evolutionary history of bats: Fossils, molecules, and morphology: 162-209. Cambridge: Cambridge University Press.

Czaplewski, N.J., and G.S. Morgan. 2015. A late-surviving apatemyid (Mammalia: Apatotheria) from the latest Oligocene of Florida, USA. PeerJ 3:e1509. [doi 10.7717/peerj.1509]

Czaplewski, N.J., G.S. Morgan, and T. Naeher. 2003a. Molossid bats from the late Tertiary of Florida with a review of the Tertiary Molossidae of North America. Acta Chiropterologica 5: 61-74.

Czaplewski, N.J., M. Takai, T.M. Naeher, N. Shigehara, and T. Setoguchi. 2003b. Additional bats from the middle Miocene La Venta Fauna of Colombia. Revista de la Academia Colombiana de Ciencias Exactas, Físicas, y Naturales 27 (103): 263-282.

Czaplewski, N.J., G.S. Morgan, and S.A. McLeod. 2008. Chiroptera. Chapter 12. In C.M. Janis, G.F. Gunnell, and M.D. Uhen (editors), Evolution of Tertiary mammals of North America, vol. 2: small mammals, xenarthrans, and marine mammals: 174-197. Cambridge: Cambridge University Press.

Czarnecki, R.T., and F.C. Kallen. 1980. Craniofacial, occlusal, and masticatory anatomy in bats. Anatomical Record 198: 87-105.

Dalquest, W.W., and H.J. Werner. 1954. Histological aspects of the faces of North American bats. Journal of Mammalogy 35: 147-160.

Dávalos, L.M. 2005. Molecular phylogeny of funneleared bats (Chiroptera: Natalidae), with notes on biogeography and conservation. Molecular Phylogenetics and Evolution 37: 91-103.

Dávalos, L.M. 2006. The geography of diversification in the mormoopids (Chiroptera: Mormoopidae). Biological Journal of the Linnean Society 88: 101-118.

Davies, K.T., P.J. Bates, I. Maryanto, J.A. Cotton, and S.J. Rossiter. 2013. The evolution of bat vestibular systems in the face of potential antagonistic selection pressures for flight and echolocation. PLoS One 8 (4): e61998.

Dwyer, P.D. 1960. New Zealand bats. Tuatara 8: 61-71. 
Ekdale, E.G. 2013. Comparative anatomy of the bony labyrinth (inner ear) of placental mammals. PLoS One 8 (6): e66624.

Emry, R.J., P.R. Bjork, and L.S. Russell. 1987. The Chadronian, Orellan, and Whitneyan North American land mammal ages. In M.O. Woodburne (editor), Cenozoic mammals of North America: geochronology and biostratigraphy: 118-152. Berkeley: University of California Press.

Eshelman, R.E., and G.S. Morgan. 1985. Tobagan Recent mammals, fossil vertebrates, and their zoogeographical implications. National Geographic Society Research Reports 21: 137-143.

Foreman, G.L. 1971. Gastric morphology in selected mormoopid and glossophagine bats as related to systematic problems. Transactions of the Illinois State Academy of Sciences 64: 273-282.

Foreman, G.L. 1972. Comparative morphology and histochemical studies of stomachs of selected American bats. University of Kansas Scientific Bulletin 49: 591-729.

Foreman, G.L. 1973. Studies of gastric morphology in North American Chiroptera (Emballonuridae, Noctilionidae, Phyllostomatidae). Journal of Mammalogy 54: 909-923.

Foreman, G.L. 1979. Alimentary tract. In R.J. Baker, J.K. Jones, and D.C. Carter (editors), Biology of bats of the New World family Phyllostomatidae. Part III. Special Publications of the Museum of Texas Tech University 16: 205-227.

Fracasso, M.P.A., and Salles, L.O. 2005. Diversity of Quaternary bats from Serra da Mesa (State of Goiás). Zootaxa 817: 1-19.

Frailey, C.D. 1978. An early Miocene (Arikareean) fauna from northcentral Florida (the SB-1A) Local Fauna. Occasional Papers, Museum of Natural History, University of Kansas 75: 1-20.

Frailey, C.D. 1979. The large mammals of the Buda Local Fauna (Arikareean: Alachua County, Florida). Bulletin of the Florida State Museum, Biological Sciences 24 (2): 123-173.

Frank, P.A. 1997a. First record of Artibeus jamaicensis Leach (1821) from the United States. Florida Scientist 60: 37-39.

Frank, P.A. 1997b. First record of Molossus molossus tropidorhynchus Gray (1839) from the United States. Journal of Mammalogy 78: 103-105.

Giannini, N.P., and N.B. Simmons. 2007a. Element homology and the evolution of dental formulae in megachiropteran bats (Mammalia: Chiroptera: Pteropodidae). American Museum Novitates 3559: 1-27.
Giannini, N.P., and N.B. Simmons. 2007b. The chiropteran premaxilla: a reanalysis of morphological variation and its phylogenetic interpretation. American Museum Novitates 3585: 1-44.

Giannini, N.P., J.R. Wible, and N.B. Simmons. 2006. On the cranial osteology of Chiroptera. I. Pteropus (Megachiroptera: Pteropodidae). Bulletin of the American Museum of Natural History 295: 1-134.

Gibbard, P.L., M.J. Head, M.J.C. Walker, and the Subcommission on Quaternary Stratigraphy. 2010. Formal ratification of the Quaternary System/Period and the Pleistocene Series/Epoch with a base at 2.58 Ma. Journal of Quaternary Science 25: 96-102.

Gimenez, E.A. 1993. Morfologia lingual comparada, filogenia e evolução dos hábitos alimentares na superfamíla Phyllostomoidea (Mammalia: Chiroptera). M.S. thesis, Instituto de Biociências, Botucatu, UNESPA.

Gimenez, E.A., H. Ferrarezzi, and V.A. Taddei. 1996. Lingual morphology and cladistics analysis of the New World nectar-feeding bats (Chiroptera: Phyllostomidae). Journal of Comparative Biology 1: 41-64.

Goodwin, R.E. 1970. The ecology of Jamaican bats. Journal of Mammalogy 51: 571-579.

Greenbaum, I.F., and C.J. Phillips. 1974. Comparative anatomy and general histology of tongues of longnosed bats (Leptonycteris sanborni and L. nivalis) with reference to infestations of oral mites. Journal of Mammalogy 55: 489-504.

Griffiths, T.A. 1978. Modification of m. cricothyroideus and the larynx in the Mormoopidae, with reference to amplification of high-frequency pulses. Journal of Mammalogy 59: 724-730.

Griffiths, T.A. 1982. Systematics of the New World nectar-feeding bats (Mammalia, Phyllostomidae), based on the morphology of the hyoid and lingual regions. American Museum Novitates 2742: 1-45.

Griffiths, T.A. 1983. Comparative laryngeal anatomy of the Big brown bat, Eptesicus fuscus, and the Mustached bat, Pteronotus parnellii. Mammalia 47: 377394.

Griffiths, T.A. 1994. Phylogenetic systematics of slitfaced bats (Chiroptera, Nycteridae), based on hyoid and other morphology. American Museum Novitates 3090: 1-17.

Griffiths, T.A., and A.L. Smith. 1991. Systematics of emballonuroid bats (Chiroptera: Emballonuridae and Rhinopomatidae), based on hyoid morphology. In T.A. Griffiths and D. Klingener (editors), Contributions to mammalogy in honor of Karl F. Koop- 
man. Bulletin of the American Museum of Natural History 206: 62-83.

Griffiths, T.A., A. Truckenbrod, and P.J. Sponholtz. 1992. Systematics of megadermatid bats (Chiroptera, Megadermatidae), based on hyoid morphology. American Museum Novitates 3041: 1-21.

Gunnell, G.F., N.B. Simmons, and E.R. Seiffert. 2014. Myzopodidae (Chiroptera) from the Late Paleogene of Egypt: emended family diagnosis and biogeographic origins of Noctilionoidea. PLoS ONE 9 (2): e86712.

Gutiérrez, E.E., and J. Moliari. 2008. Morphometrics and taxonomy of bats of the genus Pteronotus (subgenus Phyllodia) in Venezuela. Journal of Mammalogy 89: 292-305.

Habersetzer, J., and G. Storch. 1992. Cochlea size in extant Chiroptera and Middle Eocene Microchiroptera from Messel. Naturwissenchaften 79: 462-466.

Hall, E.R. 1981. The mammals of North America, 2nd ed., vol. 1: 1-600 + 90; vol. 2: 601-1181 + 90. New York: John Wiley and Sons.

Hand, S.J., M. Archer, and H. Godthelp. 2005. Australian Oligo-Miocene mystacinids (Microchiroptera): upper dentition, new taxa and divergence of New Zealand species. Geobios-Lyon 38: 339-352.

Hand, S.J., et al. 2015. Miocene fossils reveal ancient roots for New Zealand's endemic Mystacina (Chiroptera) and its rainforest habitat. PLoS ONE 10 (6): e0128871. [doi:10.1371/journal.pone.0128871]

Handley, C.O. 1959. A revision of American bats of the genera Euderma and Plecotus. Proceedings of the U.S. National Museum 110: 95-246.

Hayes, F.G. 2000. The Brooksville 2 local fauna (Arikareean, latest Oligocene): Hernando County, Florida. Bulletin of the Florida Museum of Natural History 43 (1): 1-47.

Hayes, F.G. 2005. Arikareean (Oligocene-Miocene) Herpetotherium (Marsupialia, Didelphidae) from Nebraska and Florida. Bulletin of the Florida Museum of Natural History 45 (4): 335-353.

Henson, O.W. 1970a. The ear and audition. In W.A. Wimsatt (editor), Biology of bats, vol. 2: 181-263. New York: Academic Press.

Henson, O.W. 1970b. The central nervous system. In W.A. Wimsatt (editor), Biology of bats, vol. 2: 58-152. New York: Academic Press.

Hermanson, J.W., and J.S. Altenbach. 1983. The functional anatomy of the shoulder of the pallid bat, Antrozous pallidus. Journal of Mammalogy 64: $62-75$.
Hermanson, J.W., and J.S. Altenbach. 1985. Functional anatomy of the shoulder and arm of the fruit eating bat Artibeus jamaicensis. Journal of Zoology (London A) 205: 157-177.

Hill, J.E. 1974. A new family, genus and species of bat (Mammalia: Chiroptera) from Thailand. Bulletin of the British Museum (Natural History) 27: 303-336.

Hill, J.E., and J.D. Smith. 1984. Bats: A natural history. London: British Museum (Natural History).

Holman, J.A. 1999. Early Oligocene (Whitneyan) snakes from Florida (USA), the second oldest colubrid snakes in North America. Acta Zoologica Cracoviensia 42 (3): 447-454.

Holman, J.A., and D.L. Harrison. 2000. Early Oligocene (Whitneyan) snakes from Florida (USA), a unique booid. Acta Zoologica Cracoviensia 43 (1-2): 127-134.

Holman, J.A., and D.L. Harrison. 2001. Early Oligocene (Whitneyan) snakes from Florida (USA): remaining boids, indeterminate colubroids, summary and discussion of the I-75 Local Fauna snakes. Acta Zoologica Cracoviensia 44 (1): 25-36.

Hood, C.S., and J.D. Smith. 1982. Cladistical analysis of female reproductive histomorphology in phyllostomatoid bats. Systematic Zoology 31: 241-251.

Hood, C.S., and J.D. Smith. 1983. Histomorphology of the female reproductive tract in phyllostomatoid bats. Occaisional Papers of the Museum of Texas Tech University 86: 1-37.

Hoofer, S.R., S.A. Reeder, E.W. Hansen, and R.A. Van Den Bussche. 2003. Molecular phylogenetics and taxonomic review of noctilionoid and vespertilionoid bats (Chiroptera: Yangochiroptera). Journal of Mammalogy 84: 809-821.

International Commission on Zoological Nomenclature. 1958. Opinion 462. Addition to the official list of generic names in zoology of the generic name Mormoops Leach, 1820 (Class Mammalia). Opinions and Declarations Rendered by the International Commission on Zoological Nomenclature 16: 1-12.

Jepsen, G.L. 1966. Early Eocene bat from Wyoming. Science 154: 1333-1339.

Jepsen, G.L. 1970. Origin and evolution. In W.A. Wimsatt (editor), Biology of bats, vol 1.: 1-64. New York: Academic Press.

Jiménez Vásquez, O., M.M. Condis, and E. García Cancio. 2005. Vertebrados post-glaciales en un residuario fósil de Tyto alba scopoli (Aves: Tytonidae) en el occidente de Cuba. Revista Mexicana de Mastozoología 9: 85-112.

Koopman, K.F. 1955. A new subspecies of Chilonycteris from the West Indies, and a discussion of the mam- 
mals of La Gonâve. Journal of Mammalogy 36: 109-113.

Koopman, K.F. 1971. The systematic and historical status of the Florida Eumops (Chiroptera: Molossidae). American Museum Novitates 2478: 1-6.

Koopman, K.F. 1982. Biogeography of the bats of South America. In M.A. Mares and H.H. Genoways (editors), Mammalian biology in South America. Pymatuning Laboratory of Ecology, University of Pittsburgh, Special Publication Series 6: 273-302.

Koopman, K.F. 1993. Order Chiroptera. In D.E. Wilson and D.M. Reeder (editors), Mammal species of the world: a taxonomic and geographic reference, 2 nd ed.: 137-241. Washington, D.C.: Smithsonian Institution Press.

Koopman, K.F. 1994. Chiroptera: systematics. Handbook of zoology, vol. 8, Mammalia, part 60: 1-217. New York: Walter de Gruyter.

Kwiecinski, G.G., et al. 2018. Bats of Saint Vincent, Lesser Antilles. Special Publications of the Museum of Texas Tech University 68: 1-68.

Lane, E. 1986. Karst in Florida. Florida Geological Survey, Special Publication 29: 1-100.

Legendre, S. 1985. Molossidés (Mammalia, Chiroptera) cénozoiques de l'ancien et du nouveau monde; statut systématique; intégration phylogénique de données. Neues Jahrbuch für Geologie und Paläontologie, Abhandlungen 170: 205-227.

Lessa, G., C. Cartelle, and M.P.A. Fracasso. 2005. The bat (Mammalia, Chiroptera) fossils of Brazil. In A.W.A. Kellner, D.D.R. Henriques, and T. Rodrigues (editors), Boletim de resumos, II Congresso LatinoAmericano de Paleontologia de Vertebrados, Rio de Janeiro, Brasil: 153-155. Rio de Janeiro: Museu Nacional.

Lewis-Oritt, N., C.A. Porter, and R.J. Baker. 2001. Molecular systematics of the family Mormoopidae (Chiroptera) based on cytochrome $b$ and recombination activating gene 2 sequences. Molecular Phylogenetics and Evolution 20: 426-436.

Lillegraven, J.A., M.C. McKenna, and L. Krishtalka. 1981. Evolutionary relationships of middle Eocene and younger species of Centetodon (Mammalia, Insectivora, Geolabididae) with a description of the dentition of Ankylodon (Adapisoricidae). University of Wyoming Publications 45: 1-115.

Lim, B.K. 2009. Review of the origins and biogeography of bats in South America. Chiroptera Neotropical 15: 391-410.

Macdonald, J.R. 1963. The Miocene faunas from the Wounded Knee area of western South Dakota. Bul- letin of the American Museum of Natural History 125(3): 141-238.

Macdonald, J.R. 1970. Review of the Miocene Wounded Knee faunas of southwestern South Dakota. Los Angeles County Museum of Natural History Bulletin 8: 1-82.

MacFadden, B.J., and G.S. Morgan. 2003. New oreodont (Mammalia, Artiodactyla) from the late Oligocene (early Arikareean) of Florida. In Lawrence J. Flynn (editor), Vertebrate fossils and their context: contributions in honor of Richard $\mathrm{H}$. Tedford. Bulletin of the American Museum of Natural History 279: 368-396.

Maddison, D.R., and W.P. Maddison. 2005. MacClade 4: analysis of phylogeny and character evolution. Version 4.08a. Online resource (http://macclade.org).

McDaniel, V.R. 1976. Brain anatomy. In R.J. Baker, J.K. Jones, and D.C. Carter (editors), Biology of bats of the New World family Phyllostomidae. Special Publications of the Museum of Texas Tech University 10: 147-200.

McDonough, M.M., et al. 2008. Speciation within bonneted bats (genus Eumops): the complexity of morphological, mitochondrial, and nuclear data sets in systematics. Journal of Mammalogy 89: 1306-1315.

McKenna, M.C., and S.K. Bell. 1997. Classification of mammals above the species level. New York: Columbia University Press.

Mead, J.I. 2013. Scolecophidia (Serpentes) of the Late Oligocene and Early Miocene, North America, and a fossil history overview. Geobios 46: 225-231.

Menu, H., and Sigé, B. 1971. Nyctalodontie et myotodontie, importants caractères de grades évolutifs chez les chiroptères entomophages. Comptes Rendus de Séances de l'Académie des Sciences 272: 1735-1738.

Meredith, R.W., et al. 2011. Impacts of the Cretaceous terrestrial revolution and KPg extinction on mammal diversification. Science 334: 521-529.

Miller, G.S., Jr. 1907. The families and genera of bats. United States National Museum Bulletin 57: 1-282.

Miller-Butterworth, C.M., et al. 2007. A family matter: conclusive resolution of the taxonomic position of the long-fingered bats, Miniopterus. Molecular Biology and Evolution 24: 1553-1561.

Morgan, G.S. 1989. Fossil Chiroptera and Rodentia from the Bahamas, and the historical biogeography of the Bahamian mammal fauna. In C.A. Woods (editor), Biogeography of the West Indies: past, present, and future: 685-740. Gainesville, FL: Sandhill Crane Press. 
Morgan, G.S. 1991. Neotropical Chiroptera from the Pliocene and Pleistocene of Florida. In T.A. Griffiths and D. Klingener (editors), Contributions to mammalogy in honor of Karl F. Koopman. Bulletin of the American Museum of Natural History 206: 176213.

Morgan, G.S. 1993a. Mammalian biochronology and marine-nonmarine correlations in the Neogene of Florida. Florida Geological Survey, Special Publication 37: 55-66.

Morgan, G.S. 1993b. Quaternary land vertebrates of Jamaica. In R.M. Wright and E. Robinson (editors), Biostratigraphy of Jamaica. Geological Society of America Memoir 182: 417-442.

Morgan, G.S. 1994. Late Quaternary fossil vertebrates from the Cayman Islands. In M.A. Brunt and J.E. Davies (editors), The Cayman Islands: natural history and biogeography: 465-508. Dordrecht, Netherlands: Kluwer Academic Publishers.

Morgan, G.S. 1999. Late Pleistocene climatic change and Neotropical bat extinctions. Current Research in the Pleistocene 16: 133-134.

Morgan, G.S. 2001. Patterns of extinction in West Indian bats. In C.A. Woods and F.E. Sergile (editors), Biogeography of the West Indies: patterns and perspectives, 2nd ed.: 369-407. Boca Raton, FL: CRC Press.

Morgan, G.S. 2002. Late Rancholabrean mammals from southernmost Florida, and the Neotropical influence in Florida Pleistocene faunas. Smithsonian Contributions to Paleobiology 93: 15-38.

Morgan, G.S., and N.J. Czaplewski. 1999. First fossil record of Amorphochilus schnablii (Chiroptera: Furipteridae), from the Late Quaternary of Peru. Acta Chiropterologica 1: 75-79.

Morgan, G.S., and N.J. Czaplewski. 2003. A new bat (Chiroptera: Natalidae) from the early Miocene of Florida, with comments on natalid phylogeny. Journal of Mammalogy 84: 729-752.

Morgan, G.S., and N.J. Czaplewski. 2012. Evolutionary history of the Neotropical Chiroptera: the fossil record. In G.F. Gunnell and N.B. Simmons (editors), Evolutionary history of bats: fossils, molecules, and morphology: 105-161. Cambridge: Cambridge University Press.

Morgan, G.S., and S.D. Emslie. 2010. Tropical and western influences in vertebrate faunas from the Pliocene and Pleistocene of Florida. Quaternary International 217: 143-158.

Morgan, G.S., and R.C. Hulbert, Jr. 2008. Cenozoic vertebrate fossils from paleokarst deposits in Florida. In
L.J. Florea (editor), Caves and karst of Florida, a guidebook for the 2008 National Speleological Society national convention: $248-271$.

Morgan, G.S., O.J. Linares, and C.E. Ray. 1988. New species of fossil vampire bats (Mammalia: Chiroptera: Desmodontidae) from Florida and Venezuela. Proceedings of the Biological Society of Washington 101: 912-928.

Murray, P.F., and T. Strickler. 1975. Notes on the structure and function of cheek pouches within the Chiroptera. Journal of Mammalogy 56: 673-676.

Norberg, U.M. 1970. Functional osteology and mycology of the wing of Plecotus auritus Linnaeus (Chiroptera). Arkiv fur Zoologi 33: 483-543.

Novacek, M.J. 1985a. Comparative morphology of the bat auditory region. Fortschritte der Zoologie 30: 149-151.

Novacek, M.J. 1985b. Evidence for echolocation in the oldest known bats. Nature 315: 140-141.

Novacek, M.J. 1987. Auditory features and affinities of the Eocene bats Icaronycteris and Palaeochiropteryx (Microchiroptera, incertae sedis). American Museum Novitates 2877: 1-18.

Novacek, M.J. 1991. Aspects of morphology of the cochlea in microchiropteran bats: an investigation of character transformation. In T.A. Griffiths and D. Klingener (editors), Contributions to mammalogy in honor of Karl F. Koopman. Bulletin of the American Museum of Natural History 206: 84-100.

Nowak, R.M. 1994. Walker's bats of the world. Baltimore: Johns Hopkins University Press.

O'Dea, A., et al. 2016. Formation of the Isthmus of Panama. Science Advances 2: e1600883.

Olson, D.M., et al. 2000. Terrestrial ecoregions of the world: a new map of life on earth. Bioscience 51: 933-938. [plus map online at http://www.worldwildlife.org/wildworld/ and at http://www.nationalgeographic.com/wildworld/terrestrial.html]

Orihuela, J., and A. Tejedor. 2012. Peters' ghost-faced bat Mormoops megalophylla (Chiroptera: Mormoopidae) from a pre-Columbian archeological deposit in Cuba. Acta Chiropterologica 14: 63-72.

Park, H., and E.R. Hall. 1951. The gross anatomy of the tongues and stomachs of eight New World bats. Transaction of the Kansas Academy of Sciences 54: 64-72.

Patton, T.H. 1969. An Oligocene land vertebrate fauna from Florida. Journal of Paleontology 43: 543-546.

Paula Couto, C. de. 1956. Une chauve-souris fossile des argiles feuilletées Pléistocènes de Tremembé, état de 
São Paulo (Brésil). Actes du IV Congrès International de Quaternaire, Roma-Pisa 1: 343-347.

Paula Couto, C. de. 1983. Geochronology and paleontology of the basin of Tremembé-Taubaté, state of São Paulo, Brazil. Iheringia, Geologia 8: 5-31.

Pavan, A.C., and G. Marroig. 2016. Integrating multiple evidences in taxonomy: species diversity and phylogeny of mustached bats (Mormoopidae: Pteronotus). Molecular Phylogenetics and Evolution, 103: 184-198.

Pavan, A.C., and G. Marroig. 2017. Timing and patterns of diversification in the Neotropical bat genus Pteronotus (Mormoopidae). Molecular Phylogenetics and Evolution 108: 61-69.

Pavan, A.C., P.E.D. Bobrowiec, and A.R. Percequillo. 2018. Geographic variation in a South American clade of mormoopid bats, Pteronotus (Phyllodia), with description of a new species. Journal of Mammalogy 99: 1-22.

Pocock, R.I. 1914. On the facial vibrissae of Mammalia. Proceedings of the Zoological Society of London 1914: 889-912.

Pregill, G.K., D.W. Steadman, and D.R. Watters. 1994. Late Quaternary vertebrate faunas of the Lesser Antilles: historical components of Caribbean biogeography. Bulletin of the Carnegie Museum of Natural History 30: 1-51.

Prothero, D.R., and R.J. Emry. 2004. The Chadronian, Orellan, and Whitneyan North American land mammal ages. In M.O. Woodburne (editor), Late Cretaceous and Cenozoic land mammals of North America: biostratigraphy and geochronology: 156168. New York: Columbia University Press.

Prothero, D.R., and N. Shubin. 1989. The evolution of Oligocene horses. In D.R. Prothero and R.M. Schoch (editors), The evolution of perissodactyls (Oxford Monographs on Geology and Geophysics 15): 142175. Oxford: Oxford University Press.

Ray, C.E., S.J. Olsen, and H.J. Gut. 1963. Three mammals new to the Pleistocene fauna of Florida, and a reconsideration of five earlier records. Journal of Mammalogy 44: 373-395.

Rincón, A. 1999. Los pequeños mamíferos subfósiles presentes en cuevas de la Sierra de Perijá, estado Zulia, Venezuela. El Guacharo, Boletín Informativo, Sociedad Venezolana de Espeleología 48: $1-75$.

Rivera-Marchand, B., and A. Rodríguez-Durán. 2001. Preliminary observations on the renal adaptations of bats roosting in hot caves in Puerto Rico. Caribbean Journal of Science 37: 272-274.
Rodríguez-Durán, A. 2009. Bat assemblages in the West Indies: the role of caves. In T.H. Fleming and P.A. Racey (editors), Island bats: evolution, ecology and conservation: 265-280. Chicago: University of Chicago Press.

Rodríguez-Durán, A., and T.H. Kunz. 2001. Biogeography of West Indian bats: an ecological perspective. In C.A. Woods and F.E. Sergile (editors), Biogeography of the West Indies: patterns and perspectives: 355-368. Boca Raton, FL: CRC Press.

Rodríguez-Durán, A., and J.A. Soto-Centeno. 2003. Temperature selection by tropical bats roosting in caves. Journal of Thermal Biology 28: 465-468.

Rojas, D., O.M. Warsi, and L.M. Dávalos. 2016. Bats (Chiroptera: Noctilionoidea) challenge a recent origin of extant Neotropical diversity. Systematic Biology 65: 432-448.

Salles, L.O., P.G. Guedes, and M.P.A. Fracasso. 2005. Mamíferos do Quaternário do Brasil central. In A.W.A. Kellner, D.D.R. Henriques, and T. Rodrigues (editors), Boletim de Resumos, II Congresso LatinoAmericano de Paleontologia de Vertebrados, Rio de Janeiro, Brasil: 241-242. Rio de Janeiro: Museu Nacional.

Salles, L.O., et al. 2014. Quaternary bats from the Impossível-Ioiô Cave System (Chapada Diamantina, Brazil): humeral remains and the first fossil record of Noctilio leporinus (Chiroptera, Noctilionidae) from South America. American Museum Novitates 3798: $1-31$.

Savage, D.E. 1951. A Miocene phyllostomatid bat from Colombia, South America. University of California Publications in Geological Sciences 28: 357-366.

Savage, D.E., and D.E. Russell. 1983. Mammalian paleofaunas of the world. Reading, MA: Addison-Wesley Publishing Company.

Schlosser-Strum, E., and H. Schliemann. 1995. Morphology and function of the shoulder joint of bats (Mammalia: Chiroptera). Journal of Zoological Systems and Evolutionary Research 33: 88-98.

Schneider, R. 1957. Metrische Untershuchungen am Großhirn der Chiroptera. Anatomischer Anzeiger 104: 142-149.

Schneider, R. 1972. Zur quantitativen Morphologie und Evolution des Fledermausgehirns. Anatomischer Anzeiger 130: 332-346.

Schutt, W.A. 1993. Digital morphology in the Chiroptera: the passive digital lock. Cells Tissues Organs 148: 219-227.

Schutt, W.A., and N.B. Simmons. 1998. Morphology and homology of the chiropteran calcar, with com- 
ments on the phylogenetic relationships of Archaeopteropus. Journal of Mammalian Evolution 5: 1-32.

Silva Taboada, G. 1974. Fossil Chiroptera from cave deposits in central Cuba, with description of two new species (genera Pteronotus and Mormoops) and the first West Indian record of Mormoops megalophylla. Acta Zoologica Cracoviensia 19: 33-73.

Silva Taboada, G. 1979. Los murciélagos de Cuba. La Habana: Editorial Academia.

Silva Taboada, G., and R.H. Pine. 1969. Morphological and behavioral evidence for the relationship between the bat genus Brachyphylla and the Phyllonycterinae. Biotropica 1: 10-19.

Silva Taboada, G., W. Suárez Duque, and S. Díaz Franco. 2007. Compendio de los mamíferos terrestres autóctonos de Cuba vivientes y extinguidos. La Habana: Ediciones Boloña.

Simmons, N.B. 1993. The importance of methods: archontan phylogeny and cladistic analysis of morphological data. In R.D.E. MacPhee (editor), Primates and their relatives in phylogenetic perspective (Advances in primatology): 1-61. New York: Plenum Press.

Simmons, N.B. 1998. A reappraisal of interfamilial relationships of bats. In T.H. Kunz and P.A. Racey (editors), Bat biology and conservation: 3-26. Washington, DC: Smithsonian Institution Press.

Simmons, N.B. 2005a. Order Chiroptera. In D.E. Wilson and D.M. Reeder (editors), Mammal species of the world: a taxonomic and geographic reference: 312-529. Baltimore: Johns Hopkins University Press.

Simmons, N.B. 2005b. Chiroptera. In K.D. Rose and J.D. Archibald (editors), The rise of placental mammals: origins and relationships of the major extant clades: 159-174. Baltimore: Johns Hopkins University Press.

Simmons, N.B., and T.M. Conway. 2001. Phylogenetic relationships of mormoopid bats (Chiroptera: Mormoopidae) based on morphological data. Bulletin of the American Museum of Natural History 258: $1-97$.

Simmons, N.B., and J.H. Geisler. 1998. Phylogenetic relationships of Icaronycteris, Archaeonycteris, Hassianycteris, and Palaeochiropteryx to extant bat lineages, with comments on the evolution of echolocation and foraging strategies in Microchiroptera. Bulletin of the American Museum of Natural History 235: 1-182.

Simmons, N.B., and C.O. Handley, Jr. 1998. A revision of Centronycteris Gray (Chiroptera: Emballonuri- dae) with notes on natural history. American Museum Novitates 3239: 1-28.

Simmons, N.B., and T.H. Quinn. 1994. Evolution of the digital tendon locking mechanism in bats and dermopterans: a phylogenetic perspective. Journal of Mammalian Evolution 2: 231-254.

Simmons, N.B., and R.S. Voss. 1998. The mammals of Paracou, French Guiana: a Neotropical lowland rainforest fauna. Part 1. Bats. Bulletin of the American Museum of Natural History 237: 1-219.

Simmons, N.B., K.L. Seymour, J. Habersetzer, and G.F. Gunnell. 2008. Primitive early Eocene bat from Wyoming and the evolution of flight and echolocation. Nature 451: 818-822.

Slaughter, B.H. 1970. Evolutionary trends of chiropteran dentitions. In B.H. Slaughter and W.D. Walton (editors), About bats. Fondren Science Series 11: 51-83. Dallas: Southern Methodist University Press.

Smith, J.D. 1972. Systematics of the chiropteran Family Mormoopidae. University of Kansas Museum of Natural History, Miscellaneous Publication 56: $1-132$.

Sonntag, C.F. 1925. The comparative anatomy of the tongues of the Mammalia. XII. Summary, classification and phylogeny. Proceedings of the Zoological Society London 1: 701-762.

Soto-Centeno, J.A., and D.W. Steadman. 2015. Fossils reject climate change as the cause of extinction of Caribbean bats. Scientific Reports 5: 7971. [doi:10.1038/srep07971]

Soto-Centeno, J.A., M. O'Brien, and N.B. Simmons. 2015. The importance of late Quaternary climate change and karst on distributions of Caribbean mormoopid bats. American Museum Novitates 3847: 1-32.

Sprague, J.M. 1943. The hyoid region of placental mammals with especial reference to the bats. American Journal of Anatomy. 72: 385-472.

Staněk, V.J. 1933. K topografické a srovnávací anatomii sluchového orgánu našich chiropter. Prague: Nákladem České Akademie Věd a Umění, 67 pp. + 9 plates.

Stephan, H. 1977. Encephalisationsgrad südamerikanischer Fledermäuse und Makromorphologie ihrer Gehirne. Gegenbaurs Morphologisches Jahrbuch 123: 151-179.

Stoetzel, E., A. Royer, D. Cochard, and A. Lenoble. 2016. Late Quaternary changes in bat palaeobiodiversity and palaeobiogeography under climatic and anthropogenic pressure: new insights from Marie- 
Galante, Lesser Antilles. Quaternary Science Reviews 143: 150-174.

Straney, D.O. 1980. Relationships of phyllostomatine bats: evaluation of phylogenetic hypotheses. Ph.D. dissertation, University of California, Berkeley.

Strickler, T.L. 1978. Functional osteology and myology of the shoulder in Chiroptera. Contributions Verebrate Evolution 4: 1-198.

Swofford, D.L. 2002. PAUP*. Phylogenetic analysis using parsimony ( ${ }^{\star}$ and other methods). Version 4. Sunderland, MA: Sinauer Associates. Online resource (http://paup.csit.fsu.edu).

Tedford, R.H., et al. 1996. The Whitneyan-Arikareean transition in the High Plains. In D.R. Prothero and R.J. Emry (editors), The terrestrial Eocene-Oligocene transition in North America: 312-334. Cambridge: Cambridge University Press.

Tedford, R.H., et al. 2004. Mammalian biochronology of the Arikareean through Hemphillian interval (late Oligocene through earliest Pliocene epochs). In M.O. Woodburne (editor), Late Cretaceous and Cenozoic mammals of North America: biostratigraphy and geochronology: 169-231. New York: Columbia University Press.

Teeling, E.C., et al. 2005. A molecular phylogeny for bats illuminates biogeography and the fossil record. Science 307: 580-584.

Teeling, E.C., S. Dool, and M.S. Springer. 2012. Phylogenies, fossils and functional genes: the evolution of echolocation in bats. In G.F. Gunnell and N.B. Simmons (editors), Evolutionary history of bats: fossils, molecules, and morphology: 1-22. Cambridge: Cambridge University Press.

Tejedor, A. 2006. The type locality of Natalus stramineus (Chiroptera: Natalidae): implications for the taxonomy and biogeography of the genus Natalus. Acta Chiropterologica 8: 361-380.

Tejedor, A. 2011. Systematics of funnel-eared bats (Chiroptera: Natalidae). Bulletin of the American Museum of Natural History 352: 1-140.

Tejedor, A., V.d.C. Tavares, and G. Silva-Taboada. 2005. A revision of extant Greater Antillean bats of the genus Natalus. American Museum Novitates 3493: $1-22$.

Tejedor, M.F., N.J. Czaplewski, F.J. Goin, and E. Aragón. 2005. The oldest record of South American bats. Journal of Vertebrate Paleontology 25: 990-993.

Tessman, N.T. 1969. The fossil sharks of Florida. M.S. thesis, University of Florida, Gainesville.

Thoisy, B.D., et al. 2014. Cryptic diversity in common mustached bats Pteronotus cf. parnellii (Mormoopi- dae) in French Guiana and Brazilian Amapa. Acta Chiropterologica, 16: 1-13.

Thomas, O. 1908. Missing premolar of Chiroptera. Annals and Magazine of Natural History (8) 1: 346348.

Timm, R.M., and H.H. Genoways, 2004. The Florida bonneted bat, Eumops floridanus (Chiroptera: Molossidae): distribution, morphometrics, systematics, and ecology. Journal of Mammalogy 85: 852-865.

Van Den Bussche, R.A., S.R. Hoofer, and N.B. Simmons. 2002. Phylogenetic relationships of mormoopid bats using mitochondrial gene sequences and morphology. Journal of Mammalogy 83: 40-48.

Varona, L.S. 1974. Catálogo de los mamíferos vivientes y extinguidos de las Antillas. La Habana: Academia de Ciencias de Cuba.

Vaughan, T.A. 1959. Functional morphology of three bats: Eumops, Myotis, Macrotus. University of Kansas Museum of Natural History, Miscellaneous Publication 12: 1-153.

Vaughan, T.A. 1970a. The muscular system. In W.A. Wimsatt (editor), Biology of bats, vol. 1: 140-194. New York: Academic Press.

Vaughan, T.A. 1970b. The skeletal system. In W.A. Wimsatt (editor), Biology of bats, vol. 1: 98-139. New York: Academic Press.

Vaughan, T.A., and G.C. Bateman. 1970. Functional morphology of the forelimb of mormoopid bats. Journal of Mammalogy 51: 217-235.

Velazco, P.M., et al. 2013. Quaternary bat diversity in the Dominican Republic. American Museum Novitates 3779: 1-20.

Walton, D.W, and G.M. Walton. 1970. Post-cranial osteology of bats. In B.H. Slaughter and D.W. Walton (editors), About bats: 93-126. Dallas: Southern Methodist University Press.

Webb, S.D., and S.C. Perrigo. 1984. Late Cenozoic vertebrates from Honduras and El Salvador. Journal of Vertebrate Paleontology 4: 237-254.

Wetterer, A.L., M.V. Rockman, and N.B. Simmons. 2000. Phylogeny of phyllostomid bats: data from diverse morphological systems, sex chromosomes, and restriction sites. Bulletin of the American Museum of Natural History 248: 1-200.

White, J.A. 1969. Late Cenozoic bats (subfamily Nyctophylinae) from the Anza-Borrego Desert of California. University of Kansas Museum of Natural History, Miscellaneous Publication 51: 275-282.

Wible, J.R., and K.P. Bhatnagar. 1996. Chiropteran vomeronasal complex and the interfamilial relation- 
ships of bats. Journal of Mammalian Evolution. 3: 285-314.

Wilkins, K.T. 1983. Pleistocene mammals from the Rock Springs local fauna, central Florida. Brimleyana 9: 69-82.

Wilkinson, M. (1995). A comparison of two methods of character construction. Cladistics 11: 297-308.

Woodburne, M.O., and C.C. Swisher, III. 1995. Land mammal high-resolution geochronology, intercontinental overland dispersals, sea level, climate, and vicariance. Geochronology, time scales, and global stratigraphic correlation. Special Publication, Society of Economic Paleontologists and Mineralogists 54: 336-364.

\section{APPENDIX 1}

\section{SPECimens Examined}

The list below includes all specimens examined for this study with the exception of those of Koopmanycteris palaeomormoops, which are listed in the main text under the systematic account for that species.

\section{Mormoopidae}

\section{Pteronotus parnellii species group}

Pteronotus alitonus: French Guiana: Paracou, near Sinnamary (AMNH 267406)

Pteronotus fuscus: Colombia: Magdalena, Cacagualito (AMNH 23656); Venezuela: Aragua, Rancho Grande (AMNH 144389-90, 144842, 144845); Carabobo, Las Quiguas (AMNH 31563, 31578-79); Carabobo, San Esteban (AMNH 31564-31570, 31574-31576); Yaracui, Aroa, Boliviar R.R. (AMNH 32099-103, 32126); Trinidad: St. Andrew, Tamaná, Mt. Tamaná (AMNH 175540, 246152-53, 246155); St. George, Blanchisseuse, Las Cueves (AMNH 182693).

Pteronotus mesoamericanus: Mexico: Chiapas, 1.3 mi SE Zapaluta (AMNH 252516); Honduras: Lempira, Las Flores (AMNH 129009-34, 129741, 129743-50); Guatemala: Sta. Rosa, 2 km NE Chiquimilla (AMNH 243727); Sta. Rosa, 13 km N Avellana (AMNH 243728); Nicaragua: León, 50 mi N Sébaco (AMNH 177740); Costa Rica:
Guanacaste (USNM 562734); San José, Las Pavas (AMNH 135243, 135245, 135249); Panama: Canal Zone, Chilobrillo (AMNH 143797).

Pteronotus mexicanus: Mexico: Colima, Pueblo Juarez (AMNH 188747-48); Colima, Coquimatlán, 3 km NE Jala (OMNH 26749); Colima, Coquimatlán, El Paraíso (OMNH 26758); Jalisco, $2.3 \mathrm{mi}$ SW La Cuesta (AMNH 254606); Jalisco, $7.5 \mathrm{~km}$ W Jama, Cueva D.C.V. (AMNH 204958); Jalisco, Los Masos (AMNH 27293); 6 km SEE Tunatico, Cueva del Coyote (188311-12, 188314-19, 188321-24); Nayarit (USNM 511714, 523047); Oaxaca, Tuxtepec, 5 miles west of San Jose Chiltepec (AMNH 189595); Oaxaca, Juchitan, 3 mi N El Jicaro (AMNH 185771); Oaxaca, Juchitan, Tapanatepec (AMNH 177738); Sonora, La Aduana (MSB 55416); Tamaulipas, Acuña, Sierra de Tamaulipas (AMNH 249063-64).

Pteronotus parnellii: Cuba: Oriente, Siboney, Cueva de Los Majaes (AMNH 176182); Pinar del Rio, La Mulata, Pan de Guajaibon (AMNH 176181); Jamaica: St. Catherine, St. Clair (AMNH 247594); St. Elizabeth, Balaclava, Oxford Cave (AMNH 45206-17); Hanover, Lusea (AMNH 12382-83, 12385); Portland, Hector's River (UF-M 13706); Trelawny, $5 \mathrm{mi} \mathrm{N}$ and $2.5 \mathrm{mi}$ WNW Quick Step (USNM 545139-40, 545144).

Pteronotus portoricensis: United States: Puerto Rico, Trujillo Alto, Cueva de Trujillo Alto (AMNH 39369-70).

Pteronotus pusillus: Dominican Republic: Santiago, 4 km SW Monción, Cueva Durán (AMNH 212996); San Rafael, Rancho La Guardia (AMNH 213893); Haiti: Sud, Sapoti (19 km SW Beaumont) (AMNH 236655).

Pteronotus rubiginosus: Brazil: Amazonas, Rio Bronco, Serra de Cuchy (AMNH 78121-25, 78127-31, 78133-34, 78173).

\section{Pteronotus macleayii}

Pteronotus macleayii macleayii: Cuba: Habana, Bucaranao (AMNH 174250); Oriente, Baracoa (USNM 113771); Oriente, Baracoa, Cueva de Mojana (AMNH 61151-53); Pinar del Rio, San Vicente (AMNH 17618-88). 
Pteronotus macleayii grisea: Jamaica: Hanover, Lucea (AMNH 12359); St. Elizabeth, Balaclava, Oxford Cave (AMNH 45256, 45268-75); St. James, Montego Bay (AMNH 12390, 60917, 60896, 60899, 60902, USNM 260730); Montego Bay, Providence Cave (AMNH 34884-86, 4525767); Trelawny, Windsor (AMNH 61022).

\section{Pteronotus quadridens}

Pteronotus quadridens fuliginosus: United States: Puerto Rico, San Juan, Pueblo Viejo, Cueva de Fari (AMNH 39353-59, 39363-67); Trujillo Alto (39396-03); Dominican Republic: between Cabra and Nagua, Cueva de Murcielagos (AMNH 238138); La Altagracia, Boca de Yuma (AMNH 238139); Santo Domingo, Cana Honda (AMNH 25760); Haiti: Cerca La Source (USNM 253631-32); Sud, Sapoti (19 km SW Beaumont) (AMNH 236654); Jamaica: St. Elizabeth, Balaclava, Oxford Cave (AMNH 4524855); St. Elizabeth, Accompong Town (UF-M 12684).

Pteronotus quadridens torrei: Cuba: [no additional information] (AMNH 60637-38); Oriente, 8 mi E Baracoa (USNM 113786, 121061); La Habana, Bararanao, Cueva de El Fantasma (AMNH 176061); Las Villo, Punta Caquanes, Yaguajay "Cueva de Colon" (AMNH 186970-71).

\section{Pteronotus personatus species group}

Pteronotus psilotis: Mexico: Colima, Ixtlahuacán, $1.6 \mathrm{~km}$ NE Las Conchas (OMNH 27773); Colima, Manzanillo, Playa de Oro, Cueva la Murcielaguera (OMNH 38769); Morelos, Tequesquitengo (AMNH 180443-44, 180446); Nayarit, Nayarit-Sinaloa state line, Rio Canas, near la Concha (USNM 508415); Oaxaca, Juchitan, Tapanatpec (AMNH 175018-19, 177672-93, 177695-96, 178468); Sonora, La Aduana (MSB 55419); Vera Cruz, Agua Fria (MSB 75556).

Pteronotus personatus: Colombia: Bolivar (USNM 430190, 433531); Bolivar, Cartagena (USNM 433517, 433531); Panama: San Blas, Armila (Quebrada Venado) (USNM 335085-86); Venezuela: Sucre, La Brea (AMNH 33300); Yara- cui, Aroa, Bolivar R.R. (33112, 32123-24, 3212732133, 32136-37); Trinidad and Tobago: St. George, Tacariquas; St. Augustine (AMNH 175560).

\section{Pteronotus davyi species group}

Pteronotus davyi davyi: Dominica: Grand Bay (USNM 361894); Roseau (AMNH 35923); Trinidad and Tobago: St. George, Arima Heights of Aripo (AMNH 29694); St. George, Diego Martin, Carenage (AMNH 29703-04); St. George, Port of Spain (AMNH 7445, 19122); Nariva (AMNH 207060); St. Patrick, Siparia (AMNH 179954).

Pteronotus davyi incae: Peru: Cajamarca, Jaen (AMNH 69233); Piura, Huancabamba (AMNH 63721, 64082).

Pteronotus fulvus: Mexico: Chiapas, $18 \mathrm{mi} \mathrm{W}$ Ixhuatan (AMNH 203563-64); Colima, Manzanillo, Playa de Oro (OMNH 26736); Colima, Cuauhtémoc, $0.5 \mathrm{mi} \mathrm{E} \mathrm{El} \mathrm{Cobano} \mathrm{(OMNH}$ 14243); Jalisco, $7.5 \mathrm{~km}$ W Jamai, Cueva "Deb" (204959-65); Jalisco, Los Masos (AMNH 2729496); Morelos, Cueva de Tequesquitengo (AMNH 204454-57, 204967-75); Sonora, $5 \mathrm{mi} \mathrm{W}$ Alamos (Mine Tunnel at La Aduana) (AMNH 180312); Sonora, La Aduana (MSB 53727); Ocozocoautla, Ocozocoautla (AMNH 171652); San Luis Potos, El Salto (AMNH 177588-611); Belize: Stann Creek (USNM 583006); El Salvador: La Union, Tabanco (AMNH 239229).

\section{Pteronotus gymnonotus}

Pteronotus gymnonotus: Panama: Canal Zone, Barro Colorado Island, Allee Creek (USNM 498707); Canal Zone, Madden Dam, Chillibrillo Cave (AMNH 89998, USNM 306526, 30652930); Chilibre (USNM 305177); Colombia: Bolivar, Cartagena (USNM 431544); Peru: Huanuco, Parque Nacional de Tingo Maria (MSB 49905MSB 49906); Venezuela: Yaracui, Aroa; Bolivar R.R. (AMNH 32083-89, 32091-94).

\section{Pteronotus pristinus}

Pteronotus pristinus: Cuba: Las Villas, Cueva de Jaguey, near Trinidad (ROM 59132). 


\section{Mormoops blainvillei}

Mormoops blainvillei: [no data] (AMNH 213889); United States: Puerto Rico, Mona Island (AMNH 72547); Puerto Rico, Trujillo Alto, Cueva de Trujillo Alto (AMNH 72370); Cuba: [no additional information] (AMNH 213889); Barbacoa (USNM 113766); Oriente, Siboney, Cueva de Los Majaes (AMNH 17614950); Pinar del Rio, San Vincente, Cueva del Indio (AMNH 176139); Santiago de Cuba, Cueva de los Majaes (MSB 66629); Dominican Republic: Barahano, Pedernales, Cabo Rio (AMNH 238144); San Cristobal, Cueva La Chepa, 10 km N Bayaguana (USNM 535251); San Rafael, Rancho la Guardia (AMNH 213897); Jamaica: St. Catherine, St. Clair (AMNH 246123); St. Elizabeth, Balaclava, Oxford Cave (AMNH 45197205); Trelawny Parish, Quick Step (USNM 511225-27, 545146).

\section{Mormoops megalophylla}

Mormoops megalophylla megalophylla: Mexico: Colima, $3 \mathrm{~km}$ NE Jala (OMNH 26720); Jalisco, Los Masos (AMNH 27298, 27300-03, 27305); Jalisco, $9.8 \mathrm{mi}$ E Atenquique (OMNH 31083); Morelos, Tecómen (AMNH 206692-93); Nayarit, Rancho Palo Amarillo (AMNH 2507071); Oaxaca, $5 \mathrm{mi} \mathrm{W}$ Chilltepec (AMNH 190138-39); Oaxaca, Tapamatepec (AMNH 177423-24); Sonora (USNM 314677); Sonora, 15 mi NW Guaumas (AMNH 239230, 239232); Sonora, La Aduana (MSB 19083); Tamaulipas, Acuña; Sierra de Tamaulipas (AMNH 249066).

Mormoops megalophylla intermedia: Netherlands Antilles: Aruba (AMNH 185613, 18561517); Curacao (USNM 102225); Curacao, Round Cliff (AMNH 149395-96).

Mormoops megalophylla tumidiceps: Colombia: Bolivar, Cartagena (USNM 431641); Santander, San Gil (AMNH 149257, 183315-16); Ecuador: Pichincha (USNM 513432); Venezuela: Sucre (USNM 407207, 417184); Trinidad and Tobago: [no additional information] (AMNH 3173); St. Andrew, Tamaná, Mt. Tamaná (AMNH 175566, 175576); St. George, Port of Spain, Goodwood Park (AMNH 183845).
Phyllostomidae

Macrotus waterhousii: Mexico: Jalisco, Bolaño (AMNH 2003); Morelos, Lago de Tequesquitengo, Cueva del Cerro (USNM 559490-91); Nayarit, Islas Tres Marias, Maria Madre (AMNH 180523); Oaxaca, Tehuantepec, Santo Domingo Tehuantepec, Mount San Pedro, Arroyo Ocotita (AMNH 182158); Oaxaca, Tehuantepec, Tequisistlan (AMNH 178755); Oaxaca, Tehuantepec (AMNH 171591); Dominican Republic: Caves near River Charon, E La Romana (AMNH 120975); near San Juan Bay, Rolla Seco (AMNH 91314); Haiti: Nord, Don Don (UF-M 20816); Sud, $1 \mathrm{mi}$ S Duchity (7 km S Beaumont) (AMNH 236657-58); Cuba: Maranzos, near Cidra (AMNH 61161); Jamaica: Clarendon, Mahoe Gardens, Portland Cave (USNM 511232-33); St. Catherine, Healthshire Hills (AMNH 268068); St. Elizabeth, Balaclava, Oxford Cave (AMNH 45229); St. Elizabeth, Hounslow; Money Cave (AMNH 268071); Trelawny, 1 km E Quick Step (USMN 511230); Trelawny, Windsor (AMNH 45230-31); Cayman Islands: Grand Cayman, 1 km E Spots (USNM 538120, 538127).

Macrotus californicus: United States: Arizona (USNM 314679); Pima, $4 \mathrm{mi}$ WNW Arivaca (AMNH 170823, 170826); California, Imperial, 3 mi N Potholes (AMNH 139575-78); Mexico: Sonora, Isla Tiburon (USNM 513814, 513816).

Artibeus jamaicensis: Mexico: Chiapas, $15 \mathrm{mi}$ SE Mapastepec (by road) (AMNH 251657-58); Jalisco, $2.3 \mathrm{mi}$ SW (by road) Le Cuesta (AMNH 254662); Oaxaca, Tapanatepec (AMNH 177744); Vera Cruz, $1 \mathrm{mi}$ SE Oja de Agua (AMNH 254669); Yucantan, Chichen Itza (AMNH 91236); Yucatán, Sobre La Cairetera a Tixkokof (AMNH 204983); Panama: Canal Zone, Rodman (AMNH 213402); Venezuela: El Enoatado (AMNH 135159); Ecuador: Oriente, San Jose (AMNH 67920-21); Brazil: Pará, Rio Tocantins, Iles do Tavina (AMNH 97036-37); Bolivia: La Paz, 6.6 road km downstream Caranaui, Rio Coraica Valley (AMNH 246641, 246644); Barbados: 10 mi E Bridge Town, Chancery Lane (AMNH 239927) United States: Puerto Rico, Ponce (AMNH 119631); Puerto Rico, Utuado 
(AMNH 39117-18); St. Croix, Cane Bay (AMNH 214228); Jamaica: Cambridge (AMNH 45170); St. Mary, 2 mi W Port Maria (AMNH 219170).

\section{Speonycteridae}

Speonycteris aurantiadens: United States, Florida, Hernando County, Brooksville 2 Locality, late Oligocene, early Arikareean NALMA (UF 240000 [holotype], mandible; 157759-61, isolated teeth; 157763-64, mandibles; 179952, isolated tooth; 179978, proximal femur; 182784 , isolated tooth; 182797-99, isolated teeth; 182805 , isolated tooth; 182849, isolated tooth); Florida, Alachua County, I-75 Locality, early Oligocene, Whitneyan NALMA (UF 16733, isolated tooth).

Speonycteris naturalis: United States, Florida, Alachua County, I-75 Locality (UF 121717 [holotype], left M2).

\section{Noctilionidae}

Noctilio leporinus: Mexico: Sinaloa/Nayarit border, Rio Canas (MSB 24706); Panama: Canal Zone, Chagres River (AMNH 173912); Colombia: Rio Guaimaral (USNM 281311); Brazil: Amazonas, Rio Madiera (AMHH 91937); Amazonas, Rio Madiera, Auara Igarapé (AMNH 91960-75, 91980); Pará, Fero (AMNH 93803); Pará, Rio Tocantins, Ilha do Taiuna (AMNH 96930); Peru: Amazonas, Rio Amazonas, Pt. Indiana (AMNH 93932, 93970); Pacso, Oxapampa, San Juan (AMNH 230105, 23010809); Pasco, Oxapampa, San Pablo (AMNH 230110-12); Bolivia: Beni, ca. 23 km W San Javier (AMNH 210598); Cochabamba, Jodoe Santoe (AMNH 38562); Paraguay: Boqueron, Pozo Colorado (trans-Chaco route, $\mathrm{km} \mathrm{250)}$ (AMNH 234277); Trinidad and Tobago: North Manzanilla (AMNH 175534); United States: Puerto Rico, Humacao, Old Loiza (AMNH 39574, 39587); St. Kitts-Nevis: Nelson Spring (AMNH 246993).

Noctilio albiventris: Colombia: Amazonas, Leticia (AMNH 207772, 207774); Río Cauca (AMNH 269200); Valle del Cauca, Ingenio de Mayagüez (AMNH 269228); Brazil: Amazonas,
Rio Madeira, Auarer Igarapé (AMNH 9201930); Amazonas, Rio Negro, near Manaus (AMNH 79626, 79632); Amazonas, Rio Amazonas, Villa Bella Imperatriz (AMNH 92998); Peru: Oxapampa, San Pablo (AMNH 23102); Bolivia: Beni, Cercado, ca. 23 kilometers west of San Javier, Mamore River (AMNH 210576, 210595, 210624); Beni, 5 km S Guyarmarin (AMNH 209254); Paraguay: Olempo XVI, Feurte Olempo (AMNH 234256-66).

Furipteridae

Furipterus horrens: Panama: $20 \mathrm{~km}$ SW of Changuinola (USNM 315737); Bocas Del Toro (USNM 315734); Guyana: Cuyuni-Mazaruni, Kartabo Point, Cuyuni River (AMNH 142903); Kartabo, Bartica (AMNH 42343, 42457); French Guiana: Paracou, near Sinnamary (AMNH 267214, 265975, 265979, 267212, 267214, 267507, 268572-73); Saint Laurent Du Maroni, Road to Belizon, gold mine (AMNH 244493, CT image); Brazil: Pará, Rio Xingu (USNM 549507); Brazil, Pará, Altamira, 50 km SSW, Island in Rio Xingu (Ilha Jabuti, (USNM 549598).

\section{Thyropteridae}

Thyroptera tricolor: Panama: Canal Zone, Barro Colorado Island (USNM 582082); Colombia: Magdelena, Santa Marta, Colonia Agricola De Caracolicito (USNM 281200); Magdalena, Santa Marta, Colonia Agricola De Caracolicito, Rio Ariguanicito (USNM 281939); Valle del Cauca (AMNH 239085); Ecuador: Tungurahua, Banos de Agua Santa (AMNH 67592); Peru: Río Amazonas, Orosa (AMNH 74024); Río Apayacu (AMNH 74377); French Guiana: Paracou, near Sinnamary (AMNH 266348, 266353, 266355-59, 266361, 266363-65,267215, 268575-76).

\section{Mystacinidae}

Mystacina robusta: New Zealand: Stewart Island (AMNH 160269); island off SW of Stewart Island (AMNH 214243).

Mystacina tuberculata: New Zealand: [no additional data] (MNHN 1983.1464; MVZ 
174825); North Island, Omahuta Kauri Forest (MVZ 173919; ROM 80308).

Emballonuridae

Saccopteryx bilineata: Mexico: Colima, Manzanillo, 4 kilometers east northeast of Manzanillo, Ejido Tepextiles (AMNH 172063); Oaxaca, Mixe, San Juan Mazatlan (AMNH 175300-01); Oaxaca, Mixe, San Juan Cotzocon, Nueva Raza (AMNH 178776-77); Guatemala, Tikal, Petén (UF-M 6971); Costa Rica: Heredia, Finca La Selva (MSB 34210); Puntarenas, Palmer (Pacific) (AMNH 139449); Panama: Canal Zone, Gatun Lake (USNM 514986); Chilibrillo Caves (USNM 306471); Guyana: Rupununi District, 15 mi E Dadanawa (USNM 338917); French Guiana: Paracou, near Sinnamary (AMNH 267060, 267064, 267377); Brazil: Pará, Altamira, 52 km SSW, E Bank Rio Xingu (USNM 549311); Rio Madeira, Rosarinho (AMNH 92657, 92661); Bolivia: Beni, $5 \mathrm{~km}$ NW Grande river mouth (AMNH 210469). 





\title{
SCientific Publications of the American Museum of Natural History
}

AMERICAN MUSEUM NOVITATES

BULletin of the American Museum of Natural History

anthropological Papers of the american Museum of natural History

\author{
Publications Committee \\ ROBERT S. VOSS, CHAIR \\ BOARD OF EDITORS \\ JiN MENG, PALEONTOLOGY \\ LORENZO PRENDINI, INVERTEBRATE ZOOLOGY \\ ROBERT S. VOSS, VeRTEBRATE ZOOLOGY \\ Peter M. Whiteley, Anthropology \\ MANAGING EDITOR \\ MARY KNIGHT
}

Submission procedures can be found at http://research.amnh.org/scipubs

All issues of Novitates and Bulletin are available on the web (http://digitallibrary.amnh.

org/dspace). Order printed copies on the web from:

http://shop.amnh.org/a701/shop-by-category/books/scientific-publications.html

or via standard mail from:

American Museum of Natural History-Scientific Publications

Central Park West at 79th Street

New York, NY 10024

(2) This paper meets the requirements of ANSI/NISO Z39.48-1992 (permanence of paper).

ON the cover: Portrait of the Antillean ghOST-FaCED bat MORMOOPS BLAINVILLEI FROM THE DOMINICAN REPUBLIC (TOP; ILLUSTRATION BY ADRIAN TEJEDOR) AND PARTIAL MANDIBLE OF KoOPMANYCTERIS PALAEOMORMOOPS FROM THE OLIGOCENE of Florida (occlusal VieW, middle; labial VieW, BOtTom; ILLUSTRATIONS BY NICHOLAS (ZAPLEWSKI). 